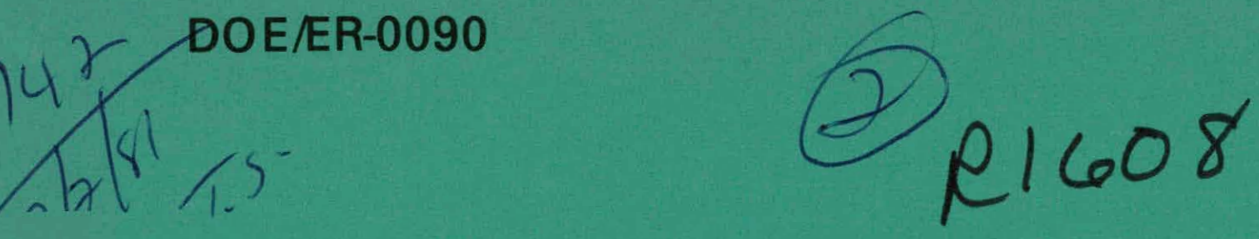

\title{
Environmental Assessment for the Satellite Power System- Concept Development and Evaluation Program- Atmospheric Effects
}

November 1980

Prepared for:

U.S. Department of Energy

Office of Energy Research

Sular Power Satellite Projccte Division

Under Contract No. 31-109-ENG -38

DOE/NASA

Satellite Power System

Concept Development

and

Evaluation Program 


\section{DISCLAIMER}

This report was prepared as an account of work sponsored by an agency of the United States Government. Neither the United States Government nor any agency Thereof, nor any of their employees, makes any warranty, express or implied, or assumes any legal liability or responsibility for the accuracy, completeness, or usefulness of any information, apparatus, product, or process disclosed, or represents that its use would not infringe privately owned rights. Reference herein to any specific commercial product, process, or service by trade name, trademark, manufacturer, or otherwise does not necessarily constitute or imply its endorsement, recommendation, or favoring by the United States Government or any agency thereof. The views and opinions of authors expressed herein do not necessarily state or reflect those of the United States Government or any agency thereof. 


\section{DISCLAIMER}

Portions of this document may be illegible in electronic image products. Images are produced from the best available original document. 


\title{
NOTICE
}

This report was prepared as an account of work sponsored by the United States Government. Neither the United States nor the United States Department of Energy, nor any of their employees, makes any warranty, express or implied, or assumes any legal liability or responsibility for the accuracy, completeness, or usefulness of any information, apparatus, product, or process disclosed, or represents that its use would not infringe privately owned rights. Reference herein to any specific commercial product, process, or service by trade name, mark, manufacturer, or otherwise, does not necessarily constitute or imply its endorsement, recommendation, or favoring by the United States Government or any agency thereof. The views and opinions of authors expressed herein do not necessarily state or reflect those of the United States Government or any agency thereof.

\author{
Avaliable from: \\ National Technical Inforwation Service (NIIS) \\ U.S. Department of Commerce \\ Springfield, Virginfa 22161 \\ Price: Printed Copy: $\$ 10.00$
}




\section{Environmental Assessment for the Satellite Power System- Concept Development and Evaluation Program- Atmospheric Effects}

November 1980

Prepared for:

U.S. Department of Energy

Office of Energy Research

Solar Power Satellite Projects Division

Washington, D.C. 20585

Prepared by:

Argonne National Laboratory

Argonne, IL 60439

Under Contract no. 31-109-ENG-38

DOE/NASA

Satellite Power. System

Concept Development

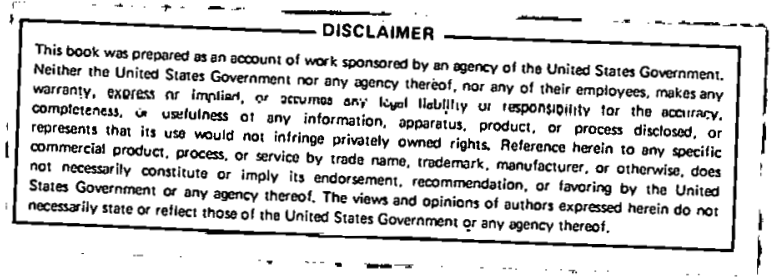

and

Evaluation Program 
EXECUTIVE SUMMARY .................... v

ACKNOWLEDGMENTS ...................... ix

ABSTRACT. . . . . . . . . . . . . . . . . 1

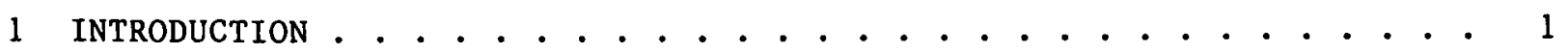

2 ASSESSMENT OF LOWER ATMOSPHERIC EFFECTS. . . . . . . . . . . 9

2.1 INADVERTENT WEATHER MODIFICATION CAUSED BY RECTENNA 11

STRUCTURE AND WASTE HEAT RELEASE. . . . . . . . . . . . 13

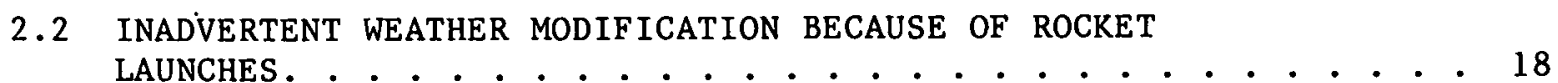

2.2.1 Midday Unstable to Neutral Boundary Layer

Capped by Dry Stable Air . . . . . . . . . . . . 22

2.2.2 Mid-Morning Conditionally Unstable Boundary

Layer Capped by Dry Stable Air . . . . . . . . . 22

2.2.3 Nighttime Absolutely Stable Condition.......... 23

2.2.4 Potentially Unstable Air, Thunderstorm Situations. . . . 23

2.3 AIR QUALITY IMPACT OF ROCKET LAUNCHES . . . . . . . . . . . . . 26

2.3.1 Degradation of Air Quality . . . . . . . . . . . . . 26

2.3.2 Formation of Acid and Acid Rain from Rocket
Exhaust Effluent..................... 36

2.3.2.1 Local Short-term Effects............. 36

2.3.2.2 Regional Long-term Effects............ 41

3 ASSESSMENT OF UPPER ATMOSPHERIC EFFECTS. . . . . . . . . . 43

3.1 THE NATURAL UPPER ATMOSPHERE. . . . . . . . . ....... . 43

3.2 SPS VS AMBIENT LOADINGS. . . . . . . . . . . . . . . . . . . . 44

3.2.1 Carbon Dioxide . . . . . . . . . . . . . . . 46

3.2 .2 Water and Molecular Hydrogen... . . . . . . . . 46

3.2 .3 Nitric Oxide . . . . . . . . . . . . . . . . 49

3.2.4 Argon Ion Plssma . . . . . . . . . . . . . . . . . . 49

3.3 EFFECTS OF ROCKET EFFLUENTS BELOW $500 \mathrm{~km}$. . . . . . . . . . . . . 50

3.3.1 Composition Changes in Stratosphere, Mesosphere,
and Lower Thermosphere . . . . . . . . . . 51

3.3.2 Ozone Depletion. . . . . . . . . . . . . . . . . . 54

3.3.3 High-Altitude Cloud Formation. . . . . . . . . . . . 55

3.3.4 Global Hydrogen-Cycle Changes. . . . . . . . . . . . . 57

3.3.5 Density and Temperature Changes. . . . . . . . . . . 58

3.3.6 Airglow Emission Changes . . . . . . . . . . . . . 59

3.3.7 D- and E-Region Effects. . . . . . . . . . . . . 60

3.3.8 F-Region Ionospheric Holes............. . . 64 
3.3.8.1 Hole Morphology . . . . . . . . . . . . 67

3.3.8.2 Airglow Enhancement . . . . . . . . . . 67

3.3.8.3 Radio Wave Propagation Effects. . . . . . . . 69

3.3.8.4 Theoretical Predictions of Radio Wave

Propagation Effects............. 71

3.3.8.5 SPS Predictions for a Single HLLV and PLV

Circularization Burn. .......... . . 73

3.3.8.6 SPS Predictions for a Single POTV Burn

Near Leo. . . . . . . . . . . . . . 73

3.3.8.7 SPS Predictions for a Single HLLV Second-

Stage Burn $(56-124 \mathrm{~km})$. . . . . . . . . . 74

3.3.8.8 Multiple Launch Effects in the F-Region . . . . 74

3.4 EFFECTS OF RUCKE'T EFFLUENTS ABOVE 500-km ALTITUDE . . . . . . . . 75

3.4.1 Plasmasphere and Magnetosphere . . . . . . . . . . . 75

3.4.2 COTV . . . . . . . . . . . . . . . . . . . . 77

3.4.3 POTV ....................... . . 77

3.4.4 Effects of POTV Emissions. . . . . . . . . . . . 80

3.4.5 Effects of COTV Emissions. . . . . . . . . . . . . 82

3.4.5.1 Artifical Airglow Emissions......... . 87

3.4.5.2 Artificial Auroral Substorms. . . . . . . . . 88

3.4.5.3 Modification of the Van Allen Radiation Belts

and Ring-Current Particles......... . 89

3.4.5.4 Generation of Plasma Turbulence and Inter-

ference with Satellite Communication Systems. . 92

3.5 ENERGY DEPOSITION AND ABSORPTION. . . . . . . . . . . . . . . . . 92

3.6 EFFECTS OF LARGE STRUCTIRFS ON THE SATELLITE ENVIRONMENT. . . . . 94

4 UPPER-LOWER ATMOSPHERIC COUPLING AND IMPLICATIONS FOR SPS

IMPACTS ON CLIMATE AND WEATHER . . . . . . . . . . . . . . . . . . 96

5 CONCLUSIONS. . . . . . . . . . . . . . . . . . . . 98

REGERENCES. . . . . . . . . . . . . . . . . . . . 102

APPENDIX A: ESTIMATE OF THE RATE OF CONVERSION OF $\mathrm{NO}_{2}$ and $\mathrm{HNO}_{3}$
IN WATER DROPLETS. . . . . . . . . . . . . . . . . . . 112

\section{LIST OF FIGURES}

No. $\quad$ Tlele $\quad \underline{\text { Page }}$

1 SPS Satellite in Geosynchronous Earth Orbit and Surface

Rectenna. . . . . . . . . . . . . . . . . . . . . . . 3

2 Scenario for Construction of Two 5-GW Salellices per Year ... . . . . 4

3 HLLV Main Burn Trajectory . . . . . . . . . . . . . . . . . . 5

4 Regions of the Atmosphere . . . . . . . . . . . . . . . . 8 
5 Potential Tropospheric Effects of Rocket Launches . . . . . . . . . 11

6 Basic Sounding for 1936 EST, December 13, 1978, Cape Canaveral, Fla. . . . . . . . . . . . . . . . . . . 21

7 Comparison of Predicted Maximum Vertical Velocity . . . . . . . . . 21

8 Comparison of Predicted Mean-Cloud, Liquid-Water Content. . . . . . . 21

9 Predicted Mean-Cloud, Liquid-Water Content and Rainwater. . . . . . . 25

10 Photostationary State Relaxation Times. . . . . . . . . . . . . 33

11 Ground-level $\mathrm{NO}_{2}$ Concentration. . . . . . . . . . . . . . 35

12 Possible Mechanism of the Aqueous Chemistry of Nitrogen Oxides......................... . 38

13 Estimated Change in Water Vapor Concentration . . . . . . . . . . 47

14 Estimated Change in Molecular Hydrogen Concentration. . . . . . . . 49

15 Rocket Emission Profile . . . . . . . . . . . . . . . . . 52

16 Estimated Reentry Production of No. . . . . . . . . . . . . . . . 52

17 Calculated Change in Water Vapor Concentration at Several Latitudes and Altitudes. . . . . . . . . . . . . . . . 53

18 Estimated Change in the NO Concentration and the NO Corridor Effect.................... . . 54

19 Ozone Column Density Corridor Effect Due to Reentry No. . . . . . . 55

20 Optical Depth in an HLLV Contrail . . . . . . . . . . . . . 57

21 Sudden Reduction in the Total Electron Content. . . . . . . . . 65

22 Obscrvation of the Ionospheric Hole Caused by the Launch of the HEAO-C Satellite... . . . . . . . . . . . . . 68

23 Map Showing Locations of Participating Ham Radio Operators. . . . . 70

24 Cross Section of Magnetosphere and Plasmasphere . . . . . . . . . . 76

25 Hypothetical Burn Sequence for a 2-Stage POTV Flight. . . . . . . . 79

$26 \mathrm{Ar}^{+}$Ion-Beam Wake in Magnetosphere.. . . . . . . . . . . . . . 85

27 Principal Components of Plasmasphere. . . . . . . . . . . . . . . . 89

\section{LIST OF TABLES}

No. Title

1 SPS Space Transportation Vehicles . . . . . . . . . . . . . 4

2 Exhaust Products of SPS Transportation Vehicles . . . . . . . . . 5

3 HLLV Main Burn Exhaust Emissions. . . . . . . . . . . . . . . 6 
4 Comparisons of Man-Made and Natural Energy Releases . . . . . . . . . 12

5 Changes of Temperature, Humidity, and Vertical Wind-Component

Profiles at the Center of the Rectenna $1200 \mathrm{hr}$. . . . . . . . . 16

6 National Ambient Air Quality Standards. . . . . . . . . . . . 27

7 Estimated Initial HLLV Ground-Cloud Composition . . . . . . . . . . 28

8 Ground-Level $\mathrm{NO}, \mathrm{NO}_{2}$, and $\mathrm{O}_{3}$ Concentrations............ 35

9 Equilibrium $\mathrm{NO}, \mathrm{NO}_{2}$, and Acid Concentrations. . . . . . . . . . . 38

10 Estimated Natural Water Concentrations above $80 \mathrm{~km}$. . . . . . . . 48

11 Significance of H-atom Emissions above IEO. . . . . . . . . . . 50

12 Significance of No Injections . . . . . . . . . . . . . . . 50

13 Significance of Ar Injections . . . . . . . . . . . . . . . . 50

14 Predicted Ionospheric Perturbations Due to Nitric Oxide Deposition. . . . . . . . . . . . . . . . . . . 62

15 Predicted Nitric Oxide and Electron Concentrations near Reentry after 6 Hours and 1 Day . . . . . . . . . . . . 63

16 CoTV Ion-Thruster Parameters. . . . . . . . . . . . . . 78

17 CoTV Description. . . . . . . . . . . . . . . . . . 78

18 Hypothetical Burn Sequence for a Typical POTV Flight. . . . . . . . . 80

19 Emissions per POTV Flight . . . . . . . . . . . . . . . . 81

20 Satellite Power System Magnetospheris Effecto . . . . . . . . . 100 
This document constitutes the final technical report of the Atmospheric Effects Assessment Program that has been conducted under the auspices of the Satellite Power Systems (SPS) Project Office of the U.S. Department of Energy as a part of the SPS Concept Development and Evaluation Program.

The objectives of the Atmospheric Effects task were to identify potentially significant effects, along with the possible mitigating strategies, of SPS-related operations on the entire Earth's atmosphere from the ground to geosynchronous orbit (GEO); to predict the nature, extent, and import of those effects within program constraints; and to assess the reliability of those predictions.

Programmatic constraints (program duration and funding levels) have limited the assessment, with a few exceptions, to use of archived data and existing assessment techniques, including mathematical/computer simulation models. However, some additional basic scientific data were acquired through measurement programs associated with certain targets of opportunity. These data have helped resolve some of the important questions that arose during the course of the assessment. Also, as a result of comparisons between theoretical model simulations and both the archived and newly acquired data, some basic improvements were made in our understanding of and ability to predict SPS-related effects.

An additional programmatic constraint was that the assessment was focused on a Reference System description of the SPS. This description, while adequate for identification and assessment of potentially significant atmospheric effects, is certain to undergo considerable change if such a system eventually is built. Selection of a specific launch site(s) and a more complete specification of the final operations system design would undoubtedly require some updating of the present atmospheric effects assessment. With the exception of some example calculations making use of the Kennedy Space Flight Center meteorological and air quality conditions, all the analyses in the present assessment are independcnt of lannch site.

The initial task of identifying potential atmospheric effects was undertaken in a series of workshops held in 1978. The proceedings of those workshops and a follow-up workshop in 1979 provided fairly extensive lists of possible effects, and summarized our state of knowledge at that time regarding the effects and their impacts on man's environment. Kecommendations for both near- and long-term research needs and approaches also resulted from those workshops. The general finding of the workshops was that essentially every level of the Earth's atmosphere is potentially affected by the construction and operation of the SPS. The principal SPS activities and their associated potential effects were initially identified as follows:

1. Rectenna waste heat releases and changes in the albedo and surface roughness of the terrain could lead to local weather modification.

2. Rocket effluents injected into the troposphere, especially near ground level, could lead to air quality degradation and weather modification. 
3. Rocket effluents injected into the upper atmosphere could result in climatic changes, ozone depletion, ionospheric depletion, enhanced airglow emissions, structural changes in the plasmasphere and magnetosphere, including Van Allen Belt modifications and changes in response of the Earth's atmosphere to magnetic storms, and changes in atmospheric properties that could affect the performance of telecommunications, navigation, and remote sensing systems and other space-borne facilities.

4. SPS stationkeeping, attitude control, and emissions from space structures could cause an alteration of the satellite environment.

Noise-related effects are dealt with in the Nonmicrowave Effects task.

In addition to elucidatiug these cause-effect relationships, an important function of the Atmospheric Effects task has been to provide basic information on changes in atmospheric properties to nther program lask areas that are reoponsible for evaluating the ultimate impacts on health, ecosystems, telecommunications, etc. On the other hand, in the case of ionospheric heating due to absorption of energy from the microwave power beam, the Ionospheric Heating task is responsible for providing basic data that serve as input to the Atmospheric Effects task's assessment of possible climatic or ocher atmospheric effects outside the beam cross section.

The assessed atmospheric effects are summarized below:

Heavy 1 ift launch vehicle (HLLV) launches have been predicted to have a significant potential for inadvertent weather modifications on a local, short-term scale. Under selected meteorological conditions such launches can affect convective patterns, alter cluud populations, and induce detectable precipitation. None of these effects are judged to be serious. Long-term, large-scale effects are unlikely, but have not been examined in detail.

Air quality impacts of HLLV launches are prodicted to be very small except posoibly with respect to nitrogen dioxide. If a short-term air quality standard is set as anticipated, then ground-level concentrations of nitrogen dioxide $\left(\mathrm{NO}_{2}\right)$ due to rocket launches could exacerbate existing problems. However, the launches by themselves are not expected to. cause an exceedance of the expected standard. The production of $\mathrm{NO}_{2}$ can also lead to slight increases in acidity of precipitation on a local, intermittent basis. It seems unlikely that the enhancement would be great enough to cause noticeable environmental effects.

Stratospheric carbon dioxide $\left(\mathrm{CO}_{2}\right)$ and water injectiuns are estimated to be complecely negligible from both the ozone depletion and greenhouse effect points of view. The fractional increase in the $\mathrm{CO}_{2}$ concentration would be only 1-2 parts per $10^{5}$, an amount too small to affect the radiation balance. Small predicted reductions $(0.01-0.02 \%)$ in the total ozone column (and therefore a corresponding increase in ultraviolet radiation at ground level) due to water injections would not be detectable.

The production of nitric oxide (NO) during reentry of the HLLV second stage is predicted theoretically to lead to an increase of about $0.02 \%$ in the 
globally averaged ozone column density, with latitude-dependent variations of a factor of 2 around this value. The uncertainty in the calculations is such that no increase or even a small decrease is possible.

Repeated injections of water in the mesosphere would result in an increase of about $8 \%$ (globally averaged) in the water vapor content at $80 \mathrm{~km}$. Over a narrow region surrounding the launch latitude at the same height, the increase may be as much as $15 \%$. At lower altitudes, the buildup is smaller and no corridor effects are expected. At higher altitudes, preliminary estimates suggest that the buildup in water vapor content will be greater, increasing the globally averaged natural content by as much as a factor of 100 or more at $120 \mathrm{~km}$ and above. On the short-term, smaller scale basis associated with individual rocket launches, significant increases in vapor concentrations are also expected. On the same basis, small-scale clouds (noctilucent) are expected to be formed but are not expected to reach global scale and, therefore, are not expected to cause climatic impacts. Temperature effects, not fully understood at present, may alter the likelihood of cloud formation and possibly increase cloud persistence. Significant visual displays at low- to mid-latitudes may result near sunrise or sunset.

The injection of water vapor and hydrogen molecules above $80 \mathrm{~km}$ will lead to an enhancement in the upward flux of hydrogen through the thermosphere. It has been estimated that the natural total flux of hydrogen (in all chemical forms) will be approximately doubled. The consequences of such an enhancement have not been examined in detail as yet. Possible consequences include an increase in escape rate of hydrogen to outer space and or an increase in atmospheric density above $800 \mathrm{~km}$.

Several mechanisms that are not completely independent of each other have been estimated to produce both large positive and negative changes in $D$ an E-region plasma densities on a local, short-term scale. It is not clear how large or persistent the net plasma density changes would be or even what sign they would take. Long-term, global-scale D-region free electron density changes appear to be quite small and probably unimportant although the predictions are uncertain at this time.

In the F-region, however, the picture is much clearer. We can predict with considerable confidence the scale of, and with somewhat less confidence the duration of, short-term F-region holes caused by various engine burns of SPS-space vehicles. Each pcroonnel nrbit transfer vehicle (POTV) injection burn would result in an ionospheric hole two to three times as large as the continental United States. HLLV circularization burns would produce holes one-tenth the size. (Personnel orbit transfer vehicle and HLLV burns occur once or twice per month and once or twice per day, respectively.) More speculatively, the periodic engine burns may lead to a chronic partial depletion in a ring-shaped global region centered around the launch latitude. Crude estimates suggest a $10 \%$ plasma reduction in this region superimposed on periodic, small-scale, but much more complete, depletions. Confirmation with more detailed model calculations, taking into account global transport processes, is required. Probably the major consequences of this partially depleted ring would be perturbations of very low frequency (VLF), high frequency (HF), and possibly very high frequency (VHF) wave propagation. According to present information such perturbations are not expected to be large. However, uncertainties exist with the current data and theoretical 
modeling studies and warrant considerable caution in attempting to scale up radio wave propagation effects. Another impact of potential importance is the enhancement of airglow emissions. The greatest enhancements observed to date are on the order of 10 kilorayleighs for certain emissions in the visible and near infrared band. The significance of these effects in terms of their impacts on astronomical observations, remote sensing and satellite-borne surveillance systems should be determined in the future, perhaps with the aid of the remote sensing and astronomy communities.

The effect of POTV and cargo orbit transfer vehicle (COTV) emissions in the magnetosphere is perhaps least well understood at present and least well supported by observations. This area of investigation could benefit by field and laboratory experiments and further improvements in theory. The masses and energies injected are unquestionably large compared to naturally occurring values and, therefore, cause concern. Heating by the argon plasma beam and the addition of cold, heavy ions may lead to enhancement of dosage of trapped relativistic electrons in the outer Van Allen Belt and perhaps in the GEO environment. Production of artificial ionospheric electric currents similar to those associated with naturally occus ring magnetic storms could be driven by the magnetosphere-argon ion beam interactions. Such currents could trip circuit-breakers of long telephone and power lines and enhance pipeline corrosion. The presence of large quantities of neutrals (from the POTV) could lead to substantial depletion of energetic, trapped, charged particles and modification of auroral response to solar activity. The possibility also exists for the triggering of plasma instabilities that could cause satellite communications interference. Finally, an appreciable amount of airglow emission may be generated, especially near LEO, by the impingement of the dense argon ion beam on the thermosphere. Again, the import of the artificial airglow should be judged by the remote sensing and astronomy communities.

The sun-weather effect that has been widely debated in the recent climate literature, if it is real, is likely to involve a coupling of the upper and lower atmosphere. Several mechanisms have been proposed to explain such a coupling. It has been conjectured that if indeed modifications in the solar wind can influence climate through some such coupling scheme, then perhaps the SPS upper atmospheric offcets thal have been discussed herein cuuld disturb the coupling scheme. In that sense, upper armnspheric EFJ effects may be callsally oonnected lo possible climate effects. However, until the sun-weather effect is placed on a firmer footing and until the SPS upper atmospheric effects themselves are better understood, the potential effect of SPS on climate and weather cannot be pviluated cxcept in terms of the direct troposplieric ettects discussed earlier. Based on present knowlerge, cignifi cant influence nf SPs-induced upper atmospheric effects on tropospheric weather is regarded as unlikely.

One final effect that has been invustigated ill the current assessment is the inadvertent weather modification likely to be caused by the rectenna structure coupled with.its release of waste heat. From the weather and climate points of view, the rectenna seems likely to have effects comparable with those due to other nonindustrial land-use changes covering the samc surface area; that is, local, detectable meteorological effects that probably have little consequence. 
In chronological order of their contributions we wish to thank the following individuals for preparing the manuscript, making it more readable, gramatically correct, aesthetically pleasing, and more technically sound.

Typists:

Graphics :

Technical Editor:

Peer Reviewers :

Dr. Paul A. Bernhardt

Dr. Yam T. Chiu

Dr. Gerald T. Davidson

Dr. James E. Jiusto

Prof. Harold Johnston

Dr. Ronald L. Lavoie

Prof. Michael Mendillo

Dr. George D. Robinson

Dr. Stephen E. Schwartz

Dr. Robert C. Whitten

Dr. John Zinn

Staff Reviewer:

Anthony Valentino
Teri Walker

Louise Benson

Lenore Murphy

Olga Skala

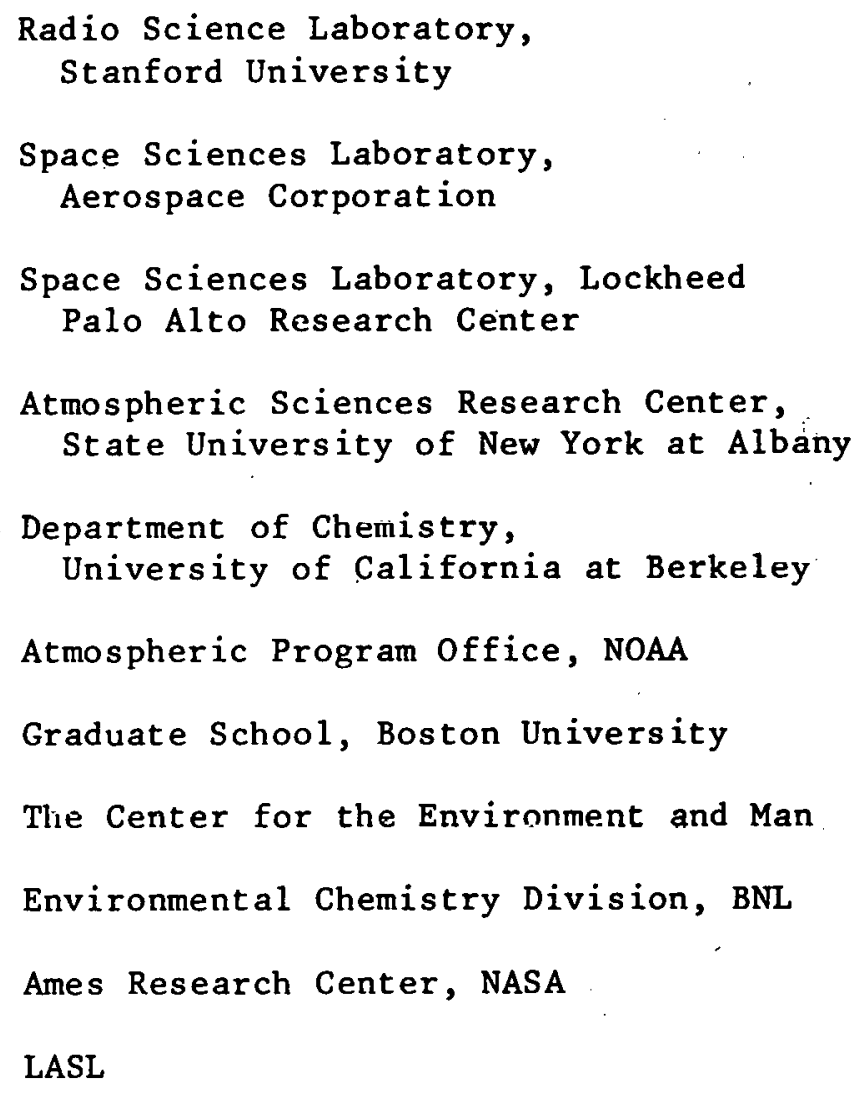

Energy and Environmental Systems Division, ANL 
ENVIRONMENTAL ASSESSMENT FOR THE SATELLITE POWER SYSTEM CONCEPT DEVELOPMENT AND EVALUATION PROGRAM: ATMOSPHERIC EFFECTS

by

Donald M. Rote, Kenneth L. Brubaker, Jiin-Lang Lee

\section{ABSTRACT}

The U.S. Department of Energy (DOE) has undertaken a preliminary, three-year program to investigate the impacts of the construction and operation of a satellite power system, of unprecedented scale. The Department of Energy's program, titled The Concept Development and Evaluation Program, focused its investigations on a Reference. System description that calls for the use of either silicon ( $S i$ ) or gallium aluminum-arsenide (GaAlAs) photovoltaic cells on 60 satellites to be constructed in GEO over a 30-yr period. Rectennas would be constructed on the ground to receive microwave energy from the satellites. Each satellite-rectenna pair is designed to produce $5 \mathrm{GW}$ of power on an essentially continuous basis for use as a baseload power source for an electric power distribution system.

The environmental assessment part of the program was divided into five interdependent task areas. The present document constitutes the final technical report on one of the five task areas, the Assessment of the Atmospheric Effects, and as such presents an in-depth surmary of work performed during the assessment program.

The issues associated with SPS activities in the troposphere are examined. These include tropospheric weather modification related to rectenna operations and rocket launches, and air quality impacts related to rocketlaunch ground clouds. Then progressing upward through the various levels of the atmosphere, the principal middle and upper atmospheric effects associated with rocket effluents are analyzed. Finally, all of the potential SPS atmospheric effects are summarized.

\section{INTRODUCTION}

The unique properties of the Earth's space environnent make it an attractive place for a broad spectrum of scientific, commercial, industrial, and military activities. The proposal, originally due to Glaser, 1 to use space as an alternative renewable energy source, as epitomized by the Satellite Power System (SPS), adds yet another dimension to this exploitation of space. The SPS would take advantage of the fact that a satellite placed in geosynchronous orbit (GEO) would be continuously (except for seasonally 
dependent short occultation periods) exposed to unattenuated solar radiation while remaining stationary relative to a point below on the Earth's surface. The Reference System ${ }^{2}$ calls for 60 satellite-rectenna pairs, an example of which is illustrated in Fig. 1. Each pair produces $5 \mathrm{GW}$ of power on an essentially continuous basis for use as a baseload power source for an electric power distribution system. As shown in the figure each satellite continuously converts solar radiation into microwave radiation in GEO, then transmits it to Earth where it is received and converted to DC current by a rectenna.

The reference system calls for the use of either silicon (Si) or gallium aluminum-arsenide (GaAlAs) photovoltaic cells spread over a low mass-density structure about $5 \times 10 \mathrm{~km}$ in area. The microwave transmission antenna is about $1 \mathrm{~km}$ in diameter and rotatco relalive to the solar cell array etructure to permit simultaneous exposure to the sun and tranomissiull to a fixed point. (roctcnna sile) on the Earth's surface. For mid-latitnde eitca, the elliptically shaped rectenna has dimenstons of about $10 \times 13 \mathrm{~km}$. The peak microwave power density at the rectenna center would be $230 \mathrm{~W} / \mathrm{m}^{2}$.

As is characteristic of solar powered systems designed to provide a substantial fraction of the U.S. total electrical energy demand ( $20 \%$ by the time frame 2020-2040), the scale of the SPS and related resource requirements is very large. In addition, the SPS also has space transportation requirements of unprecedented proportions. The 30-year construction program calls for the completion of two 5-GW satellites per year. Corresponding space transportation system requirements for both photovoltaic cell options are outlined in Fig. 2. The number of flights does not include those required for maintenance operations, which could become substantial after several satellites have been in operation for a number of years. Some of the pertinent details of the four vehicle types composing the system, including their operating altitude ranges are listed in Table 1 . The masses of the principal rocket exhaust products, as a function of altitude, are given in Table 2. Note that both in terms of size and launch frequency, the heav.y lift 1 aunch vehicle (HLLV) dominates the sysletl. It has a payload roughly five imes that of the Saturn $V$ vehicle used in the Apollo Program. Allowing for maintenance operations, one or two HLLVs would be launched per day. The trip from the ground to low Earth orbit (LEO) will involve the use of a Hohman transfer ellipse, in which the HLLV will climb to $124 \mathrm{~km}$ and then slightly lose altitude while gaining speed. Cutoff of the second stage occurs near 111 $\mathrm{km}$, from which point the vehicle travels into an elliptie ritjutiory up Lu 477 $\mathrm{km}$ altitude, whire a eirculalizarton burn puts it into parking orbit. After depositing its payload, the HLLV makes a de-orbit burn and returns to the surface for re-use. Reentry heating near $60-90 \mathrm{~km}$ will inject a significant quantity of nitric oxide (NO) into the atmosphere. The HLLV ascent trajectory is shown in Fig. 3, and exhaust emission data are presented in Table 3 .

In view of the program scale as well as the potential coste and benefits, DOE, in conperation with NASA, decided to undertake a three-year program to investigate the technical feasibility, economic viability, and social, political, institutional, and environmental impacts of the SPS option and the comparison of those impacts with other energy options. The Concept Development and Evaluation Program, as it became known, focused these investigations, among others, on the Reference System design ${ }^{2}$ cited above. The environmental assessment part of that program was divided into the following five interdependent major task areas: 


\section{Solar Power Satellite}

\section{FUELED BY THE SUN'S RAYS}

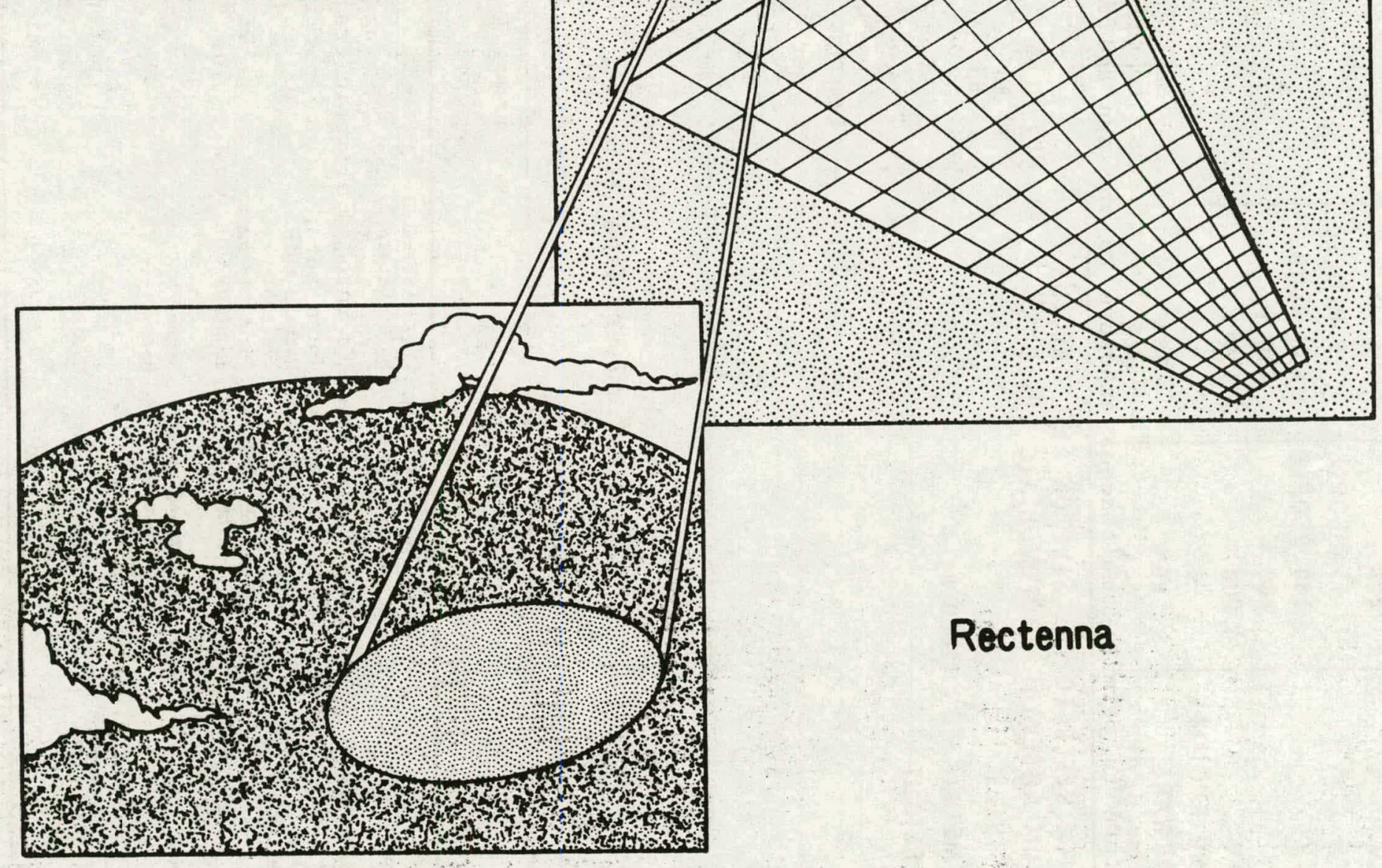

Fig. 1 SPS Satellite in Geosynchronous Earth Orbit and Surface Rectenna 
SILICON

\begin{tabular}{|l|r|r|}
\hline SPS MASS & $50,984 \mathrm{t}^{*}$ & $34,159 \mathrm{t}$ \\
PAYLOADS & $424 \mathrm{t}$ & $424 \mathrm{t}$ \\
HLLV & 75 PEOPLE & 75 PEOPLE \\
PLV & 160 PEOPLE & 160 PEOPLE \\
POTV & $400 \mathrm{t}$ & $400 \mathrm{t}$ \\
& $4,000 \mathrm{t}$ & $3,500 \mathrm{t}$ \\
COTV & $85 \%$ & $95 \%$ \\
PACKING FACTORS & $95 \%$ & $95 \%$ \\
HARDWARE & & \\
PROPELLANTS & $95 \%$ \\
\hline
\end{tabular}

SI AND Ca REFER TO THE SILICON AND GALLIUM ALUMINUM ARSENIDE PHOTOVOLTAIC OPTIONS RESPECTIVELY

$*_{\mathrm{t}}=$ METRIC TON $(1000 \mathrm{~kg})$

**FLT $=$ FLIGHT

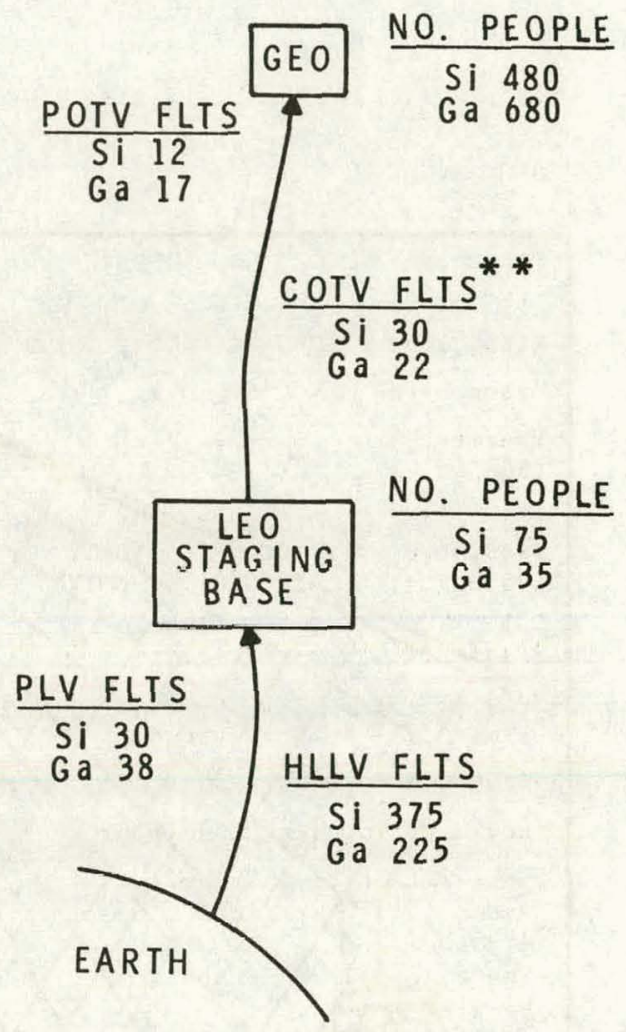

Fig. 2 Scenario for Construction of Two 5-GW Satellites Per Year

Table 1 SPS Space Transportation Vehicles

\begin{tabular}{|c|c|c|c|c|c|c|}
\hline Name & Abbreviation & Function & Propellants & $\begin{array}{l}\text { Launcha } \\
\text { Rate } \\
\left(\text { year }^{-1}\right)\end{array}$ & $\begin{array}{l}\text { Operating } \\
\text { Altitude } \\
\quad(\mathrm{km})\end{array}$ & $\begin{array}{c}\text { Main Exhaust } \\
\text { Products }\end{array}$ \\
\hline $\begin{array}{l}\text { Heavy-lift } \\
\text { launch vehicle }\end{array}$ & HLLV & $\begin{array}{l}\text { Transport of } \\
\text { materials } \\
\text { earth surface } \\
\text { to LEO }\end{array}$ & $\begin{array}{l}\left.\mathrm{CH}_{4} / \mathrm{O}_{2} \text { (Stage } 1\right) \\
\mathrm{H}_{2} / \mathrm{O}_{2} \text { (Stage 2) } \\
\mathrm{H}_{2} / \mathrm{O}_{2} \text { (eircular } \\
\text { ization/deorbit) }\end{array}$ & $\begin{array}{l}375 \\
375 \\
375\end{array}$ & $\begin{array}{c}0-57 \\
57-120 \\
450-500\end{array}$ & $\begin{array}{r}\mathrm{CO}_{2}, \mathrm{H}_{2} \mathrm{O} \\
\mathrm{H}_{2} \mathrm{O}, \mathrm{H}_{2} \\
\mathrm{H}_{2} \mathrm{O}, \mathrm{H}_{2}\end{array}$ \\
\hline $\begin{array}{l}\text { Personnel } \\
\text { launch vehicle }\end{array}$ & PLV & $\begin{array}{l}\text { Transport of } \\
\text { personnel } \\
\text { earch surface } \\
\text { to LEO }\end{array}$ & $\begin{array}{l}\text { Details not } \\
\text { available } \\
\text { (probably same } \\
\text { as HII.V) }\end{array}$ & 30 & $0-500$ & $\mathrm{CO}_{2}, \mathrm{H}_{2} \mathrm{O}, \mathrm{H}_{2}$ \\
\hline Cargo-orbit & COTV & $\begin{array}{l}\text { Transport of } \\
\text { materials } \\
\text { LEO to GEO }\end{array}$ & $\begin{array}{l}\text { Argon } \\
\mathrm{H}_{2} / \mathrm{O}_{2}\end{array}$ & 30 & $500-35,800$ & $\begin{array}{c}\text { Ar ion plasma } \\
\mathrm{H}_{2} \mathrm{O}, \mathrm{H}_{2}\end{array}$ \\
\hline $\begin{array}{l}\text { Personnel-orbit } \\
\text { Lransfer vehicle }\end{array}$ & POTV & $\begin{array}{l}\text { Transport of } \\
\text { personnel } \\
\text { LEO to GEO }\end{array}$ & $\mathrm{H}_{2} / \mathrm{O}_{2}$ & 12 & $500-35,800$ & $\mathrm{H}_{2} \mathrm{O}, \mathrm{H}_{2}$ \\
\hline
\end{tabular}

a Assuming construction of two (silicon option) 5-GW satellites/year. 
Table 2 Exhaust Products of SPS Transportation Vehiclesa

\begin{tabular}{|c|c|c|c|c|c|c|c|c|}
\hline \multirow{2}{*}{$\begin{array}{l}\text { Atmospheric } \\
\text { Region }\end{array}$} & \multirow{2}{*}{$\begin{array}{l}\text { Altitude } \\
\text { Range } \\
\text { (km) }\end{array}$} & \multirow[b]{2}{*}{ Sourceb } & \multirow{2}{*}{$\begin{array}{r}\text { Total } \\
\text { Mass } \\
(\mathrm{kg})\end{array}$} & \multicolumn{2}{|c|}{ Mass (kg) of } & \multicolumn{3}{|c|}{ Specific Emission Products } \\
\hline & & & & $\mathrm{CO}_{2}$ & $\mathrm{CO}$ & $\mathrm{H}_{2} \mathrm{O}$ & $\mathbf{H}_{2}$ & Ar \\
\hline $\begin{array}{l}\text { Troposphere } \\
(0-13 \mathrm{~km})\end{array}$ & $\begin{array}{l}0-0.5 \\
0.5-13\end{array}$ & $\begin{array}{l}\text { HLLV, PLV } \\
\text { HLLV, PLV }\end{array}$ & $\begin{array}{l}6.50(5) c \\
2.85(6)\end{array}$ & $\begin{array}{l}2.60(5) \\
1.14(6)\end{array}$ & $\begin{array}{l}1.17(5) \\
5.13(5)\end{array}$ & $\begin{array}{l}2.60(5) \\
1.14(6)\end{array}$ & $\begin{array}{l}1.30(4) \\
5.70(4)\end{array}$ & -- \\
\hline Stratosphere & $13-50$ & HLLV, PLV & $3.03(6)$ & $1.21(6)$ & $5.46(5)$ & $1: 21(6)$ & $6.06(4)$ & $-\infty-\infty$ \\
\hline Mesosphere & $50-80$ & HLLV, PLV & $7.58(5)$ & $1.99(5)$ & $8.96(4)$ & $4.50 .(5)$ & $1.91(4)$ & $--\infty-\infty$ \\
\hline $\begin{array}{l}\text { Thermosphere } \\
(80-500 \mathrm{~km})\end{array}$ & $\begin{array}{c}80-125 \\
477 d \\
477\end{array}$ & $\begin{array}{l}\text { HLLV, PLV } \\
\text { HLLV, PLV } \\
\text { POTV }\end{array}$ & $\begin{array}{l}2.03(6) \\
3.29(4) \\
4.60(5)\end{array}$ & $\begin{array}{l}-- \\
-- \\
--\end{array}$ & $\begin{array}{l}-- \\
-- \\
--\end{array}$ & $\begin{array}{l}1.96(6) \\
3.17(4) \\
4.43(5)\end{array}$ & $\begin{array}{l}7.10(4) \\
1.15(3) \\
1.12(4)\end{array}$ & --י- \\
\hline $\begin{array}{l}\text { Exosphere } \\
(>500 \mathrm{~km})\end{array}$ & $\begin{array}{c}\text { GEOd } \\
477-\text { GEO }\end{array}$ & $\begin{array}{l}\text { POTV } \\
\text { coTv }^{\text {e }}\end{array}$ & $\begin{array}{l}1.53(5) \\
9.85(5)\end{array}$ & -- & -- & $1.47(5)$ & $4.69(3)$ & $9.85(5)$ \\
\hline
\end{tabular}

amass emissions per flight.

bPLV emissions are chemically similar to those of the HLLV, but are not otherwise determined at this time. The numbers shown are emissions of the HLLV only.

c6.50 (5) denotes $6.50 \times 10^{5}$

dLow Earth orbit (LEO) is at $477 \mathrm{~km}$, geosynchronous orbit (GEO) is at $35,800 \mathrm{~km}$.

eIn addition to mass emissions, the argon plasma engines of the coTv will inject a siguificant amount of energy into this altitude range. Also, argon plasma engines will be used for satellite altitude control at GEO; these emissions are unknown at present and have not been included.

The mass of COTV propellant given is for the $S i$ option. For the GaAlAs option, the Art-mass would be $2.12(5)$.

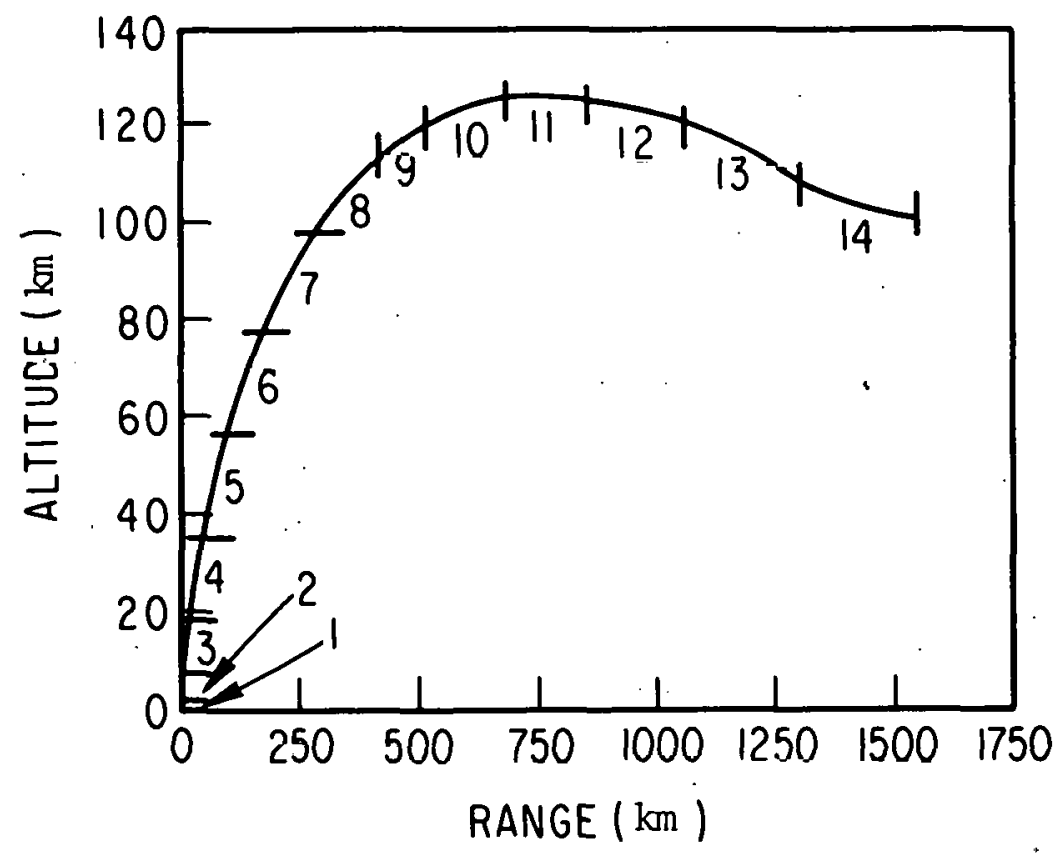

Fig. 3 HLLV Main Burn Trajectory 
Table 3 HLLV Main Burn Exhaust Emissions

\begin{tabular}{|c|c|c|c|c|c|c|c|}
\hline \multirow[b]{2}{*}{ Step } & \multirow{2}{*}{$\begin{array}{l}\text { T1me } \\
\text { (sec) }\end{array}$} & \multirow{2}{*}{$\begin{array}{c}\Delta(\text { Alt1tude }) \\
(k \mathbb{k})\end{array}$} & \multirow{2}{*}{$\begin{array}{c}\Delta \text { (Range) } \\
(\mathrm{km})\end{array}$} & \multicolumn{4}{|c|}{ Emisalons $\left(10^{9} \mathrm{kB}\right)$} \\
\hline & & & & $\mathrm{H}_{2} \mathrm{O}$ & $\mathrm{H}_{2}$ & $\mathrm{CO}_{2}$ & CO \\
\hline 1 & 30.8 & 1.71 & 0.00 & 553.2 & 27.7 & 553.2 & 249.0 \\
\hline 2 & 29.2 & 6.00 & 2.09 & 524.5 & 26.2 & 524.5 & 236.0 \\
\hline 3 & 30.0 & 11.29 & 12.24 & 538.9 & 26.9 & 538.9 & 242.5 \\
\hline 4 & 30.0 & $15: 73$ & 25.02 & 538.9 & 26.9 & 538.9 & 242.5 \\
\hline 5 & 35.2 & 22.06 & 57.26 & 577.3 & 28.9 & $577 . .3$ & 259.8 \\
\hline 6 & 34.0 & 20.64 & 77.43 & 219.9 & 8.0 & 0 & 0 \\
\hline 7 & 40.0 & 19.15 & 99.55 & 253.1 & 9.2 & 0 & 0 \\
\hline 8 & 40.0 & 14.20 & 116.4 & 253.1 & 9.2 & 0 & 0 \\
\hline 9 & 40.0 & 9.25 & 133.2 & 253.1 & 9.2 & 0 & 0 \\
\hline 10 & 40.0 & 4.33 & 153.6 & 253.1 & 9.2 & 0 & 0 \\
\hline 11 & 40.0 & -0.32 & 177,7 & 253.1 & 9.2 & 0 & 0 \\
\hline 12 & 40.0 & -4.02 & 205.2 & 253.1 & 9.2 & 0 & 0 \\
\hline 13 & 40.0 & -5.90 & 238.0 & 253.1 & 9.2 & 0 & 0 \\
\hline 14 & 35.5 & -3.15 & 244.6 & 217.1 & 7.9 & 0 & 0 \\
\hline
\end{tabular}

1. Microwave Effects on Health and Ecosystems

2. Nonmicrowave Effects on Health and Ecosystems

3. Atmospheric Effects

4. Effects of Ionospheric Heating on Telecommunications.

5. Electromagnetic Systems Compatibility

The initial assessment covering these five areas was published by DOE in October 1978.3,4 The first revision to that preliminary environmental assessment report was subsequently prepared in the summer of 1979 and appeared in print in January of $1980.5,6$ The second and final revision of that repurt is publichcd in six volumes: one for each of the five tasks listod above aud one that provides all uvervlew of the whole environmental assessment. This report covers Task 3 .

The objectives of the Atmospheric $\Lambda$ sessment task area are to identify potentially significant effects of SPS-related operations on the entire Earth's atmosphere from the ground to GEO; to predict the nature, extent and significance of those effects within program constiaiuls; and to assess the rellability of those predictions. If effects are found that are judged to be significant, an additional objective is to identify possible mitigating strategies.

Programmatic constraints (program duration and funding levels) have 1 imited the assessment (with a few exceptions) to use of archived data and existing assessment techniques, including mathematical/computer simulation models. Some additional basic scientific data have been acquired through measurement programs associated with certain targets of opportunity. This data has helped resolve some of the important questions that have arisen during the course of the assessment. Moreover, as a result of comparisons between theoretical model simulations and both archived and newly acquired data, some basic improvements have been made in our understanding and ability to predict SPS-related effects. 
Every level of the Earth's atmosphere is potentially affected by the construction and operation of the SPS. The principal SPS activities and their associated potential effects were initially identified as:

1. Rectenna waste heat releases and changes in the albedo and surface roughness of the terrain could lead to local weather modification.

2. Rocket effluents injected into the troposphere, especially near ground level, could lead to air quality degradation and weather modification.

3. Rocket effluents injected into the upper atmosphere could result in climatic changes, partial ozone depletion, partial ionospheric depletion, enhanced airglow emmissions, structural changes in the plasmasphere and magnetosphere, including Van Allen Belt modifications and changes in the response of the Earth's atmosphere to magnetic storms, as well as changes in atmospheric properties that could affect the performance of telecommunications, navigation, and remote sensing systems.

4. SPS stationkeeping, attitude control and emissions from space structures could cause an alteration of the satellite environment.

In addition to elucidating these cause-effect relationships, an important function of Task 3 has been to provide basic information on changes in atmospheric properties to other task areas that are responsible for evaluating the ultimate impacts on health, ecosystems, telecommunications, etc. On the other hand, in the case of ionospheric heating due to absorption of energy from the microwave power beam, Task 4 is responsible for providing basic data that serves as input to Iask 3's assesoment of possible climatic or other atmospheric effects outside the beam cross section.

The initial task of identifying potential atmospheric effects was undertaken in a series of workshops held in 1978. The proceedings of these workshops $7-10$ and a folluw-up workshop in 197911 provide fairly extensive lists of possible effects, and summarize our state of knowledge at that time regarding the effects and their impacts on man's environment. Recommendations for both near- and long-term research needs and approaches also resulted from these workshops.

The issues associated with SPS activities in the troposphere, including inadvertent weather modification there, through rectenna operations and rocket launches, are taken up first, followed by a discussion of air quality impacts associated with rocket launch ground clouds. Then, progressing upward through the various levels of the atmosphere illustrated in Fig. 4, the principal middle and upper atmospheric effects associated with rocket effluents are addressed. For convenience, all of the potential SPS atmospheric effects are summarized in the conclusions. 


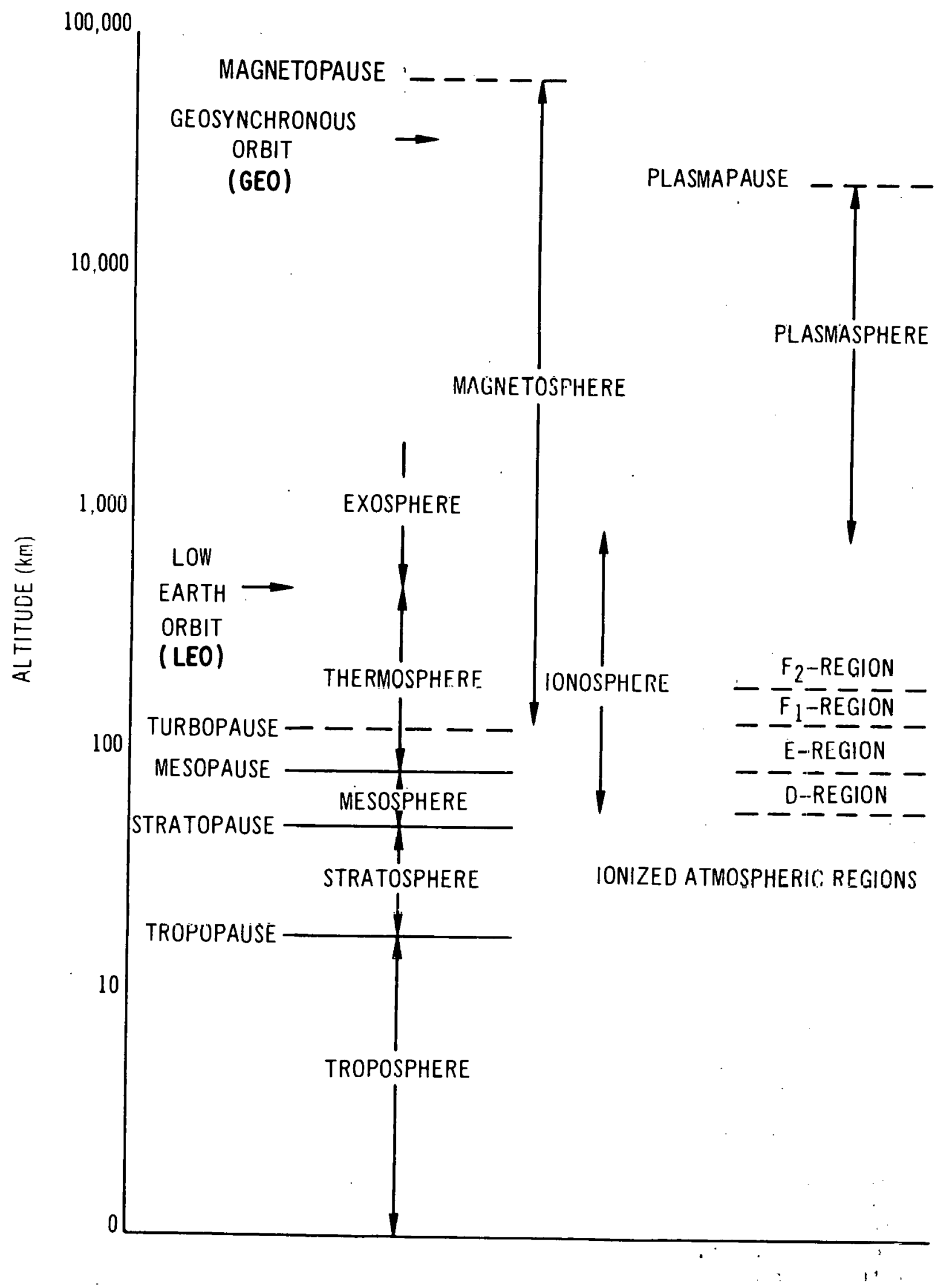

Fig. 4 Regions of the Atmosphere 


\section{ASSESSMENT OF LOWER ATMOSPHERIC EFFECTS}

The term "lower atmospheric effects" refers here to the SPS-related effects occurring in the troposphere, the lowest region of the atmosphere, corresponding to altitudes below about $10 \mathrm{~km}$ at high latitudes and $16-17 \mathrm{~km}$ near the equator. Tropospheric effects are of particular interest, since all plant and animal life, including human beings, are susceptible to changes in this region.

The composition of the tropospheric atmosphere is one of its most important characteristics from the environmental point of view. The major constituents are molecular nitrogen, molecular oxygen, and argon, comprising $78.08,20.95$ and $0.93 \%$ by volume of dry air, respectively; these precentages change only over geologic periods of time, and may be taken as constant for most purposes. The remaining fraction consists primarily of a variable and steadily increasing quantity of carbon dioxide currently approaching 335 ppmv (parts per million by volume), 12 trace (i.e., part-per-million level or less) quantities of other inert gases, methane, and substances such as ozone and various oxides of nitrogen that are generally regarded as air pollutants. In addition to these components of dry air, the atmosphere contains a variable amount of water vapor, ranging up to several percent (water also appears in the atmosphere in its liquid form as fog, clouds, and rain, and in solid form as snow, hail, and ice crystals). As to weather processes, water is by far the most important constituent of the atmosphere. Large quantities of energy are released or absorbed during condensation and evaporation, with profound consequences for atmospheric phenomena. Water vapor, like carbon dioxide, also affects atmospheric radiation properties, and accordingly helps govern the thermal conditions in the atmosphere.

The planetary boundary layer comprises the lowest 1-2 km of the troposphere, the area within which friction between the Earth's surface and the atmosphere significantly affects atmospheric motions induced by large-scale pressure variations and by the diurnal solar heating cycle. The wind and temperature structure in the planetary boundary layer determine the meteorological conditions in which most human activities take place, and its depth and turbulent characteristics affect the ground-level concentrations of various pollutants emitted into the atmosphere by these same human activities.

The construction and operation of a satellite power system (SPS) will directly affect the troposphere in several ways, the most important of which are the effect of the SPS rectennas on local meteorological variables, the effect of SPS-related rocket launches on cloud formation and weather in the vicinity of the launch site, and the effect of sps-related rocket launches on air quality and the acidity of prccipitation.

The presence of a rectenna covering an area of approximately $100 \mathrm{~km}^{2}$ would be expected to alter the aerodynamic characteristics of the surface in its immediate vicinity. A change in surface roughness affects the vertical fluxes of momentum and thermal energy, and a change in radiative properties (albedo for solar radiation and emissivity for terrestrial radiation) affects the surface energy budget. The operation of a rectenna would also add an additional heat source at the surface. The primary consequences of these changes could be to alter the wind velocity profile and stability of the planetary boundary layer and hence to alter the local cloud population. These effects are considered in Ser. 2.1 . 
The possible influence of microwave transmission through the troposphere would arise from the absorption, especially in clouds, of microwave energy along the beam path, causing local heating. On the other hand, the presence of convective or turbulent air motions and the existence of hydrometeors* cause refraction, scattering, and absorption of microwave energy and can lead to beam wandering and spreading. (Many issues of concern regarding the effects of atmospheric conditions on SPS beam propagation can be found in the proceedings of a workshop held in August 1978,7 and are not discussed here).

The proposed heavy lift launch vehicle (HLLV) and personnel launch vehicle (PLV) would emit a large amount of exhaust effluent into the atmospheric boundary layer. These rucket effluents may affect the local environment of the launch site in several ways, all related to the development and subsequent evolution of the rocket ground cloud. The ground cloud cunsists of thc exhausl tmitted by the rocket during the first 15-25 s following ignition and liftoff, together with a large quantity of entrained air, cooling water, dust, and other debris. After the rocket has accelerated to an appreciable velocity, the exhaust products are deposited in a thin column that disperses quickly in the ambient air and would have no significant adverse environmental effects.

Immediately after formation, the ground cloud, due to the buoyant effect of its high thermal energy content, rises to an altitude of between several hundred and several thousand meters, depending upon ambient meteorological conditions. As the cloud rises, much of the surface dust and debris falls out, the distance over which the fallout occurs being determined by the wind speed, by the nature of the turbulence within the cloud, and by the size of the particles. This distance may be as great as a few kilometers. At the same time, the upward convective motion of the ground cloud and the surrounding air may result in the formation of a water-saturatcd cloud (a phenomenon observed after several previous rocket launches) or cven a snnvertive otorm. In addiclon, cloud microphysical processes may be affected by the production in the rocket exhanst nf both cloud cundelisarion nuclei (CCN) and ice-forming nuclei (IN), and by the entrainment of giant nuclei during lift-off. The meteorological effects of such a ground cloud are discussed in Sec. 2.2.

The ground cloud also represents a snurge of air pulluliun and assoiialed effects. The cloud disperses over a period of time, the rate of dispersion being determined by the level of turbulence both in the cloud itself and in the ambient atmosphere. Depending on the rhemical nature of the rocket exhausi products, adverse environmental effects may or may not be produced at ground level. The Reference system design ${ }^{2}$ for both the HLLV and PLV calls for the use of 1 iquid methane and liquid oxygen in the first stage, instead of a solid propellant such as is used in most current rockets. A major exhaust product of solid-fueled rockets is hydrochloric acid. In contrast, the mafor exhaust products of the HLLV and PLV boosters are carbon dioxide and water. Smaller quantities of nitrogen oxides, primarily nitric oxide and nitrogen dioxide, are expected to be produced from a possible molecular nitrogen impurity in the liquid oxygen, from a nitrogen impurity in

*Cloud water droplets, raindrops, hail, ice crystals, etc. 


$$
\because \because \quad \text { a }
$$

the fuel, or from entrainment and heating of ambient air in the hot rocket exhaust. In addition, possible impurities, such as sulfur, in the fuel would give rise to a corresponding amount of oxidation products, such as sulfur dioxide. As described below, sulfur dioxide has been measured in at least one ground cloud because of a sulfur impurity in the hydrocarbon fuels currently in use. Thus, for liquid-fueled rockets like the HLLV and PLV, the potential air quality impacts must arise from substances present in relatively small amounts, the principal exhaust products being environmentally inocuous. The exhaust products of a solid-fueled booster would cause much greater environmental problems. Two types of air quality effects are considered in Sec. 2.3. One, is the direct increase of the atmospheric concentration of gaseous air pollutants; the other, is the effect of rocket exhaust constituents on the acidity of precipitation. The potential tropospheric effects of rocket launches are illustrated in Fig. 5. Many of the effects shown were discussed in a workshop held in September 1978.8

\subsection{INADVERTENT WEATHER MODIFICATION CAUSED BY RECTENNA STRUCTURE AND WASTE HEAT RELEASE}

Human activities have altered the surface of the Earth long before the present era.13 The first major change started when man developed agriculture. Agriculture and lumbering have led to mesoscale climatic changes

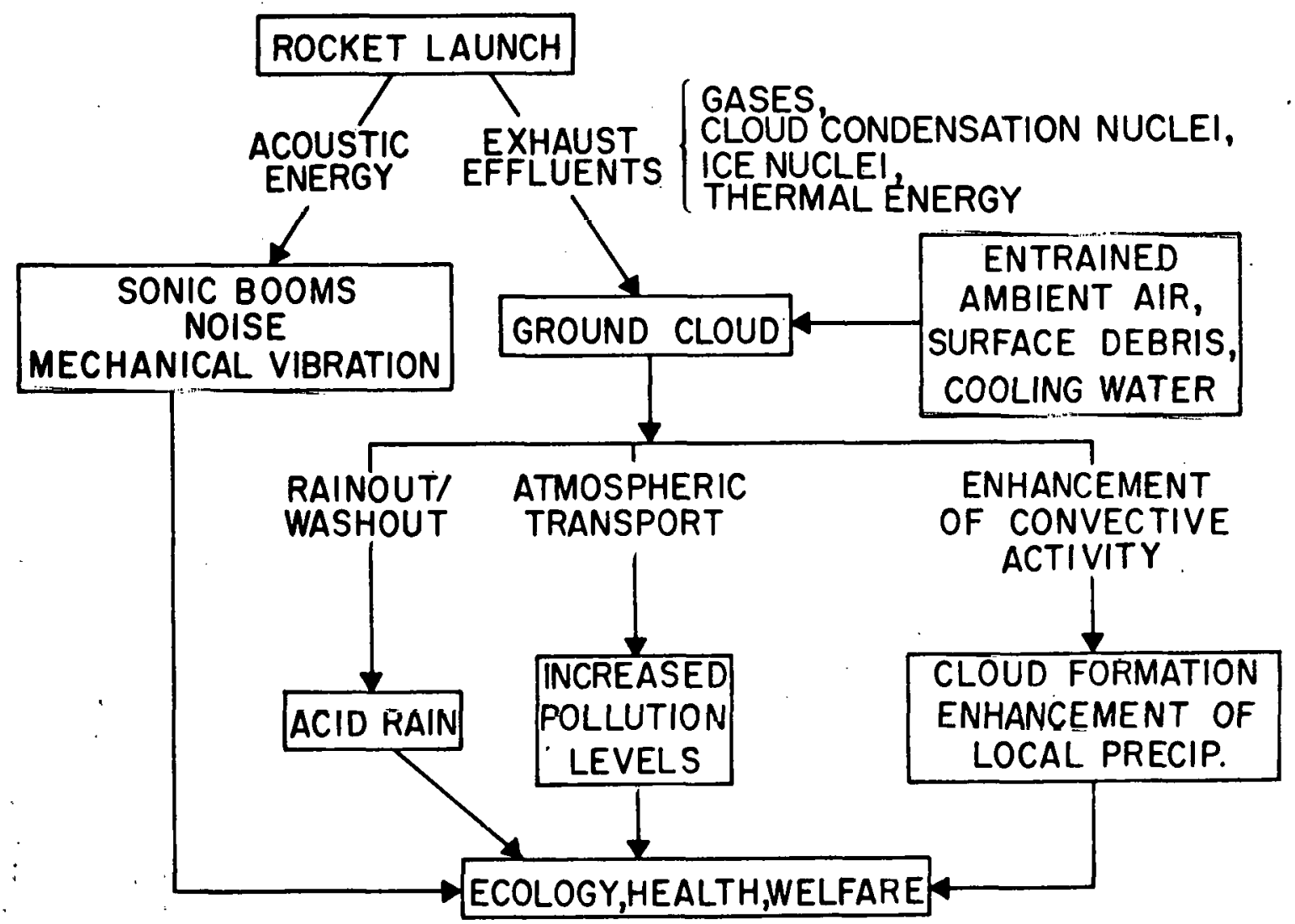

Fig. 5 Potential Tropospheric Effects of Rocket Launches 
owing to the alterations of surface albedo. However, by far the most noticeable and well-documented human impact on local weather and climate is that due to the process of urbanization. Temperature and precipitation anomalies have been observed within and downwind, respectively, of large cities.14,15,16

Huff et al, 17 and Hanna and Gifford 18 presented a comparison of the energy release rates associated with both natural phenomena and man-made features; some of these values are reproduced in Table 4. Based on energy considerations, it appears highly unlikely that large cyclones will be affected in their overall behavior by man's works. However, large cities, having the same spatial scales and energy release rates as thunderstorms, and large islands in the ocean do produce measurable downwind effects on rainfall, storm, and hail frequencies, etc.15 Weather and climate modifications caused by large cities are largely dominated by anthropogenic features, while modifications by large islands are basically affected by natural causes. A 5-fW conventional steau electric generation plant releases approximately $10 \mathrm{GW}$ of waste heal to the atmosphere, a rate close to that of a city, but the area of release is much smaller (i.e., of much higher power density). Increases in cloudiness and convective activity, precipitation augmentation, fogging, icing, and a long visible plume often result. The waste heat of the proposed SPS rectenna is less than $10 \%$ of that of conventional steam electric generation with an area of dissipation comparable to the scale of a "heat island." It is anticipated on this basis that the rectenna waste heat term in the thermal energy balance at the Earth's surface would have negligible meteorological effects.

A preliminary assessment of the possible meteorological effects from SPS rectenna operation was conducted in 1977 at the Lyndon Johnson Space Center.19 The assessment was based upon the maximum power density in the microwave beam of about $230 \mathrm{~W} / \mathrm{m}^{2}$ and an average of $7.5 \mathrm{~W} / \mathrm{m}^{2}$ of waste heat release at a rectenna, covering about $100 \mathrm{~km}^{2}$. The findings were that the

Table 4 Comparison of Man-Made and Natural Energy Releases

\begin{tabular}{|c|c|c|c|}
\hline Energy Source & Area $\left(\mathrm{km}^{2}\right)$ & Duration & $\begin{array}{l}\text { Approx. Power } \\
\text { (CW) input to } \\
\text { Atmosphere }\end{array}$ \\
\hline 'st. Louis & 250 & continuous & 16 \\
\hline Chicago & 1800 & continuous & 53 \\
\hline Aruba Island & 180 & dayt ime & 35 \\
\hline Surteey volcano & 1 & month & 100 \\
\hline Thunderstorm & & & \\
\hline$(2 \mathrm{~cm}$ of $\mathrm{rain} / \mathrm{hr})$ & 100 & hour & 100 \\
\hline $\begin{array}{l}\text { One-megaton nuclear device } \\
\text { Great Lake snow squall }\end{array}$ & . & dissipated over $1 \mathrm{hr}$ & $10^{3}$ \\
\hline$(4 \mathrm{~cm}$ of $s$ now $/ \mathrm{hr})$ & $10^{4}$ & hour & $10^{4}$ \\
\hline Cyclone $(1 \mathrm{~cm}$ of $\mathrm{rain} / \mathrm{day})$ & $10^{6}$ & day & $10^{5}$ \\
\hline 5-GW steam electric & & & ' \\
\hline Power Plant & $1-10$ & continuous & 10 \\
\hline SPS rectenna waste heat & 100 & continuous & 0.75 \\
\hline
\end{tabular}


effects of an SPS rectenna on weather and climate would be small, compared to the direct environmental consequences of construction, and that the rectenna's influence would be similar to that of an average suburban development. The intensity of the atmospheric perturbation resulting from rectenna operation should be very small compared with that of other man-made installations. Microwave heating of the lower atmosphere through gaseous absorption would be negligible. Any actual effects of microwave heating inside a cloud would not be detected in the presence of the natural variance of cloud and storm phenomena. Scattering by particles, even in a heavily-polluted atmosphere, would also be negligible.

The above study was reviewed at the August 1978 workshop ${ }^{7}$ and the conclusions were updated. Three main topics were discussed: the effects of waste-heat release on the atmosphere at the rectenna site, microwave interactions with the atmosphere, and the possible effects of the microwave beam on atmospheric electrification processes. The following brief summaries highlight the most important issues.

Rectenna Waste Heat and Structure

Construction of a rectenna would modify the thermal and radiative properties of the ground on which it is built; operations would introduce a heat source at the surface. Although the magnitude of the perturbation of the average surface heat budget would be on the order of $10 \%$, microwave beam wandering and spreading due to atmospheric refraction may occasionally give rise to larger effects. (However, according to the Reference System design, 2 beam wandering would be prevented by the beam phase control system.)

It is possible to investigate the effects of the rectenna by studying the effects of 1 and-use changes. Small temperature changes (of the order of $1^{\circ} \mathrm{C}$ ) can be expected under light wind conditions. Changes in cloud populations can also he expected. Somewhat larger man-made dissipation rates over comparable areas have been associated with apparent anomalies in the distribution of rainfall.

In hilly terrain, on scales smaller than the rectenna dimensions, diurnally varying changes occur in the surface energy budget that are larger than the projected rectenna waste heat. It is expected therefore that the meteorological effects of a rectenna would vary from site to site, and that the central maximum heat dissipation (approximately 16 $\mathrm{W} / \mathrm{m}^{2}$ ) might become important in augmenting a naturally occurring topographic effect.

Assessment of possible weather and climate effects over areas larger than the mesoscale should not be confined to the influence of the rectenna alone -- the whole satellite power system must be considered in the context of the energy demand it is designed to meet. The overriding feature of the system is that the major inefficiency, the rejection of waste 
heat, occurs in space. Furthermore, there are no significant emissions of material into the troposphere during operation. These aspects are obvious benefits.

\section{Microwave Propagation}

The atmospheric absorption of microwave energy at the proposed SPS frequency is negligible in clear air for the projected tropospheric path lengths of about $20 \mathrm{~km}$. However, some absorption by condensed water (clouds and precipitation) would occur when storms entered the beam path.

\section{Atmospheric Electricity}

Direct interactions with the atmospheric electrical fields are not thought to be important at the proposed frequency. However, the mere physical presence of the rectenna might have some modifying influence on the occurrence and electrical behavior of thunderstorms over and around the rectenna.

To support these conclusions and to carry out recommendations made during the 1978 workshop, some detailed model calculations were conducted. As mentioned earlier, the rectenna may influence local weather and climate through several mechanisms, namely, the release of waste heat from power conversion, and the alteration of surface roughness and the change in radiative properties from the rectenna structure. More important, the degree of influence depends strongly.upon meteorological conditions. Therefore, in the assessment of rectenna effects, at loast four basic variables should be considered in principle in this stage of evaluatinn; they are: typc of site, weather situation, system operation conditinns, and roctenna otructule.

A realistic simulation has been carried out for $24 \mathrm{hr}$ for a potentially unstable boundary layer with 1 ight wind over moist, flat terrain, using a limited-area, primitive-equation, meteorological model.20 The calculations were performed for sun positinns appropriate for 21 . Iune over an area of $39 \mathrm{x}$ $33 \mathrm{~km}$ with and without a rectenna in normal operation. A 3-km square grid was used with eight sub-surface levels down to a depth of $0.8 \mathrm{~m}$ and 18 atmospheric levels up to a height of $2000 \mathrm{~m}$. The site was assumed flat with surface roughness equivalent to long grass, and at two-thirds of its saturated moisture capacity. The atmospheric lapse rate was approximately moiet adiabatic. The physical constants of the soil and initial meteorological conditions were based on observations at $0^{\prime}$ Neill, Nebraska, in May 1953 (Great Plains Project). The surface albedo was taken to be 0.18 , and longwave emissivity 1.0 .

The rectenna structure was taken to be $12 \mathrm{~m}$ high with a $46^{\circ}$ slope, appropriate to $40^{\circ} \mathrm{N}$. latitude. The surface roughness within the rectenna boundary was taken to be equivalent to that of a forest. The microwave beam power level distribution was based on the Reference System report.2. The total waste heat was $423 \mathrm{MW}, 81$ absorbed in the top soil layer and 342 distributed uniformly over the lowest $16 \mathrm{~m}$ above grade. At the present time, the detailed 
radiative properties of the rectenna structure are unknown. The site albedo was assumed to be unchanged by the structure. An approximate analysis indicated that rectenna albedo change is potentially the source of larger perturbations of surface heat balance than is the waste heat, but that practicable adjustments to the surface finish could greatly modify these perturbations. On the other hand, perturbations due to waste heat and roughness change are relatively uncontrollable. It was decided, therefore, to concentrate attention on the effects of waste heat and roughness change.

The results of the calculations showed that at $1200 \mathrm{hr}$ ( $6 \mathrm{hr}$ after start of simulation), the temperature at $16 \mathrm{~m}$ is slightly lowered at all points in the presence of the rectenna. The maximum change is $0.2^{\circ} \mathrm{C}$ in the center of the rectenna, and there is a small temperature reduction $\left(20.05^{\circ} \mathrm{C}\right)$ outside the rectenna area. The absolute humidity at $16 \mathrm{~m}$ is higher by 0.2 to $0.25 \mathrm{~g} / \mathrm{kg}$ (grams of water per kilogram of dry air) within the rectenna area and 0.05 to $0.1 \mathrm{~g} / \mathrm{kg}$ outside the rectenna area, and the changes persist directly downwind.

At $0600 \mathrm{hr}(24-\mathrm{hr}$ elapsed time), the 16-m temperature with rectenna in operation is slightly higher, by about $0.1^{\circ} \mathrm{C}$ within the rectenna boundary and $0.03^{\circ} \mathrm{C}$ outside. The absolute humidity is higher by about $0.1 \mathrm{~g} / \mathrm{kg}$ within the rectenna area, and unchanged, on the average, outside the boundary.

The most notable changes occur in the cloud amount and cloud base height. At midday the cloud amount is increased within the rectenna area by 0.2-0.3 (cloud amount is measured on a scale of 0 to 1,1 meaning complete cloud cover) and its base lowered by 100-200 m. Outside the rectenna area there are small decreases in cloud amount.

Table 5 shows the vertical profiles of the temperature, humidity, and vertical wind component changes at the center of rectenna at midday. The surface temperature is rcduced hy almost $2^{\circ} \mathrm{C}$, and the greatest temperature change is about a $3^{\circ} \mathrm{C}$ reduction at a depth of $1 \mathrm{~cm}$. The temperalure ehange decreases monotonically with height except in the cloud-containing layers around 500-800 m. The absolute hmmidity is lower at the surface, higher in all layers up to cloud base and marginally lower above.

At midnight, the surface temperature at the center of the rertenna is slightly warmer (by about $0.15^{\circ} \mathrm{C}$ ). The air layers are slightly warmer up to the 32-m level with no significant change above. The absolute humidity is slightly higher at the lower $6.4-\mathrm{m}$ layer. The soil is slightly warmer down to a $2.5-\mathrm{cm}$ depth.

The simulations indicated that, excluding the effects of albedo changes, the major cause of the perturbation is the change in surface roughness rather than the release of waste heat. Air and soil temperature decreased during the daytime and increased only marginally at night. The increased mechanical mixing resulted in increased evaporation and absolute humidity, increased cloud amount, and decreased cloud-base height. The decrease in solar radiation resulting from the increase in cloud amount is greater than the waste heat contribution. Cloud modification would be expected to be quite different if the roughness had not been changed. 
Table 5 Changes of Temperature, Humidity, and Vertical Wind Component Profiles at the Center of the Rectenna, $1200 \mathrm{hr}$

\begin{tabular}{cccc}
\hline Height $(\mathrm{m})$ & Temp. Change $\left({ }^{\circ} \mathrm{C}\right)$ & Humidity Change $(\mathrm{g} / \mathrm{kg})$ & $\begin{array}{c}\text { Vertical Velocity } \\
\text { Change }(\mathrm{cm} / \mathrm{s})\end{array}$ \\
\hline 1500 & -0.002 & 0 & 0.142 \\
1000 & -0.005 & 0 & 0.177 \\
800 & -0.010 & -0.004 & 0.229 \\
600 & +0.004 & -0.300 & 0.008 \\
400 & -0.049 & -0.003 & 0.215 \\
200 & -0.084 & +0.098 & 0.126 \\
100 & -0.111 & +0.167 & 0.048 \\
16 & -0.205 & +0.254 & 0 \\
3.2 & -0.420 & +0.322 & -0.002 \\
0.0 & -1.727 & -2.340 & 0 \\
-0.013 & -2.914 & & \\
-0.050 & -1.742 & & \\
-0.200 & -0.104 & & \\
\hline
\end{tabular}

The simulation showed that for the given site characteristics and meteorological conditions, weather/climate effects of the construction and operation of a rectenna are small, particularly outside the boundary of the structure. From these results it seems clear that an albedo change is potentially the source of greater perturbations than appear in this simulation. An approximate analysis of the problem of rectenna albedo and its diurnal variation suggested that it would be difficult to simulate the albedo, even initially, to better than \pm 0.02 , which at summer noon corresponds to a greater perturbation than the maximum waste heat in the center of the rectenna. It will be necessary in future work to quantify the albedo of a realistic structure with a realistic surface $f i n i s h$, and investigate the combined effects of albedo and roughness changes.

A first examination of the combined effects caused by the rectenna waste heat, surface roughness, and radiative properties was done by a series of model simulations with various boundary oonditious (more specifically, by varying surface boundary temperature). The model used in thene simulatious was a three-dimeusional, secund=order turbulence closure equation set.2l Roughness lengths for the rectenna area and its surrounding were assumed to be $1 \mathrm{~m}$ and $3 \mathrm{~cm}$, respectively. Meleorological conditions were selected for a daytime, boundary-layer situation (constaut potential temperature up to $650 \mathrm{~m}$ in height, then increasing with height at a rate of $3.5^{\circ} \mathrm{C} / \mathrm{km}$ ) with 1 logarithmic wind profile up to $4 \mathrm{~m} / \mathrm{s}$ and remaining constant above that. The surface temperature was gradually increased with time (from $25-30^{\circ} \mathrm{C}$ during; the 8-hr integration) to simulate an unstable boundary layer. A constant relative humidity of $50 \%$ was assumed. No clouds were formed in this (dry convection) situation. The following linear relationships summarize results: for some variables of interest for dry convection conditions, provided that the surface temperature difference between the rectenna and its environs remains smali ( $0<$ $\left.\mathrm{T}<2^{\circ} \mathrm{C}\right)$ : 


$$
\begin{aligned}
\mathrm{v}_{2} / \mathrm{v}_{1} & =0.733+0.014 \Delta \mathrm{T} \\
\mathrm{u}_{2}^{*} / \mathrm{u}_{1}^{*} & =1.88+0.1 \Delta \mathrm{T} \\
\mathrm{w} & =7.2+3.9 \Delta \mathrm{T} \text { and } \\
\mathrm{H}_{2} / \mathrm{H}_{1} & =3.47+1.555 \Delta \mathrm{T}
\end{aligned}
$$

where:

$$
\begin{aligned}
& \mathrm{H}= \text { surface heat } \mathrm{flux}, \\
& \mathrm{u}^{*}= \text { friction velocity, } \\
& \mathrm{V}= 14 \mathrm{~m} \text { horizontal wind speed, } \\
& \Delta \mathrm{T}\left({ }^{\circ} \mathrm{C}\right)= \text { excess surface temperature of the } \\
& \text { rectenna area over the upwind boundary, and } \\
& \mathrm{w}(\mathrm{cm} / \mathrm{s})= \text { maximum vertical velocity; } \\
& \text { subscripts } 1 \text { and } 2 \text { denote values at the upstream edge and } \\
& \text { the center of the rectenna area, respectively. }
\end{aligned}
$$

The results of this numerical simulation indicated that increased roughness over the rectenna area considerably increases the friction velocity (by a factor of 1.9) and decreases the surface wind speed (by a factor of 0.73 ) at the center of the rectenna area in comparison with values at the upstream boundary. The resulting convergence of horizontal wind causes a maximum vertical wind component of $7.2 \mathrm{~cm} / \mathrm{s}$ about $10 \mathrm{~km}$ downwind from the rectenna center and $700 \mathrm{~m}$ above grade. If sufficient energy is available at the surface boundary, an increase in surface heat flux of up to a factor of 3.5 could result from enhancing vertical turbulent mixing due to the increase in surface roughness inside the rectenna area, without perturbing the surface temperature. Sufficient energy could presumably be made available by reducing the surface albedo; under the simulated condition', however, unrealistically large surface albedo change would be required. The simulated heat fluxes at the upstream boundary and the rectenna center are 91 and $316 \mathrm{~W} / \mathrm{m}^{2}$, respectively. Inclusion of $8 \mathrm{~W} / \mathrm{m}^{2}$ of waste heat would cause a surface temperature perturbation of only $0.06^{\circ} \mathrm{C}$, a negligibly small value. These simulations should, by no means, be considered very realistic. However, the results do show that an increase in roughness results in more efficient transport of vertical turbulent fluxes without significantly increasing the surface temperature. Therefore, it may be appropriate to conclude that surface roughness and albedo changes are the major causes of perturbation and that they may be of equal importance.

In examining the effects of the rectenna and its operatiun, consideration must also be given to the possible effect of the microwave beam itself, particularly due to absorption in water droplets. Information regarding the amount of microwave absorption per. unit path length as a function of rainfall rate is available. 22 With the most extreme rainfall rate of 254 $\mathrm{mm} / \mathrm{hr}$ as an example, the attenuation at the proposed $2.45-\mathrm{GHz}$ frequency is estimated to be rabout $0.063 \mathrm{db} / \mathrm{km}$. At the proposed maximum power density of $230, \mathrm{~W} / \mathrm{m}^{2}$, the absorbed microwave power inside the storm would be approximately $3.2^{\prime} \times 10^{-3} \mathrm{~W} / \mathrm{m}^{3}$, which is approximately two orders of magnitude smaller than the release rate of the buoyant energy of a typical cumulus cloud. Therefore, it is reasonable to conclude that the absorption of SPS microwave power by a 
storm will have no significant influence on cloud dynamics and thermodynamics and the associated precipitation.

\subsection{INADVERTENT WEATHER MODIFICATION BECAUSE OF ROCKET LAUNCHES}

The principal concerns about inadvertent weather modification by SPS rocket effluents are (1) the possibility that the ground cloud might temporarily modify local weather and (2) the cumulative effects of 375 or more 1 aunches per year. We shall discuss these issues of concern through the consideration of (1) the immediate dynamical and thermodynamical responses to the inputs of thermal energy and moisture from the rocket exhaust for given ambient meteorological conditions and (2) the possible alteration of the microphysical prucesses of clouds in the general area because of rocket effluents and debris and cooling water entrained during the launch. An analysis of the first aspect, namely, the immediate response of the atmoophere to the rocket effluents seems, at least at first glance, to be relatively straight-forward. Presumably one can use existing cloud models validated by previous rocket launch observations to simulate the convective motion of the cloud and the associated precipitation. Such models require as input, the initial thermal energy and total water content of the ground cloud and column cloud. However, measurements of these quantities are not generally available, and they must be estimated. The assessment of potentially significant inadvertent weather modification in terms of changes of cloud microphysical processes is similar to the assessment of planned weather modification. The degree of possible modification is complicated and not easy to assess; it depends upon the time of year, the site location, the origin of the air mass, and the various scales of weather patterns. Unfortunately, the assessment of possible rocket-related, inadvertent modification is even more difficult because there have been few observations made during past rocket launches that are relevant to both aspects.

The central issue with regard to cloud microphysical procesees is the possible production of cloud condensation nuclei (CCN) and ice nuclei (IN) in the rocket-exhaust grnund $r 1$ nud. Cloud oondenoation nuilei serve as particles upon which water vapor condenses to form water droplets that in turn form clouds and fogs. They play an important role in determining the colloidal stability of clouds and the formation of precipitation. In general, the addition of $\mathrm{CCN}$ may tend to slow down the warm rain-formation processes if the total CCN exceeds $10^{3} \mathrm{~cm}^{-3}$. However, if very large hydroscopic particles ( $g$ iant nuclei with radii $>25 \mu \mathrm{m}$ like those expected to come from launch pad debris) are present, the rain-formation process may be accelerated. In the Florida area, some rainfalls are associated with condensation-freuding processes in a deep convection cloud system. In an IN-deficient, supercooled cloud, the addition of IN is expected to stimulate ice nucleation processes and lead to precipitation, although the effectiveness of this process (the basis for artificial cloud seeding) remains controversial. The global concentration of $I N$ is about one per 1 iter effective at $-20^{\circ} \mathrm{C}$. In planned weather modification, approximately 10 effective ice-forming nuclei per 1 iter are added at a supercooled cloud temperature of approximately $-10^{\circ} \mathrm{C}$ to,$-15^{\circ} \mathrm{C}$ for precipitation enhancement, and one to several hundred IN per liter are added for thunderstorm modification. 
The measurements of the November 1978 Atlas/Centaur (a liquid, hydrocarbon-fueled rocket) 23,24 ground cloud indicated that the concentrations of ice-forming nuclei generated by the rocket launch had limited potential for weather modification. However, because of uncertainties in measurement techniques and evidence for the creation of new IN as the ground cloud aged, the potential for weather modification due to the production of ice-forming nuclei cannot be assessed with confidence at this time. The concentrations of $\mathrm{CCN}$ in the Atlas/Centaur ground cloud were meteorologically significant. The initial emission was about $1.2 \times 10^{17} \mathrm{CCN}$ (active at $0.5 \%$ supersaturation), equivalent to a 10-s emission by the City of Denver. In addition, CCN were produced in the ground cloud at a rate of about $1 \mathrm{CCN} \mathrm{cm}-3 \mathrm{~s}^{-1}$. It should be noted that field and laboratory measurements $23,24,25$ of Titan III (solid-fueled booster) ground clouds concluded that both the IN and $C C N$ concentrations were of meteorological significance. The maximum IN concentration active at $-20^{\circ} \mathrm{C}$ could be as high as $2 \times 10^{5}$ per liter, which leads to an estimate of $10^{18}$ IN being produced per launch. The initial emission of $C C N$ from the Titan III rocket was 1018 (active at $0.5 \%$ supersaturation). In addition, the $C C N$ production rate within the cloud was fairly constant at $0.5-1 \mathrm{CCN} \mathrm{cm}^{-3} \mathrm{~s}^{-1}$ for a period of four hours after launch. The proposed HLLV would be liquid fueled. According to Table 1, the exhaust products from this 1iquid propellant are not considered to produce effective ice nuclei; any IN present in the exhaust ground cloud would presumably be derived from debris and cooling water entrained during rocket launch. It is not possible at this time to estimate whether the HLLV would produce a significant number of effective IN in terms of weather modification potential. The long-lasting concentrations of cloud condensation nuclei observed in both solid and liquid-fueled rocket clouds could alter the. frequency and persistence of fogs and haze on the surface and the precipitation processes in warm clouds. In view of the high launch frequency proposed for the SPS space vehicles, a potential may exist for cumulative effects. More studies are needed in this regard.

Notable concentrations of dry particles as large as $200 \mathrm{\mu m}$ in diameter have been detected within a few minutes after launch in the 1978 Atlas/Centaur ground cloud.26 A distinct particle mode around $200 \mu \mathrm{m}$ and some much larger particles $(\approx 500 \mu \mathrm{m})$ were also found in the particle spectrum measured in the 1978 Titan III ground cloud. 26 Although the $\approx 500 \mu \mathrm{m}$ particles in the Titan cloud were liquid drops, they probably represent entrained debris or cooling water spray droplets, since it is difficult to grow raindrops this large within a few minutes by condensation or collection processes. The entrained debris in the Atlas/Centaur ground cloud and its contribution to the population of giant nuclei were evident from elemental analysis of sample particles. The presence of these giant nuclei in the ground cloud will speed up the formation of precipitation if meteorological conditions are favorable.

In addition to these microphysical effects, the thermal energy and moisture contained in the rocket exhaust ground cloud are directly responsible for inducing a water-saturated, wet convective cloud and associated precipitation under certain meteorological conditions. The thermal energy provides sufficient buoyancy to lift the ground cloud and surrounding air to higher altitudes. During ascent, air cools through adiabatic expansion and, under certain conditions, reaches saturation to form a water-saturated cloud. Subsequently, cloud convection is further enhanced through the release of latent heat, leading in some cases to precipitation. 
The phenomenon of a saturated, wet cloud formed by rocket exhaust has been observed on several occasions. Perhaps the most comprehensive and unique data are those obtained during a Titan III launch on December 13, 1978, at Kennedy Space Center. These data together with those observed during the November 1978 Atlas/Centaur launch were used to validate a cloud model* for use in the assessment of HLLV impact. For the case of the Titan III launch, temperature and dew point soundings prior to the time of launch ( $1940 \mathrm{EST}$ ) indicated that air in the surface boundary layer was humid but potentially stable as shown in Fig. 6. Rocket effluents produced a saturated white cloud having the characteristics of a moderately-sized, vigorous cumulus cloud. Aircraft measurements of the column cloud at 4 minutes after launch at a height of $1110 \mathrm{~m}$ indicated the cloud had droplet concentrations of $1 \mathrm{nnn} \mathrm{cm}^{-3}$ and a pcak liquid water cuntent (measured by the Johnson-Williams hot wire) of $1.2 \mathrm{~g} / \mathrm{m}^{3}$. The liquid water was observed to decrease steadily later on. Measurements of the ground cloud were not made until $25 \mathrm{~min}$ allel launch; at that time the ground cloud was still saturated, with a liquid water content of about $0.1 \mathrm{~g} / \mathrm{m}^{3}$. Thereafter, only portions of the ground cloud were found to be saturated; however, the liquid water content was still detectable until 51 min after launch. The persistence of 1 iquid droplets, long after the cessation of detectable updraft might be due to impurities in the liquid water (perhaps related to the presence of $\mathrm{HCl}$ ).

The proposed HLLV would emit approximately $1.08 \times 1.0^{11} \mathrm{cal} / \mathrm{s}$ of thermal energy together with $2.02 \times 10^{7} \mathrm{~g} / \mathrm{s}$ of water to the atmosphere. Approximately 15 seconds of exhaust would be contained in the ground cloud. Model calculations indicated that, under the same meteorological condition, the HLLV thermal effluent could generate a much more vigorous convective cloud than the Titan effluent, as shown in Fig. 7. The maximum cloud liquid water content in the HLLV cloud was predicted to be about three times that of the Titan cloud, as shown in Fig. 8 (an initial thermal energy of $9.4 \times 10^{10}$ cal was assumed in the Titan cloud). Furthermore, light precipitation with a maximum rainwater content of $0.07 \mathrm{~g} / \mathrm{kg}$ was predicted for the HLLV cloud, but the duration of a saturated cloud was shorter. Virtually all the liquid watcr and precipitation arises from water initially present in the atmosphere, not from the water content of the HLLV and Titan rocket exhaust. The vigor of the perturbation generated by both rockets lasts for only a short time and the duration of both saturated clouds is less than $30 \mathrm{~min}$. The calculated duration of a wet cloud being shorter than the observed one probably is due to the fact that the model calculation does not consider any impurities in the 1 iquid water in the Titan ground cloud. Such impurity effects could be important and should be considered in future studies.

It should be noted that results given above should not be used to scale predictions of HLLV effects for all weather conditions. The degree of

\footnotetext{
* The model used was a modified version of one given by Lee (1971)27 in which the eddy diffusivity is parameterized to be proportional to the deformation tensor, similar to that used by Cotton, 28 and the time rate of change of cloud radius is parameterized to be proportional to the eddy diffusivity. Documentation and validation (with observed rocket exhaust ground cloud) of the model are in preparation.
} 


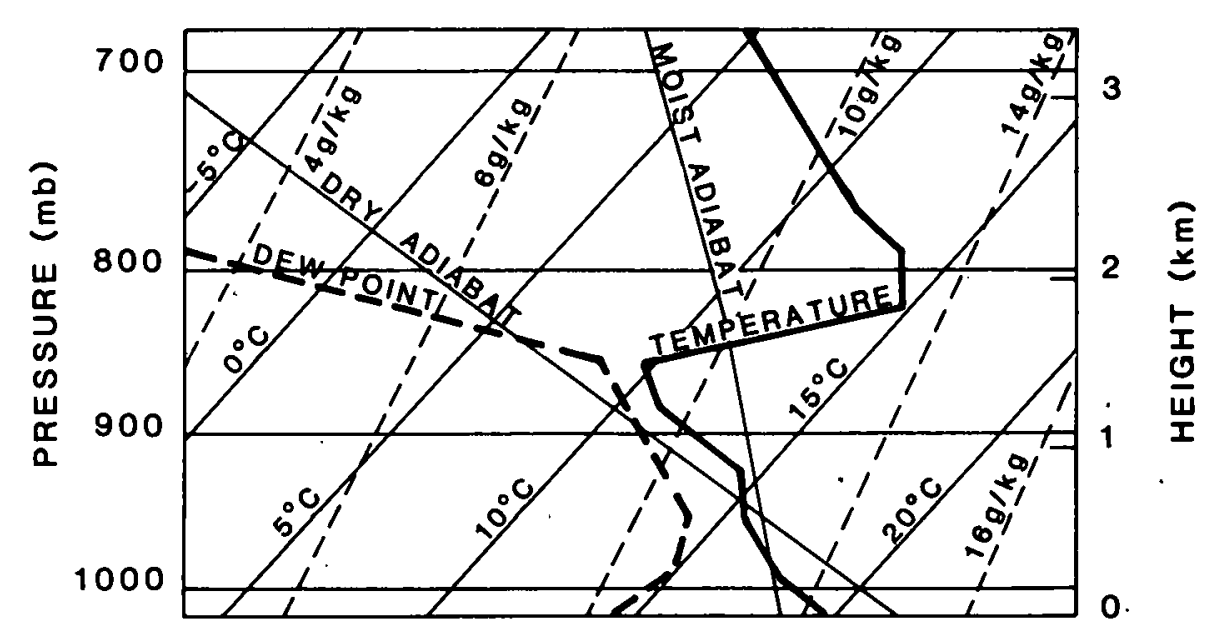

Fig. 6 Basic Sounding for 1936 EST December 13, 1978, Cape Canaveral, Florida
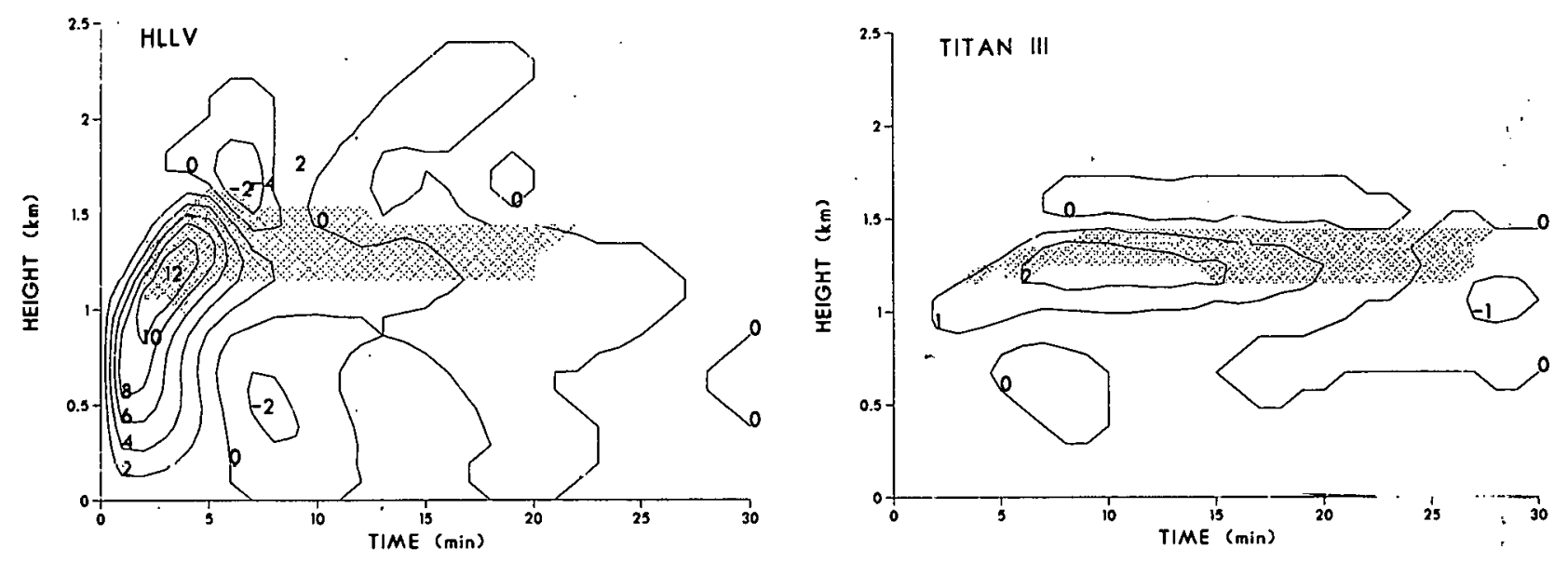

Fig. 7 Comparison of Predicted Maximum Vertical Velocity (m/s): HLLV and Titan III ground clouds (shaded areas are saturation regions)
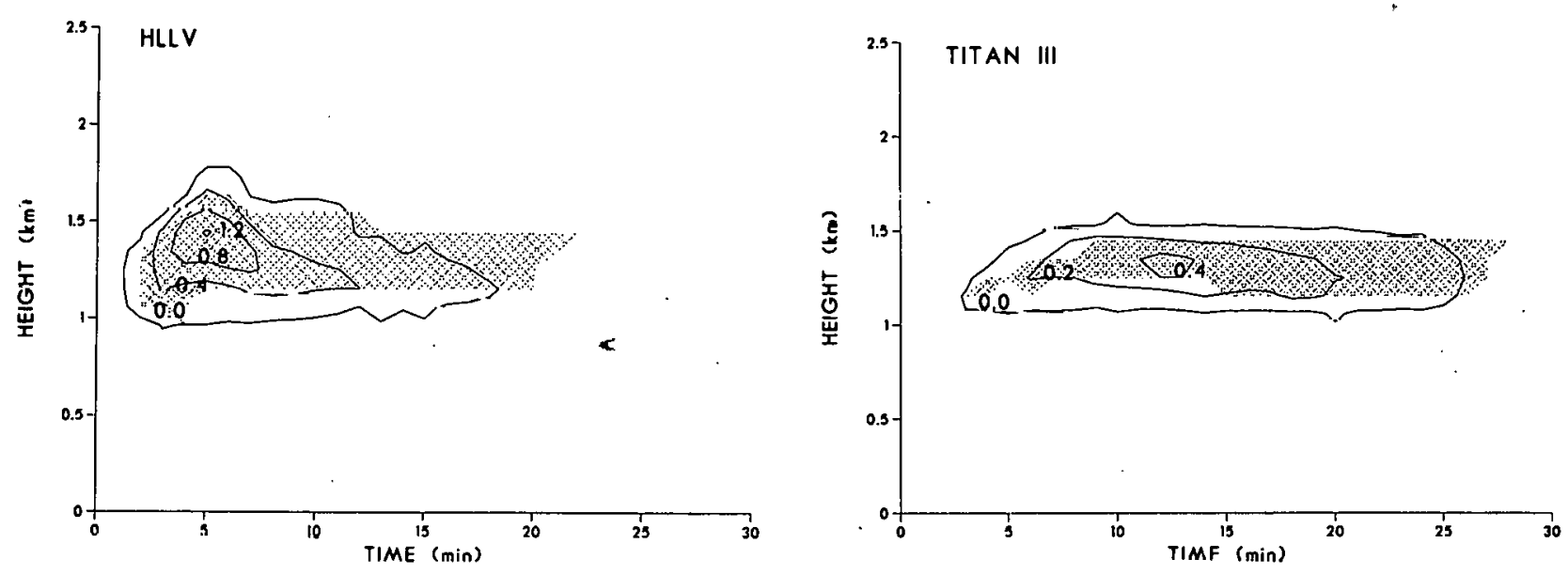

Fig. 8 Comparison of Predicted Mean Cloud Liquid Water Content $(\mathrm{g} / \mathrm{kg})$ : HLLV and Titan III Ground Clouds (shaded areas are saturation regions) 
impact among variono sizes of rockets varies from one meteorological condition to atother. some examples, in addition to the above situation, representing typical conditions in the Florida area for various times of day and synoptic situations are discussed briefly in the following cases.

\subsubsection{Midday Unstable to Neutral Boundary Layer Capped by Dry Stable Air}

This situption is typical at midday when air is influenced by the anticyclonic high pressure system. Soundings used for this case were taken at 1304 EST, on April 16, 1972, at Cape Kennedy during the Apollo 16 iaunch.29 The air, having an adibatic lapse rate (on the average), was capped by dry stable. air starting at about $2 \mathrm{~km}$ in height. Temperature and dew point soundings shor that the atmoophere (wilh $58 \%$ relative humidity near the surface and $83 \%$ at $2 \mathrm{~km}$ ) was potentially unstable (but relatively more stable than Case 2.2.4 belowi) with a lifting condensation level at about $1.2 \mathrm{~km}$.

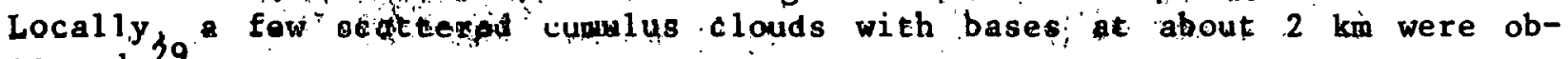
served. 29

A real-tije mofion picture of the evolution of the ground cloud formed after the Satura $\forall$ rocket launch is available from. NASA. In reviewing this

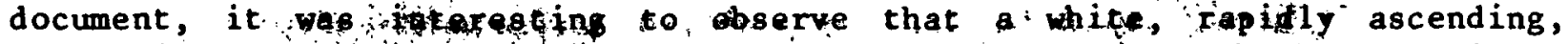
convective cloud formo ap apoximately 2 min after laubch win the faintly visible brownish of of exhaust gas. This formation was followed by an optically dense convective wite bubble penetrating through the top of the brownish ground cloud. Meanwile, a natural cumulus cloud entered the circulation cell, descended and dissipated within a couple of minutes. Unfortunately, this document only showed the evolution of the ground cloud for the first 5-10 min.

Model simulations under these conditions showed that quasi-steadystate, convective cloud motions with similar intensities were generated by all types of rockers, even those for which the exhaust thermal energies are different, by two orders of magnitude (such as the HuLV and the At las/Centaur).. The resulted differ only for the firct 1020 pin as indicated by the vertical velocity fields, and approach each other later on. The predicted maximu cloud liquid water for the HLLY cloud was about $1.3 \mathrm{~g} / \mathrm{kg}$ with light prectipitation at bout $0.13 \mathrm{~g} / \mathrm{kg}$ of rainwater. The predicted precipitation is only $y_{x}$ light 1 y lawer for other smaller rocket clouds.

\subsubsection{Mid-Morning Conditionally Unstable Boundary Layer Capped by Dry Stable Air}

The synoptic influence is similar to the case above. During midmorning, the air in the surface boundary layer has not yet absorbed enough solar energy to develop a neutral boundary layer.

A Titan IIIC rocket (AF-777) was launched at the Rennedy Space Center at 1004 EDT on May 20, 1975. Archived sounding data30 taken immediately after Haukh show that a subsidence inversion existed with a base of about $2 \mathrm{~km}$. Below this dry stable air was a boundary layer with a temperature lapse rate averaging between dry and moist adiabatic and a nearconstant relative humidity of about $62 \%$. The Titan ground cloud was observed 
to rise to an altitude of $2 \mathrm{~km}$ and stabilize at that altitude. Model calculations showed that the HLLV exhaust cloud would penetrate several hundred meters higher through the inversion layer and then subside to the $2-\mathrm{km}$ altitude. Except for a brief period (between 2 and $10 \mathrm{~min}$ ) of saturation, no significant cloud modification was calculated for the HLLV exhaust ground cloud.

\subsubsection{Nighttime Absolutely Stable Condition}

The sounding used here is that taken at 0059 EST on November 13, 1978, at Cape Canaveral during the Atlas/Centaur launch. A marine inversion at about $700 \mathrm{~m}$ above grade was capped by a dry stable layer above. Relative humidity in the marine inversion layer was about $95 \%$. A strong nocturnal ground-base inversion of approximately $130 \mathrm{~m}$ in thickness was also present. Immediately after launch, a cloud was observed to rise vertically from the launch pad to the stable atmospheric layer at about $1100 \mathrm{~m}$; it was then observed to rapidly subside between 2 and 15 min after launch. The ground cloud stabilized within $200 \mathrm{~m}$ at $600 \mathrm{~m}$ above grade. The cloud was subsaturated and no 1 iquid water was detected. 24

Model prediction showed that the HLLV thermal effluent (about 100 times that of the Atlas/Centaur) would raise the ground cloud to a height of $2 \mathrm{~km}$, penetrating through the stable dry layer, and then stabilize-within this stable layer centered at about $1.2 \mathrm{~km}$ in height. A couple of brief periods of saturation were predicted, with a maximum liquid water content of only about $0.16 \mathrm{~g} / \mathrm{kg}$. No significant cloud modification from the HLLV exhaust was predicted in this case.

\subsubsection{Potentially Unstable Air, Thunderstorm Situations}

Viking $B$ was launched during the time when a culd front was passing through the Florida Peninsula on September 9, 1975. Thunder to the west was audible, and cumulonimbus clouds were observed in all quadrants at the time of launch. 31 The sounding taken at 1424 EDT ( 15 min before launch) shows that the atmosphere was potentially highly unstable with a dry adiabatic temperature lapse rate below $900 \mathrm{~m}$ and a moist adiabatic lapoc rate ahnve $2300 \mathrm{~m}$. Relative humidities were above $80 \%$ throughout the entire layer below $6 \mathrm{~km}$ with saturation recorded around the $3.5-$ and $6-\mathrm{km}$ levels. Wind speeds were light with little shear throughout the layer. The ground cloud formed by the Titan III rocket effluent was observed to rise to $1.7 \mathrm{~km}$ at 8 min after launch and then to subside to about $1.5 \mathrm{~km}$ at $12 \mathrm{~min}$ after launch. During this period the track of a thunderstorm cell located to the west of the launch site intersected the exhaust ground cloud.31 No further report about the groundcloud trajectory was available thereafter. The model calculation using rawinsonde data taken at Cape Canaveral AFS prior to the launch confirmed the observed trajectory. It also showed that the ground cloud only encounters a brief period of saturation (between 4-8 min after launch) between $1.1-1.3 \mathrm{~km}$, with a maximum liquid water content of less than $0.1 \mathrm{~g} / \mathrm{kg}$. The characteristic pattern of dry convection is seemingly not influenced by the small amount of latent. heat of condensation. 
It is interesting to see the calculated results for the HLLV under these conditions. The thermal energy contained in the HLLV ground cloud induces a violent convective storm reaching $6 \mathrm{~km}$ in height after 60 min of convection. The first light precipitation. reaches the surface at about 15 $\mathrm{min}$, and is followed by a pulse of heavy rainfall at $40 \mathrm{~min}$ and a much weaker pulse at $52 \mathrm{~min}$. Fig. 9 shows the calculated mean cloud liquid water content and rainwater as functions of time and height for this case. The storm cloud was predicted to dissipate rapidly and became insignificant after 60 min of calculation.

This result demonstrates an example of a situation in which a convective instability is present, but only the larger rocket has sufficient energy input to "trigger" the instability.

The above discussion highlights only the possible effects in some chosen metentological conditious. In view of the nonlinearity and the relative inecnsitivily of the results to the rocket energy output in some situations, a complete future assessment should include a climatology of the HLLV impacts for a given launch site for an updated HLLV design.

In summary, the HLLV with its huge amount of thermal effluent will produce a larger and higher cloud than other existing smaller rockets. Because of its ability to raise the cloud and the surrounding air to higher elevations, the SPS rocket is more likely to generate a saturated wet cloud and light precipitation under high relative humidity but potentially stable conditions, and has a higher potential of releasing an existing convective instability than smaller rockets. The degree of cloud modification attributable to the lauaching of various rockets is not linearly related and depends sensitively upon meteorological conditions. Generally, the conditions that favor onshore flow without strong westerlies above the planetary boundary layer are conducive to greater inadvertent weather modification by SPS rocket launches in the Florida area. Sharaoteristic syuuprtc weather regimes that would fall inlu this category were identified in a thenretioal atudy uf space-rhuttle exliausi clouds. 32 The conditions include hurricanes; easterly waves of summer; stagnating frontal zones; cool-season squall lines; coolseason, low-latitude, mid-tropospheric troughs; warm-season, weak, mid-tropospheric troughs; and coastal sea-breeze convergence regimes.

The upper-bound probabilities for disturbed conditions resulting from the aforementioned pyents arc given $i$ the shuttle ground cloud study. 32 Disturbed conditions (cumulonimbus coverage 20-50\%), persisting 24-72 hr may encompass the Cape Canaveral area once every three or four years due to the influence of hurricanes or tropical storms. Easterly waves with disturbed conditions persisting 12-24 hr may reach the Florida area every four or five days between mid July and September. Stagnating fronts across central Florida happen five to six days in March and December (less in January and February) and two to three days in early June and late September. Disturbed conditions and accompanying rainfall may persist for 12-24 hr. Occasional squall lines with precipitation duration of one hour or less may sweep across central Florida in winter. Cool season, low-latitude, mid-tropospheric troughs occur only once every three years. Finally, warm-season, weak, mid-tropospheric troughs can interact with the sea breeze convergence regime to produce potentially highly unstable conditions several days each month. This leads to a general rule for mitigation in terms of rocket launches. With 

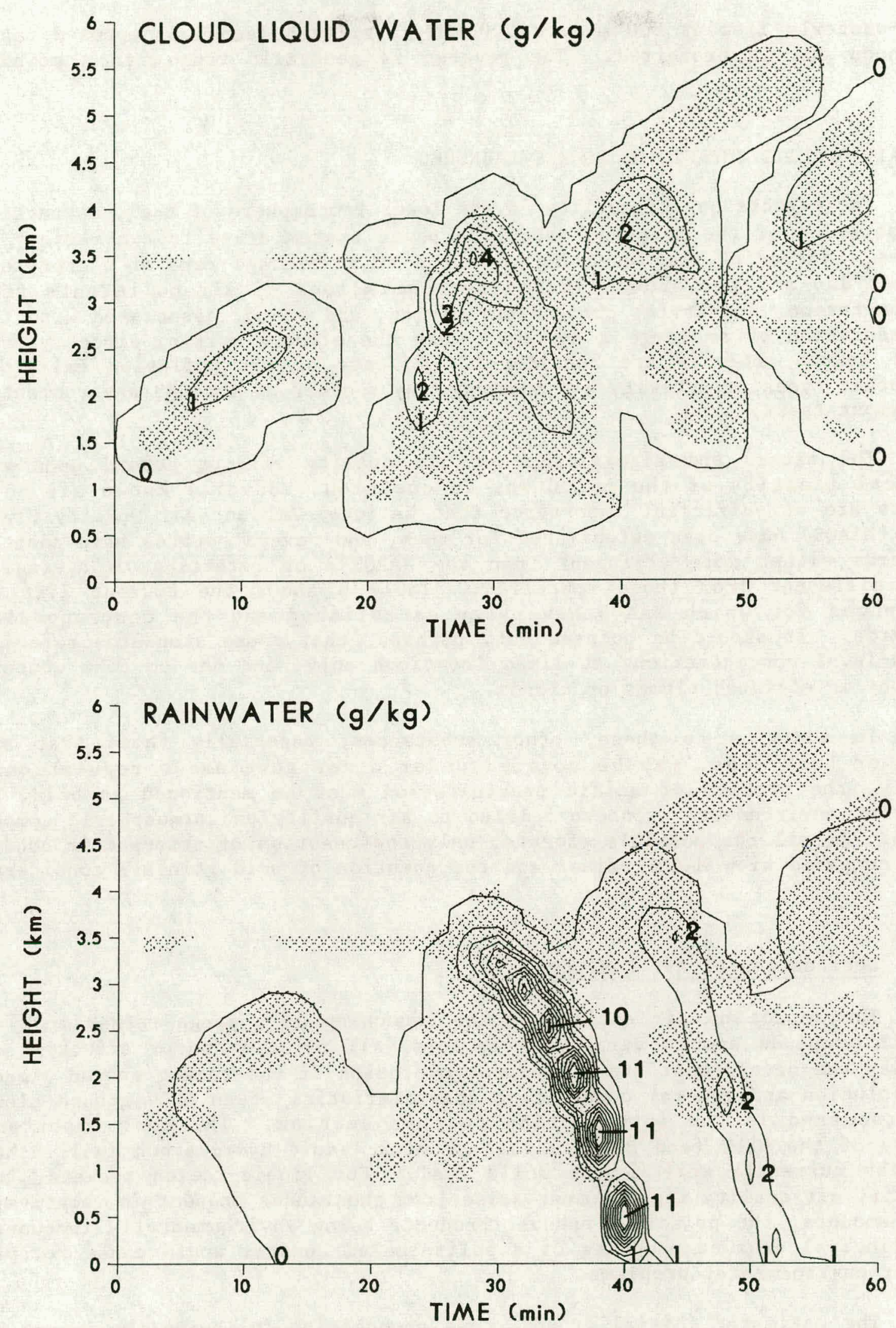

Fig. 9. Predicted Mean Cloud Liquid Water Content and Rainwater Induced by the HLLV Thermal Effluent for Potentially Unstable Air on September 9, 1975 (shaded areas are saturation regions) 
south-westerly flow at $850 \mathrm{mb}$ at $1200 \mathrm{GMT}$, a morning launch as opposed to an afternoon one is preferred. The reverse is generally true with a morning flow.

\subsection{AIR QUALITY IMPACTS OF ROCKET LAUNCHES}

The effects on air quality in the lower troposphere of the construction and operation of the proposed satellite power system arise from a variety of sources, including the launching of HLLVs at an average rate of better than one per day and the growth in indirect emissions of air pollutants from transportation, industrial production, mining, and so on, associated with the implementation of so large a system. Only the effects arising directly from rocket launch activity are considered. Effects of air pollution emissions from other types of activity are addressed by another of the SPS environmental assessment tasks.

The nature and significance of air quality effects depend upon the chemical identity of the pollutant in question. Several known air pollucants are of sufficient importance that National Ambient Air Quality Standards (NAAQS) have been established for them, and several states have adopted standards either more stringent than the NAAQS 33 or referring to averaging times different from those specified. Table 6 shows the current 1 ist of substances for which NAAQS have been established and the corresponding standards. It should be pointed out, perhaps, that these standards refer to ground-level concentrations at fixed locations only, and not to peak concentrations in elevated plumes or clouds.

In addition to these, other substances, especially those that are toxic or hazardous, may be covered under other government regulations. Finally, the problem of acidic precipitation must be mentioned as being an important environmental concern related to air quality and atmospheric compnsition. Of all the possible effects, only the question of atmospheric conditions compared with NAAQS values and the question of acid rain are considered here.

\subsubsection{Degradation of Air Quality}

The impact on air quality of the launching of a large rocket such as the HLLV depends upon a variety of factors, all relating to or affecting in some way the development and subsequent evolution of the rocket ground cloud. The evolution and general composition characteristics of an HLLV ground cloud are discussed in the introduction to this section. The most important feature of the HLLV (and PLV) is the use of a liquid hydrocarbon fuel rather than the currently more common solid fuel. For liquid-fueled rockets, the potential air quality impacts must arise from substances present in relatively small amounts, the principal exhaust products being environmentally inocuous. The principal exhaust products of a solid-fueled booster would cause notably greater environmental problems.

The estimated initial ground cloud composition following the launch of an HLLV is given in Table 7. In preparing these estimates, the quantity of exhaust products involved was taken to be that generated during the first 
Table 6 National Ambient Air Quality Standard;

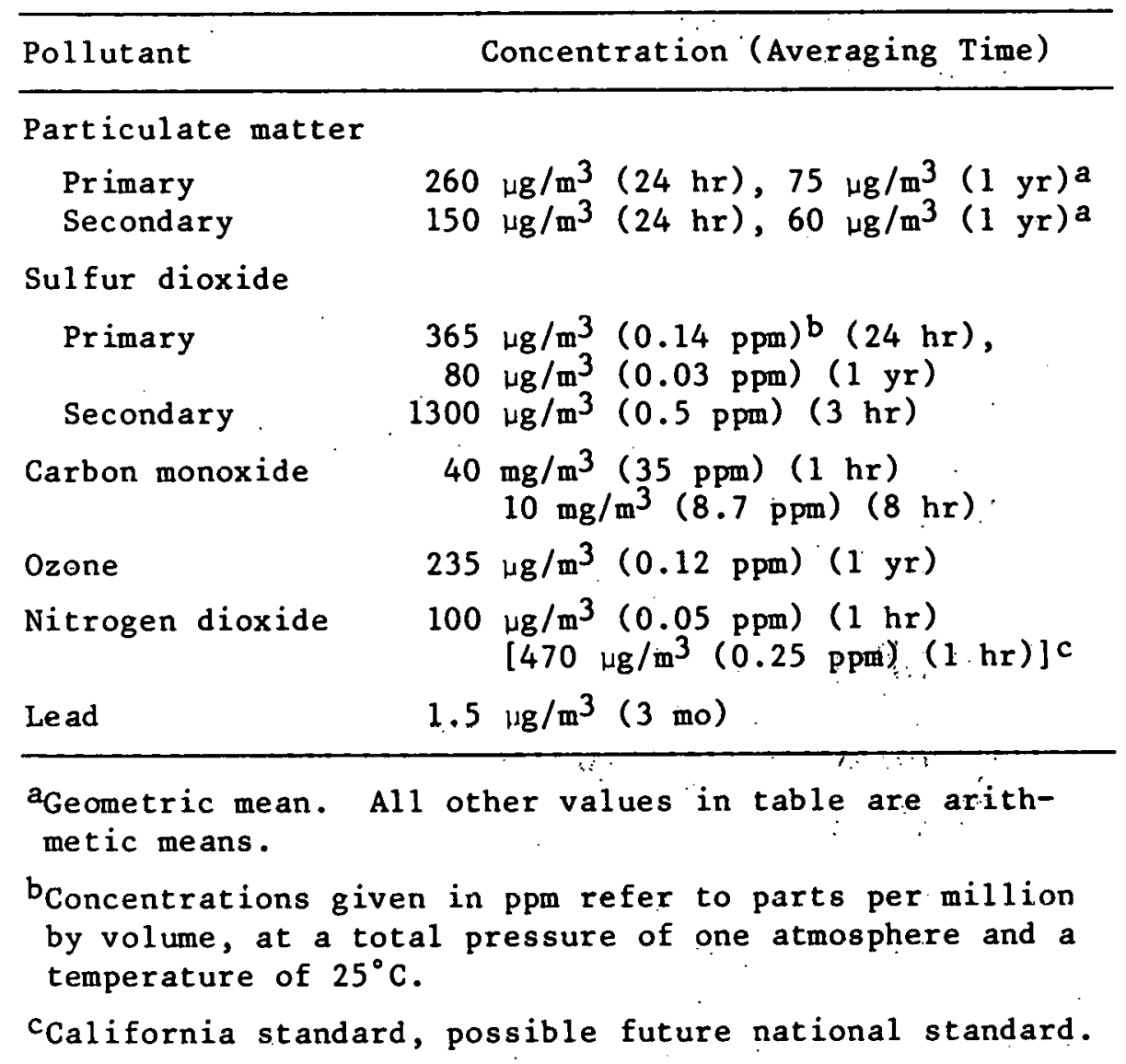

15-25 s followng ignition and 1 ifluff, and all the molecular hydrngen and carbon monoxide present in the exhaust at the rocket engine nozzle was assumed to be converted to water and carbon dioxide by afterburning. In addition, the presence of a sulfur impurity in the fuel at the $0.05 \%$ level was assumed; this figure corresponds to about the average sulfur content of hydrocarbon fuels now in use. Tlie actual level of a sulfur impurity in the proposed liquid methalic fuel may be considerably lower.

In Table 7, the concentrations given for $\mathrm{SO}_{2}, \mathrm{NO}$, and $\mathrm{NO}_{2}$ represent the maximum values actually measured in the ground cloud of an Atlas/Centaur rocket, as discussed below. In using the same values for the HLLV ground cloud, the assumptions are that the amounts of $\mathrm{NO}$ and $\mathrm{NO}_{2}$ produced are in the same proportion to the total amount of exhaus: in both rockets and that the exhaust is diluted with ambient air by the same factor, which is approximately 4600 , based upon the maximum observed $\mathrm{SO}_{2}$ concentration in the Atlas/Centaur cloud and the corresponding fuel analysis that indicated a sulfur impurity of $0.047 \%$. Also, based on this dilution factor and the data in Table 7 the total initial volume of an HLLV ground cloud will be in excess of $10^{10} \mathrm{~m}^{3}$.

These assumptions are supported by airborne measurements of peak $\mathrm{NO}_{x}$ concentrations in several ground clouds associated with launches of the Titan III solid-fueled rocket. 36 In those measurements, the greatest peak $\mathrm{NO}_{\mathbf{x}}$ concentration observed was 1.4 ppmv; two other peak values 
Table 7 Estimated Initial HLLV Ground-Cloud Composition

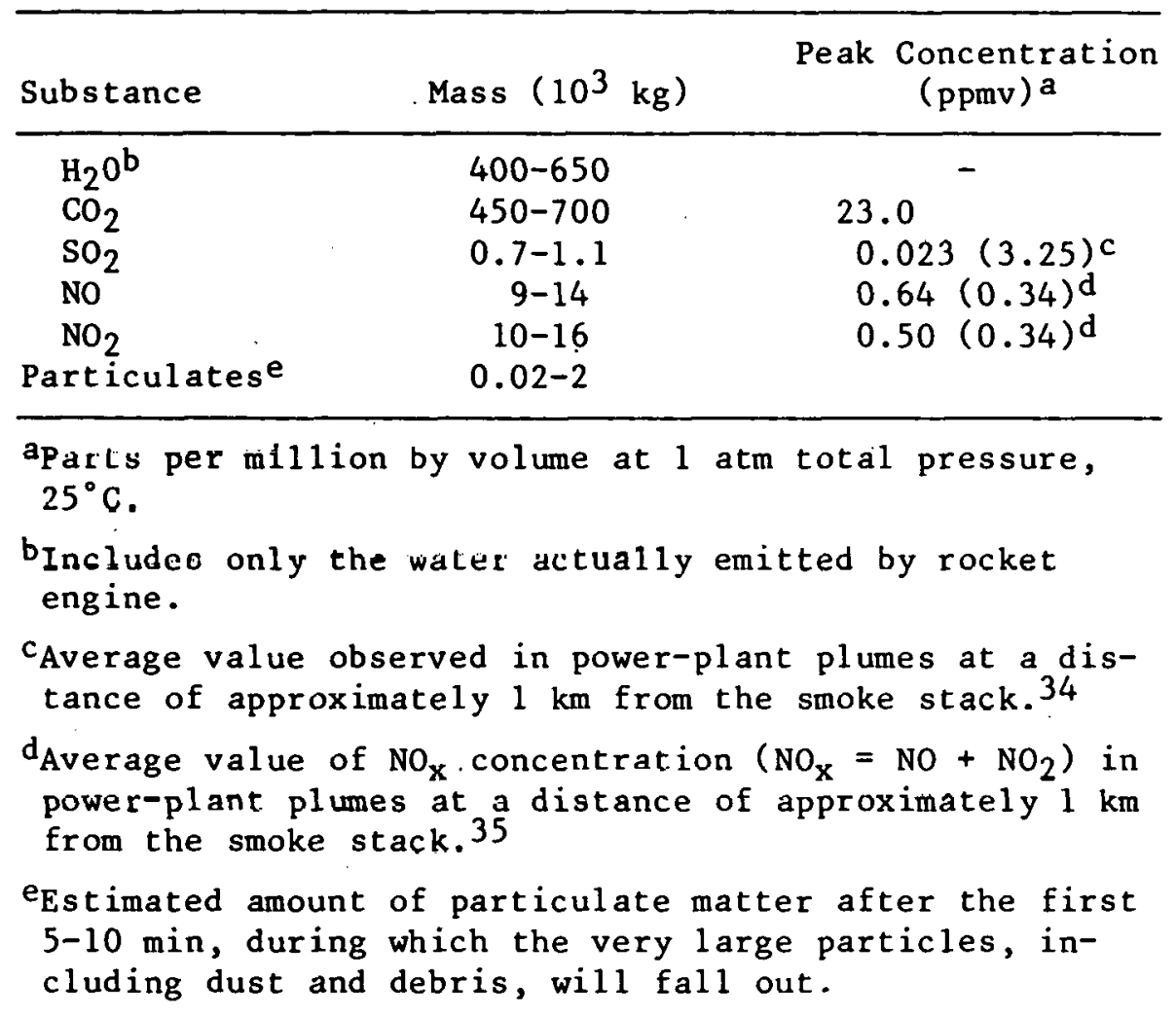

in excess of one ppm were also reported ( 1.1 and 1.0 ppmv), and the remaining values ranged from 0.65 to 0.25 ppmv. The values shown in Table 7 are quite comparable to these even though the two rockets are significaully different, the Atlas/Centaur rocket being liquid fupled and having only abuut $22 \%$ the gross liftoff weight of the Titan III. The agreement tends to indicate that the peak $N \Omega_{x}$ concentrationo are nearly independent of the type of rocket, in support of the assumptions made in Table 7.

Other factors that affect the extent to which a rocket launch gives rise to air quality degradation include (1) the altitude to which the ground cloud rises because of its initial thermal energy content and (2) the ambient meteorological conditions, which not only affect the ground cloud stabilization altitude but also determine the rates of dispersion of an air pollutant and the rates at which the pollutant is removed from the stmospliere by wet and/or dry deposition or by absorption in liquid water droplets. In addition, the local topography (including presence or absence of a coastline) affects the local wind patterns and thereby the transport of the ground cloud and/or other pollutants. Finally, in the case of chemically reactive substances such as NO and $\mathrm{NO}_{2}$, the presence of pollutante such as ozune and ocher photochemical smog-related substances will affect the ground cloud concentrations and the rate at which acidic substances such as nitric acid are produced. From this brief 1 ist, it should be clear that making a complete assessment of air quality effects under all possible conditions is a difficult and complex task. 
In order to prepare the best possible assessment within time and budgeting constraints, a combination of field monitoring and theoretical modeling approaches was adopted. Prior to the SPS CDEP program, no data obtained by field monitoring of actual launches existed for a liquid-fueled rocket. Field data for solid-fueled rockets were not considered satisfactory in view of the differences in the chemical nature of the exhaust products from solid and liquid fuels. A field monitoring program was undertaken to acquire data considered necessary for the present assessment. The launch of an Atlas/ Centaur rocket on November 13, 1978, provided an opportunity to acquire the extensive set of airborne measurements made in connection with that launch. 24,37

A total of 52 passes were made through the Atlas/Centaur ground cloud over a $21 / 2-h r$ period following the launch, using the University of Washington's instrumented B-23 research aircraft. A variety of parameters was measured, including among others the concentrations of several gaseous chemical species, the particle size distribution, the $C C N$ and IN concentrations, and the physical dimensions of the cloud. The maximum concentrations of $\mathrm{NO}, \mathrm{NO}_{2}$, and $\mathrm{SO}_{2}$ were measured during the second pass, 5 min after liftoff (the aircraft did not travel through the center of the cloud during the first pass), and are given in Table 7 as indicated above. The cloud stabilized within an inversion layer between approximately 450 and $650 \mathrm{~m}$ above ground level, and remained at that altitude until it merged with an industrial plume about $2 \mathrm{hr}$ after launch. Dispersion of the cloud in the vertical direction was strongly limited by the inversion layer, and the contribution of the cloud to ground level concentrations was certainly negligible in this case. The cloud grew horizontally during the measurement period, and cloud concentrations decreased accordingly until at $110 \mathrm{~min}$ after launch, measured peak concentrations were $7 \mathrm{ppbv}\left(\mathrm{SO}_{2}\right), 65 \mathrm{ppbv}\left(\mathrm{NO}_{2}\right)$, and $45 \mathrm{ppbv}$ (NO). Systematic conversion of NO to $\mathrm{NO}_{2}$ was observed as the cloud dispersed. This conversion may be attributed to the presence of ozone in the ambient air at a concentration of approximately 55 ppbv; as the ground cloud grew in size and entrained more and more ambient air, the ozone reacted with NO in the cloud, forming $\mathrm{NO}_{2}$. This explanation is supported by ozone measurements in the cloud, which show that the ozone concentration is strongly depressed below the ambient level until the cloud is just barely detectable by other means. The rate of conversion is also in accord with independent measurements of the rate of growth of the cloud.

The Atlas/Centaur launch took place at 12:24 am local time, i.e., shortly after midnight, and, as indicated, stabilized above the ground cloud within an inversion layer at about $500 \mathrm{~m}$ above ground. Meteorological conditions at night are often such that vertical dispersion of an elevated cloud is suppressed; under such conditions, ground-level concentrations of substances in the ground cloud are below detection limits. During the day, however, the level of atmospheric luibulence and the associated rate of dispersion may be very much higher, and the possibility of significant ground-level concentrations of various substances from the ground cloud must be considered. The wind direction frequency in the vicinity of the launch site is an important factor in assessing the importance of ground-level pollutant concentrations. In the vicinity of Kennedy space Center, Florida, a rocket ground cloud may drift over land about $50 \%$ of the time, based upon data presented in the XSC environmental impact statement. 36 This frequency should be kept in mind during the following discussion, which assumes that the ground cloud is over 1 and. 
The only substances present in the ground cloud of the Atlas/ Centaur, and, by analogy, in the cloud from an HLLV, that are meaningful from an air quality point of view are $\mathrm{SO}_{2}$, $\mathrm{NO}$, and $\mathrm{NO}_{2}$. The composition of the cloud was quite similar to that of a plume from a coal-fired electric power generating plant with defective control equipment burning low-sulfur coal. In order to put the expected environmental effects of an HLLV launch into perspective, it is useful to pursue this analogy. Table 7 shows that the expected $\mathrm{NO}_{\mathrm{x}}$ concentrations in an HLLV cloud are 3-4 times higher than those prevalent in power plant plumes while a sulfur impurity of $0.05 \%$ leads to $\mathrm{SO}_{2}$ concentrations that are only $15-30 \%$ of those present in typical power-plant plumes. In addition, the cloud elevation is comparable to plume elevations from large (1000 MW or more) power plants, and therefore the maximum ground-level concentrations of $\mathrm{SO}_{2}$ and $\mathrm{NO}_{\mathrm{x}}$ may be expected to be $15-30 \%$ and $300-400 \%$, respectively, of those from a typical large power plant. It must be kept in mind, however, that the ground cloud represents a short, intense emission whereas a plume represents a continuous emission. In order lu cumpare ettects, an averaging time nust be introduced. In fact, the relevant averaging times are explicitly specified in the corresponding air quality standards. For example, the federal secondary standard for $\mathrm{SO}_{2}$ specifies that the ambient $\mathrm{SO}_{2}$ concentration averaged over a 3-hr period should not exceed 500 ppbv more than once per year, as shown in Table 6. Reference to Table 7 shows, however, that even the maximum $\mathrm{SO}_{2}$ concentration in the center of the ground cloud is much less than this value. In fact, the maximum $\mathrm{SO}_{2}$ concentration is even less than the primary annual $\mathrm{SO}_{2}$ standard of $0.03 \mathrm{ppmv}$. The conclusion is that any reasonable level of sulfur in the fuel will not give rise to. significant ambient ground-level $\mathrm{SO}_{2}$ concentrations, particularly when dispersion and cloud elevation are considered.

No adverse effects of any kind are expected from the level of $\mathrm{CO}_{2}$ shown in Table 7. To put these emissions into perspective, the total annual emission of $\mathrm{CO}_{2}$ from the entire first-stage burn of the HLLV ( 375 flights) amounts to $1 \times 10^{9} \mathrm{~kg}$. By way of comparison, the annual emission from a single 1000 $\mathrm{MW}$, coal-fired power plant is approximately $4.5 \times 10^{9} \mathrm{~kg}$ (using $207 \mathrm{lb} \mathrm{CO}_{2} / 10^{6}$ Btu heat content, $34 \%$ efficiency, $55 \%$ annual average load fartar). Thuo, the entirc annual $\mathrm{CO}_{2}$ emisston trom SPS-related spaceflight amounts to only $23 \%$ of the total from a single typical power plant, a totally negligible amount from the point of view of the global $\mathrm{CO}_{2}$ content. No local, short-term effects of any kind are expected, since the peak concentration is only 23 ppmv above an ambient value of about 335 ppmv.

No short-term federal air quality standard currently exists for any of the nitrogen oxides. However, it is likely that within a year. or two, a one-hr etandard for $\mathrm{NO}_{2}$ of approximately 9.25 ppmv will be promulgated. The problem. that one encounters in attempting co predict $\mathrm{NO}_{2}$ and $\mathrm{NO}$ concentrations is that both are reactive substances, and the common techniques used to predict atmospheric concentrations of air pollutants do not apply in this case. The $\mathrm{NO}_{2}$ concentration is determined by the initial amounts of NO and $\mathrm{NO}_{2}$ preoent in the cloud, by the extent of dispersion of the cloud, by the composition of the ambient air, particularly the ambient ozone level, and by the ambient light intensity. Nitrogen dioxide is continually photolyzed by sunlight to form NO and atomic oxygen (which in turn combines with ambient molecular oxygen to form ozone), and at the same time No and ozone react to re-form $\mathrm{NO}_{2}$. The concentrations of all three species are determined by the relative rates of these competing processes. Standard atmospheric dispersion 
modeling techniques are not applicable under these circumstances. In order to assess the potential contribution of an HLLV ground cloud and the associated $\mathrm{NO}_{\mathrm{x}}$ emissions to ground-level $\mathrm{NO}_{\mathrm{x}}$ concentrations, a new modeling approach, applicable specifically to the estimation of short-term $\mathrm{NO}_{2}$ concentrations and developed for general $\mathrm{NO}_{x}$ sources, was used. The principal chemical reactions 38,39 involving $\mathrm{NO}_{2}$ and $\mathrm{NO}$ in the atmosphere are (1) the photolysis of. $\mathrm{NO}_{2}$ in the presence of molecular oxygen to produce No and ozone $\left(\mathrm{O}_{3}\right)$ :

$$
\mathrm{NO}_{2} \stackrel{\mathrm{hu}, \mathrm{O}_{2}}{\longrightarrow} \mathrm{NO}+\mathrm{O}_{3}
$$

and (2) the reaction between $\mathrm{NO}$ and $\mathrm{O}_{3}$ to reform $\mathrm{NO}_{2}$ :

$$
\mathrm{NO}+\mathrm{O}_{3} \longrightarrow \mathrm{NO}_{2}+\mathrm{O}_{2}
$$

The rate coefficient for reaction $A\left(k_{A}\right)$ varies from zero at night to about $0.6 \mathrm{~min}^{-1}\left(0.01 \mathrm{sec}^{-1}\right)$ for an overhead sun. 36 The rate coefficient for reaction $B\left(k_{B}\right)$ is equal to $2.1 \times 10^{-12} \exp (-1450 / T) \mathrm{cm}^{3} \mathrm{sec}^{-1} 40$ ( $T$ being the temperature (Kelvin)), or $24.0 \mathrm{ppm}^{-1} \mathrm{~min}^{-1}$ at $25^{\circ} \mathrm{C}$, 1 atmosphere total pressure. The rates of these two reactions are fast compared with the rates of other reactions involving these substances, for typical tropospheric concentrations. Since $A$ and $B$ are the reverse of each other, an approximate photostationary state is established in which the two reactions balance each other. 41 In such a state, the atmospheric concentrations of $\mathrm{NO}, \mathrm{NO}_{2}$, and $\mathrm{O}_{3}$ are related by

$$
\frac{[\mathrm{NO}]\left[\mathrm{O}_{3}\right]}{\left[\mathrm{NO}_{2}\right]}=\mathrm{K}
$$

in which

$$
\mathrm{K}=\frac{\mathrm{k}_{\mathrm{a}}}{\mathrm{k}_{\mathrm{b}}}
$$

Given an initial mixture of these substances that does not satisfy Eq. 5, chemical reactions $A$ and $B$ will occur in such a way as to change the concentrations until they do satisfy the photostationary state relation. The final (stationary-state) concentrations may be calculated by the following procedure: denote the change in the $\mathrm{NO}_{2}$ concentration $\left[\mathrm{NO}_{2}\right]_{s s}-\left[\mathrm{NO}_{2}\right]_{i}$ by c (ss denoting stationary state, $i$ denoting initial); then the changes in the No and $\mathrm{O}_{3}$ concentrations are equal to $-c$, so that $[\mathrm{NO}]_{s s}=\left[\mathrm{NO}_{i}-c\right.$, and similarly for the ozone concentration. Substitution into Eq. 5 yields a quadratic equation for $c$, the physically realizable solution of which is

$$
c=1 / 2\left\{(a+k)-\left[b^{2}+k\left(4\left[\mathrm{NO}_{2}\right]_{i}+2 a+k\right)\right]^{1 / 2}\right\}
$$

in which

$$
a=[\mathrm{NO}]_{i}+\left[\mathrm{O}_{3}\right]_{i}
$$

and

$$
b=[\mathrm{NO}]_{i}-\left[\mathrm{O}_{3}\right]_{i}
$$


The time required for the photostationary state to be reached depends upon the values of the rate coefficients $k_{A}$ and $k_{B}$ and upon the initial concentrations. A convenient measure of this time is the relaxation time ( $\tau$ ) for the stationary state, defined by

$$
\tau^{-1}=k_{A}+k_{B}\left([\mathrm{NO}]_{S S}+\left[\mathrm{O}_{3}\right]_{s s}\right)
$$

Figure 10 shows the variation of $\tau$ as a function of the stationary state concentrations for various values of $k_{A}$, with $k_{B}$ equal to $24.0 \mathrm{ppm}^{-1} \mathrm{~min}^{-1}$.

A number of investigators have reported deviations of measured atmospheric concentrations from Eq. 5. Calvert 42 suggested that deviations are caused by spatial inhomogeneities in the atmospheric composition, these inhomogeneities being averaged out in the measurements. Seinfeld 41 presented an analysis in support of this suggestion, in which Eq. 5 was assumed to hn1 only locally. More rerently, Choek and Kumar43 have pointed out that in order to test rigorously the photostationary state equation in the atmosphere, measurements will need to be made with instruments having response times less than the time interval over which significant composition changes are encountered. The validity of the equation has been verified in laboratory studies. 44

The modeling approach adopted for assessing the potential $\mathrm{NO}_{2}$ contribution at ground level from HLLVs is based on the assumption that the photostationary state relation, Eq. 5 , is valid locally within a diffusing cloud (or plume) initially containing a mixture of $\mathrm{NO}_{x}$ and $\mathrm{O}_{3}$ different from that in the ambient atmosphere. This assumption is equivalent to the assumption that the rate at which the concentrations within a small parcel of air approach the photostationary state (as measured, for example, by the relaxation time $\tau$ ) is large compared with the rate at which those concentrations are changing because of diffusional processes. Analyses based upon the assumption of a local photostationary state have been found to explain accurately observations within power-plant plumes at discances sufficiently near the stack.34, 35,45 In order to make use of Eq. 5 in a dispersion model, a prediction of the atmospheric composition that would obtain in the absence of chemical processes must be available; in particular, one must be able to estimate the volume mixing ratio $(X)$ of effluent from the source in question on the assumption that the effluent is unreactive. Given an estimate of $X$, which will in general depend on the position and time at which a prediction is to be made, one calculates "initial" values of the $\mathrm{NO}, \mathrm{NO}_{2}$, and $\mathrm{O}_{3}$ concentrations from

$$
[x]_{i}=(1-x)[x]_{\text {ambient }}: x[x] \text { source }
$$

where

$$
\begin{aligned}
& \underset{\begin{array}{l}
\text { ambient } \\
\text { and }
\end{array}}{\text { source }}=\text { ambient and undiluced source concentrations, respectively } \\
& \qquad \mathrm{X}=\text { any of the } \mathrm{NO}, \mathrm{NO}_{2} \text {, or } \mathrm{O}_{3}
\end{aligned}
$$




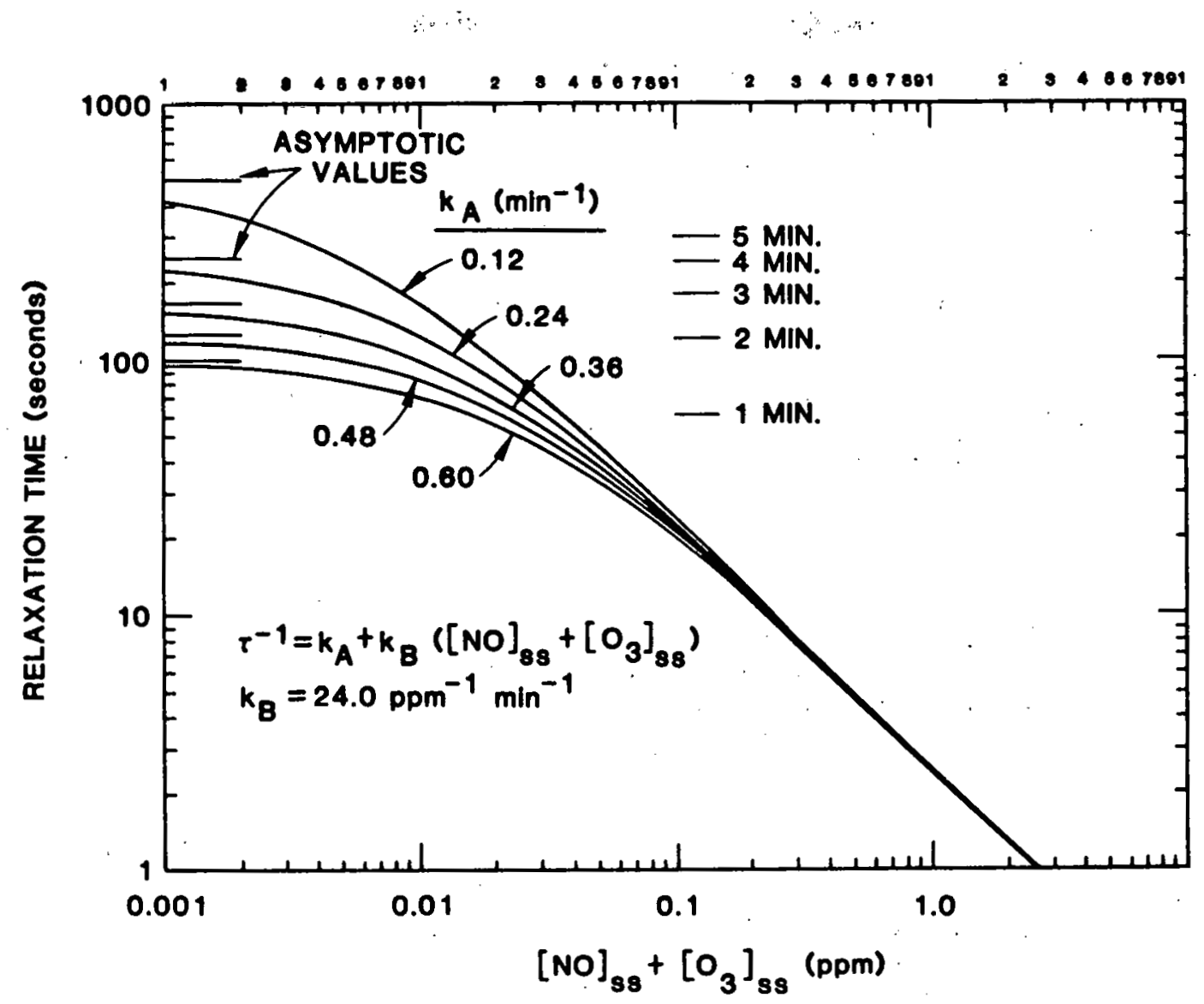

Fig. 10 Photostationary State Relaxation Times

Substitution into Eqs. 7-9 allows the quantity $c$ to be calculated, and thereby the concentrations that satisfy the photostationary state for the location and time in question.

Application of this procedure requires a method for estimating $X$. In the case of a rocket ground cluud, the model used for this purpose consisted of an assumed Gaussian distribution $g(r, t)$ in the horizontal plane, the center location and standard deviation $\sigma(t)$ of which are independent of altitude but are time dependent, with the vertical distribution $f(z, t)$ being determined as the numerical solution to a one-dimensional diffusion equation with an (eddy) diffusivity dependent on altitude but constant in time. Thus, the cloud is assumed to be cylindrically symmetric with a vertical axis of symmetry at all times, and the mixing ratio may be written

$$
x_{k}(r, t)=A g(r, t) \quad f_{k}(t)
$$

where

$$
\begin{aligned}
A= & \text { a normalization coefficient, and } k \text { denotes the vertical grid } \\
& \text { point } z_{k} \text { at which the quantity } f_{k}(t)=f\left(z_{k}, t\right) \text { is being eval- } \\
& \text { uated, and the function } g \text { is given by }
\end{aligned}
$$




$$
g(r, t)=\frac{1}{2 \pi \sigma^{2}(t)} \exp \left[-1 / 2\left(\frac{r}{\sigma(t)}\right)^{2}\right]
$$

The coefficient $A$ is determined by the initial condition that was used; specifically, that the ground cloud was uniformly distributed vertically between 1100 and $1500 \mathrm{~m}$ altitude, the initial value of $\sigma$ being determined from the estimated volume of rocket exhaust involved and the estimated initial dilution factor of 4600 . It was also assumed that an elevated inversion layer existed between 1300 and 1700, and therefore that the ground cloud had partially penetrated the inversion layer. The assumed initial conditions approximate the stabilization of a ground cloud at an elevated inversion at a typical altitude for daytime conditions.

The eddy diffusivity used in the numerical evaluation of the quantities $f_{k}(t)$ and the horizontal standard dcviatiun $O(t)$ were essentially those estimated by Lamb et al.44 for unstable conditions based upon numerical simulations of dispersion in the $p$ lanetary bounday layer. I'he initial value of 8 was estimated be $2.2 \times 10^{3} \mathrm{~m}$, and the rate of change of $\sigma$ with time given by Lamb et al., when dimensionalized by an assumed friction velocity of 0.5 $\mathrm{m} / \mathrm{sec}$, resulted in $\sigma(t)$ being given by

$$
\sigma^{2}(t)=\sigma^{2}(0)+0.653 t^{2}(\sec ) \text {. }
$$

Table 8 gives the ground-level concentration of $\mathrm{NO}, \mathrm{NO}_{2}$, and $\mathrm{O}_{3}$ as functions of the scaled distance from the cloud axis $(r / \sigma)$ at the time of maximum ground-level $\mathrm{NO}_{2}$ concentration, about 20 min after cloud stabilization. At this time, $\sigma=2.335 \times 10^{3} \mathrm{~m}$. Ambient concentrations were: [ $\mathrm{NO}_{\mathrm{x}}$ ] $=0.25 \mathrm{ppm}$ and $\left[\mathrm{O}_{3}\right]=0.12 \mathrm{ppm}$. Ambient temperature and pressure were $27^{\circ} \mathrm{C}$ and 1 atmosphere, $k_{A}$ was taken to be $4 \times 10^{-3} \mathrm{sec}^{-1}$ and the photostationary state constant $K$ was therefore equal to $9.82 \times 10^{-3} \mathrm{ppm}$. The depression of the ozone concentration by $50 \%$ at the cloud centerline compared with the ambient value and the increase in $\mathrm{NO}_{2}$ concentration by $0.0 \% \mathrm{ppm}$ above the ambient level are clearly seen. Figure 11 shows the time evolution of the ground-level $\mathrm{NO}_{2}$ concentration as a function of $(r / \sigma)$ for the same set of conditions. The values designating the different contours are given in ppm. Nitrogen dioxide $\left(\mathrm{NO}_{2}\right)$ concentrations in excess of 0.25 ppm persist at the cloud centerline for nearly $2 \mathrm{hr}$; if the average velocity of the cloud were less than about $4 \mathrm{~km} / \mathrm{hr}$, some region at ground level would be exposed to $\mathrm{NO}_{2}$ concentrations in excess of the (possible) l-hr standard for a period longer than an hour and an exceedance of the standard would occur. Thus, it seems possible that in some circumstances the launch of an HLLV might cause an exceedance of a possihle $0.25 \mathrm{ppm} 1$-hr $\mathrm{NO}_{2}$ etandard.

It was not possible to consider a variety of conditions in order to identify the range of those under which a possible exceedance of such a standard might occur. In the example given above, the ambient concentration was already close to the $0.25 \mathrm{ppm}$ value, and the maximum increase due to the ground cloud was only $0.07 \mathrm{ppm}$. In addition, under neutral rather than unstable conditions, the rate of vertical dispersion is significantly less and so are the calculated ground-level concentrations. On the other hand, the ground-level concentrations are sensitively dependent upon the assumed cloud stabilization height and could be much increased if the cloud stabilized at a lower altitude. Fumigation-type situations brought about by launches just 
Table 8 Ground tevel $\mathrm{NO}, \mathrm{NO}_{2}$, and $\ddot{\mathrm{O}}_{3}$ Concentrations

\begin{tabular}{|c|c|c|c|c|}
\hline Scaled Distance & {$\left[\mathrm{NO}_{2}\right]$} & [NO] & 3 & {$\left[0_{3}\right]$} \\
\hline$(r / \sigma)$ & (ppm) & (ppm) & & (ppm) \\
\hline 0.0 & 0.304 & 0.050 & & 0.060 \\
\hline 0.5 & 0.297 & 0.045 & & 0.065 \\
\hline 1.0 & 0.279 & 0.034 & & 0.080 \\
\hline 1.5 & 0.258 & 0.026 & $\therefore$ & 0.098 \\
\hline 2.0 & 0.243 & 0.020 & & 0.110 \\
\hline 2.5 & 0.235 & 0.019 & & 0,117 \\
\hline 3:0 & 0.232 & 0.019 & & 0.119 \\
\hline & $0.231^{b}$ & $0.019^{b}$ & $\vdots$ & $0.120^{b}$ \\
\hline
\end{tabular}

$a_{20}$ min after cloud stabilization.

${ }^{b}$ Concentrations outside the plume.

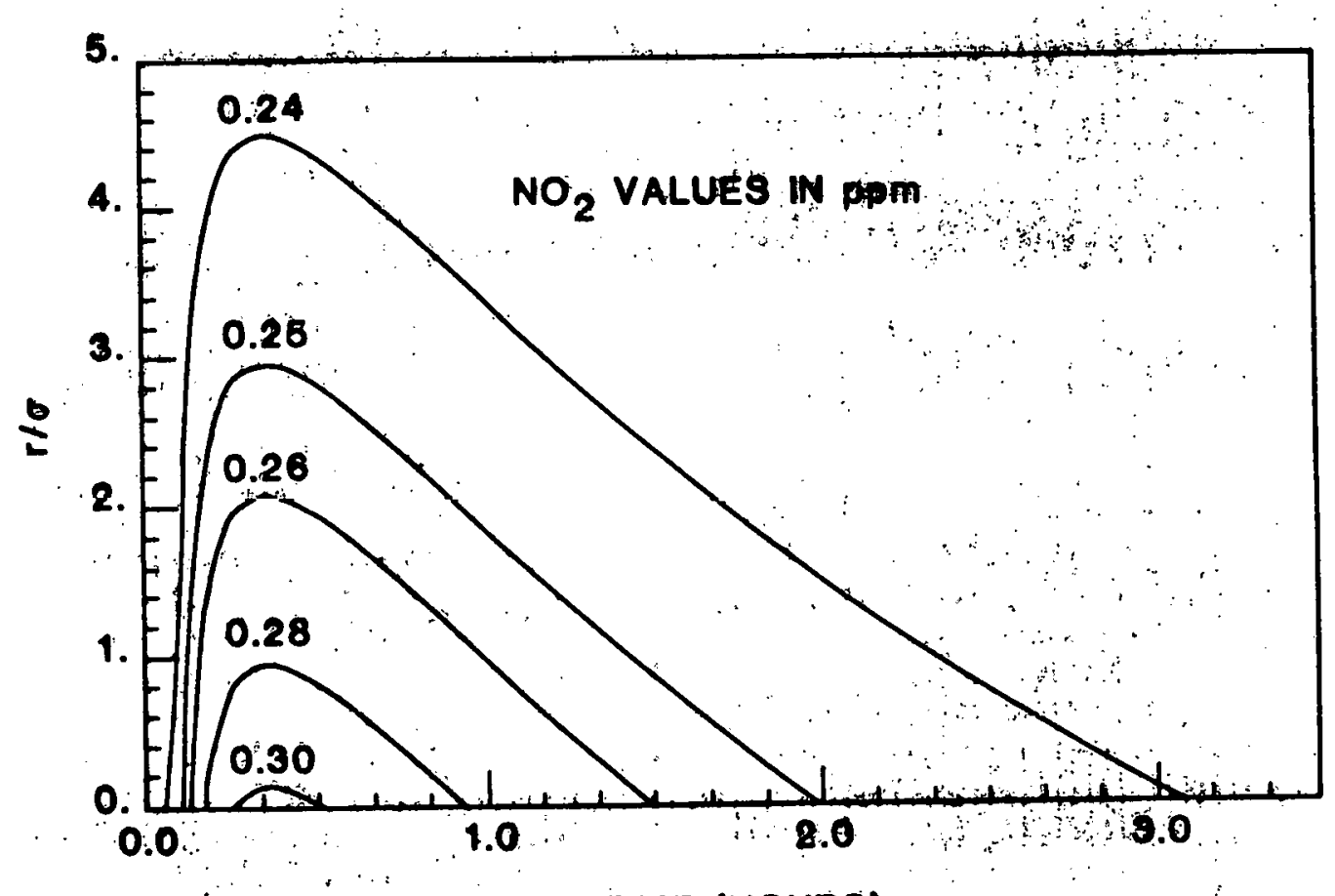

TME (HOURS)

Fig. 11 Ground-Level $\mathrm{NO}_{2}$ Concentration

prior to sunrise might also represent notably adverse conditions and should be considered. The general conclusion is therefore that the possibility exists of an. HLLV launch making a significant contribution to ground-level $\mathrm{NO}_{2}$ concentrations, but that the combinations of meteorological conditions and ambient pollutant levels in which an exceedance of the $0.25 \mathrm{ppm}$ level would result have not been fully identified. Once these situations have been determined, however, the obvious mitigating strategy of not launching a rocket under those conditions could be effectively applied. 
A potential problem related to the question of $\mathrm{NO}_{\mathrm{x}}-\mathrm{O}_{3}$ chemistry in a ground cloud is the possible formation of ozone in excess of ambient levels after several hours of travel. The generation of ozone concentrations in excess of ambient levels has been observed on several occasions in powerplant plumes.47-51 This phenomenon is not well understood at present, although there seems to be no reason why it cannot be accounted for by using known chemistry. The possibility exists that a similar phenomenon might occur in the ground cloud from an HLLV in view of its chemical similarity to a power-plant plume, although ground-level ozone concentrations would probably not be greatly affected. It would be desirable to examine the question using a suitable theoretical model in order to determine the conditions under which such a phenomenon is expected to occur and the extent to which an HLLV ground cloud may produce the same effect.

\subsubsection{Formation of Ac1d and Acid Rain from Rocket Exhaust Effluent}

The increase in acidity of precipitation in the notheastern llnited Staces and eastern Canada in recent years is a subject of serious concern, 52-54 and has prompted the U.S. Environmental Protection Agency to undertake an extensive research program to examine various aspects of the problem.55. Although the formation of sulfuric acid from gaseous sulfur dioxide is considered to be the main cause of the observed acid rain, nitric acid formed from oxides of nitrogen has also been implicated.53, 55-57 As each piece of additional information becomes available, the scope of the problem seems to increase; thus, evidence for trends of increasing acidity was recently published for Colorado, 56 and Florida.57 In view of the widespread nature of the problem and the current level of concern, an assessment of the possible significance for acid rain of the effluent from nearly 400 HLLV launches per year was undertaken.

Two main aspects must be considered: (1) the question of local, intermittent effects associated with indiyidual launches and (2) regional, long-term contributions representing cumulative effects over the entire period of high-rocket-launch activity. In many respects, the first aspect is the more difficult of the two to access, because one is more concerned with the details of the chemistry and transport; this aspect is treated in the following section. The potential long-term, reginnal contributions may be reasonably assessed by evaluating the significance of the HLLV launches as sources of acid precursors compared with other sources in the area of the launch site; this approach will be taken in the discussion of long-term effects.

\subsubsection{Local Short-term Effects}

Two general mechanisms may be proposed by which oxides of nitrogen are converted to acids in the atmnsphere. The first involves the absorption of $\mathrm{NO}^{\circ}$ and $\mathrm{NO}_{2}$ into existing droplets and subsequent chemical conversion to acids. The acids which must be considered are nitric acid $\left(\mathrm{HNO}_{3}\right)$, a strong acid, and nitrous acid $\left(\mathrm{HNO}_{2}\right)$, a weak acid. Of the two, nitric acid is much more important as a potential contributor to the acidity of water droplets in the atmosphere. The second general mechanism involves the conversion of No and $\mathrm{NO}_{2}$ to nitric acid in the gas phase, followed by absorption of the acid 
in ambient droplets. Gas-phase conversion occurs by reaction with free-radical components present in photochemical smog. 38,39 . In addition, in the presence of sodium chloride aerosol and $\mathrm{NO}_{2}$, hydrochloric acid may be evolved. 58 Each process is considered in turn.

The chemistry of $\mathrm{NO}$ and $\mathrm{NO}_{2}$ in aqueous solution is rather complex.59-61 Two general reactions must be considered: (1) the reaction of $\mathrm{NO}_{2}$ to form $\mathrm{HNO}_{2}$ and $\mathrm{HNO}_{3}$ :

$$
2 \mathrm{NO}_{2}+\mathrm{H}_{2} \mathrm{O}=\mathrm{HNO}_{2}+\mathrm{H}^{+}+\mathrm{NO}_{\overline{3}}
$$

and (2) the formation of $\mathrm{HNO}_{2}$ from an equimolar mixture of NO and $\mathrm{NO}_{2}$ :

$$
\mathrm{NO}+\mathrm{NO}_{2}+\mathrm{H}_{2} \mathrm{O}=2 \mathrm{HNO}_{2} \text {. }
$$

Both reactions are reversible, as indicated by the equality signs. A third reaction of ten considered, the disproportionation of $\mathrm{HNO}_{2}$,

$$
3 \mathrm{HNO}_{2}=\mathrm{H}^{+}+\mathrm{NO}_{3}^{-}+2 \mathrm{NO}+\mathrm{H}_{2} \mathrm{O}
$$

is not. independent of the first two, but may be obtained by subtracting twice reaction (D) from reaction (C). A possible mechanism by which these reactions proceed is shown in Fig. 12.61-65 The mechanism shown is compatible: with the observations and in particular accounts for the observed rates of the forward and reverse reactions (C) as studied by Abel and Schmid66 in the 1920 s and 1930s. According to the reactions shown, nitric acid is formed by reaction of $\mathrm{N}_{2} \mathrm{O}_{4}$ ( $\left(\right.$ the dimer of $\mathrm{NO}_{2}$ ) with water, and an equimolar mixture of the two acids is formed initially on dissolving only $\mathrm{NO}_{2}$ in water. As the concentrations of acid increase, $\mathrm{HNO}_{2}$ is recycled and converted to $\mathrm{HNO}_{3}$, the entire system eventually approaching equilibrium. Equilibrium constants are known for reactions (C) to (E), and it is possible to calculate the concentrations of NO and $\mathrm{NO}_{2}$ in the gas phase and the concentrations of $\mathrm{HNO}_{2}$ and $\mathrm{HNO}_{3}$ in the liquid phase at equilibrium, given an initial gas-phase composition and the ratio of the volume of solution to the volume of gas at equilibrium. Such a calculation was carried out in order to estimate the equilibrium concentration of $\mathrm{HNO}_{3}$ in water droplets in the presence of initial concentrations of $\mathrm{NO}$ and $\mathrm{NO}_{2}$ equal to the maximum concentrations expected in the HLLV ground cloud. The atmospheric liquid water content was assumed to be $5.6 \times 10^{-6} \mathrm{~L}$ per $\mathrm{L}$ of air at equilibrium, corresponding approximately to a rainfall rate of $10 \mathrm{~mm} / \mathrm{hr}$ with an average droplet radius of $0.15 \mathrm{~mm}$. Only the equilibria between gaseous $\mathrm{NO}$ and $\mathrm{NO}_{2}$ and aqueous solutions of $\mathrm{HNO}_{2}$ and $\mathrm{HNO}_{3}$ were considered:

$$
\begin{aligned}
& \frac{\left[\mathrm{HNO}_{2}\right]^{2}}{\mathrm{P}_{\mathrm{NO} \mathrm{NO}_{2}}}=\mathrm{K}_{\mathrm{B}}=122\left({ }^{65}\right) \text { at } 25^{\circ} \mathrm{C} \\
& \frac{\left[\mathrm{HNO}_{2}\right]\left[\mathrm{H}^{+}\right]\left[\mathrm{NO}_{3}\right]}{\mathrm{P}_{\mathrm{NO}_{2}}}=\mathrm{K}_{\mathrm{A}}=4.3 \times 10^{5}(65) \text { at } 25^{\circ} \mathrm{C}
\end{aligned}
$$

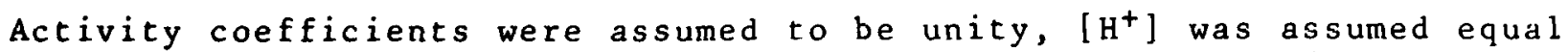
to [ $\left.\mathrm{NO}_{3}\right]$, and both equal to [ $\left.\mathrm{HNO}_{3}\right]$. Concentrations are in mol/L, pressures in atmospheres. The initial and equilibrium concentrations and partial pressures are given in Table 9. The acid concentratiuns shown in the table correspond to a $\mathrm{pH}$ of 2.62 , which represents the $\mathrm{pH}$ after sufficient time has 


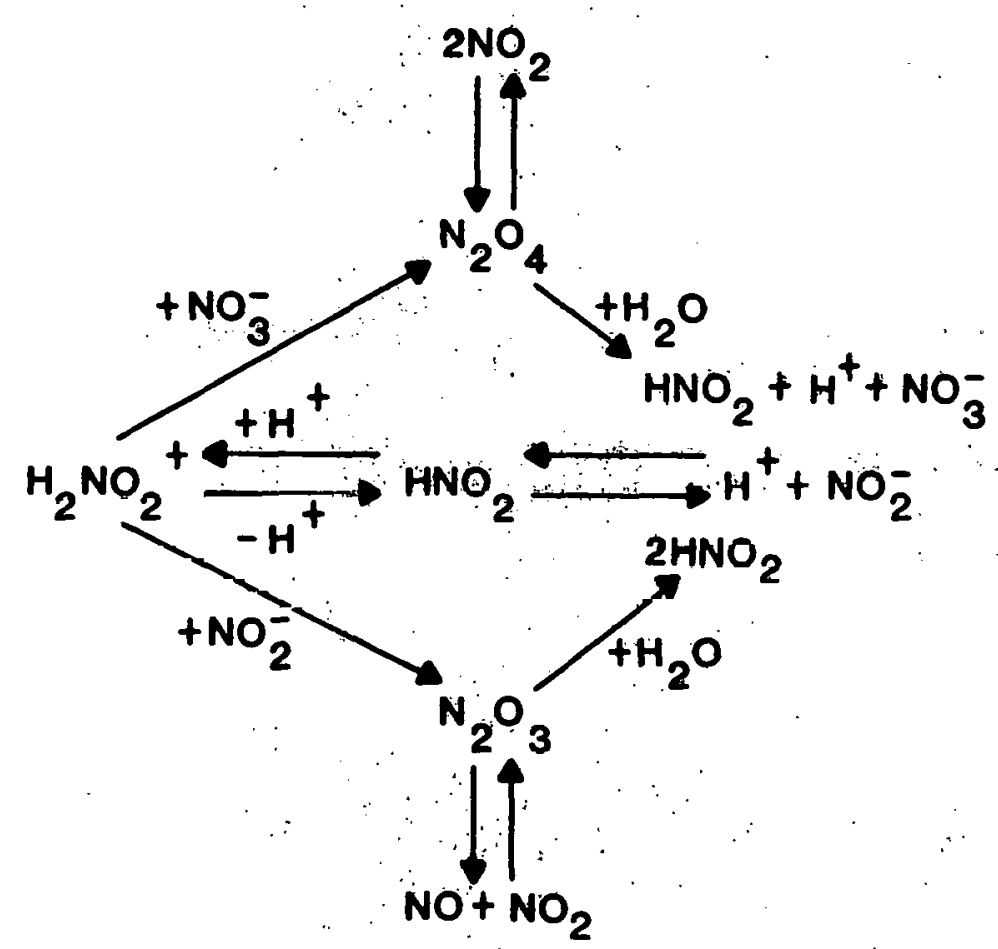

Fig. 12 Possible Mechanism of the Aqueous Chemistry of Nitrogen Oxides

elapsed for the system to come to equilibrium. Estimates of this time are given below. The results depend on the liquid water content; lower values of the water content would yield lower pH values, and the consideration of reaction kinetics becomes more important for obtaining reasonably accurate estimates.

Somewhat similar but more extensive calculations have been carried out in an attempt to explain observed nitrate and sulfate concentrations in atmospheric aerosol.67-69 In those calculations, the equilibrium expressions corresponding to reactions (C) to (E) were assumed to hold at all times, and the aerosol dynamics were asoumed to be driven by the rate of oxidation of $\mathrm{SO}_{2}$.

Table 9 Equilibrium NO, $\mathrm{NO}_{2}$ and Acid Concentrations

\begin{tabular}{lccccc} 
& \multicolumn{2}{c}{ Partial Pressures $(\mathrm{atm})$} & \multicolumn{2}{c}{ Concentrations (mol/L) } \\
\cline { 2 - 5 } & $\mathrm{N}_{0}$ & $\mathrm{NO}_{2}$ & & $\mathrm{HNO}_{2}$ & $\mathrm{INO}_{3}$ \\
\hline Initial & $6.40 \times 10^{-7}$ & $5.00 \times 10^{-7}$ & 0 & 0 \\
Final & $8.06 \times 10^{-7}$ & $2.63 \times 10^{-9}$ & $5.08 \times 10^{-7}$ & $2.42 \times 10^{-3}$ \\
\hline
\end{tabular}

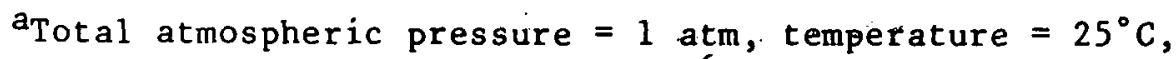
1 iquid water content $=5.6 \times 10^{-6} \mathrm{~L} / \mathrm{L}$ air. 
Individual measurements of precipitation $\mathrm{pH}$ in the northeastern U.S. have given values as low as $2.1,52$ and average values are as low as 4.1 in a few locations.53 The average in north Florida is about 4.6, with individual measurements as low as 3.8.57 As indicated earlier, however, most of this acidity is attributed to sulfuric acid rather than nitric acid, and the estimated $\mathrm{pH}$ given above for droplets in an HLLV ground cloud is undoubtedly too low (i.e., too acidic), due primarily to the assumption of equilibrium. A better estimate must take into account the finite rates of transfer of gaseous $\mathrm{NO}$ and $\mathrm{NO}_{2}$ into solution and the rates of the chemical reactions by which $\mathrm{HNO}_{3}$ is produced.

Not all the rate information that would be in principle necessary for this task is available. However, an upper-bound estimate of the rate of $\mathrm{HNO}_{3}$ production in water droplets in the presence of gaseous $\mathrm{NO}_{2}$ can be made. The details of the derivation are given in the appendix to this report; the result, for an atmospheric water content of $5.6 \times 10^{-6} \mathrm{~L} / \mathrm{L}$ and an $\mathrm{NO}_{2}$ concentration of $500 \mathrm{ppb}$, is

$$
\left[\mathrm{HNO}_{3}\right]=\left[\mathrm{HNO}_{3}\right]_{\mathrm{O}}+\left(1.4 \times 10^{-10} \mathrm{~mol} / \mathrm{L} / \mathrm{s}\right) \mathrm{t}
$$

where

$t=$ the elapsed $t$ ime in seconds and

$\left[\mathrm{HNO}_{3}\right]_{0}=$ an assumed initial nitric acid concentration.

This estimated rate of nitric acid production is extremely slow; if a value of $\left[\mathrm{HNO}_{3}\right]_{0}$ corresponding to a pH of 4.6 (the annual north Florida average) is assumed and the length of time it would take for the $\mathrm{pH}$ to drop by $0: 1$ unit is calculated, the result is $5 \times 10^{4} \mathrm{~s}$, or about $14 \mathrm{hr}$. Conversely, the amount of acid produced in the time required for a droplet of lidius $0.15 \mathrm{~mm}$ to fall through the ground cloud and hit the ground would be completely undetectable. It should also be pointed out that the approximations made in the course of the calculation, specifically the neglect of the chemical effect of $\mathrm{NO}$, the neglect of the removal of $\mathrm{NO}_{2}$ from the air (and in fact of any process such as atmospheric dispersion that would tend to decrease the ambient $\mathrm{NO}_{2}$ partial pressure), and the neglect of evaporation of $\mathrm{HNO}_{3}$ from the droplet, are all conservative in the sense that they all lead to an overestimate of the aqueous $\mathrm{HNO}_{3}$ concentration. It seems safe to conclude, therefore, that acid production by this mechanism can be neglected in an assessment of short-term effects of an HLLV ground cloud. This qualitative result would still hold, although less comfortably, if the acid production rate were an order of magnitude higher.

Production of acid in the gas phase by involvement in photochemical smog takes place primarily by reaction of $\mathrm{NO}_{2}$ with hydroxyl radicals:38,39

$$
\mathrm{OH}+\mathrm{NO}_{2} \stackrel{(\mathrm{M})}{\longrightarrow}-\mathrm{HNO}_{3}
$$

The hydroxyl radicals themselves are generated by a variety of processes, including photolysis of ozone, to give molecular oxygen plus an excited oxygen atom and subsequent reaction of the excited oxygen atom with ambient water vapor. The significance of this process for short-term effects is difficult to establish without detailed modeling of the gas-phase chemistry 
occurring within the cloud, a task outside the scope of this assessment. However, it is possible to estimate the amount of nitric acid produced over 1-2 hr by this reaction by using a representative tropospheric daytime hydroxyl radical concentration of $1 \times 10^{6} \mathrm{~cm}^{-3} 70$ in combination with the rate constant for reaction (F) of $1.1 \times 10^{-11} \mathrm{~cm}^{3}$ molecule $\mathrm{sec}^{-1}$. $^{-1}$ The product of these two quantities gives an approximate conversion rate of $4 \% \mathrm{hr}^{-1}$ for $\mathrm{NO}_{2}$ conversion to $\mathrm{HNO}_{3}$. While nitric acid is being produced at this rate, the ground cloud disperses in both vertical and horizontal directions. If the horizontal distribution of the cloud is assumed to be Gaussian, the vertically integrated $\mathrm{NO}_{2}$ concentration will also be Gaussian (neglecting chemical interaction of cloud constituents with ambient ozone), and the maximum (central) value of the integrated $\mathrm{NO}_{2}$ concentration will decrease with time by the factor $h(t)$ given by (with $t$ in $h r$ ):

$$
h(t)=\frac{1}{1+1.14 t^{2}}
$$

This expression represents the ratio $\sigma^{2}(0) / \sigma^{2}(t)$ and may be easily obtained from Eq. 14. If nitric acid is assumed to be uniformly produced at a constant rate of $0.04 \mathrm{hr}^{-1}$, the central vertically integrated $\mathrm{HNO}_{3}$ gas-phase concentration will be given by

$$
\int\left[\mathrm{HNO}_{3}\right](\text { gas }) d z=\left(8.2 \times 10^{-3} \frac{\mathrm{mol}}{\mathrm{m}^{2}}\right)\left(1-\mathrm{e}^{-0.04 t}\right) \mathrm{h}(\mathrm{t})
$$

in which $8.2 \times 10^{-3} \mathrm{~mol} / \mathrm{m}^{2}$ is the estimated central, vertically integrated $\mathrm{HNO}_{3}$ concentration in the initial ground cloud. The highest value attained by the integrated $\mathrm{HNO}_{3}$ concentration is reached about $1 \mathrm{hr}$ after launch, and is equal to $1.5 \times 10^{-4} \mathrm{~mol} / \mathrm{m}^{2}$. If the vertical distribution after $1 \mathrm{hr}$ is taken to be uniform up to an assumed inversion height of $1500 \mathrm{~m}$, the corresponding gas-phase nitric acid concentration is $1 \times 10^{-7} \mathrm{~mol} / \mathrm{m}^{3}$ corresponding to $1 \mathrm{x}$ $10^{-10} \mathrm{~mol} / \mathrm{L}$ or $24.5 \mathrm{ppb}$. Assuming that all thic nitric acid is absorbed into rainfall ( $\mathrm{V}_{1 \mathrm{ig}} / \mathrm{V}_{\mathrm{air}}=5.6 \times 10^{-6} \mathrm{~L} / \mathrm{L}$ ), the risresponding aqueous acid concentration is $1.8 \times 10^{-5} \mathrm{~mol} / \mathrm{L}$. For purposes of comparison, an aqueous solutinn with a $\mathrm{pH}$ of 4.6 contains $2.5 \times 10^{-5}$ moles of hydrogen ions per liter, and if the estimated contribution from the ground cloud $\mathrm{NO}_{2}$ is added to this, the $\mathrm{pH}$ would decrease by 0.23 units to 4.37 .

In many respects, the approximations involved in the above calculation lead to an overestimate of the amount of acid produced. Due to the limitations of the study, no attempt was made to identify adverse or worst-case meteorological or other conditione. It seems safe to conclude that, on a local, short-term basis, the nitric acid produred by an HLLV launch will not have any siguilicane adverse effects, although an assessment of ecological effects is also outside the scope of this analysis. It would, however, be desirable to take a more detailed look at the question, taking into account both the gas-phase chemistry of the ground cloud as well as the dynamics of the cloud itself, in order to establish with grealer certainty the conclusion just reached.

The third process by which atmospheric $\mathrm{NO}_{2}$ may give rise to acid is that reported by Robbins et al.58 In that work, it was found that in mixtures of sodium chloride $(\mathrm{NaCl})$ aerosol and gaseous $\mathrm{NO}_{2}$ in air of varying 
degrees of humidity, the sodium chloride was replaced to an extent (dependent on humidity) by sodium nitrate, and an equivalent amount of hydrochloric acid was produced. In the experiments, up to $80 \%$ of the initial $\mathrm{NaCl}$ aerosol was converted to $\mathrm{NaNO}_{3}$ within less than ten minutes at $97 \%$ relative humidity. The experimental conditions generally involved $\mathrm{NO}_{2}$ and $\mathrm{NaCl}$ levels several orders of magnitude higher than natural levels, although one experiment was carried out with $0.1 \mathrm{ppm} \mathrm{NO}_{2}$ and $12 \mathrm{~g} \mathrm{NaCl} / \mathrm{m}^{3}$ at $88 \%$ relative humidity, with the result that $44 \%$ of the $\mathrm{NaCl}$ was converted to $\mathrm{NaNO}_{3}$, and presumably also resulted in the simultaneous production of $9 \times 10^{-11} \mathrm{~mol} \mathrm{HCl} / \mathrm{L}$ air. Using a value of $7 \mathrm{~g} / \mathrm{m}^{3} 58$ for the concentration of $\mathrm{NaCl}$ aerosol on the Florida coast and assuming complete conversion into $\mathrm{HCl}$, the corresponding $\mathrm{HCl}$ concentration is estimated to be $1.2 \times 10^{-10} \mathrm{~mol} \mathrm{HCl} / \mathrm{L}$ :

If this acid is completely absorbed into droplets $\left(\mathrm{v}_{1 \mathrm{ig}} / \mathrm{v}_{\mathrm{air}}=5.6 \mathrm{x}\right.$

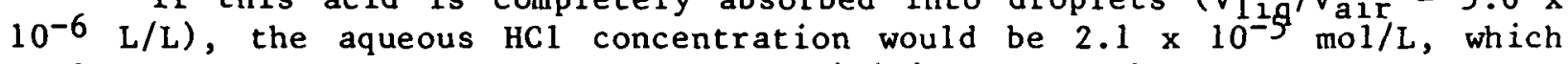
would reduce the $\mathrm{pH}$ from an assumed 4.60 initially to 4.34 . The amount of $\mathrm{NO}_{2}$ used up in the process is also $1.2 \times 10^{-10} \mathrm{~mol} / \mathrm{L}$ so that the initial ground cloud level of $500 \mathrm{ppb}\left(2.0 \times 10^{-8} \mathrm{~mol} / \mathrm{L}\right)$ would not be noticeably affected and the other acid-forming processes discussed above would operate as before. If the possible $1.2 \times 10^{-10} \mathrm{~mol} / \mathrm{L}$ of strong acid from the aerosol reaction is combined with $1.0 \times 10^{-10} \mathrm{~mol} / \mathrm{L}$ from photochemical conversion, the total hydrogen ion concentration in 1 iquid droplets with $\mathrm{v}_{1 \mathrm{iq}} / \mathrm{V}_{\mathrm{air}}=5.6 \times 10^{-6} \mathrm{~L} / \mathrm{L}$ would be $3.9 \times 10^{-5} \mathrm{~mol} / \mathrm{L}$, corresponding to a total $\mathrm{pH}$ change from 4.6 to 4.2. A change in $\mathrm{pH}$ from 4.6 to 4.2 corresponds to increasing the hydrogen ion concentration by a factor of about 2.5. It does not seem likely that the $\mathrm{pH}$ level in a single precipitation event in north Florida could be lowered by an amount significantly greater than this due to a single HLLV launch.

\subsubsection{Regional, Long-term Effects}

For the purpuse of assesaing long-term effects, it is most convenient to consider the projected $375 \mathrm{HLLV}$ launches/yr in comparison with other $\mathrm{NO}_{x}$ sources and in combination with available data regarding the effect of oxides of nitrogen on acidic precipitation in Florida. Recently, data has been published by Brezonik et al.57 that indicates that over the past 20-25 years, the average $\mathrm{pH}$ of precipitation in northern Florida has fallen by about one unit to a present average value of 4.6-4.7. This decrease has been accompanied by a $60 \%$ increase in the concentration of "excess" sulfate, that amount in excess of the quantity due to sea spray, and an increase by a factor of 4.5 in the nitrate concentration in precipitation. Ionic balance in precipitation samples indicate that sulfuric acid is 2.0-2.5 times more important than nitric acid, that the two together account for nearly all the acidity of Florida rainfall, and that the geographic distribution of $\mathrm{NO}_{\overline{3}}$ is relatively isotropic, indicating that nitric acid contributes a "diffuse background of $\mathrm{H}^{+}$to precipitation. . .157

Multiple regression analyses indicated that $75 \%$ of the variation in $\mathrm{H}^{+}$ could be explained by a linear two-variable equation, including the concentrations of sulfate and calcium ions; inclusion of ritrate did not improve the correlation. The interpretation of this result was that, in general, the acidity of Florida rainfall may be accounted for in terms of an interaction between sulfuric acid and terrestrial basic calcium salts (e.g., limestonecalcium carbonate), although an isotropic contribution from nitric acid would not have been detected in the regression analysis. 
In order to estimate the effect of a single new source of $\mathrm{NO}_{\mathrm{x}}$ on regional or statewide precipitation acidity, it has been assumed that the average hydrogen ion concentration can be written approximately as

$$
\left[\mathrm{H}^{+}\right]=a+b\left(\left[\mathrm{NO}_{\overline{3}}^{-}\right]+\left[\mathrm{SO}_{\overline{4}}\right]_{\mathrm{Xs}}\right)-c\left[\mathrm{Ca}^{++}\right]_{\mathrm{XS}}
$$

in which the subscript xs indicates excess over the sea spray contribution. This equation is similar to that of Brezonik et al.57 but with a term linear in nitrate added with the same coefficient as sulfate. If now the average nitrate concentration is increased by a factor $(1+\mu)$, due to an assumed new source of nitric acid, the new hydrogen ion concentration becomeo

$$
\left[\mathrm{H}^{+}\right]_{\text {new }}=\left[\mathrm{H}^{+}\right]_{\mathrm{old}}\left(1+\mathrm{b \mu} \frac{\left[\mathrm{NO}_{3}^{-}\right]_{\mathrm{O}} \mathrm{d}}{\left[\mathrm{H}^{+}\right]_{\mathrm{old}}}\right) .
$$

The quantity $\mu$ may be identified with the fractional increase in $\mathrm{NO}_{x}$ emissions due to the new source, assuming that contributions to acidity are proportional to $\mathrm{NO}_{\mathrm{x}}$ source strengths. Ambiguity in this procedure arises when one tries to decide exactly what other $\mathrm{NO}_{\mathbf{x}}$ sources to use in the comparison. The apparent isotropy of the nitric acid contribution may imply that the other relevant sources are all those within the entire statewide area. To be on the conservative side, we consider only $\mathrm{NO}_{x}$ emissions from within Brevard Co., the county in which Kennedy Space Center is located; the result will be a substantial overestimate of the impact. Total estimated annual $\mathrm{NO}_{\mathrm{x}}$ emissions for Brevard Co. for the year 1985 are $3.1 \times 10^{7} \mathrm{~kg}, 34$ while the estimated total $\mathrm{NO}_{\mathrm{x}}$ production from $375 \mathrm{HLLV}$ launches per year amounts to approximately $1.13 \mathrm{x}$ $107 \mathrm{~kg} / \mathrm{yr}$, or $36 \%$ of the 1985 Brevard Co. total. Taking $\mu=0.36$ and using values of $b=0.54,\left[\mathrm{NO}_{3}^{-}\right]_{\mathrm{Old}}=1.41 \times 10^{-5} \mathrm{~mol} / \mathrm{L}$ and $\left[\mathrm{H}^{+}\right]_{\mathrm{O}} \mathrm{dd}=$ $1.73 \times 10^{-5} \mathrm{~mol} / \mathrm{L}, 57$ the fractional increase in the average hydrogen-ion concentration is estimated from Eq. 19 to be 0.16 , and the corrcoponding decrease in the average $\mathrm{pH}$ value is 0.07 units. A change of this magnitude would probably not be detectable using present methods. 


\section{ASSESSMENT OF UPPER ATMOSPHERIC EFFECTS}

\subsection{THE NATURAL UPPER ATMOSPHERE}

The stratosphere and mesosphere are the lowest of those regions that taken all together constitute the "upper atmosphere" as shown in Fig. 4. The stratosphere lies immediately above tra lowest atmospheric region, the troposphere, in which mankind conducts its daily activities and which contains approximately $85 \%$ of the total mass of the atmosphere. The classification of atmospheric regions is most commonly made with regard to the observed variation of temperature with altitude, although if one is mainly concerned with ionic processes, a different classification scheme is often used for altitudes above about $60 \mathrm{~km}$. Thus, the mean temperature of the atmosphere is observed to decrease up to an altitude of about 11-12 km, depending, for example, upon latitude and seasons of the year.

The tropopause may be defined as the altitude at which the atmospheric temperature stops decreasing, and marks the boundary between the troposphere and the stratosphere. The lower stratosphere (up to about $20 \mathrm{~km}$ ) is nearly isothermal, but from $20 \mathrm{~km}$ up to about $50 \mathrm{~km}$ the temperature increases. The altitude at which this increase stops and the temperature begins to fall again is termed the stratopause and marks the boundary between the stratosphere and the mesosphere. The mesosphere is that region in which the temperature is observed to decrease with altitude again, and spans the range from 50 to about $80 \mathrm{~km}$. Above $80 \mathrm{~km}$ (the mesopause), the temperature is observed to increase with altitude again, and this higher region is termed the thermosphere. The thermosphere, which extends up to about $500 \mathrm{~km}$ where it blends into the exosphere, is a transition region in which the temperature becomes uniform with altitude. The exosphere is so named because of neutral particles that are meving at escape velocity (about $10 \mathrm{~km} / \mathrm{s}$ at $1000 \mathrm{~km}$ ) or greater can escape from Earth's gravitational field once they leach thie altitude. It is well known that Earth continuously loses hydrogen atoms via this route. As high-velocity hydrogen atoms escape from the exosphere, other $H$ atoms continuously diffuse upward from the denser regions of the atmosphere toward maintaining thermodynamic equilibrium in Earth's gravitational field. This upward transport and removal of hydrogen is called the "natural hydrogen cycle."

At an altitude of about $60 \mathrm{~km}$, the ambient concentration of ionic species and electrons begins to be high enough to affect the propagation of radio waves, and the ionosphere is generally considered to begin a,t about this altitude. Historically, the ionosphere has been divided into several overlapping regions: the D-region, which essentially coincides with the mesosphere, extends from about $60-90 \mathrm{~km}$; Llie E-rcgion, which occupies the lowest portion of the thermosphere and extends up to about $140-150 \mathrm{~km}$; and the F-region, which extends out to about $800-1000 \mathrm{~km}$ where it blends smoothly into the plasmasphere.

Because of the competing production (photoionization) and loss (diffusion and recombination) mechanism, the density of free electrons in the ionosphere increases to a peak value, called the $F 2$ peak, around $250-400 \mathrm{~km}$. Regions above and beluw this level are referred to as the topside and bottomside ionosphere, respectively. Radio waves transmitted from the earli's surface having a frequency below the critical frequency characteristic of. 
the $F 2$ peak are reflected from the bottomside ionosphere. Frequencies above the critical frequency are transmitted through the ionosphere. Depending upon the frequency, the amplitude and/or phases of the transmitted waves may become altered.

The D- and E-region ion population consists primarily of molecular ions, but the F-region ion population is dominated by atomic ions, especially atomic oxygen ions $\left(0^{+}\right)$. Above about $1000 \mathrm{~km}$ protons (atomic hydrogen ions, $\mathrm{H}^{+}$) become the dominant ionic species.

Near the upper boundary of the E-region, the mean free path becomes long enough so that charged-particle motion becomes strongly influenced by the geomagnetic field. This altitude marks the beginning of the magnetosphere. In this plasmasphere, extending from aluut $1000 \mathrm{~km}$ to $4 R_{E}$ (Earth radii), thermal ions collide with other particles about as often as they bounce back and forth along the dipole-like geomagnetic field lines, whereas energetic particles are likcly to gyıale and bounce back and forth for much longer periods of time before colliding with other particles.

The overall temperature structure of the atmosphere is such that it tends to inhibit the transport of material from one region to the next. Consequently, the extent to which one region influences another is often quite unclear and involves coupling mechanisms of a rather subtle nature. Furthermore, while the atmosphere becomes increasingly rarified with altitude, its susceptibility to change, due both to natural and man-made perturbations, increases. Unfortunately, since our knowledge of detailed processes in the atmosphere tends to diminish with increasing altitude, the problem of assessing the impacts of large-scale, man-made perturbations is difficult. In the next section an attempt is made to place the possible extent of SPS-related perturbations in perspective.

\subsection{SPS VS AMBIENT LOADINGS}

The Satellite Power System involves an extremely large opace cunstruction project, each of 60 proposed satellites having a solar collector array of dimensions $5 \times 10 \mathrm{~km}$ and a mass of 35,000-50,000 tons. Construction of two such satellites at geosynchronous orbit (GEO) at $35,800-\mathrm{km}$ altitude would involve the launch of a vehicle five times the size of the Space Shuttle at a rate of once or twice per day for 30 years. Both the vehicle oire and launch frcquency are unprecedented. The purpose of this section is to put the emissions from the various space transportation vehicles required for GrS iulu perepcctive by comparing them with ambient concentrations of the variouo exhaust constiturnts in diffcrent atüuspheric regions. Such comparisons are intended to give a very rough idea of the potential importance of the rocket effluents. More detailed analyses are given in the following sections.

In order to make this comparison in a meaningful way, it is convenient to introduce a dimensiunless quantity that we term the perturbation factor. (PF). The perturbation factor is defined as the ratio of the change in concentration of a given chemical substance divided by the ambient unperturbed concentration, and is therefore simply the fractional change in concentrations: 


$$
\text { PF }=\frac{\text { Expected Concentration Change }}{\text { Ambient Concentration }}
$$

As can be seen from this definition, the numerical value of the $P F$ in a particular situation is a measure of the significance of the change in concentration of a given substance being injected into the atmosphere relative to its ambient concentration. Thus, for example, a value of unity for the PF would indicate that the concentration of the particular substance is expected to increase by an amount equal to its existing concentration, and a PF value of very much less than one, would indicate that the expected fractional change in concentration will be small.

In order to estimate numerical values for the $P F$, an estimate of the expected concentration changes must be made. Although in general the atmospheric concentration of a given rocket exhaust effluent will change with time following a launch, the simplifying assumption will be made here that the SPS emissions are continuous at the average yearly emission rate corresponding to the proposed launch frequency. A simple one-dimensional model was used to estimate the corresponding change in the steady-state concentration of water vapor at altitudes up to $1000 \mathrm{~km}$. For other effluents, the following approximate linear relation was used:

$$
\begin{aligned}
& \text { Expected Concentration Change }= \\
& \text { (Injection Rate) } x \text { (Residence Time), }
\end{aligned}
$$

which applies in a steady-state situation, provided that the Residence Time is taken to be the inverse of the effective rate of disappearance of the given substance from the domain in question. It may be shown that Eq. 21 represents a lower bound to the result obtained when using a more sophisticated mniel for a steady-state situation. The Residence Time represents the. combined effects of transport and chemical (or photochemical) removal, and in general is given by an expression of the form

\section{(Residence Time) $)^{-1}=$ Transport Removal Rate + Chemical Removal Rate.}

The concept of a PF is very convenient for indicating the potential magnitude of the expected effects.

This section is concerned primarily with rocket emissions into the stratosphere and above. Emissions into the troposphere are expected to have only localized effects, which are discussed in Sec. 2. The principal exhaust products, as discussed in the introduction, are $\mathrm{CO}_{2}$ and $\mathrm{H}_{2} \mathrm{O}$ from the HLLV main burn up to staging at $56 \mathrm{~km}, \mathrm{H}_{2} \mathrm{O}$ and $\mathrm{H}_{2}$ between 56 and $125 \mathrm{~km}$ from the HLLV second stage, $\mathrm{H}_{2} \mathrm{O}$ and $\mathrm{H}_{2}$ at LEO due to $\mathrm{HLLV}$ second stage circularization and deorbit burns, NO between about 60 and $90 \mathrm{~km}$ due to HLLV second stage reentry, $\mathrm{H}_{2} \mathrm{O}$ and $\mathrm{H}_{2}$ due to POTV transit between LEO and GEO, and an $\mathrm{Ar}^{+}$ion plasma between LEO and GEO due to the COTV. Each substance is considered in turn. 


\subsubsection{Carbon Dioxide}

In Sec. 2.3, it was pointed out that the total annual emissions from 375 HLLV launches would amount to only $23 \%$ of the quantity produced by a typical 1000-MW, coal-fired power plant in a year. If emissions into the stratosphere are considered and a stratospheric residence time for $\mathrm{CO}_{2}$ of one year is assumed, Eqs. 20 and 21 yield values of the perturbation factor that range about an average of $4 \times 10^{-6}$, depending on the specific value chosen for the ambient $\mathrm{CO}_{2}$ number density. 9 The previous conclusion that $\mathrm{CO}_{2}$ emissions would not be significant is strongly supported by this result.

\subsubsection{Water and Molecular Hydrogen}

Total emissions of $\mathrm{H}_{2} \mathrm{O}$ and $\mathrm{H}_{2}$ were given in the introduction. The distribution in altitule of thoeg omiooiono io sueh that lieatly as mull waler is deposited in the $120-125 \mathrm{~km}$ altitude range as in that of $0-5 \mathrm{~km}$, but the ambient density at $120 \mathrm{~km}$ is only $2 \times 10^{-8}$ times that at sea level; the overall effect at $120 \mathrm{~km}$ is very large.

Figure 13 gives the corresponding change in the water vapor concentration as a function of altitude from $0-1000 \mathrm{~km}$, based on a simplified steady-state, one-dimensional model with diffusive transport and an altitude-dependent, effective chemical removal rate coefficient. The concentration profile for water in the absence of chemical reaction with oxygen ions $\left(\mathrm{O}^{+}\right)$is also shown, and the importance of this process for removing water is clearly seen. Iu: $\mathrm{O}^{+}$profile used in the calculation is also given. The peak in the $\mathrm{H}_{2} \mathrm{O}$ profile at $120 \mathrm{~km}$ is a result of the large emission rate near that altitude; the peak in the lower stratosphere results from the relatively low value of the eddy diffusivity at thost altitudes.

In order to compute the perturbation lactor as a function of altitude using Eq. $\overline{2} \overline{0}$, values of the dubiell waler concencration at various altatudes are needed. The problem of measuring and explaining water vapor concentrations in the stratosphere and mesosphere has occupied atmospheric scientists For many years, and several recent reviews and discussions are available. $71-73$ Up to about $80-90 \mathrm{~km}$, ti.e water mixing ratio is a reasonably constant. 3-4 ppmv; no measurements are available above this altitude range. Model calculations 74,75 indicate that the water-mixing ratio drops dramatically above $80 \mathrm{~km}$ because of the increasing rates of photolysis and reaction with ambient species such as $U^{+}$. A calculation was carried out using the same one-dimensional model used to estimate the change in the water concentration because of SPS-related emissions, but in which the flux at $80 \mathrm{~km}$ was adjusted so as to produce a mixing ratio of $3 \mathrm{ppmv}$ at $80 \mathrm{~km}$. No rocket enissions were included. Table 10 lists some of the results and also gives, for comparison, the expected contributions from rocket emissions and the corresponding values of the perturbation factor. Again, the effect of emissions in the vicinity of $120 \mathrm{~km}$ may be seen, and the expected effect on water concentrations above 120 $\mathrm{km}$ is an increase of approximately a factor of 130-150.

As indicated in the introduction, HLLV emissions of molecular hydrogen are about one-third of the water emissions on a number basis. Model calculations 74,75 indicate, however, that the natural abundance of $\mathrm{H}_{2}$ is two or more orders of magnitude higher than that of $\mathrm{H}_{2} \mathrm{O}$ in the lower thermosphere. As a 
CHANGE IN WATER CONCENTRATION VS. ALTITUDE

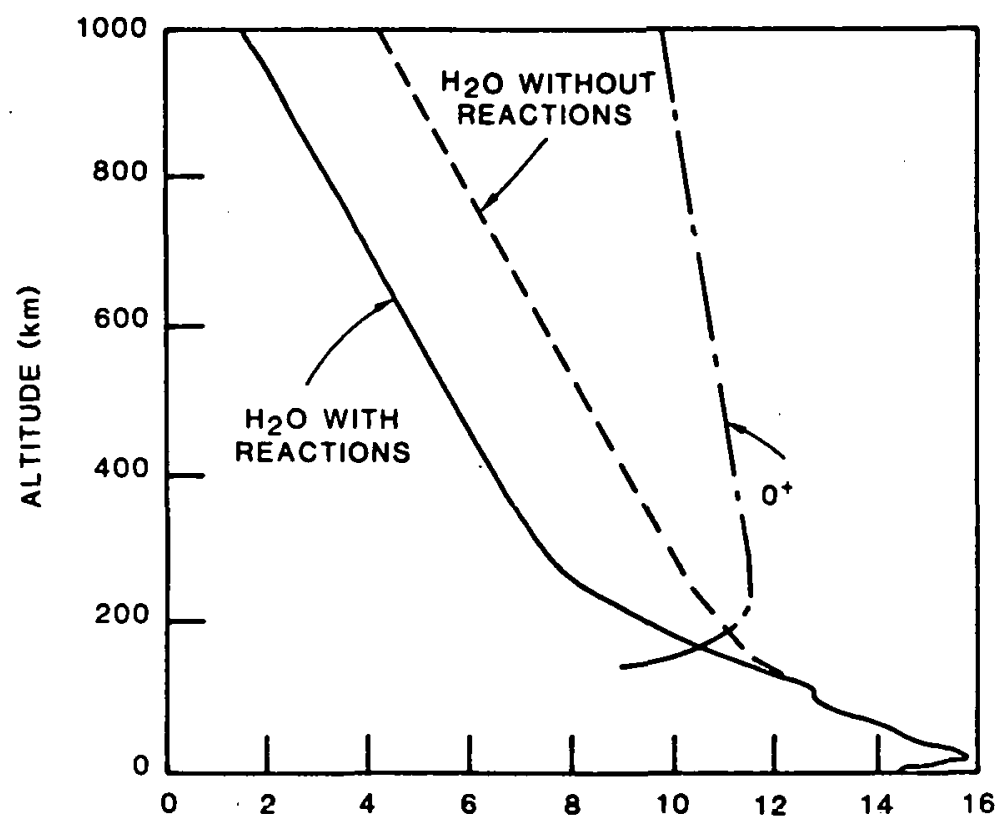

LOG (CONCENTRATION (molecules/m3))

Fig. 13 Estimated Change in Water Vapor Concentration

result, the molecular hydrogen emissions are far less significant with respect to natural ambient concentrations than are the water emissions. Figure 14 gives the estimated rhange in the $\mathrm{H}_{2}$ concentration because of sPS-related rocket emissions.

Taking both water and molecular hydrogen into account, the exhaust emissions from SPS activities will be about double the total hydrogen content of the thermosphere above about $125 \mathrm{~km}$. This increase is projected based on the calculations, shown in Figs. 13 and 14, of the expected changes in $\mathrm{H}_{2} \mathrm{O}$ and $\mathrm{H}_{2}$ concentrations and the observation that the natural total hydrogen content in the lower thermosphere is of the same order of magnitude as these expected changes. A doubling of the hydrogen content could affect the natural hydrogen cycle and perhaps increase the exosphere density.

Enhancements in the water concentration by factors of 100 or more may notably affect the free electron density above $150-200 \mathrm{~km}$. The electron density is determined by the balance between the rate of electron production (mainly by photoionization) and the rate of electron loss via recombination with ambient positive molecular ions to form neutral molecules. In the normal ionosphere, the principal positive ion above $160-180 \mathrm{~km}$ is $0^{+}$. Charge exchange between the $0^{+}$ions and the dominant neutral species $\mathrm{N}_{2}$ and $\mathrm{O}_{2}$ leads to the relatively slow formation of molecular ions that recombine with electrons to form neutral species. If water molecules are deposited in the ionosphere, however, charge transfer between $\mathrm{H}_{2} \mathrm{O}$ and $\mathrm{O}^{+}$occurs much more rapidly than with $\mathrm{N}_{2}$ or $\mathrm{O}_{2}$ to produce $\mathrm{H}_{2} \mathrm{O}^{+}$and 0 , and the $\mathrm{H}_{2} \mathrm{O}^{+}$ion recombines very rapidly 
Table 10. Estimated Natural Water Consentrations above $80 \mathrm{~km}$

\begin{tabular}{cccc}
\hline $\begin{array}{c}\text { Altitude } \\
(\mathrm{km})\end{array}$ & \multicolumn{2}{c}{ B $_{2}$ O Concentration $(\mathrm{m}-3)$} & $\begin{array}{c}\text { Perturbation } \\
\text { Pactor }\end{array}$ \\
\cline { 2 - 4 } 500 & $2.67(3)^{\mathrm{a}}$ & $3.98(5)$ & 148 \\
450 & $6.98(3)$ & $1.04(6)$ & 148 \\
400 & $1.82(4)$ & $2.70(6)$ & 148 \\
350 & $5.33(4)$ & $7.90(6)$ & 148 \\
300 & $1.83(5)$ & $2.67(7)$ & 146 \\
250 & $1.36(6)$ & $1.91(8)$ & 140 \\
200 & $2.56(7)$ & $3.45(9)$ & 135 \\
150 & $1.56(9)$ & $2.03(11)$ & 130 \\
125 & $2.51(10)$ & $3.20(12)$ & 127 \\
120 & $3.90(10)$ & $4.97(12)$ & 127 \\
115 & $1.75(11)$ & $6.40(12)$ & 36.6 \\
110 & $3.11(11)$ & $7.83(12)$ & 25.2 \\
105 & $2.77(12)$ & $6.83(12)$ & 2.47 \\
100 & $5.24(12)$ & $5.83(12)$ & 1.11 \\
80 & $1.15(15)$ & $1.42(13)$ & \\
\hline
\end{tabular}

$a_{2.67}$ (3) denotes $2.67 \times 10^{+3}$.

with electrons (dissociatively). The net result, therefore, of depositing significant amounts of water in the ionosphere is to increase the rate at which $0^{+}$ions and electrons are removed and to shift the overall balance in the direction of lower free electron density. The same effect is expected from injections of $\mathrm{H}_{2}$, which can function in much the same manner as $\mathrm{H}_{2} \mathrm{O}$. Significant localized regions of electron depletion (or "holes") have been observed following single rocket launches.78 The degree to which electron depletion is expected to occur on a global scale will be discussed in later sections. Suffice it to say here that the results of the one-dimensional, steady-state calculation indicate a possibility that detectable, global-scale electron depletions may result from the projected SPS transportation systems.

The rocket exhaust products cool to very low temperatures in expanding to the low ambient pressures above $70-80 \mathrm{~km}$, and a certain fraction (5-35\%) of the water vapor will condense to form ice crystals.77 Effects of condensation have not been considered in the calculations for Fig. 13.

Some water vapor (and hydrogen) is also emitted at higher altitudes by the COTV* and POTV in their passage from LEO to GEO. The perturbation calcu1 ation is ouclined in Table 11 .

\footnotetext{
*A Chemical Propulsion System may be used in lieu of battery storage for attitude control during occultations.
} 


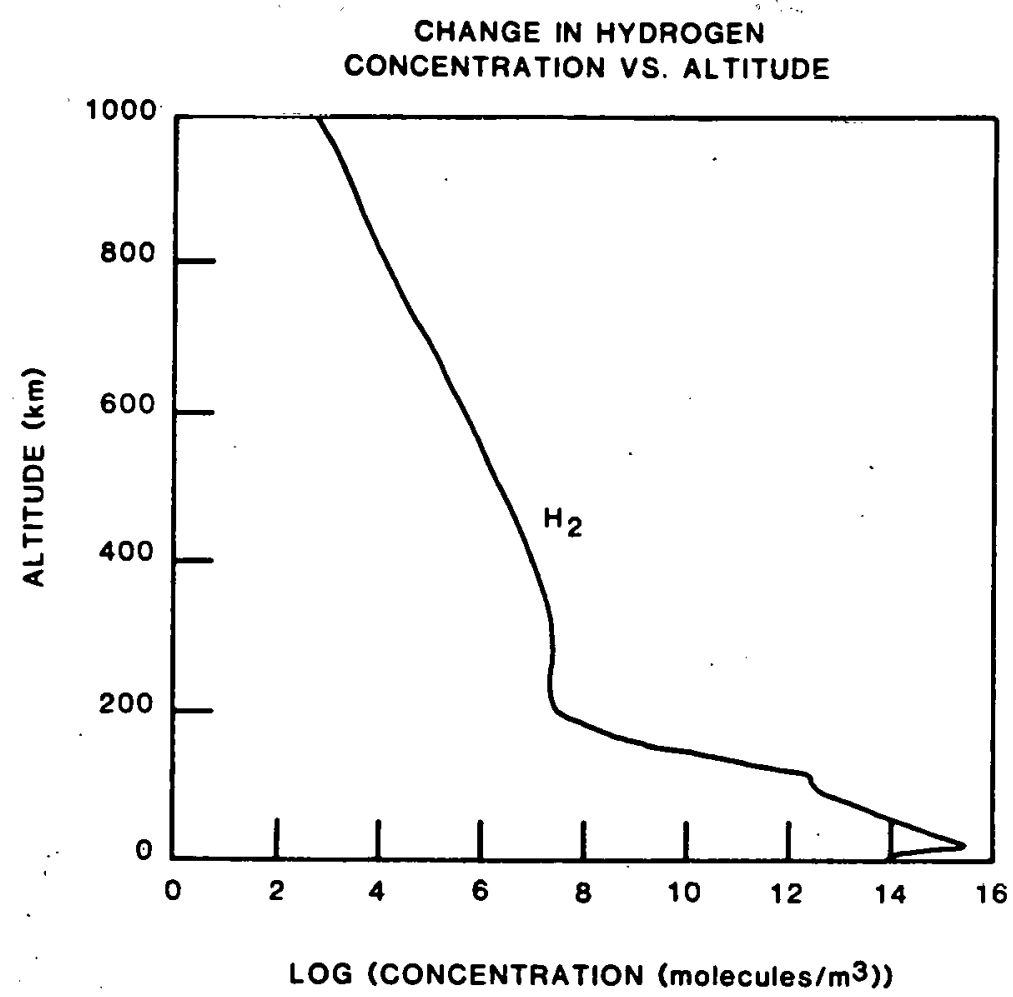

Fig. 14 Estimated Change in Molecular Hydrogen Concentration

\subsubsection{Nitric Oxide}

During reentry of the HLLV second stage a rather large quantity of air is heated above $2000 \mathrm{~K}$, and a significant amount of nitric oxide is formed. This nitric oxide then "freezes-in" as the air cools, the net result being equivalent to a direct injection. The possible mesospheric significance in terms of a perturbation factor is 1 isted in Table 12. The question of effects due to nitric oxide is discussed later. The principal importance of No in the $80-100 \mathrm{~km}$ altitude region is that it can be ionized by the rather intense solar hydrogen Lyman $\alpha$ line $(120.7 \mathrm{~nm})$, and thus leads to an increased level of ionization in this lowest portion of the ionosphere. At lower altitudes, NO may affect the ozone concentration.

\subsubsection{Argon Ion Plasma}

The COTV uses electrical propulsion, in particular a 1-5 keV argon ion plasma, in traveling between LEO and GEO. Thus, a very large number of argon ions (and the accompanying lower energy neutralizing electrons) are injected into the extremely tenuous magnetosphere. An indication of the attributable perturbation is given in Table 13; note that the "residence time" applies to the processes of de-energization and de-ionization and is rather uncertain.

The magnetosphere is a region in which the overall physics is quite different from that of lower altitudes because of the very low density and 
Table 11 Significance of H-atom Emissions Above LEO

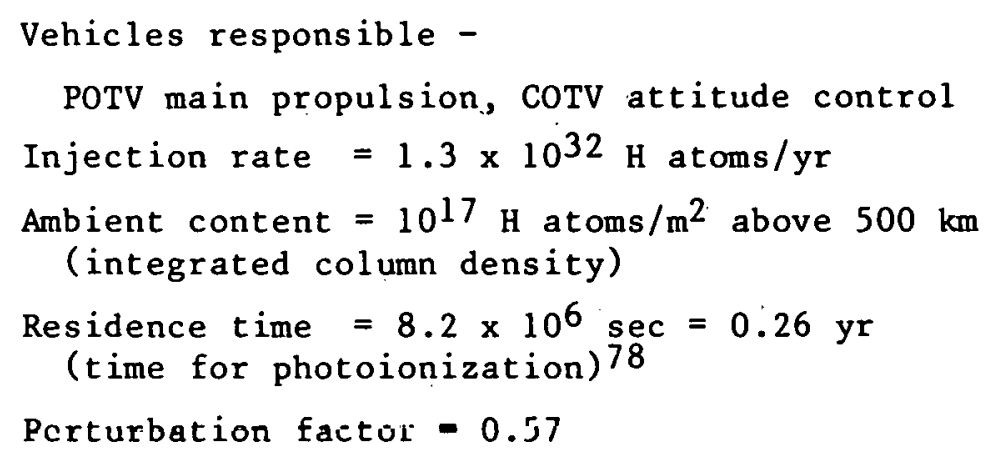

Table 12 Significance of No Injections

$\begin{array}{ll}\text { Altitude: } & 55-100 \mathrm{~km} \text { (peak effect at } 70 \mathrm{~km} \text { ) } \\ \text { Vehicles involved: } & \text { HLLV Second Stage (reentry) } \\ \text { Injection rate: } & 6 \times 10^{32} \text { molecules/yr } \\ \text { Ambient loadings: } & 4.7 \times 10^{32} \text { molecules } \\ \text { Residence time: } & 4 \text { days } \simeq 0.011 \mathrm{yr} \\ \text { Perturbation factor: } & 0.014\end{array}$

Table 1.3 Signifirance of Ar Injectione

\begin{tabular}{ll}
\hline Alticude: & LEO to GEO \\
Vehicles involved: & COTV main propulsion \\
Injection rate: & $4 \times 10^{32} \mathrm{Ar}^{+}$ions/year \\
Ambient loading: & $4 \times 10^{25} \mathrm{inns}$ \\
Residence time: & $1-10$ days \\
$\quad$ (time for de-ionization & \\
$\quad$ and de-energization) & \\
Perturbation factor: & $\gg 1$
\end{tabular}

relatively high degree of ionization, so that the long-range coupling between charged particles and the geomagnetic field dominates the phenomenology. The disturbances arising from SPS injections are large, but the overall effects of the argon plasma injection are not as clearly defined as are those of lower altitude injections. A recent discussion of the possible effects was given by Chiu et al. 79

\subsection{EFFECTS OF ROCKET EFFLUENTS BELOW $500 \mathrm{~km}$}

A perspective on the importance of SPS rocket effluents relative to ambient concentrations is given in Sec. 3.2. In the present section specific 
issues regarding these effluents are addressed in detail. Subsections 3.3.1 through 3.3.6 deal with neutral atmospheric impacts. The remaining subsections address effect:s on the ionized components of the atmosphere.

\subsubsection{Composition Changes in Stratosphere, Mesosphere, and Lower Thermosphere}

As indicated in the introduction and in Sec. 3.2, injections of water, molecular hydrogen, and nitric oxide would take place in the stratosphere, mesosphere, and lower thermosphere. One- and two-dimensional model calculations were carried out 80 to estimate the magnitudes of the resulting perturbations to the trace composition of these regions of the atmosphere. A description of the models used may, be found in Refs. 80-82; the 1-D model extends to $120 \mathrm{~km}$, and the 2-D todel to $90 \mathrm{~km}$. Figure 15 shows the exhaust emission profile used in the calculations, and Fig: 16 shows the No production due to reentry of an HLLV second stage 80 Figure 15 represents the reference design exhaust emission figures ${ }^{2}$ and an estimate of the amount of No produced by rocket exhaust afterburning 9 Figure 16 represents the results of calculations 80 carried out to estimate the amount of no produced on reentry. These calculations were carried out for steep; nominal, and shallow reentry trajectories, all of which corresponded to a landing site in southern California; only' the results for the "nominal" trajectory are shown. The reentry trajectory is such that the No production, rate depends on both altitude and latitude, and the production rate is shown on Fig. 16 as a function of altitude for latitudes from $10^{\circ}-35^{\circ} \mathrm{N}$ :

Stratospheric perturbations were all found to be substantially less than $1 \%$ of the natural abundance, in qualitative agreement with preliminary estimates reported earlier. 9 The effect on ozone, and particularly the integrated-ozone-column density is sumarized in the next section.

Figure 1780 shows the calculated change in the water vapor concentration for three different latitudes and for altitudes between 30 and 90 $\mathrm{km}$. Also shown is the percent increase in the water concentration as a function of altitude at the assumed launch latitude of $30^{\circ} \mathrm{N}$. No water vapor "corrider effect," i,e, enhanced concentration or buildup in a latitude band encircling the globe, exists below about $70 \mathrm{~km}$. Above $70 \mathrm{~km}$, a definite maximum is observed in the water concentration considered as a function of latitude at a given altitude; at $90 \mathrm{~km}$, the change in the water concentration is approximately $6-7 \times 10^{8} \mathrm{~cm}^{-3}$ at $30^{\circ} \mathrm{N}$, but only about $2 \times 10^{8} \mathrm{~cm}^{-3}$ at $10^{\circ} \mathrm{N}$ and $50^{\circ} \mathrm{N}$. At the launch latitude of $30^{\circ} \mathrm{N}$, the estimated percent increase in the water concentration increases dramatically above $80 \mathrm{~km}$, is in qualitative agreement with the simple 1-D results discussed in Sec. 3.2, and is already $15 \%$ at $80 \mathrm{~km}$. The corresponding global-average percent increase at $80 \mathrm{~km}$ is expected to be about $8 \%$.

Figure $18^{80}$ shows the expected increase in No concentration in the mesosphere as a function of altitude for various latitudes. The spatial distribution of the NO production rate is somewhat complicated, as shown on Fig. 16 and one cannot think in terms of a single specific reentry latitude; nevertheless, reentry occurs roughly, between $15^{\circ} \mathrm{S}$ and $30^{\circ} \mathrm{N}$ latitude, with the maximum No production taking place at between $20-30^{\circ} \mathrm{N}$. The resulting corridor effect is clearly seen in Fig. 18 , and is much more pronounced than the 


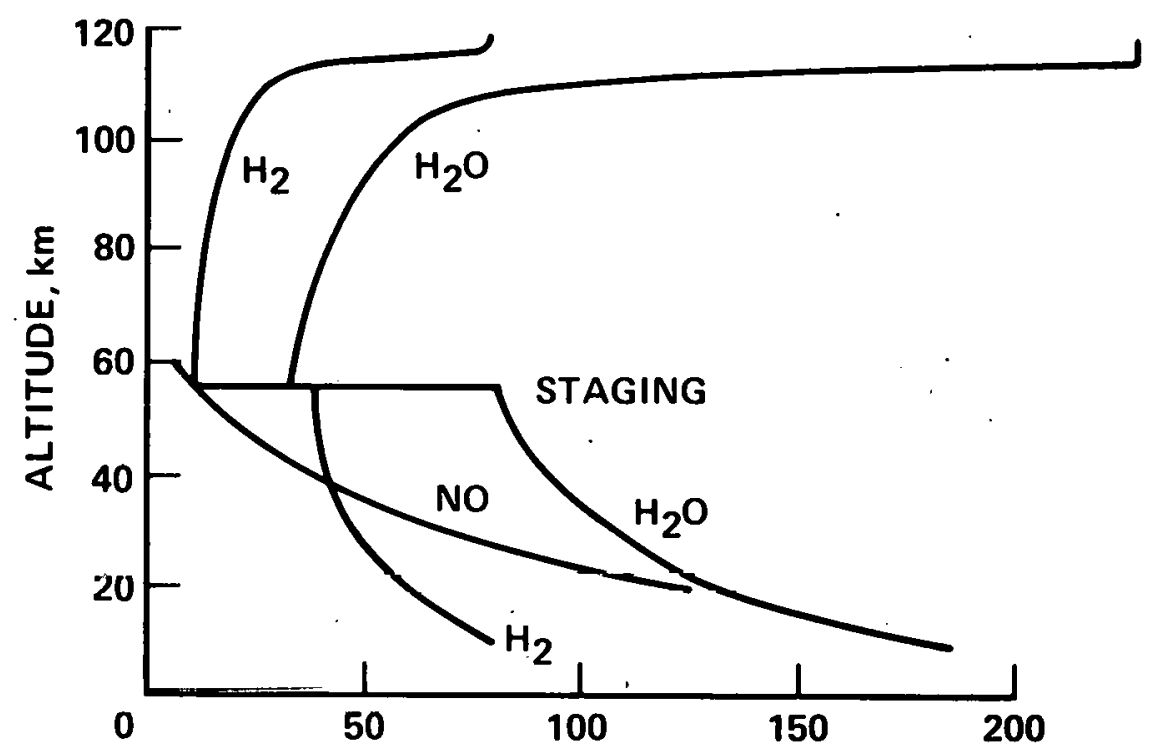

$\mathrm{H}_{2}, \mathrm{H}_{2} \mathrm{O}$ DEPOSITION, molecules $\mathrm{cm}^{-1} \times 10^{23}$ NO DEPOSITION, molecules $\mathrm{cm}^{-1} \times 10^{20}$

Fig. $15^{\circ}$ Rocket Emission Profile

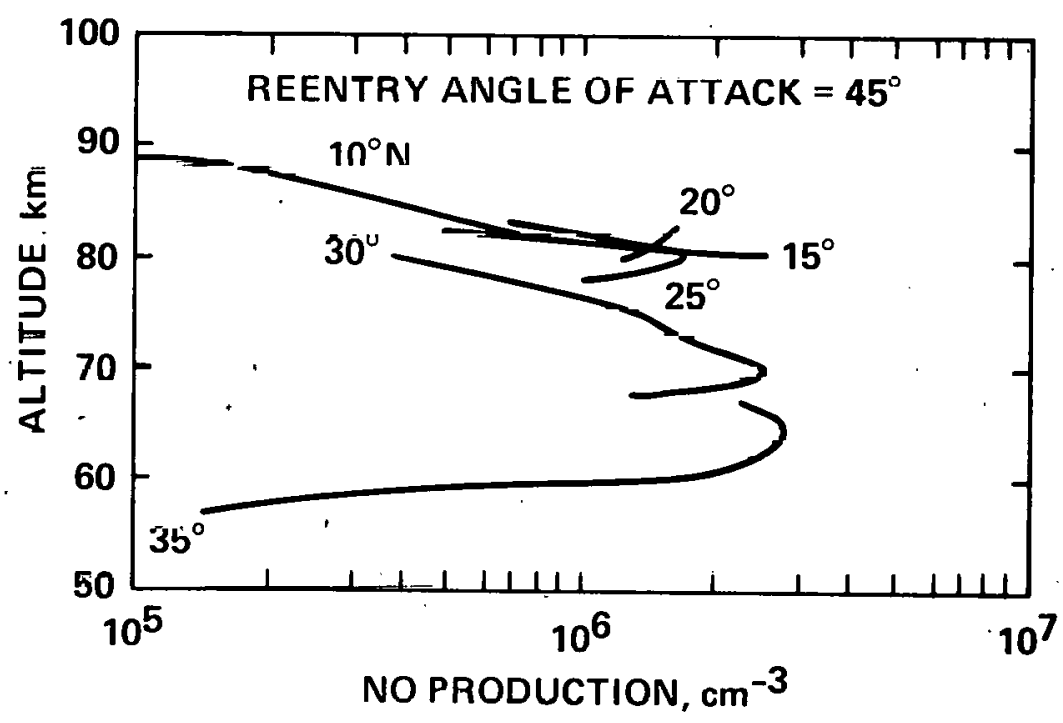

Fig. 16 Estimated Reentry Production of NO 


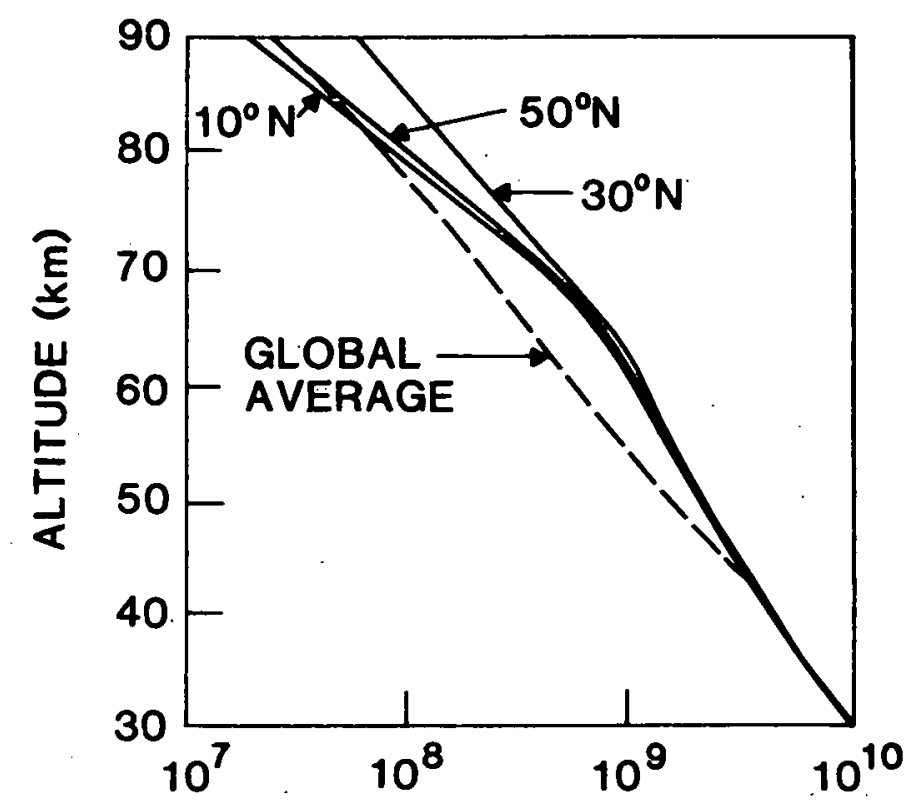

(a)

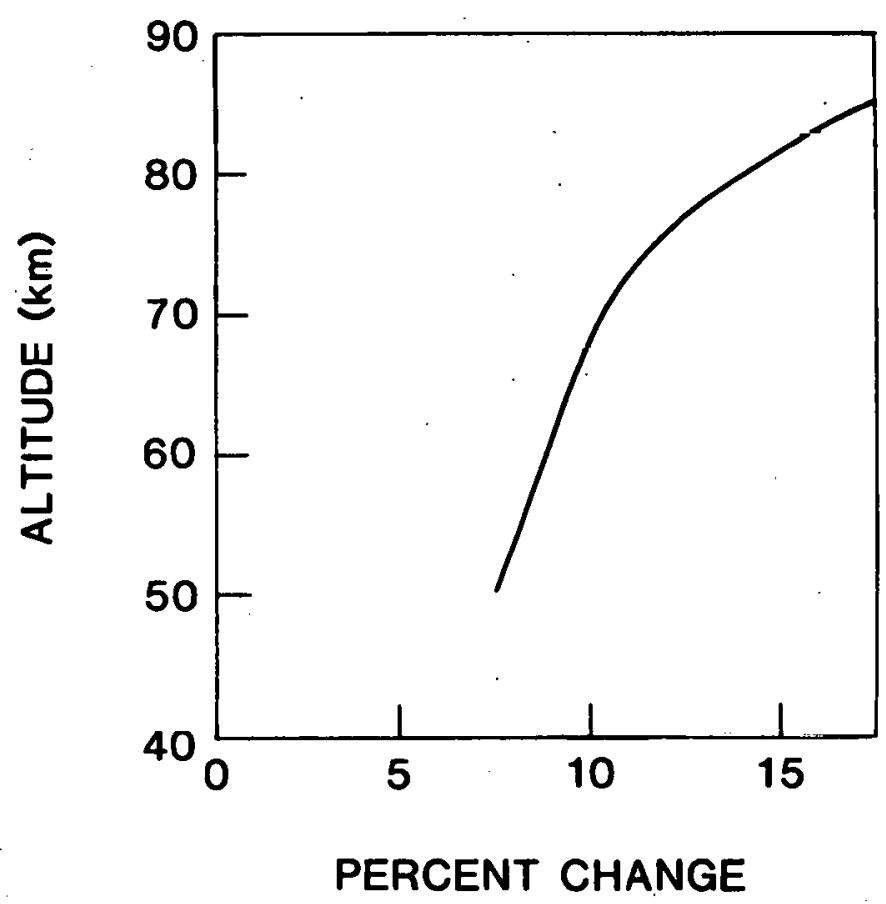

(b)

Fig. 17 Calculated Change in Water Vapor Concentration at Several Latitudes and Altitudes 
mesosphere would reduce the total integrated-ozone column by approximately $0.02 \%$, with the greatest change occurring in the mesosphere. 9 More recent calculations, 80 involving both $1 \mathrm{D}$ and $2-\mathrm{D}$ models, including both water injections and No deposition in the stratosphere due to exhaust afterburning indicate that the expected change in the ozone column is approximately $-0.015 \%$, globally averaged, in agreement with the earlier results. The effect of NO deposition owing to reentry of the HLLV second stage on the ozone column is an increase by about $0.02 \%$, globally averaged. Very little corridor effect is present in the results of the water vapor calculations, except at altitudes above $70 \mathrm{~km}$, but a slight corridor effect may be seen in the results of the reentry-produced NO calculations as shown in Fig. 19. A change in ozone-colum density of the order of magnitude indicated by these results would be undetectable with available measurement techniques.

It should also be pointed out that the predicted effects of reentryproduced NO on the ozone-column density are subject to considerable uncertainty, and that if realistic error bounds are attached to the predicted values as shown in Fig. 19, they would include the possibility of a net zero or a small negative effect. In addition, new values of tiie rate coefficients for $\mathrm{OH}+\mathrm{HNO}_{3}, \mathrm{OH}+\mathrm{H}_{2} \mathrm{O}_{2}, \mathrm{HO}_{2}+\mathrm{HO}_{2}$, and $\mathrm{OH}+\mathrm{HO}_{2}$ will probably alter the values of the change in ozone computed by Whitten, et al.80 The smaller ozone gain is expected to become a small ozone loss (Whitten, private communication, Aug. 1980).

\subsubsection{High-Altitude Cloud Formation}

Formation of artificial noctilucent clouds following rocket launches has been observed on several occasions.85-87 Noctilucent clouds are very

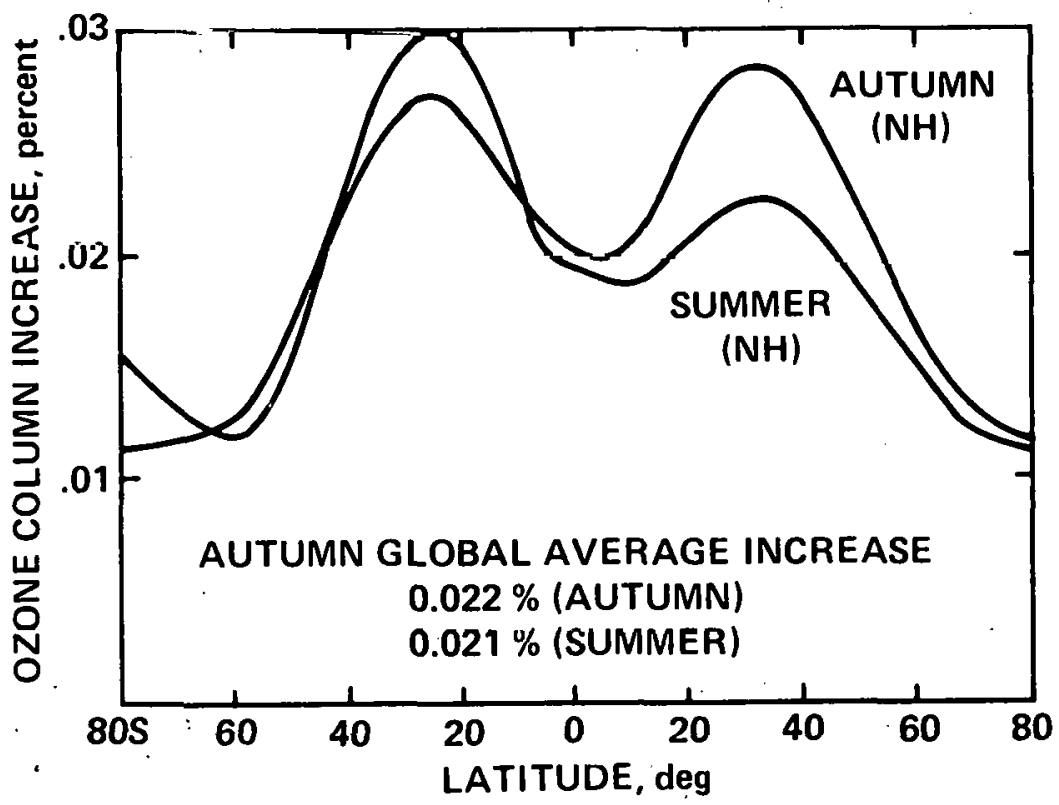

Fig. 19. Ozone Column Density Corridor Effect Due to Reentry NO 
tenuous, optically thin clouds occurring at or near the mesopause, the location of the minimum in atmospheric temperature marking the upper boundary of the mesosphere, at an altitude, of about $80-85 \mathrm{~km}$. Natural noctilucent clouds occur only during the summer months at latitudes above approximately $65^{\circ} \mathrm{N}$, and can be observed only with a glancing solar angle due to their optical thinness. The significance of the observations of such clouds following rocket launches is in part that they were made at latitudes of $45^{\circ} \mathrm{N}$ in winter on two occasions, $85.35^{\circ} \mathrm{N}$ in late spring, 86 and $35^{\circ} \mathrm{N}$ in autumn, 87 and indicate, therefore, a potential for enhanced noctilucent cloud formation at mid-latitudes from SPS-related rocket launches. That such a potential exists may be emphasized perhaps by noting that on two occasions, 85 the artificial cloud was apparently produced or triggered by a relatively small research rocket that reportedly deposited on $1 \mathrm{y} 260 \mathrm{gm}$ of water in the 80-90-km-altitude range, whereas an HLLV second stage will deposit approximately $1.3 \times 10^{7} \mathrm{gm}$ of water in the same altitude range. It may be significant that each of the four reported clouds was associated with the launch of a solid-fueled, rather than a liquid-fucled, rocket, although this observation may be due simply to the prevalence of solid-fueled rockets and the very small number of sightings.

It seems highly probable on this basis alone that transient noctilucent clouds or, perhaps more correctly, persistent contrails will be formed in association with individual HLLV or PLV launches. Theoretical calculations 80 support this conclusion and indicate that the increase in optical depth following an HLLV launch may approach 25 along the trall axis 1 hr after launch. (Optical depth is defined as the negative of the natural logarithm of the ratio of the observed light intensity at a point to the light intensity incident on the absorbing medium in which the observation is made. An optical depth of unity implies that $1 / \mathrm{e}$ of the incident 1 ight has been absorbed before reaching the observer, or equivalently, that $63 \%$ of the incident light is transmitted.) An optical depth of 25 implies that the fraction of light transmitted along the cloud axis is only $1.4 \times 10^{-11}$. However the cloud comprises ice particles that quickly disperso and evaporate, and the expected cloud lifetime is less than one day. The optical depth perpendicular to the cloud axis would be much smaller.

Figure 20 shows the results of a calculation. of the dynamics of the contrail of an HLLV in the altitude range near the mesopause. 80 The contrail diffuses from a cross-sectional area of about $1 \mathrm{~km}^{2}$ immediately after passage of the rocket to $900 \mathrm{~km}^{2}$ after a period of a day. The corresponding evolution of the associated optical depth is show. Immediately after injection into the atmosphere, a period exists during which homogeneous nucleation occurs and, because of the high super-saturation, the particles grow rapidly to radii on the order of $1 \mu \mathrm{m}$. Nucleation and growth cease after the water. vapor coneentralion has fallea lo near the saturation point, and turbulent dispersion of the contrail becomes the dominant process, with coagulation and sedimentation being important secondary processes. As the expansion of the contrail proceeds, the water vapor concentration remains essentially constant at saturation because of evaporation of the ice particles. Eventually, a point is reached at which evaporation proceeds very rapidly, and the contrail consists mainly of a region containing no ice particles and in which the water vapor concentration is just at saturation. This point is determined by the ambient temperature; hence after some time, the contrail is confined to the coldest region of the atmosphere, and disappears entirely when that region becomes unsaturated. 


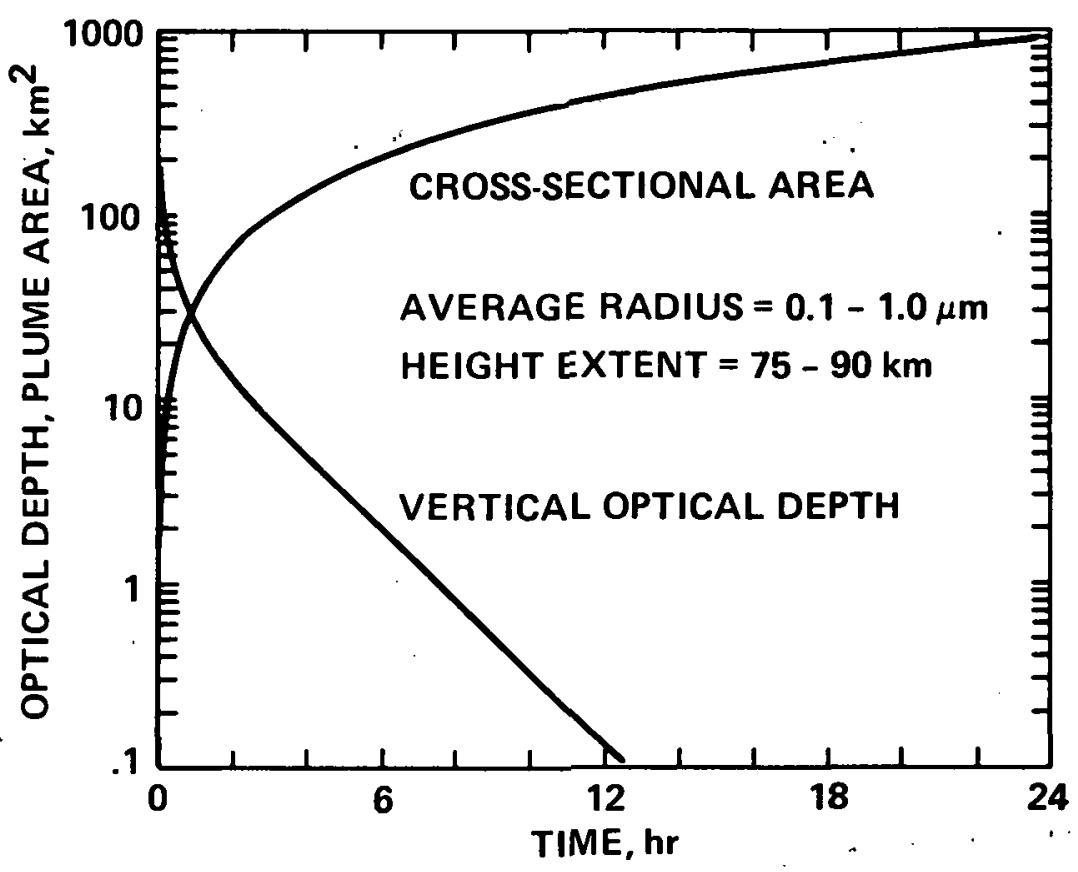

Fig. 20 Optical Depth in an HLLV Contrail

The calculations and the results shown in Fig. 20 indicate that a sub-visible cloud could persist for about a day before water saturation is reached at all altitudes, and a visual noctilucent cloud display is therefore possible at the first dusk or dawn following an HLLV launch.

Based upon the theoretically expected increase in the globally averaged water vapor concentration at $80-90 \mathrm{~km}, 80$ an increase of only $1 \times 10^{-4}$ in the optical depth at visible wavelengths is expected in the natural noctilucent cloud zone. If the optical depth were increased by the same amount over the entire earth, the estimated temperature change would be only $-1 \times 10^{-3} \mathrm{~K}$, compared with the accepted threshold for perceptible climate change of $0.1 \mathrm{~K} .80$ Thus, although transient artificial noctilucent clouds are expected to form in association with individual rocket launches and may, on occasion, give rise to colorful displays under the right viewing conditions, no globalscale increase in optical depth is expected and no detectable climatic effects are expected.

\subsubsection{Global Hydrogen-Cycle Changes}

Hydrogen, chemically bound, in the form of water and molecular hydrogen will be deposited in significant quantities by the HLLV-second-stage main burns, as already mentioned. These molecules will eventually undergo photodissociation as well as chemical, charge exchange, and dissociative-recombination reactions that will liberate hydrogen atoms. Preliminary calculations by $\mathrm{Zinn}$ et $a 1.88$ and whitten et al.80 of the source terms, suggest that this source of H-atoms could lead to a doubling of the natural upward flux of 
hydrogen into the thermosphere and exosphere. This problem has not been addressed in detail by either group of investigators. While the mass of these H-atoms would probabiy not substantially increase the neutral atmosphere density in the thermosphere, it could result in a significant increase in the total mass density above about $800 \mathrm{~km}$ where hydrogen is the dominant constituent. Two major sources of uncertainty in the H-atom balance problem are the magnitude of the natural upward flux of $\mathrm{H}$-atoms and how an enhancement of this flux would affect the global escape rate. While this natural upward flux is diffusion 1 imited below $100 \mathrm{~km}$, it is governed by other mechanisms, including charge exchange and Jeans escape, at higher altitudes.

Several current reviews are available that discuss the natural hydrogen cycle.74,75,89-91 If these additional H-atoms from the SPS rocket exhaust were to accumulate and significantly increase the density above $800 \mathrm{~km}$, important consequences could result. Since satellite drag measurements have been used to detect variations in atmospheric density at al.titudes as high as $1100 \mathrm{~km}$ or more, it is plausible that large chronic changes in density in that same range could slowly alter satellite orbits, especially sun-synchronous orbits near $900 \mathrm{~km}$. Although rather speculative, it has also been suggested that substantially increased upper thermospheric densities may alter wind patterns at those altitudes and also may affect ionospheric-magnetospheric coupling processes, especially those involving the precipitation of high energy particles. Such processes are believed to be a principal source of energy to the high latitude thermosphere. The problem of altering the natural $\mathrm{H}$-atom cycle requires further analysis.

\subsubsection{Density and Temperature Changes}

As mentioned above, injections of $\mathrm{H}$-atoms in the form of $\mathrm{H}_{2} \mathrm{O}$ and $\mathrm{H}_{2}$ molecules could lead to enhancement of exospheric densities ahnve $800 \mathrm{~km}$ if the natural H-atom escape rate did not increase. Density changes below this altitude due to injection of exhaust mass are not likely to he very 1 arge because of the relatively massive neutral atmosphere. However, mechanisms have been suggested for the alteration of the upper atmospheric temperature that could lead to a number of consequences, including thermospheric density changes. Unfortunately, these mechanisms involve compositional changes,estimates of which have only just begun to become availahle. Hence, temperaturc and density changes will have to await future analysis. of particular interest are possible temperature effects of the addition of the IR active $\mathrm{H}_{2} \mathrm{O}$ molecules and $\mathrm{OH}$ radicals produced from the $\mathrm{H}_{2} \mathrm{O}$ and $\mathrm{H}_{2}$ exhaust molecules. It has been suggested that the presence of theoe IR-active species cuuld lead to a net radiative cooling near the mesopause. This could lead in turn to the formation of more persistent noctilucent clouds (see Subsec. 3.3.3).

Some experimental evidence for a cooling effect has been reported by Chenurnoy and Charina.92 They studied variations in hydroxyl band IR emission before, during, and after a noctilucent cloud display and concluded that higher $\mathrm{H}_{2} \mathrm{O}$ concentrations before formation lead to enhanced $\mathrm{OH}^{-}$emission, causing local cooling. After formation, the water vapor is condensed into cloud particles that, according to these authors, reduce the IR emission. 
Another mechanism for temperature and density change arises in the upper ionosphere and plasmasphere. Chiu et al.93 have estimated, that a substantial fraction of the energy carried by the ion beam from a COTV would be converted into thermal energy in the mid-latitude ionosphere. This conversion would result in a marked temperature increase and a transformation of the plasmasphere from a region dominated by H-atoms to one dominated by $\mathrm{Ar}$ and 0 atoms. Consequences of this change are discussed in a subsequent subsection.

\subsubsection{Airglow Emission Changes}

Natural airglow emissions occur over a broad range of the electromagnetic spectrum from the far IR to the extreme ultraviolet (EUV). Some regions of this spectrum are used for sateilite-borne, remote sensing, and surveil1 ance systems, and, therefore, account must be made of the natural background radiation levels and their natural fluctuations. The release of $\mathrm{H}_{2} \mathrm{O}$ and $\mathrm{H}_{2}$ molecules in the mesosphere and thermosphere will lead to interactions with ambient neutrals, ions, and electrons, producing reaction products in excited states that upon decay will emit photons in the airglow spectrum. The following reactions have been proposed:

$$
\begin{aligned}
\mathrm{O}^{+}+\mathrm{H}_{2} \mathrm{O} & \rightarrow \mathrm{H}_{2} \mathrm{O}^{+}+\mathrm{O} \\
\mathrm{H}_{2} \mathrm{O}^{+}+\mathrm{e}^{-} & \rightarrow \mathrm{O}\left({ }^{\mathrm{l}}\right)+\mathrm{H}_{2} \\
& \rightarrow \mathrm{O}\left({ }^{\mathrm{S}}\right)+\mathrm{H}_{2} \\
& \rightarrow \mathrm{OH}\left({ }^{2} \pi\right)+\mathrm{H}
\end{aligned}
$$

Decay of the excited states of oxygen atoms produced in reactions ( $\mathrm{Ha}$ ) and (Hb) result in the emission of red lines (630 and $636.4 \mathrm{~nm}$ ) and a green line $(557.7 \mathrm{~nm})$, respectively. The $\mathrm{OH}$ radicals produced in reaction(Hc) could be vibrationally excited, in which case decay would yield $\mathrm{OH}$ band emissions. Another source of the red and green lines could be the reaction sequence:

$$
\begin{aligned}
\mathrm{O}^{+}+\mathrm{H}_{2} & \rightarrow \mathrm{OH}^{+}+\mathrm{H} \\
\mathrm{OH}^{+}+\mathrm{e}^{-} & \rightarrow \mathrm{O}\left({ }^{1} \mathrm{D}\right)+\mathrm{H} \\
& \rightarrow \mathrm{O}\left({ }^{1} \mathrm{~S}\right)+\mathrm{H} \\
& \rightarrow \mathrm{O}\left({ }^{3} \mathrm{P}\right)+\mathrm{H}
\end{aligned}
$$

Again the reactions $(\mathrm{Ja})$ and $(\mathrm{Jb})$ result in excited states of the oxygen atom but the reaction ( $H C$ ), which is supposed to be more probable, leads to the ground state of the oxygen atom and, therefore, no decay photon is emitted.

The artificial airglow emissions produced by chemicals released in the upper atmosphere have been observed in the Lagopedo experiments of 197794,95 and in the monitoring of the HEAO-C Satellite launch 96,97 in September, 1979. In both cases, strong emissions were observed at 630 and $557.7 \mathrm{~nm}$ as expected. However, in the case of the Lagopedo experiments the chemical release was produced by an explosive discharge whose products include $\mathrm{H}_{2} \mathrm{O}, \mathrm{H}_{2}$, and $\mathrm{CO}_{2}$. The reaction sequence 


$$
\begin{aligned}
\mathrm{O}^{+}+\mathrm{CO}_{2} & \rightarrow \mathrm{O}_{2}^{+}+\mathrm{CO} \\
\mathrm{O}_{2}^{+}+\mathrm{e}^{-} & \rightarrow 0\left({ }^{1} \mathrm{D}\right)+0 \\
& \rightarrow 0\left({ }^{1} \mathrm{~S}\right)+0
\end{aligned}
$$

was believed to be the dominant source of the red and green lines. In the case of the HEAO-C satellite launch, the burning of the second-stage rocket engine produced only $\mathrm{H}_{2} \mathrm{O}$ and $\mathrm{H}_{2}$. The only other emission detected in the Lagopedo experiments was a weak signal at $666 \mathrm{~nm}$. However, rather than being produced from the decay of excited $\mathrm{OH}$ radicals produced by reaction (Hc) as first expected on theoretical grounds, it was produced by the scattering of sunlight by ice crystals. The 666-nm line was not observed in the HEAO-C monitoring experiment. However, emission in the $2.9 \mathrm{~nm}$ OH band was observed in the latter experiment and is not fully understood at present.

Airglow emission intensitice (rcd and green liues) of the order of 10 kiloRayleighs were observed over about a 30-minute period, covering an area of $10^{5}$ to $10^{6} \mathrm{~km}^{2}$, following the launch of the HEAO-C satellite. Since the number of exhaust molecules injected into the 200-500-km region during this launch is essentially equal to that of an HLLV circularization burn, similar airglow enhancements can be expected from such burns. The impact of such airglow enhancements on the performance of remote sensing equipment and astronomical observations is not known for certain; and although probably not very important, the impact should be determined. Emissions in near-UV or IR regions might be more significant for remote sensing (see "Artificial Airglow Emissions", Section 3.4.5). For example, the observed emission at $2.9 \mathrm{~nm}$ may be important to remote sensing systems. The nature of this emission requires further investigation. Unfortunately, no measurements have been made that would indicate the extent of artificial airglow emissions produced by an HLLVsecond-stage burn. It is important to note that the branching ratios for the abovementioned reaction sequences have not been measured in the laboratory.

\subsubsection{D- and E-Region Effects}

The participants in the Ionospheric and Magnetospheric Workshop 10 held in August 1978 suggested that water injection will tend to convert the region from $80-100 \mathrm{~km}$ from one dominated by light molecular ions to one duninated by heavier water-cluster ions that can recombine more rapidly with the free electrons. This action will lead to a reduction in the daytime free-electron density. The idea has since received further support both by participants at the La Jolla Workshop 11 and by calculations recently performed by Forbes.98 It has most recently been invertigated by Whillen ct 01.80 liorbes has estimated that water vapor concentrations of approximately 100 ppmv (parts per million by volume) would lead to a near complete conversion to water cluster ions within a cylindrical volume between 70 and $100 \mathrm{~km}$ altitude and having an area of $20,000 \mathrm{~km}^{2}$. Combined with the loss of electron production caused by screening of UV radiation by water molecules, Forbes estimates a $75 \%$ reduction in the daytime free-electron density over this same volume. If such depletions were indeed limited to such small volumes, they would not be expected to be of much concern. The size of the affected region and the possibility for cumulative effects is critically dependent on a number of parameter values used by Forbes, including neutral wind speeds, diffusion rates, and the photolytic lifetime of water. Unfortunately, Forbes used 
a photolytic lifetime for water of only two days. The accepted value of this parameter is substantially greater and is strongly dependent on altitude. For example, $\mathrm{Zinn}$ et al.88 have examined the photolytic lifetime of $\mathrm{H}_{2} \mathrm{O}$ in the upper atmosphere and have determined that it varies rapidly with altitude between 50 and $100 \mathrm{~km}$ (in agreement with other investigators) and approaches an asymptotic value of four days near $125-150 \mathrm{~km}$. The four-day lifetime assumes that the $24-\mathrm{hr}$ average photodissociation rate coefficient is one-half the peak value at noon at $150 \mathrm{~km}$.

Zinn et al.88 obtain a lifetime for water of 36 days at $85 \mathrm{~km}$ and about 15 days at $100 \mathrm{~km}$. Assuming a longitudinal transport rate quoted by Forbes, 98 this data would suggest the possibility that a launch rate of once or twice per day could lead to cumulative effects. That is, that effluents deposited by one rocket could be transported at the launch latitude around the globe (in about 1-2 weeks) in time to be augmented by another rocket launch before being completely removed by chemical or transport processes. Of course, the concentration of effluents would be greatly diminished by horizontal and vertical diffusion during the time required for transport around the globe. Whitten et al.80 have examined the extent of free electron depletion in the region from $70-100 \mathrm{~km}$ caused by ion-water cluster formation. On the long-term, global scale they found that for altitudes below $80 \mathrm{~km}$ the water vapor concentration was increased by only about $7-8 \%$, or less, above ambient, and since the clustering is already rapid in that region, the change in ionic composition and free electron density was quite small. Above $80 \mathrm{~km}$; even though they predicted increases in water vapor concentration $\gtrsim 20 \%$ near the launch latitude, they still did not find marked reductions in free electron content, because, according to the authors, the water clustering to ions was found to be too inefficient. They did not report on the effect of enhanced-ion-water clusters on the short-term, local scale. However, one would expect significant short-term, local-scale electron depletions in accordance with Forbes' result cited above.

Another potential effect of the 1 arge injections of water is a significant enhancement of the populations of $\mathrm{OH}$ radicals and $\mathrm{H}$ atoms. The hydroxyl radicals are important sources of airglow emissions in the near infrared. The H atoms will participate in mesospheric chemistry to some extent, but most will tend to diffuse into the thermoophere, as mentioned earlier. A qualitative estimate by Forbes 98 suggests that this upward flux of $H$ atoms will result in about a $10 \%$ or more attenuation of Lyman a radiation on a global scale. This attenuation would probably produce a small chronic reduction in $D-$ and E-region daytime ionization. On the other hand, increased concentra$t$ ions of $\mathrm{H}$ atoms in the thermosphere and exosphere will scatter Lyman $\alpha$ radiation at nighttime, which will cause an increase in nighttime D- and E-region ionization. It is not known what effects such long-term changes in the diurnal pattern of ionization would have. However, it has been noted that such patterns are related to electromagnetic coupling between the $E-$ and F-regions.

A possible compensating effect on the $D$ - and E-region plasma density could result from the production of No by reentering space vehicles and debris. Since ionization of naturally occurring No by solar Lyman $\alpha$ radiation is the main source of free electrons in the $D$ - and lower E-region, enhanced No concentration is expected to result in increased free-electron content. Whitten et al.80 performed two preliminary case studies of the long-term 
global increases in the NO and free-electron concentrations. The Case 1 study consisted of calculations using their one-dimensional photochemical model and provided a lower bound on the expected results. Case 2 utilized their twodimensional photochemical model and provided an upper bound on the expected results. The results are shown in Table 14. Note that the maximum increase in $e^{-}$is about $18 \%$ and that there is a slight decrease in $e^{-}$above $85 \mathrm{~km}$ and at $60 \mathrm{~km}$. The decreases are caused by the ion-water clustering, which slight1y enhances the recombination rate over the increased production rate because of increased No concentration. A longterm increase of up to $18 \%$ in the $e^{-}$ concentration in a band surrounding Earth may not be insignificant and should be examined further in the future.

Since the D-region causes reflection of very low frequeney (VLF) radio waves. (3-30 kllz) and actenuation of high frequency ( $\mathrm{HF}$ ) radio waves (3-30 $\mathrm{MHz}$ ), changes in $\mathrm{e}^{-}$will result in corresponding changes in radio wave propagation properties. Whitten et al.80 have estimated that the corresponding increase in $\mathrm{HF}$ attenuation in the frequency range of $3-30 \mathrm{MHz}$ is about $10 \%$ during the daytime. Since much larger increases in attenuation that create serious communication problems are encountered during large-scale geophysical disturbances (e.g., aurora, solar proton events, and sudden ionospheric disturbances), it is doubtful whether a $10 \%$ increase in $D$-region absorption would be very serious. However, the question does deserve further attention. The effect of an $18 \%$ increase in the electron density on extremely low frequency (ELF) radio wave propagation was also examined by Whitten et al. They estimated the effects to be neglibible.

Short-term, local effects of No production by reentry are expected to be quite large, but confined to the immediate neighborhood of the reentry trajectory. Note that since such trajectories will not in general overlap launch trajectories; one. would not expect short-term local compensating

Tahle 1/1 Predicled Tonospheric Perturbations from Nitric Oxide Depositinn (from Ref. B0)

\begin{tabular}{|c|c|c|c|c|c|c|c|}
\hline \multirow[b]{2}{*}{$\begin{array}{l}\text { Alt. } \\
\text { (km) }\end{array}$} & \multicolumn{2}{|c|}{ Unperturbed } & \multicolumn{4}{|c|}{ Perturbed } & \multirow[b]{2}{*}{$\begin{array}{l}\text { Collision } \\
\text { Frequency }\end{array}$} \\
\hline & $\begin{array}{l}1 \mathrm{NO}] \\
\mathrm{cm}^{-3}\end{array}$ & 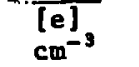 & [NO] & $\frac{1}{[e]}$ & [NO] & $\frac{2}{\text { (E) }}$ & \\
\hline 100 & $1.0(8)^{a}$ & $4.5(4)$ & $1.0(8)$ & $4.5(4)$ & $1.0(8)$ & $4.5(4)$ & $3.2(4)$ \\
\hline 90 & $4.8(7)$ & 7.5 (3) & 4.8 (7) & $7.4(4)$ & 4.8 (7) & $7.4(3)$ & $1.9(5)$ \\
\hline 85 & $1.5(7)$ & 4.1 (3) & $1.6(7)$ & 3.9 (3) & $1.6(7)$ & 3.9 (3) & $4.5(5)$ \\
\hline 80 & $1.0(7)$ & $8.0(2)$ & 1.1 (7) & $8.3(2)$ & $1.3(7)$ & 8.7 (2) & $1.1(6)$ \\
\hline 75 & $1.0(7)$ & $6.1(2)$ & $1.3(7)$ & $6.5(2)$ & $1.5(7)$ & $6.8(2)$ & $2.4(6)$ \\
\hline 70 & $1.0(7)$ & 1.7 (2) & $1.4(7)$ & 1.9 (2) & 1.9 (7) & 2.3 (2) & $5.3(6)$ \\
\hline 65 & $9.6(6)$ & 2.9 (1) & $1.7(7)$ & 3.4 (1) & $2.4(7)$ & 3.8 (1) & $1.1(7)$ \\
\hline 60 & 6.5 (7) & $7.6(0)$ & $7.3(7)$ & $7.2(0)$ & $8.5(7)$ & $7.2(0)$ & $2.2(7)$ \\
\hline
\end{tabular}

$a_{1.0}(8) \equiv 1.0 \times 10^{8}$ 
effects such as arise in the long-term global-scale situation discussed above. Table 15, from Whitten et al., 80 shows estimates of the No and corresponding $e^{-}$number densities as a function of altitude and time after reentry. Comparing the perturbed $e^{-}$densities with the unperturbed daytime values (last column, Table 15), it appears that the density increases are up to almost two orders of magnitude even after $24 \mathrm{hr}$. Comparing the perturbed No densities in Table 15 with the unperturbed values given in Table 14, it is seen that after $24 \mathrm{hr}$ the perturbed values range from two to three orders of magnitude greater. However, the authors caution that their estimates are based on a very simplistic modeling approach and, in light of the magnitude. of the increases, require a more sophisticated examination.

In summary, preliminary calculations suggest that the long-term global changes in $e^{-}$in the $\mathrm{D}-$ and E-regions will probably be relatively small ( $\left.\leqslant 10 \%\right)$ owing to a combination of enhanced recombination by increased positive ionwater clustering and enhanced production resulting from increased NO concentrations caused by reentry. Changes of this magnitude probably could not seriously affect radio wave propagation. Changes in Lyman $\alpha$ intensity in both the daytime and nighttime $D-$ and lower E-region conceivably could have a somewhat greater effect, but they have not been investigated in detail. On the other hand, short-term local changes due to water injection (promotion of ion-water cluster formation) and No production by reentry appear to be very large and have lifetimes of the order of days. It remains to be determined through more sophisticated theoretical studies and field experiments focused on actual rocket launches whether these large magnitude effects are real, what their actual temporal and spatial scales are, and what consequences they would have on radio wave propagation.

The only experimental evidence pertaining to VLF propagation effects caused by a rocket launch is that obtained during the monitoring of the HEAO-C Satellite launch by an Atlas-Centaur rocket in September 1979. One of the groups of participants in that monitoring campaign, Meltz and DarRold,99 observed VLF propagation $(10-13 \mathrm{kHz})$, using an operational radionavigation

Table 15 Predicted Nitric Oxide and Electron Concentrations near Reentry after 6 Huurs and 1 Day

\begin{tabular}{|c|c|c|c|c|c|}
\hline \multirow{3}{*}{ (klt. } & \multicolumn{4}{|c|}{ Densities $\left(\mathrm{cm}^{-3}\right)$} & \multirow{3}{*}{$\begin{array}{l}\text { Unperturbed } \\
\mathrm{n}_{\mathrm{e}} \text { from Table } 1\end{array}$} \\
\hline & \multicolumn{2}{|c|}{ No } & \multicolumn{2}{|c|}{$\mathrm{e}^{-}$} & \\
\hline & 6 Hours & 1 Day & 6 Hours & 1 Day & \\
\hline 100 & $2.0(+9)$ & $6.0(+8)$ & $6.0(+4)$ & $4.8(+4)$ & $4.5(+4)$ \\
\hline 90 & $9.0(+10)$ & $9.0(+9)$ & $2.7(+5)$ & $8.6(+4)$ & $7.5(+3)$ \\
\hline 80 & $6.2(+10)$ & $1.2(+10)$ & $1.8(+5)$ & $7.3(+4)$ & $8.0(+2)$ \\
\hline 70 & $1.5(+11)$ & $2.5(+10)$ & $2.6(+4)$ & $8.0(+3)$ & $1.7(+2)$ \\
\hline 60 & $8.0(+10)$ & $1.5(+10)$ & $1.6(+1)$ & $8.5(+0)$ & $7.6(+0)$ \\
\hline
\end{tabular}


system "OMEGA" before, during, and after the launch. Such a system utilizes the earth-ionosphere waveguide mode of propagation. For such a mode the observed VLF phase delay between the transmitter and receiver is sensitive to changes in the D- and lower E-regions. For example, a sudden ionospheric disturbance (SID) such as caused by an $X$-ray burst from a solar flare will change the phase delay. A similar change of phase could be caused by the deposition of rocket-exhaust vapor if the $e^{-}$density or collision frequency of electrons with neutrals were changed. On the basis of their observations, Meltz and DarRold suggested that the exhaust products from the Centaur stage of the rocket (injected between 211 and $501 \mathrm{~km}$ ) descended into the upper D-region and altered its composition. The observed-phase advance suggests that the electron density and/or collision frequency was increased and in turn either increased the phase velocity or lowered the pffective reflcction height. A satisfactory theoretical explanation of these phenomena has not yet been put forward. The investigators observed VLF-phase anmalies up to $24 \mathrm{hr}$ afler the rocket launch and claimed that they wcrc eaused by lhe launch. There were two solar flares that produced characteristic phase-change signatures during this same period. The principal evidence in support of the claim that the rocket launch produced anomalies over and above those caused by the solar flares is the fact that of the two transmitter-receiver propagation paths used in the observations both showed the influence of the solar flares, but the one that passed near the rocket trajectory showed a distinctly different phase-delay pattern that continued to appear anomalous during the evening following the launch when no solar flares occurred. If such phase anomalies are indeed a characteristic feature of rocket launches, then the extent to which they affect navigation should be examined further.

A somewhat more subtle issue of concern regarding potential $D$ - and E-region effects relates to the fact that the high-latitude conductivity distribution is especially important because the high-latitude ionosphere completes the electrical rirritit that couplco the aurual zune to the outer magnetosphere: The electrical currents that flow through this cilcuil undergo large fluctuations during magnetic substormo and have beell klluwn co induce damaging current surges in long telephone and power transmission lines. Alteration of the auroral zone conductivity (in the E-region) could modify the morphology of this current system and influence the occurrence or intensity of terrestrial current surges, perhaps moving them to more populated areas.

Finally, Markson 100,101 has suggested that since the lower ionosphere is part of the global atmospheric electric circuit through which currents are driven by thunderstorms, large-scale perturbations in the conductivity, especially if they reach down to the middle stratosphere, may influence thunderstorm processes and thereforc weather and $61 \mathrm{imatc}$

The present state of knowledge regarding the alteration of the morphology of the auroral current system and Markson's suggestion does not permit an assessment of these effects at this time.

\subsubsection{F-Region Ionospheric Holes}

Rocket effluents ( $s u c h$ as $\mathrm{H}_{2} \mathrm{O}$ and $\mathrm{H}_{2}$ ) react rapidly with the dominant $\mathrm{F}_{2}$-region ions $\left(\mathrm{O}^{+}\right)$to form molecular ions $\left(\mathrm{e} . \mathrm{g}, \mathrm{H}_{2} \mathrm{O}^{+}\right.$), which recombine very rapidly with free electrons. The net results are the removal of elec- 
tron-ion pairs at a rate 1000 times faster than normal, the production of prompt, intense chemical airflow, and the release of -large numbers of hydrogen atoms. The rapid loss of electron-ion pairs results in an ionospheric hole that extends far beyond the local source of injected molecules and may be extended to the conjugate ionosphere (i.e., cause a hole at the opposite end of the geomagnetic line that passes through the initially depleted region).

The 1973 launch of Skylab with a Saturn V rocket injected a substantial amount of rocket exhaust into the $\mathrm{F}_{2}$-region of the ionosphere. The trajectory of that rocket accidentally crossed radio-signal ray paths connecting the ATS-3 communication satellite with the ground-based observatory at Sagamore Hill in Massachusetts. The deep depression in the total electron content (TEC) observed at Sagamore Hill after the rocket passed the intersection point is shown in Fig. 21. Based on observations made at four other ground-based observatories whose lines-of-sight with ATS-3 also were intercepted by the resulting depleted region, it was reported that the ionospheric hole had a radius of about $1000 \mathrm{~km}$ and lasted for about $4 \mathrm{hr} .76$. Because the observations were not planned, however, they were somewhat incomplete.

The first successful attempt to produce a mid-latitude, ionospheric depletion under controlled experimental conditions occurred in September 1977. Project "Lagopedo"94 involved two rocket-borne experiments. Each rocket carried $88 \mathrm{~kg}$ of high explosives and an instrument package that was separated from the rocket prior to detonation of the explosive. The detonation products included about $30 \mathrm{~kg}$ of $\mathrm{H}_{2} \mathrm{O}, 16 \mathrm{~kg}$ of $\mathrm{CO}_{2}$, and $20 \mathrm{~kg}$ of $\mathrm{N}_{2}$. These experiments generally confirmed theoretical predictions of a signature effect, i.e., an initial period of several seconds during which the ambient plasma was swept away by the rapidly expanding detonation cloud over a distance of less than

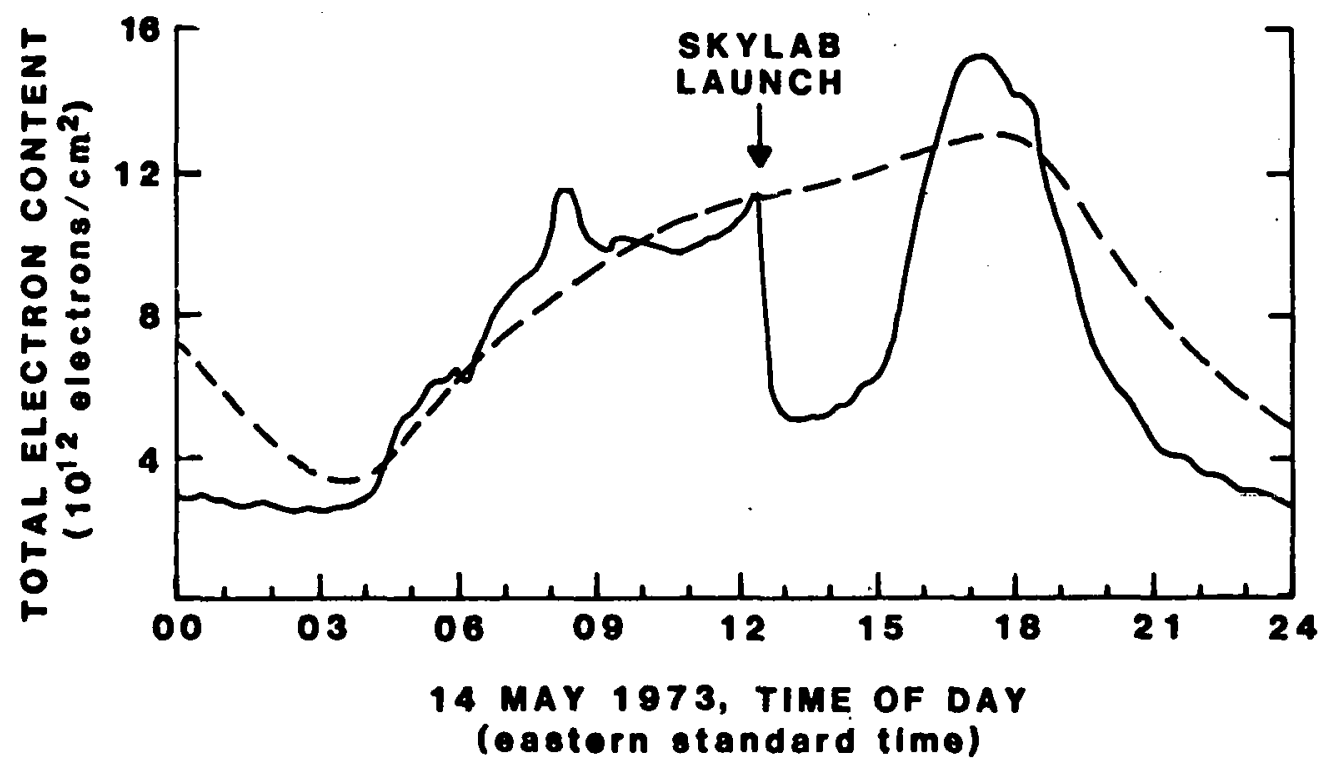

Fig. 21 Sudden Reduction in the Total Electron Content 
$\mathrm{l} \mathrm{km}$, followed by a much larger-scale, plasma-depletion process lasting for at least $30 \mathrm{~min}$ and extending to a radius of $30 \mathrm{~km}$ or more. In addition to the cocket-borne instrument package, which, unfortunately, only sampled the listurbed area for 2-3 min, ground-based instruments monitored the hole for about 30 min until the satellite beacon being used as a diagnostic device was turned off.

A major question that arose from these two experiments was the importance of the suppression of the participation of the water molecules in the alectron-ion removal process through initial formation of ice crystals, followed by gravitational settling to lower altitudes where the presence of the water was unimportant. This was an especially important question for prediction of SPS effects since $\mathrm{H}_{2} \mathrm{O}$ and $\mathrm{H}_{2}$ are the major exhanst producto of the HLLV, PLV, aud POTV, all of which inject such products above the $F_{2}-$ region. If most of the water is frozen into ice crystals as originally suggested by preliminary analysis of the lagnperdo data, then the cryscals would fall chrough the $\mathrm{F}_{2}$-region more rapidly than water vapor molecules and would not contribute to the formation of ionospheric holes, according to $\mathrm{Zinn}$ et al.88 If on the other hand, most of the water molecules remained in the vapor state, then they could substantially increase the extent of the ionospheric holes. Furthermore, preliminary analys is of the ionospheric hole caused by the launch of Skylab in 1973 suggested that the hole should have lasted much longer than it appeared to. Consequently, in an attempt to make the model predictions correspond to the apparent lifetime of the hole created by Skylab, it was assumed that the water molecules did not participate in the hole formation process because of ice crystal formation.

Subsequently, however, it was learned that even complete suppression of the water molecules wnuld not bring the lleorerical model predictions into agreement with the skylab observations. Something else was happening that had not been previously considered. In addition, Bernhardt and his collaborators 77 made an investigation of the extent lu whloh water vapor molecules form ice erystals in the upper atmosphere and found in particular liut the degree of condensation depends on the initial conditions of release. For explosive, spherically symmetriral releases such as the Lagopedo releases the Initial high pressure and temperature of the exhaust cloud does not permit reliable estimation of the degree of condensation. For water molecules released from a rocket nozzle the initial exit pressure ic about $10^{5}$ Limes lowe $i$ and the degree of condensation has been calculated to be 7,24 , and $31 \%$ for the Spaçe Shuttle OMS anginco, Gaturu J-2 engines, and Space Shuttle Main Engines (SSME), respectively. Note that the second stage of the proposed HLLV would use 14 SSMEs. Hence, the range of condenocd mass $\Gamma_{1}$ diclions agreed upon by workers in the field is about $5-35 \%$ for rnoket nozalc releases. This fialion would nul signiflcantly influence the extent of the $F_{2}$-region ionospheric hole.

The previously unaccounted for factor in determining the lifetime of the ionospheric hole created by the Skylab launch vehicle efflucnt that was alluded tu above, was believed to be the thermospheric wind pattern that, according to $\mathrm{Zinn}$ et al.,88 probably moved the depleted region out of the line of sight of the observatories, yielding the apparent lifetime of $\pm 4 \mathrm{hr}$. Based on current estimates, including the probable effects of such transport winds, Zinn et al. conclude that the hole probably did not recover until the following day, some $16 \mathrm{hr}$ after launch. Unfortunately, no actual thermospheric wind observations were made at the time of the Skylab launch. 
Hence! through 1978, the sum total of data relevant" to ionospheric. holes consisted of an incomplete set of accidental observiations made during the Skylab launch of 1973 and the planned but rather short-term and smal1scale observations of the two explosive. releases of the Lagopedo experiments. The planned launching of the HEAO-C Satellite in Septetber 1979 did provide an excellent opportunity 102 to observe a large-scale ionospheric modification caused by an $\mathrm{LO}_{2} / \mathrm{LH}_{2}$-fueled-rocket-engine burn. Through careful planning and coordination, a monitoring campaign involving some 17 separate research groups plus the cooperation of approximately 150 Ham : Radio Operators 103 and several commercial station operators and listeners provided the most complete case study of a large-scale ionospheric modification to date. 104 Figure 22 shows the ground track of the rocket launch trajectory through the ionosphere and several of the ray paths to the SIRIO, ATS-3, and ATS-5 comminications satellites used to monitor the ionospheric disturbance. The ionospheric hole is shown as a dashed, kidney-bean-shaped area. The Centaur stage: of the Atlas/ Centaur launch vehicle burned from 211-501 km altitude and injected about $7 \times 10^{29} \mathrm{H}_{2} \mathrm{O}$ and $\mathrm{H}_{2}$ molecules. For comparison, the HLLV circularization burn at $477-\mathrm{km}$ altitude will inject about $9 \times 10^{29}$ molecules. " Except for the relatively minor difference in the altitude distribution of the injection, the HEAO-C launch is a good simulation of the HLLV circularization burn. Consequently, the results of the monitoring campaign, 104 which are summarized below, are quite useful for assessing the short-term effects of a circularization burn.

\subsubsection{Hole Morphology}

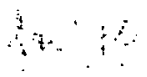

The hole formed within a few minutes of the passage of the rocket. Nearly a $100 \%$ depletion of electrons was observed within $75 \mathrm{~km}$ of the trajectory. At its maximum extent, the hole was about $2500=\mathrm{km}$ long, 800 wide, and 300-400 thick. The hole remained until shortlyifter surise some $4 \mathrm{hr}$ after launch. During that time, it remained at roughly the same latitude for the first $2 \mathrm{hr}$ or so and then drifted slowly arthward " The hoile did nol appear to be symmetrical in its north-south extent about the trajectory.

\subsubsection{Airglow Enhancement}

Airglow emissions offer a useful diagnostic source for determining hole morphology, rates of formation of excited states of reaction pioducts, and potential interference with remote sensing and surveillance systetas: Emissions from excited oxygen atoms and hydroxyl radicals were of greatest interest because the corresponding reactions play major roles in the depletion process but have never been measured in the laboratory. The oxygen.red line and to a lesser extent the green line were of much greater intensity but of shorter duration than anticipated. This activity was consistent with the greater than expected initial growth rate of the hole. The natural red airglow intensity at $6300 \AA$ was enhanced from a pre-launch ivalue of 100 to about 8300 Rayleighs (viewed vertically upward). The intensity. of the green line at $5577 \mathrm{~A}$ increased from $300-900$ Rayleighs. The red line enhancement peaked within a few minutes of the rocket's passage and then dropped of $f$ by a factor of 10 within about $20 \mathrm{~min}$, as reported by Stone and $\mathrm{zinn} 97$ and by Kofsky et al.96 In general, the model calculations of zinn ext al, 88 both for airglow and hole morphology, are in relatively good agreement with the 


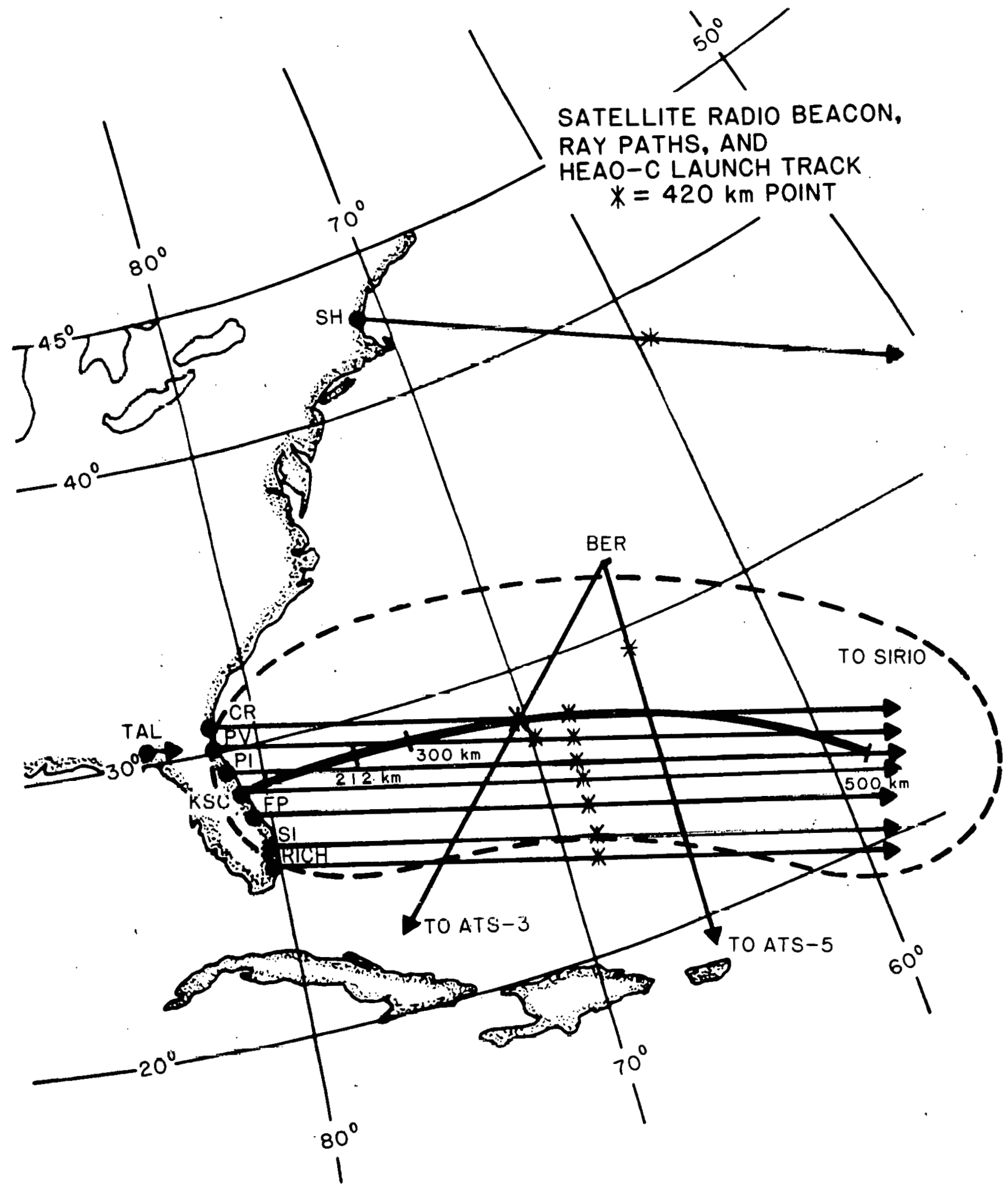

Fig. 22 Observation of the Ionospheric Hole Caused by the Launch of the HEAO-C Satellite 
observations. Emissions from excited $\mathrm{OH}$ radicals were also sought in the HEAO-C experiment. Current theory is consistent with the failure to detect the $6660 \mathrm{~A}$ emission line. However, the $30 \%$ enhancement of the background 2.9 $\mathrm{mm} \mathrm{OH}$ band that was observed requires further theoretical analysis. Such an enhancement may have implications for remote sensing systems.

\subsubsection{Radio Wave Propagation Effects}

Plasma depletion in the bottomside ionosphere was examined using VLF transmissions at $10-13 \mathrm{kHz}$ and $\mathrm{HF}$ transmissions from 3.6-21.0 MHz. The maximum usable frequency was in excess of $21 \mathrm{MHz}$. These transmissions would be reflected from the unperturbed bottomside ionosphere. Frequencies. from 50-400 $\mathrm{MHz}$ that would penetrate the ionosphere were used to look for plasma structural irregularities (striations).

The VLF data99 showed significant phase changes that occurred several hours after the launch and could not be associated with known natural disturbances, e.g., solar flares (see discussion in Sec. 3.3.7).

The HF diagnostics included a Coherent Backscatter Radar.105,106 Observers noted an alteration in the character of Earth backscatter that began $6 \mathrm{~min}$ after the launch and lasted for $5 \mathrm{~min}$. A strong interfering signal was also detected at the same time, which may have been the result of anomalous refraction, but further analysis is required, HF communication experiments performed in the frequency range of $8-13 \mathrm{MHz}$ did not show any severe long-term disruptions or even any effects unequivocally tied to the rocket launch, but signals recorded after the launch appeared to have somewhat lower amplitudes and the general tendency was for fading to be more intense than before. 105 Analysis of reports received from over 150 Amateur Radio Operators 107 that participated in $\mathrm{HF}$ communication experiments $(3.6-50.0 \mathrm{MHz})$ indicated that no unueual effects or major band dropouts were seen at any of the frequency bands observed. While some signal fading at 14 and $21 \mathrm{MHz}$ was noted after the rocket passed through the $F_{2}$ peak, such fading was not distinguishable from that caused by natural ionospheric fluctuations that were seen before and after the rocket launch. Most attention, based on the prelaunch prediction of the maximum usable frequency, was focused on the 14 . MHz band. It turned out, however, that the maximum usable trequency was in excess of $21 \mathrm{MHz}$. The map in Fig. 23 shows the locations of the reporting Ham Radio Operators. From the transmitting station in Puerto Rico, the stations cover an azimuthal range labelled $\phi$ in the figure, from about $310-360^{\circ}$. The azimuthal range labelled $\theta$ covers all the stations, amongst others, that reported signal fading at 14 and $21 \mathrm{MHz}$. More is said about this below.

Observations of commercial radio links 108 (15-21 $\mathrm{MHz})$ indicated some minor fading believed to be connected to the rocket launch. In particular, the Radio Nederland Signal at $15.3 \mathrm{MHz}$ faded out for $30 \mathrm{~s} 8 \mathrm{~min}$ after the launch and the Deutsche Welle Signal at $17.8 \mathrm{MHz}$ faded out for 5-6 min after the launch.

The search for plasma irregularities produced ambiguous results. One observer 105 noted what appeared to be signal scintillations in the ATS-5 communications satellice beacun uperating at $136.47 \mathrm{MHz}$. Another observer 109 noted signal dropouts from a polar-orbiting Navy Navigation satellite beacon 


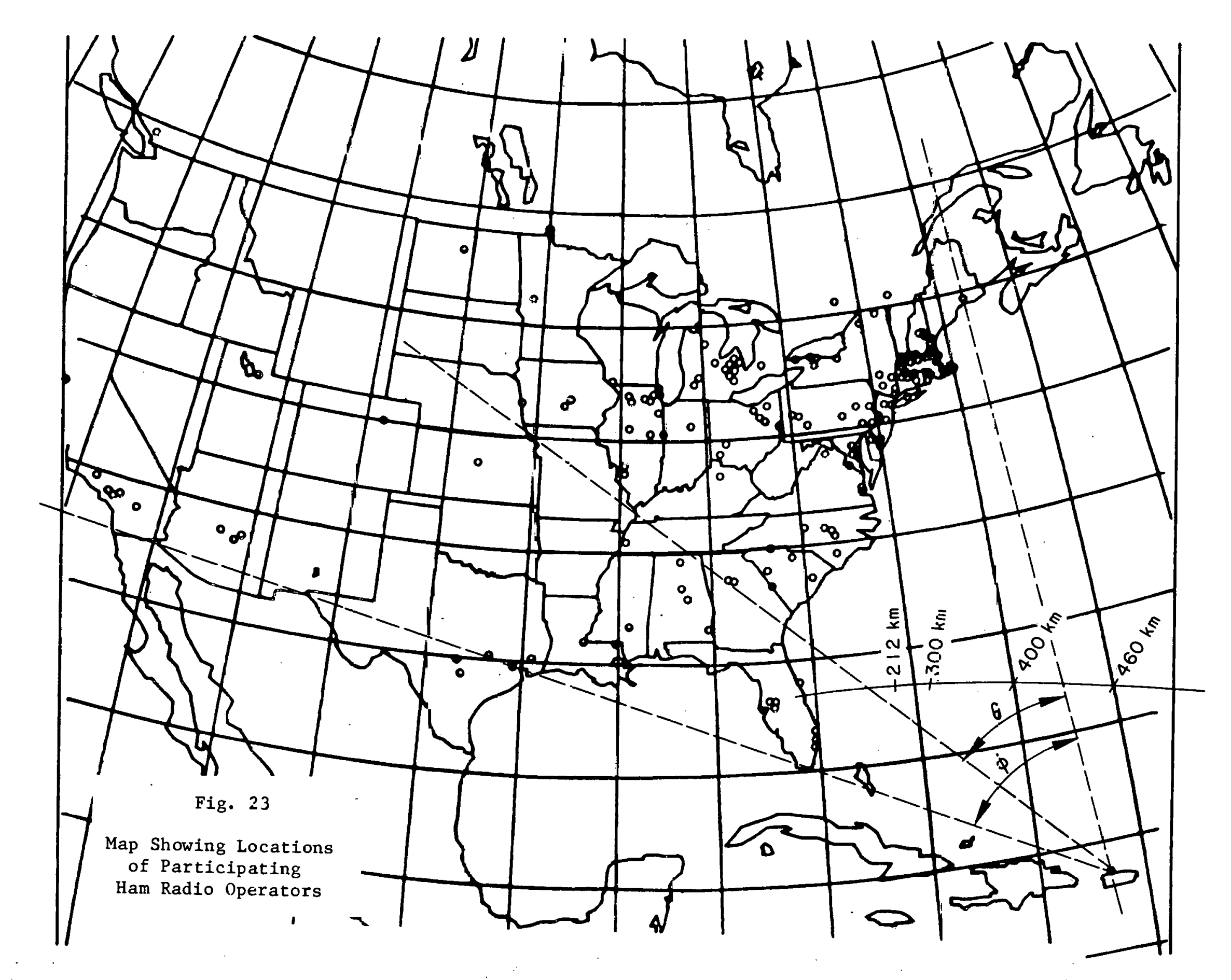


at $140 \mathrm{MHz}$ during substantial portions of the time when the ray path traversed the center region of the hole on two passes. On the other hand, observers $110,111,112$ monitoring the SIRIO satellite beacon 113 ( $136.14 \mathrm{MHz}$ ) and the LES 8 satellite beacon ( $250 \mathrm{MHz}) 114$ saw no evidence of scintillations. Results of optical measurements also showed no irregular structures or striations down to a size range $\geqslant 1 \mathrm{~km}$ ( 1 imit of resolving power).

\subsubsection{Theoretical Predictions of Radio Wave Propagation Effects}

It is worthwhile comparing the effects observed during the HEAO-C launch with theoretical expectations.

Through the use of model simulations of ionospheric depletions combined with ray tracing techniques, it is possible to estimate theoretically the effects of such depletions on electromagnetic waves in various frequency ranges.77 The VLF waves propagate either via the earth-ionosphere waveguide or along field-aligned ducts in Earth's magnetosphere. Since the first propagation mode uses the lower boundary of the ionosphere, ( $D-$ and E-regions), any changes in that boundary are likely to influence such propagation. On the other hand, F-region modifications as observed in the HEAO-C launch can influence coupling between the earth-ionosphere waveguide and the ducts in the magnetosphere. Hence, VLF waves that might otherwise propagate via the duct mode may be prevented from either entering or leaving such a duct by F-region modifications.' It is not known at present if the VLF observations during the HEAO-C experiment are consistent with modifications to either of these propagation modes.* One final way in which VLF propagation might be influenced by F-region depletion is via the formation of artificial ducts caused by the depletion of plasma from an entire magnetic flux tube. According to theoretical estimates 77 such a depletion duct requires about $3 \mathrm{hr}$ to form and could have been formed in the HEAO-C launch releases.

$\mathrm{HF}$ waves (3-30 MHz) can be refracted by plasma density gradients in F-region holes. Hence, such holes can produce focusing, defocusing, and/or fading, depending on the relative locations of the transmitter, receiver, and hole. In the case of the HEAO-C launch, estimates were made of the most probable locations for observing refraction effects of the F-region hole. Weak fading effects were indeed seen at 14 and $21 \mathrm{MHz}$, as expected, but their magnitude and duration were similar to those caused by natural effects unre1 ated to the rocket launch. In fact, the question that bothered most investigators with respect to the HF observations during the HEAO-C launch was: In view of the fact that a region of the ionosphere of the order of $600-1000 \mathrm{~km}$ in north-south extent and $2000 \mathrm{~km}$ or more in the downrange direction was affected, and the middle of that region suffered a $75 \%$ of total verticalcolumn, electron-content loss, why were no significant effects seen in the HF propagation for paths that went through that region?

This question has not been satisfactorily answered as yet although some suggestions have been made. First, as suggested by Klobuchar et al.107 and illustrated in Bernhardt's paper, 73 HF propagation does not depend upon a

* Such a determination would require additional data analysis and model simulations beyond the scope of the present program. 
point reflection from a small area in the ionosphere, but rather involves an ensemble of all possible ray paths that connect the transmitter and receiver. Such an ensemble of ray paths can cover a fairly large geographic region having varying degrees of refractivity. Hence, if the disturbed region is not sufficiently large, many ray paths could still connect receiver to transmitter or, possibly, new ray paths could be formed. This explanation seems plausible and suggests that for similar-sized-rocket-engine burns one would expect similar insignificant effects. It also suggests, however, that if the disturbed region were larger, it would not be possible to scale up the expected effects in any simple way. A threshold may exist beyond which single-reflection-type communication links might be severely disturbed, although no evidence for such a threshold now exists. In fact, the whole question of how ray paths can be influenced by holes of varying sizes requires a substantially more detailed analysis. Second, the geometry of the Ham Radio Operator network relative to the launch trajectory could have been more favorable. The entire launch trajectory was east to southeast across the ocean, making placement of diagnostic equipment difficult. As shown in Fig. 23 from the transmitter location in Puerto Rico, the Ham network was contained within the azimuthal range $\phi$ of $310-360^{\circ}$. Referring back to Fig. 22 , it is seen that this azimuthal range covers the Centaur stage burn from ignition at 211 to about $400 \mathrm{~km}$ altitude. The Ham network monitored frequencies up to $21 \mathrm{MHz}$ that were below the maximum usable frequency $(\approx 22 \mathrm{MHz})$ and therefore would be reflected from the bottomside ionosphere (below 300-400 km altitude). Only those exhaust molecules injected into or settling downward from above the region of $200-400 \mathrm{~km}$ would affect the bottomside reflection paths.

Because the exhaust molecules are injected with a net absolute velocity (rocket-velocity-exhaust) in the forward direction, not all of the molecules injected below 400 and within. $\phi$ end up within $\phi$. Hence, only a fraction of the molecules would be expected to influence ray paths in $\phi$. To put it differently, of the total region affected by the exhaust molecules $(800 \times 2500$ $\mathrm{km}$ ), only about $1 / 2$ or less was being monitored by the Ham network. Furthermore, only a relatively small fraction of the Ham operators were tuned into the $21 \mathrm{MHz}$ frequency band that was most likely to be affected. Those operators that reported fading at 14 and $21 \mathrm{MHz}$ were located within the azimuthal range labelled $\theta$ in Fig. 23, as noted earlier. (Note that not all the stations pictured within $\theta$ were tuned into these frequencies and of those that were, not all reported signal fading, possibly connected with the rocket. launch.)

VHF waves (30-300 $\mathrm{MHz}$ ) are expected to be much less affected than $\mathrm{HF}$ waves. However, free-electron density changes cause changes in the phase and polarization of VHF waves, which is, in fact, the principle upon which changes in coral electron content measurements are made. So long as the hole is fairly large, with smoothly varying densities, the refraction of VHF waves is expected to be very small. However, if the hole were unstable and tended to break up into small irregular regions as has been predicted 77 for depletions in magnetic equatorial F-regions, (equatorial spread-F), then the possibility arises that amplitude and phase scintillations could be generated in transionospheric waves (satellite-borne communication links).

Although the HEAO-C F-region depletion occurred in mid-magnetic latitudes, evidence for plasma irregularities or striations was still sought. The results of this search, as mentioned, were ambiguous. 
The major uncertainty in VHF effects is whether exhaust releases at the magnetic equator will trigger plasma irregularities as mentioned above. Such releases would result from HLLV launches to equatorial LEOs. Evidence for effects of equatorial launches may be obtainable from future Ariane rocket launches. Also, a special burn of the Space Shuttle OMS is plannedl15 for the future to search for such effects.

\subsubsection{SPS Predictions for a Single HLLV and PLV Circularization Burn}

Zinn et al.,88 predicted that a noontime circularization burn would give rise to a $1000 \times 2000 \mathrm{~km}$ region within which the electron concentration would be reduced to $1 / 3$ its normal daytime value. The ionosphere would return to normal in about $5 \mathrm{hr}$. A nighttime hole would be deeper and remain until shortly after sunrise, as did the HEAO-C hole. Based upon experience with the HEAO-C launch, a hole of at least the size predicted by $Z$ inn et al and perhaps one somewhat larger in the downrange direction can be expected. In addition, one would expect airglow intensities and radio wave propagation effects similar to those seen in the HEAO-C case. The circularization maneuver would likely occur over the south Indian Ocean or Australia for a launch from Cape Kennedy. The radio wave effects would probably be detectable if looked for, but would not be expected to seriously degrade amateur or commercial shortwave radio operations. The impacts could conceivably be somewhat more important if the entirety of the hole were located over Australia or any other populated large land mass. Effects on VLF and VHF beacon propagation seem rather uncertain at this time and should be looked into further. If LEO is to be located near the magnetic equator, then observations should be made to verify or refuse the prediction of creation of artificial Spread-F.

\subsubsection{SPS Predictions for a Single POTV Burn Near LEO}

A single POTV injection burn produces 10 times as many exhaust molecules $\left(10^{31}\right)$ as the HLLV circularization burn. That is, about as many exhaust molecules as the Skylab burn of 1973. If other things remain unchanged, then the geographic area covered by the hole would be roughly 10 times that of the HLLV circularization burn hole or ahout $2 \times 10^{7} \mathrm{~km}^{2}(2.6$ times the size of the continental U.S.). It is known, however, that the size of the hole does not scale linearly with the number of exhaust molecules.116 The Saturn $V$ hole morphology is not completely known because of incompleteness of the data. Mendil10 reported that it covered an area of about $4 \times 10^{6} \mathrm{~km}^{2}$ and lasted for about $4 \mathrm{hr}$ after a noon-time launch. Zinn et al.,88 however, has suggested that if characteristic thermospheric winds prevailed at launch time (no actual wind data is available), the hole actually lasted until sunrise the next day. Zinn et al. reconcile their estimate with the 4-hr lifetime reported by Mendillo by pointing out that the hole was probably blown out of the observatory's line of sight with the ATS-3 satellite after 3 or $4 \mathrm{hr}$.

Hence, it is expected that a noontime POTV burn would produce a hole lasting for 4-16 hr. Since the hole will cover an area as big or bigger than the continental U.S.A., the radio wave propagation effects would be more wide-spread but not necessarily more severe or longer lasting than those observed during the HEAO-C launch. The severity and duration of the fading of $\mathrm{HF}$ signals during that launch were judged to be unimportant. However, as 
already noted, the relative magnitude of the observed effects is not completely understood at present and therefore it is not possible to transfer those observations to other situations, especially when 10 times as many molecules are involved. The geographic location of the POTV burn has not been specified.

\subsubsection{SPS Predictions for a Single HLLV Second-Stage Burn $(56-124 \mathrm{~km})$}

Unfortunately, no data is available to assist in the prediction of the F-region depletion caused by the HLLV second-stage burn, and it is necessary to rely entirely on the theoretical model calculations, Each such burn releases about $2 \times 10^{6} \mathrm{~kg}$ of exhaust, most of it in an altitude range of 110-124 km. Zinn et al.88 have performed a calculation taking into account. only those molecules released betwepn 118 and $124 \mathrm{~km}$ (about $40 \%$ of the total second-stage emissions). Following a launch at noon from Cape Kennedy, some of the exhaust molecules slowly diffuse up to the $F_{2}$ layer where they react with $0^{+}$ions. During the daytime $0^{+}$ions are produced about as fast as they are destroyed and the net effect of an HLLV launch is only a $10 \%$ reduction in plasma density. However, during the following nighttime, the $0^{+}$and free-electron concentrations were gradually reduced to about $70 \%$ of their normal values in the model simulation. These $10-30 \%$ reductions in daytime and nighttime plasma densities are likely to continue for a few days until the remaining $\mathrm{H}_{2} \mathrm{O}$ and $\mathrm{H}_{2}$ are photolyzed by sunlight. This low-level, long-lived depletion from a single second-stage engine burn is not expected to have any significant impacts. In fact, it would probably be difficult to detect except possibly during magnetically quiet times. However, since second-stage HLLV burns occur once every 12-24 hr, these low-level depletions will be long-1asting and may spread over a large portion of the globe.

\subsubsection{Multiple Launch Effects in the F-region}

No detailed calculations have been possible of the effects of multiple launches on the F-region. Existing models are not adequate to handle the global-scale processes. The development of appropriate modeling techniques would require a minimum of one to three years effort and additional bacic data. Hence, for the purposes of this assessment, only relatively simple, crude estimates can be made.

The total number of electrons and ions in the ionosphere is of the order of $10^{32}$. Taking into account $2 \mathrm{HLLV}$ launches/24-hr period and the fact that each exhaust molecule can potentially recombine 2 electron-ion pairs, the theoretical maximum number of pairs that could be removed in a 24-hr period, assuming that the exhaust molecules were ideally distributed $(100 \%$ efficiency), is 4 times as great as the number naturally present. This is, of course, a gross overestimate. If the HILV-exhaust-distribution aystem were $2.5 \%$ efficient (still an overestimate), the total global ionosphere would suffer a chronic 10\% depletion (varying with time of day and location). For the sake of comparison, about $2.5 \%$ of the exhaust molecules from the Saturn $V$ burn of 1973 participated in the recombination of ions and electrons. For the HEAO-C launch the efficiency was about $15 \%$. However, in both cases the molecules were released in the sensitive F-region. 
It is therefore at least plausible that a belt-like region of the ionosphere surrounding the globe at the launch latitude would have a roughly $10 \%$ or more chronically reduced free-electron density in addition to the twice daily depleted regions of $1000 \times 2500 \mathrm{~km}$ size. To this would be added one POTV burn per month producing a depleted region of the order of $3000 \mathrm{x}$ $8000 \mathrm{~km}$. Such a belt could have a width of the order of $2,000-10,000 \mathrm{~km}$, which would require an overall electron/ion recombination efficiency of between $0.2 \%$ and $1.0 \%$ for all of the HLLV exhaust molecules. The consequences of such a belt of partial depletion on HF communications have not been assessed as yet. However, since lesser developed countries are most likely to utilize HF skywave (F-region) in lieu of satellite VHF communication links, even minor reductions in the utility of this communication mode may be important. Again, it must be stressed that this discussion of potential globalscale, F-region effects from multiple to rocket launches is very preliminary.

\subsection{EFFECTS OF ROCKET EFFLUENTS ABOVE $500 \mathrm{~km}$ ALTITUDE}

\subsubsection{Plasmasphere and Magnetosphere}

As shown in Fig. 4, the plasmasphere and magnetosphere make up the outermost regions of the Earth's atmosphere. Figure 24 shows a very simplified cross-sectional view of these regions in a plane perpendicular to the Earth's orbital plane. The curved lines represent some of the geomagnetic field lines. The structure of Earth's magnetic field resembles that of a dipole field within the toroidally shaped region referred to as the plasmasphere but departs dramatically from such a simple structure beyond the plasmapause at roughly $4 R_{E}$ due to interactions with the flux of charged particles or plasma that constitutes the solar wind. Aside from distorting the field lines, this interaction plays an important but not completely understood role in various auroral and other processes that influence upper atmospheric dynamics and terrestrial radio communications. Recently, serious consideration has been given to the role that such interactions may play in tropospheric weather. In fact, the so-called "solar terrestrial weather effect" was the subject of a symposium/workshop entitled, Solar-Terrestrial Influences on Weather and Climate, that was held at Ohio State University of July 24-28, 1978.117

The plasmasphere is populated with charged particles (i.e., a plasma) whose density falls off rather abruptly at the plasmapause. The innermost region of the plasmasphere is bounded by the ionosphere (not shown in the figure because it is too small on the scale of the figure to be distinguished from Earth's surface.) An important feature of the plasmasphere is the region of maximum density of high-energy-charged particles that is called the inner radiation or Van Allen Belt. The outer Van Allen Belt is located roughly between the plasmapause and the region of geosynchronous orbit, i.e., between about 3 and $7 R_{E}$. Hence, the SPS satellites will corotate with Earth in the equatorial plane at the outer edge $\left(6.6 R_{E}\right.$ ) of the outer Van Allen Belt (VAB). For simplicity, the VAB is not shown in the figure.

The two SPS-related sources of disturbance of the natural plasmasphere and magnetosphere are (1) the rocket effluents used to propel the cargo carrying vehicles (COTVs) and personnel carrying vehicles (POTVs) 


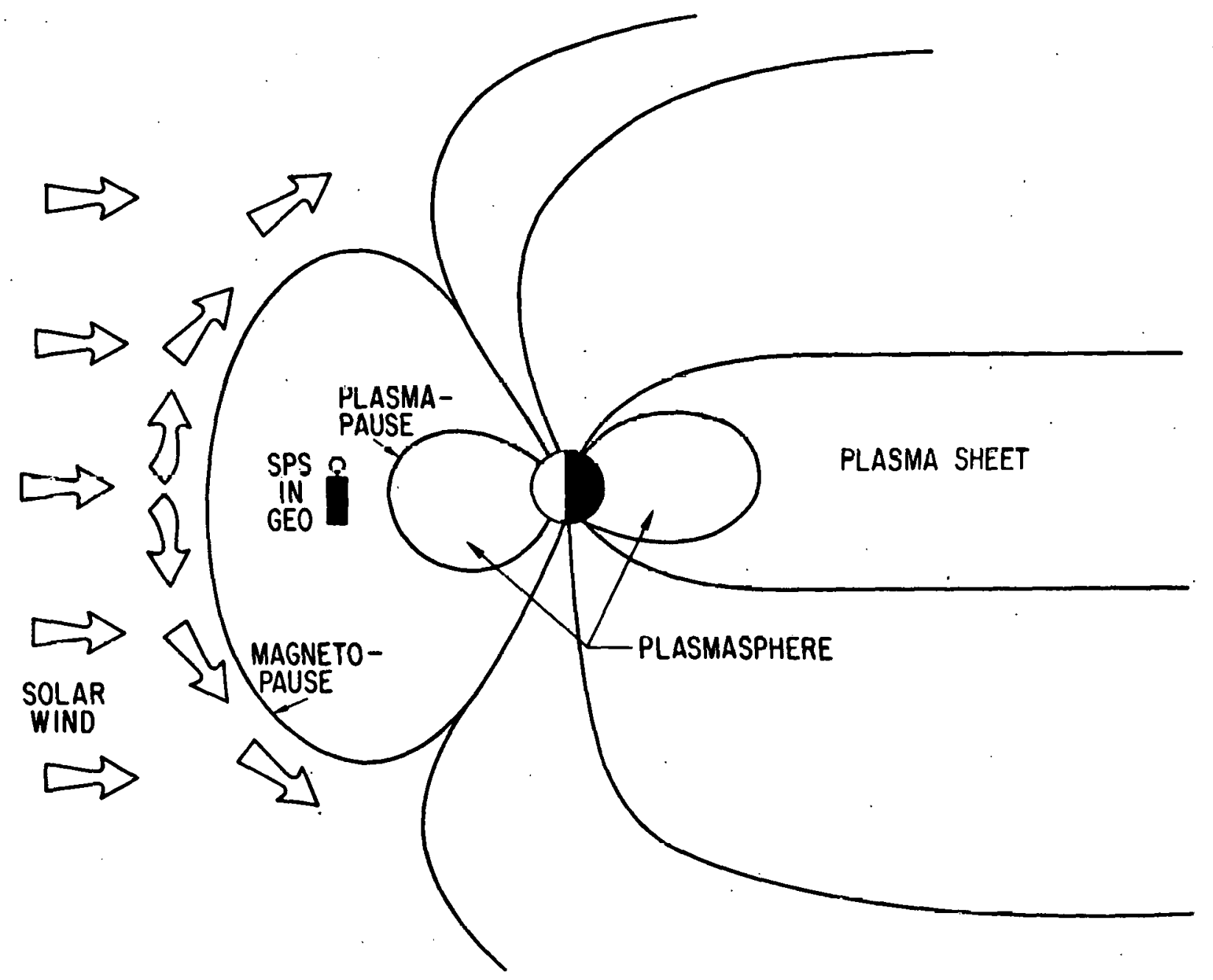

Fig. 24 Cross Section of Magnetosphere and P1asmasphere

between LEO and GEO and (2) the presence of the satellite structures themselves (including debris). The consensus reached at both the Westmont 10 and La Jollall Workshops held in August 1978 and June 1979, respectiveiy, was that the presence of the satellite structures themselves would probably not lead to notable environmental effects. On the other hand, exhauot emissions from propulaion and stationkeeping activities of SPS spacecraft would be expected to induce substantial modifications of magnetospheric processes on both the local and the global scale. This expectation is due primarily to the relatively large mass and energy contents of these emissions when compared with the total mass and energy contents of the inner magnetoophcre.

As a consequence of these opinions, the major emphasis in the Atmospheric Effects Assessment Program was devoted to the exhaust effluent effects. 


\section{$3.4 .2 \mathrm{COTV}$}

Before discussing specific effects, it is important to set forth a reasonable emission scenario for the relevant Reference system ${ }^{2}$ space transportation operations. Unfortunately, neither the POTV nor the COTV have been defined in great detail at this time. However, in view of the present state of knowledge regarding the potential impacts of propellant exhaust in the magnetosphere and plasmasphere, it is completely consistent to specify the characteristics of the POTV and COTV in an approximate manner. That is, at this stage of the assessment estimates to within a factor of 2 are regarded as acceptable.

According to the Reference System design, ${ }^{2}$ two options for the COTV are being considered. Tables 16 and 17 give the relevant propulsion system characteristics and operational description of these two options. Table 16 also 1 ists ion thruster parameters for two other options that have been discussed in the literature.

Details regarding the degree of divergence of the " $\mathrm{Ar}^{+}$(argon ion) beam are not available. Smaller ion bombardment-type thrusters have been built and tested in high altitude test chambers. According to Reynolds, 119 who has summarized the results of such tests, the degree of divergence of these beams varies considerably with their design. Since the ratio of the actual thrust obtained to the one ideally available (called the thrust factor) varies inversely with the beam divergence, it is obviously desirable to minimize the divergence. According to a January 1980 private communication from D.C. Byers of Lewis Research Center, beams having low divergence have a representative angular density profile $f_{\ell}(\theta)$ defined by

$f_{\ell}(\theta) \approx \exp \left[-[36(1-\cos \theta)]^{1.83}\right]$,

where

= the polar angle measured. from the beam axis:

while those having high divergence have a profile $f_{h}(\theta)$ defined by

$$
f_{h}(\theta) \approx \exp \left[-[8.1(1-\cos \theta)]^{2.24}\right]
$$

Using data presented in Reynolds, 117 the low divergence beams $f_{\ell}(\theta)$ above, would have about $75 \%$ of the beam contained within about $10^{\circ}$ of the beam axis, corresponding to a thrust factor of 0.98 . High divergence beams have $75 \%$ of the beam enclosed within about $\leqslant 30^{\circ}$ of the beam axis, with a corresponding thrust efficiency of $90 \%$. These details regarding beam parameters are presented here because they do influence the potential atmospheric impacts of the COTVs, even though not critically. The details also serve to connect the discussion of impacts given below with laboratory beam experiments and various discussions of beam impacts given elsewhere.

\subsubsection{PÖTV}

According to the Reference System design, 2 the POTV is a 2-stage, chemically-propelled $\left(\mathrm{LO}_{2} / \mathrm{LH}_{2}\right)$ vehicle having a payload from LEO to GEO 
Table 16 COTV Ion-Thruster Parameters

\begin{tabular}{cccccccc}
\hline OPTION & Isp(s) & V(km/s) & E(keV) & D (cm) & N & n & T(N) \\
\hline- & 5000 & 49 & 0.49 & - & - & - & - \\
Si & 7000 & 69 & 0.97 & 120 & 4 & 269 & - \\
GaAlAs & 13000 & 127 & 3.34 & 100 & 1 & 259 & 13 a \\
- & 16000 & 157 & 5.06 & - & - & - & -
\end{tabular}

NOTE: Isp = specific impulse;

$\mathrm{V}=$ argon ion speed $=\mathrm{gIsp}$, where $\mathrm{g}$ is the acceleration due to gravity;

$E=$ beam particle kinetic energy $=\frac{1}{5} \mathrm{mV}^{2}$, where $\mathrm{m}$ is the argon ion mass;

$\mathrm{D}=$ thruster diameter,

$N=$ number of thruster arrays per CóTV;

$\mathrm{n}=$ number of thrusters per array;

$T=$ thrust per thruster in newtons.

${ }^{a}$ Assumes $90 \%$ thrust factor including effects of double ionization and beam divergence (Ref. 118).

Table 17 COTV Description

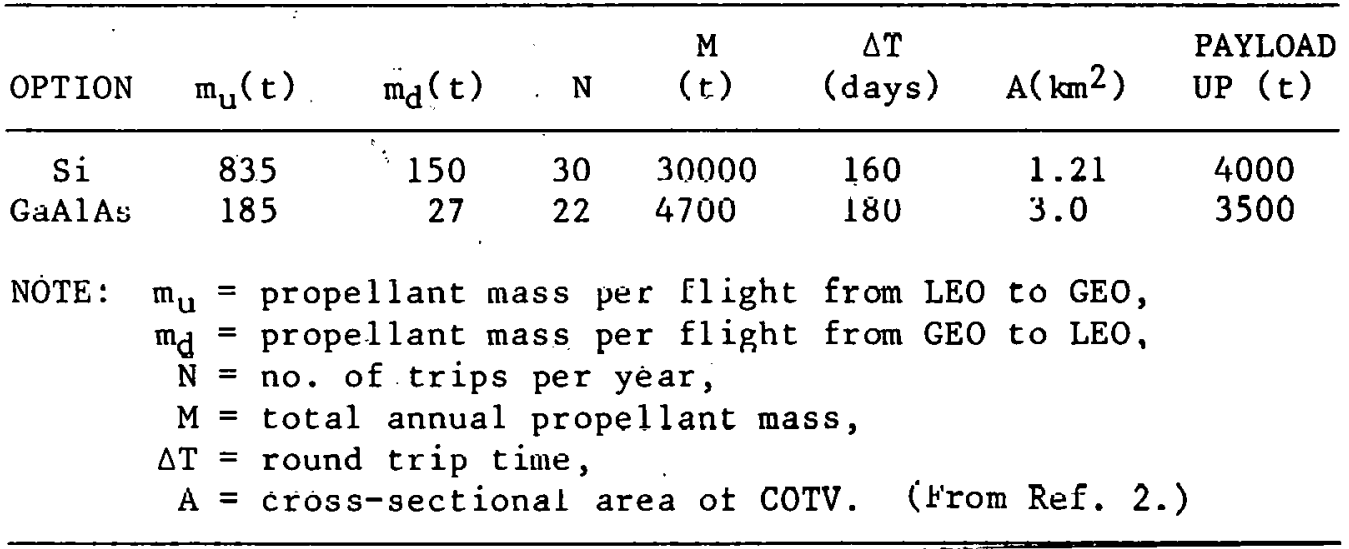

of $151 \mathrm{t}$ and a return payload of $55 \mathrm{t}$. Using these payloads and the fact that each stage has an inert mass of $30 \mathrm{t}$, an approximate flight acenario can be estimated. Such a scenario, as illustrated in Fig. 25 consists of 5 burns. Burns 1 and 5 are stage-1 burns. Burn 1 injects the POTV into an elliptical orbit having an apogee at GEO. After burn 1 is completed, stage 1 is separated and returns to LEO where burn 5 circularizes the orbit of the stage 1 vehicrle at LEO. Burns 2,3 , and 4 are stage-2 burns that circularize the orbit at GEO, deorbit from, GEO for the return flight to LEO, and circularize again at LEO, respectively. Assuming the above payloads and burn sequence, and a typical specific impulse for $\mathrm{LO}_{2} / \mathrm{LH}_{2}$ engines of $390 \mathrm{~s}$, the required propellant masses obtained from a self-consistent but approximate calculation are as given in Table 18. 


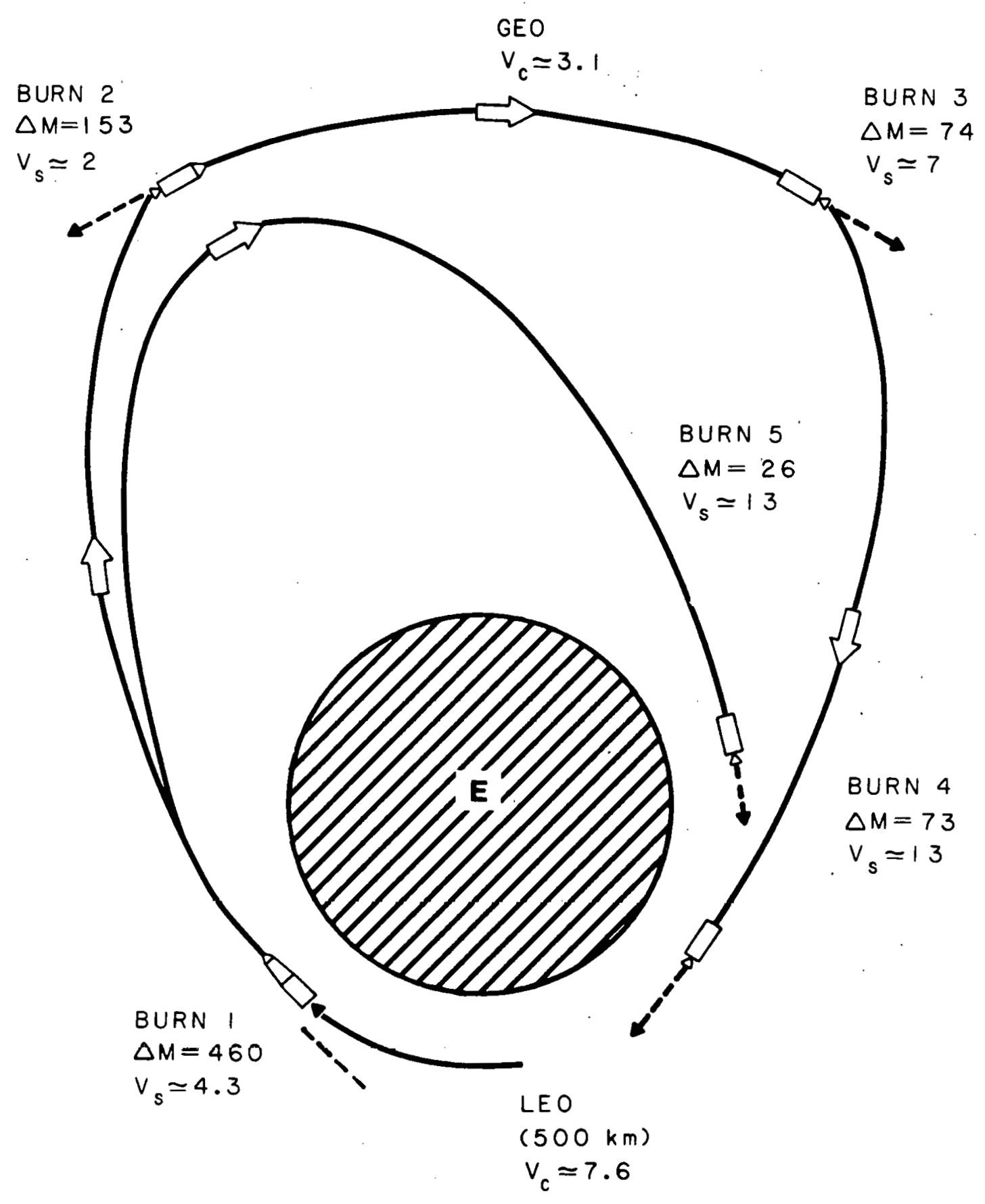

$$
\begin{aligned}
& \triangle M=\text { MASS OF FUEL USED. TONNES } \\
& V_{S}=\text { ABSOLUTE SPEED OF EFFLUENT, } \mathrm{km} / \mathrm{s} \theta \mathrm{C} \\
& V_{c}=\text { ORBITAL SPEED, } \mathrm{km} / \mathrm{sec} \\
& \text { ESCAPE SPEED: } L E O=10.76 \mathrm{~km} / \mathrm{seC} \\
& \text { GEO }=4.34 \mathrm{~km} / \mathrm{seC}
\end{aligned}
$$

Fig. 25 Hypothetical Burn Sequence for a 2-Stage POTV Flight 
Table 18 Hypothetical Burn Sequence for a

Typical POTV Flight

\begin{tabular}{cccl}
\hline VELOCITY & $\begin{array}{c}\text { PROPELLANT } \\
\text { CHANGE } \\
(\mathrm{km} / \mathrm{sec})\end{array}$ & $\begin{array}{c}\text { MASS } \\
(t)\end{array}$ & \multicolumn{1}{c}{ FATE OF EXHAUST } \\
GAS
\end{tabular}

TOTAL

PROPELLANT

$\operatorname{MASS}(t)$

786

avelocity changes are from Park.120 (His propellant masses correspond to different payload and vehicle assumptions.)

The total mass of the rocket at the start of burn 1 would be the sum of the total propellant required, the payload up $(151 \mathrm{t})$ and the inert mass of both stages $(60 \mathrm{t})$. Allowing for the fact that some additional propellant would be required for on-orbit maneuvering, attitude and reaction control, and reserve, the total propellant mass would have to be somewhat in excess of $800 \mathrm{t}$. The corresponding total mass of the rnoket wnuld have to be somewhat in excess of $1000 \mathrm{t}$. The Reference system document ${ }^{2}$ (page 53) quotes a value of $830 \mathrm{t}$ for propellant and a total mass of $1,041 \mathrm{t}$ for the rocket, which is quite consistent with the above calculation.*

\subsubsection{Effects of POTV Emissions}

Table 18 lists the fate of the POTV exhaust products for each of the 5 burns. These fates are determined by comparing the absolute velocity of the exhaust molecules with the gravitational escape velocity at the altitude of the burns. Only for burns 1 and 2 will the exhaust molecules remain within the atmosphere. The exhaust molecules from burns 3, 4, and 5 will exceed the gravitational escape velocity and will therefore, on the average, escape into outer space.

Estimates of the mass of $\mathrm{H}_{2} \mathrm{O}$ and $\mathrm{H}_{2}$ injected at LEO and GEO by POTV burns 1 and 2, respectively, are given in Table 19. On an annual basis, of the order of $5 \times 10^{32}$ and $2 \times 10^{32} \mathrm{H}$ atoms would be injected at LEO and GEO, respectively, and about one-half as many oxygen atoms. The normal H-atom content between $500 \mathrm{~km}$ and the plasmapause $\left(4 \mathrm{R}_{\mathrm{E}}\right)$ is about $3 \times 10^{32}$ atoms. Atomic hydrogen is the dominant component above $800 \mathrm{~km}$.

*The propellant requirement of $460 t$ indicated in Fig. 31 on page 55 of the Reference System document ${ }^{2}$ is obviously inconsistent with the above numbers and has therefore been ignored. 
Table 19 Emissions per POTV Flighta

\begin{tabular}{ccccccc}
\hline & \multicolumn{2}{c}{ Mass of Exhaust Molecules $(t)$} & & No. of Exhaust Molecules $\left(10^{30}\right)$ \\
\cline { 2 - 3 } \cline { 5 - 6 } & $\mathrm{H}_{2} \mathrm{O}$ & $\mathrm{H}_{2}$ & & $\mathrm{H}_{2} \mathrm{O}$ & $\mathrm{H}_{2}$ \\
\hline Burn 1 & 443 & 17 & 14.8 & 5.1 \\
Burn 2 & 147 & 6 & 4.9 & 1.8 \\
\hline
\end{tabular}

${ }^{a}$ Assumes an oxidizer to fuel ratio of 6.0 .

Burn 1 will result in the deposition of a large amount of exhaust molecules above the F-region of the ionosphere. After injection, the exhaust molecules will have a net component of velocity in the forward direction, and, hence, will follow ballistic trajectories as they gradually descend into the F-region of the ionosphere. As discussed earlier, these molecules will cause a rather substantial ionospheric hole to form. (See Sec. 3.3.8 for further details.) The exhaust molecules injected at GEO during burn 2 will have sufficient velocity in the forward direction to remain gravitationally trapped in elliptical orbits centered around $15,000 \mathrm{~km}$ above Earth's surface. Since the velocity of the molecules is distributed over a range of magnitudes and directions, one would expect the orbiting cloud to gradually grow in size and cover a large portion of the magnetosphere from about 3,000-40,000 km altitude.93 Although the density of the artificial cloud would be comparable to that of the neutrals naturally present in that region, it would not be sufficient to alter the relatively collision-free character of that region. Hence, the orbiting cloud would be expected to live for a fairly long time (of the order of weeks to months). As the POTV launch rate is once or twice per month, the possibility of an accumulating artifical cloud exists. This possibility has not been assessed at this time because of large uncertainties regarding loss processes and ambient densities.

The neutral exhaust cloud from a single poTV burn 2 would overlap a region of space normally occupied by the Van Allen Radiation Belts and the ring current. The ring current is formed during magnetic storms and consists of magnetically trapped particles in the energy range of $1-100 \mathrm{keV}$. This feature of the magnetosphere is associated with a part of the time-varying component of the geomagnetic field observed during magnetic storms and also is supposed to play a role in the precipitation of radiation belt particles into the atmosphere.

The Van Allen Belt particles have energies in excess of $100 \mathrm{keV}$ and consequently pose a significant radiation hazard to equipment and personnel operating in or traversing that region of space. Magnetically trapped particles characteristically follow spiral orbits along magnetic field lines and reverse direction or "mirror" at sufficiently high altitudes to remain in the collision-free environment. A sudden change in the magnetic field or in the particle trajectory may scatter the particle into the so-called "loss cone." Trajectories with pitch angles within the loss cone have mirroring altitudes so low that the particles collide with neutral constituents of the atmosphere and escape magnetic confinement. High-energy particlesinaturally precipitated into the auroral zones (not necessarily from stable trapped 
orbits) are a major source of thermal energy, ionizing radiation, and auroral displays at high latitudes. A number of mechanisms have been proposed to explain the natural precipitation of high-energy particles either from the inner magnetosphere that is normally occupied by magnetically stably trapped particles or from the outer magnetosphere (including the tail region). One mechanism, relevant to the SPS case, for removing relativistic electrons from magnetic confinement via precipitation into the the atmosphere involves the interaction of ring-current ions with Van Allen Belt electrons. This mechanism is discussed later.

In addition to precipitation, magnetically trapped, high-energy, ions can also escape confinement by charge exchanging with ambient, low-energy neutral particles. The lifetime for charge exchange is quite long, varying from $1 \mathrm{hr}$ near LEO to weeks or months at GEO.93 The result of a typical chargeexchange process would be the production of a fast. nelural that, deponding upon its direction of travel, would elther enter the atmosphere or escape into outer space, and a slow charged particle that would be magnetically trapped.

The main effect of the neutral POTV exhaust cloud is that it would serve as an artificial source for charge-exchange interactions with ring-current ions.93 The natural lifetime of ring-current ions has been estimated to be of the order of $10^{5} \mathrm{~s}$ (about a day), based on the duration of the recovery phase of magnetic storms. Chiu et al.93 have estimated that the enhanced charge-exchange caused by the neutral POTV exhaust cloud could reduce the 1 ifetime to between $10^{3}$ and $2 \times 10^{4} \mathrm{~s}$, i.e., an $80-99 \%$ reduction. This reduction might be regarded as a benefit if it corresponded to a reduction in the recovery phase of a magnetic storm, since there would be a shorter time during which natural electromagnetic interference effects would be experienced.

The Van Allen Belt radiation ions have much higher energies (average energy $\approx 100 \mathrm{keV}$ ) than the ring-current ions and are rolativcly immunc to charge-exchange loss induced by the neutral poTV exhaust cloud, according to Chiu et al.93 However, these investigators note that a plasma effect called the "critical-velocity phenomenon" may play an important rolo in determining the effects of the neutral cloud. Characteristically, this phenomenon results in the conversion of a fraction of neutrals into thermal ions when the neutrals are moving with velocity $V_{s}=\left(|e| v_{i} / m\right)^{\frac{1}{2}}$ relative to an ambient plasma, where $\mid e / V_{i}$ is the ionization potential energy of the neutral particles of mass m. Although this phenomenon has not been extensively verified in the laboratory or in space, Chui et al.93 suggest that it may result in the conversion of at least part of the POTV neutral exhaust molecules into low-energy atomic oxygen ions. The effects of these ions would be similar to those of the $\mathrm{Ar}^{+}$ions emitted by the COTV in the plasmasphere that are discussed below. In particular, the presence of cold heavy ions suppresses one of the mechanisms supposedly responsible for the removal of relativistic electrons from the Van Allen Belts, leading therefore to the enhancement of the relativistic electron dosage.

\subsubsection{Effects of COTV Emissions}

As already indicated, the number of $\mathrm{Ar}^{+}$ions injected into the plasmasphere between $500 \mathrm{~km}$ and the plasmapause $\left(4 R_{E}\right)$ is roughly comparable to the 
number of $\mathrm{H}$ atoms naturally present and exceeds the natural $\mathrm{Ar}^{+}$ion content by several orders of magnitude. Hence, not only is the mass of effluent greater than that naturally present, but the kinetic energy of the $\mathrm{Ar}^{+}$ion $(\approx 3.5 \mathrm{keV})$ is about three orders of magnitude greater than the thermal energy normally present in that region and is comparable on an annual average basis to the energy injected by magnetic storms during relatively quiet periods. Hence, the magnitude of the perturbations to the natural state of the near-Earth space environment $(500-36,000 \mathrm{~km})$ is expected to be large.

The overall spatial and temporal distribution of the COTV effluents is governed both by the relatively low thrust of the ion engine array and by the inclination of the LEO plane. If the HLLVs are launched from the U.S., the LEO plane will be inclined relative to the equatorial plane (GEO is in the latter plane). Therefore, it will be necessary to make a plane transition during the course of the trip from LEO to GEO, meaning that during at least part of the trip, the $\mathrm{Ar}^{+}$ion beam will not be pointed orthogonal to the geomagnetic field lines. In fact, it has been suggested 121 that the most fuel-efficient transfer orbit would involve oblique angles between the COTV velocity vector and the ion engine thrust vector, i.e., oblique angles between the geomagnetic field $\vec{B}$ and mean beam velocity $\vec{V}$. These angles would be varied as a function of altitude. However, the consequences of varying the angle between $\vec{B}$ and $\vec{V}$ with regard to magnetospheric impacts have not been examined in detail and have been examined in only a preliminary manner with respect to the fate of the $\mathrm{Ar}^{+}$by Holze and Liemohn.121 Consequent1y, it will be assumed that, for the most part, $\vec{V} \perp \vec{B}$. The low thrust characteristic of ion propulsion systems requires that the transfer from LEO to GEO occur over a gradually unraveling spiral trajectory about the Earth requiring about 130 days. During that time, the orbit period with respect to the rotating Earth will increase from about 1 1/2 hours to infinity (geosynchronous). The beam from the ion thruster array consists of a neutral plasma of $\mathrm{Ar}^{+}$ions and electrons. These charged particles do not recombine within the bean. For purposes of this discussion, we are assuming that the $\mathrm{Ar}^{+}$ions are ejected with a kinetic energy of $3.5 \mathrm{keV}$ and that the beam is of the lowdivergence type, i.e., it is confined to within about $10^{\circ}$ of the beam axis.

In order for the beam to propagate across the geomagnetic field $\vec{B}$, the $\frac{1}{c} \vec{V}_{b} \times \vec{B}$ force, when $\vec{V}_{b}$ is the beam propagation velocity, and $c$ is the velocity of light, must be balanced by an electric field $\overrightarrow{\mathrm{E}}$ called the polarization electric field. This field is established within the beam by the separation of the $\mathrm{Ar}^{+}$ions and the electrons. So long as the equality $\mathrm{E}=\frac{1}{\mathrm{C}} \vec{V}_{\mathrm{b}} \mathrm{X} \mathrm{B}$ can be satisfied, the beam will propagate as an entity across the geomagnetic field lines. However, as the beam expands and becomes more dilute, the polarization electric field becomes weaker and may even be partially shorted out by the ambient plasma if current paths can be established, either across the field or through a conductor at the ends of the field lines. Hence, the beam would slow down in accordance with the above expression and eventually come to rest (unless it escaped the magnetic field altogether).

The total energy content of the beam is partitioned between a thermal component associated with random particle motion, a net kinetic energy of beam propagation $\left(\frac{1}{2} \mathrm{MV}_{\mathrm{b}}{ }^{2}\right.$, where $M=$ total beam mass propagating at velocity $V_{h}$ ), and the kinetic energy associated with the ordered, individual particle motion relative to $\vec{V}_{b}$. Depending upon the specific mechanism involved, stopping of the beam as a whole would not necessarily dissipate a large 
fraction of the total beam energy. The precise nature of the interaction between the dense, energetic $\mathrm{Ar}^{+}$plasma beam from the COTV and the ambient plasma embedded in the geomagnetic field is not presently known for certain and no actual experiments have been performed that come even close to the parameter values envisioned here. (The archived results of beam experiments and ion-release experiments have been reviewed by Chiu.)122 Consequently, some basic questions such as the following must be addressed:

1. What are the dominant interactions between the beam, the ambient plasma, and $\vec{B}$ ?

2. Will those interactions cause the beam to propagate as an entity or will the beam rapidly break down into particles interacting individually with the cnvironment?

3. Will the beam be brought to rest within the geomagnetic field or will the bulk of it escape into outer space?

4. Will any $\mathrm{Ar}^{+}$ions be stripped away from the beam and become individually confined within the geomagnetic field?

5. What will become of the ion kinetic energy and beam streaming energy?

The answers to the above questions, to a large extent, determine the impacts that the COTV effluents will have on both the near-Earth Space environment and the terrestrial environment. Unfortunately, it is currently not possible to provide definitive answers to any of the above basic questions. Rather, it is necessary, for the purposes of this assessment, to try to obtain some idea of the range of possible effects based upon extrapolation of archived data and current theories and models. It is not surprising, therefore, that no complete consensus exists regarding the pntential impacts of the COTV effluents. Several models* have been proposed to describe the evolution of the $\mathrm{Ar}^{+}$ions after injection from the COTV ion thruster array. of those models, that of Chiu et al.33. has been developed and studied in the greatest detail, and while it relies on experimental data and theories of uncertain applicability to the SPS case, it appears at least plausible within the scientific community. (That is not to say that other models are implausible). It also admits the greatest range and magnitude of environmental impacts, and, therefore, if it turns out to be in error, it will be to the benefit of the environment. Conclusions based on the Chiu et al. work will be compared in the following discussion, where appropriate, with those of other investigators.

According to the chiu et al. model, 93 the beam creates a wake in the geomagnetic field line structure as it emerges from the thruster array, much as a boat creates a wake in water as pictured in Fig. 26. This distortion of the field lines is described as the propagation of a wave along the field lines through the ambient plasma and is called an Alfvén wave. The Alfućn wave propagates the polarization electric field poleward along the $\vec{B}$ field

\footnotetext{
*The term "mode1" is used here not to denote a formal mathematical computerized model but rather to denote a more descriptive construction, including statements of the applicable physics and governing mathematical equations.
} 


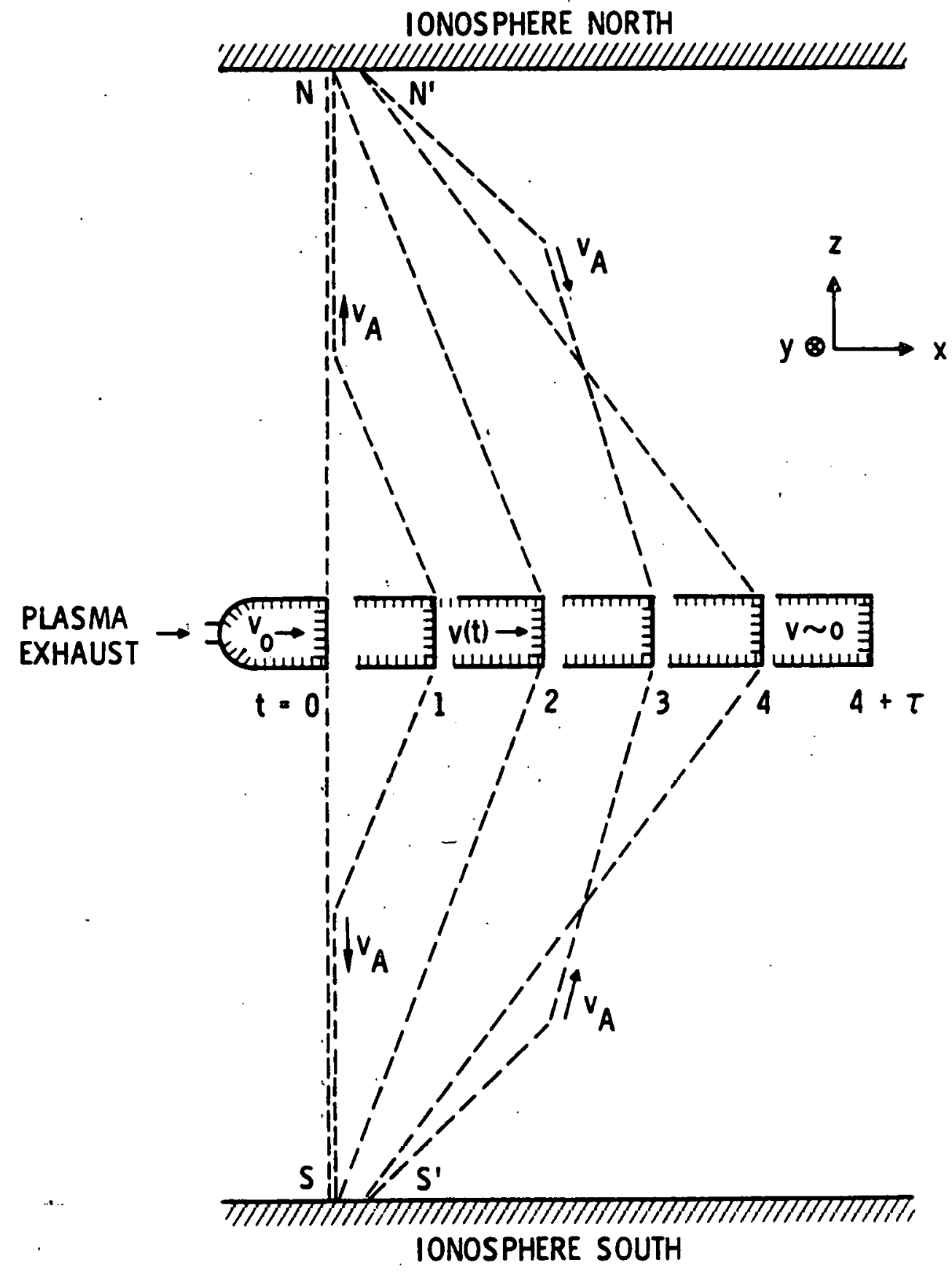

Fig. $26 \mathrm{Ax}^{+}$Ion-Beam Wake in Magnetosphere 
lines until the lines enter the ionosphere ("foot" of the field line) where the ambient ion density is high enough so that the conductivity can cause a cross-field current to flow and short out the polarization field. The shorting out process dissipates energy via Joule heating near the foot of the field 1 ines and consequently drains energy from the propagating ion beam. Hence, according to the Chiu et al. model, the beam slows down and comes to rest relative to the geomagnetic field within 1000-2000 km. At that point, most of the $3.5 \mathrm{keV}$ kinetic energy of the $\mathrm{Ar}^{+}$ions has been dissipated in the poleward regions of the ionosphere so that the ions constitute a relatively low energy or cold plasma. Of course, some of the ions will have energies ranging from a few eV up to the original $3.5 \mathrm{keV}$.

Holze and Liemohn, 121 on the other hand, do not invoke the Alfvén wave mechanism and assume rather that after a pcriod of initial expansiun uf the beam within the ambient plasma the polarization field is reduced to thc point where the beam ran no longor propagate $\left(V_{b}-0\right)$. Ilowever, the ious will retain essentially all of their original kinetic energy, since there is no mechanism such as Joule heating in their model to dissipate this energy. They assume that since the initial LEO plane is inclined to the equatorial plane, a substantial component of the ion velocities will be parallel to the $\vec{B}$ field lines so that the ions will disperse from the beam and move in spiral orbits along the field lines and become magnetically trapped as a relatively high energy or hot plasma $(\approx 3.5 \mathrm{keV})$. Both the Chiu et al. model and the Holze-Liemohn model conclude that the bulk of the $\mathrm{Ar}^{+}$ions become trapped in the geomagnetic field. In the former model, most of the $\mathrm{Ar}^{+}$ions enter with very low energy, the balance being dissipated as heat in the lower and mid-latitude ionosphere. In the latter model, the ions become trapped with most of their energy intact.

A third picture, due to Curtis and Grebowsky, 123 claims that the Alfvén wave mechanism is not applicable and will not be effective in stopping the beam as an entity, or in dissipating its energy in the ionosphere because the Alfvén wave propagation speed is too slow relative to the initial beam propagation speed. Chiu ct al.93 have estimated the Al[vén wave propagation speed to be about one order of magnitude greater than that of the beam and therefore adequate to permit the Alfuén wave mechanism to effectively dissipate the beam energy. The Curtis and Grebowsky model assumed a slightly greater initial ion velocity than the Chiu et al. model $(155 \mathrm{~km} / \mathrm{s} v \mathrm{~s} 130 \mathrm{~km} / \mathrm{s}$, respectively), but this difference is probably not significant relative to their argument. The Curtis and Grebowsky model also assumed a murh more divergont boam (2 $2^{\circ}$ relative to the beam axis) than the Chiu et al. model ( $10^{\circ}$ relative to the beam axis). The importance of this opening angle difference is not clear.

In contrasl to Holze and Liemohn who say that after an inilial period of expansion the beam particles become individually trapped in the geomagnetic field, Curtis and Grebowsky claim that the polarization $\vec{E}$ field is never reduced to the point where the beam propagation ceases and the individual ions disperse. They claim that the bulk of the beam propagates out of the geomagnetic field tu uuler space. Only the ions making up the outer sheath of the beam where the $\vec{E}$ field is very weak are separated from the main beam and become magnetically trapped at essentially $3.5 \mathrm{keV}$. 
In summary then, the three models suggest that:

Chiul et al.:93 The beam is stopped relative to the magnetosphere within about 1000 to $2000 \mathrm{~km}$. Most of the kinetic energy is dissipated in the ionosphere poleward from the equator. Most of the $\mathrm{Ar}^{+}$ ions are magnetically trapped with very low energies.

Holze \& Liemohn: 121 Essentially all of the $\mathrm{Ar}^{+}$ions are magnetically trapped with their original kinetic energies.

Curtis \& Grebowsky: 123 About 90\% of the beam escapes to outer space intact. The remaining fraction of $\mathrm{Ar}^{+}$ions are magnetically trapped with their original kinetic energy.

At present, there is no experimental data that can be invoked to decide which description is the closest to reality. Hence, until more appropriate experiments are performed and more theoretical work is undertaken, considerable caution is advised in interpreting the results of these models.

The four main potential impacts of $\mathrm{Ar}^{+}$ions beam are:

1. Airglow emission enhancement due to interactions of the beam with ambient constituents, especially near LEO where the atmospheric density is greatest.

2. Alteration of auroral processes and response to changes in the solar wind.

3. Modification of the Van Allen Radiation Belts.

4. Generation of plasma instabilities that can cause interference with radio wave communication links involving satellites.

\subsubsection{Artificial Airglow Emissions}

Artificial Airglow is important because of possible interference with optiral remnte sensing systems. Space-based optical sensors are currently used for military, scientific, and earth-resource applications. For data interpretation purposes, such systems must take into consideration the background optical emissions from atmospheric constituents. The latter emissions, ranging from the far infrared (FIR) to the extreme ultraviolet (EUV), are collectively called airglow. CoTv effluents could stimulate artificial airglow via two mechanisms: 93

1. Dissipation of the beam streaming energy in the form of thermal energy heats the ionosphere to the level of a few eV, which is comparable to the energy of natural photoelectrons that produce natural airglow. Its intensity, however, would be much greater than that of natural airglow because the artificially heated thermal electron flux would be orders of magnitude higher than the photoelectron flux.93 It is not possible to assess the impact of the artificial airglow produced via this mechanisin both because the exact level of thermal modification is not known and because the portion of the airglow spectrum is not extensively used, by present space-based sensing systems. 93 
2. In the vicinity of LEO the energetic ion beam can have a direct impact on the relatively dense atmosphere. This impact will stimulate the near-UV part of the airglow spectrum (more properly auroral spectrum). This stimulation is more serious since this portion of the spectrum is utilized by present-day sensors. Chiu et al.93 have estimated the intensity of this "artificial aurora" and given upper limits of the order of $10^{6}$ to $10^{7}$ Rayleighs for the altitude range of $350 \mathrm{~km}$ down to $150 \mathrm{~km}$ and for the wavelength range of $2500-5500 \AA$. For comparison, the natural auroral intensities are of the order $10^{5}$ Rayleighs at $150 \mathrm{~km}$. If artificial intensities are indeed an order of magnitude greater than values arising in natural aurorae of moderate strength, then it may be necessary to employ mitigating strategies. A possible strategy would be to direct the beam essentially orthogonal to the $B$ field until the COTV is $\approx 2000 \mathrm{~km}$ from LEO; that is, avoid plane changes until after an altitude of $2000 \mathrm{~km}$ above LEO has been achieved.

\subsubsection{Artificial Auroral Substorms}

As discussed above; the Alfven waves generated by the movement of the ion thruster beam through the ambient plasma propagates the polarization electric field down a magnetic field line to the denser regions of the ionosphere. Here, due to the relatively high conductivity, a cross-field electric current can flow like natural aurorai currents created during magnetic storms. Two known consequences of the natural ionospheric currents are, first, the induction of current surges in terrestri:l conductors such as pipelines and telephone and electric power transmission lines. Electrical currents in pipelines enhance corrosion, 93 while surges in telephone and transmission lines cause tripping of circuit breakers.124-126 The second effect is the dissipation of energy due to Joule heating ( $T^{2} R$ loss). The natural cncrgy dissipation process is an important source of thermal energy in the auroral zones that together with the direct solar radiation energy input near the equator is believed to give rise to the thermospherir wind patterns.127 Diurnal and seasonal variations in these two energy inputs cause corresponding temporal variations in the thermospheric wind patterns. The extent to which these wind patterns influence tropospheric weather processes is not knnwn at present. However, modulation of auroral energy input processes, including the precipitation of high energy particles into the upper atmosphere by variations in the solar wind, has been suggested as a possible mechanism for the socalled "solar-terrestrial weather effect."

The main difference between the natural and "artificial auroral" processes is that the natural ones occur sporadically and over a large area in the high latitude regions. The natural energy dissipation rate is aboul 1017 crgo/s. The "artificial auroral" processes occur continuously and at mid-latitude regions. The corresponding energy dissipation rate is about $5 \times 10^{15} \mathrm{ergs} / \mathrm{s}$. Hence, averaged over a several-month period, the total energy dissipated is comparable.93 The fact that the sps-related processes occur in mid-latitude regions means that if electrical currents are induced in cerrestrial conductors, they will occur in more populated areas than is the naturally occurring case and, therefore, could be a greater nuisance.

Based on a comparison with the natural heating processes of particle precipitating and Joule heating (roughly equal in magnitude), the artificial Joule-heating process could conceivably raise the temperature of the ambient 
plasma to a few eV $\left(10^{3}-10^{4} \mathrm{~K}\right) .8$ Chiu et al.93 used a simple, four-constituent, steady-state model to estimate the effect of heating the ambient plasma (including $\mathrm{Ar}^{+}$ions injected by the COTV) to $5 \mathrm{eV}$. The other constituents were $\mathrm{H}^{+}, \mathrm{O}^{+}$, and $\mathrm{e}^{-}$. The results, shown in Fig. 27, indicate that the presence of the $\mathrm{Ar}^{+}$ions by themselves will not upset the normal distribution of plasmaspheric $\mathrm{H}^{+}$and $\mathrm{O}^{+}$, but the addition of thermal energy via Joule heating to $5 \mathrm{eV}$ substantially increases the density of $\mathrm{O}^{+}$and $\mathrm{Ar}^{+}$ions at high altitudes.

\subsubsection{Modification of the Van Allen Radiation Belts and Ring-Current Particles}

The appearance of $\mathrm{O}^{+}$and $\mathrm{Ar}^{+}$ions (or any other heavy, relatively cold plasma constituents) in the region normally occupied by relativistic electrons can have serious consequences for the radiation dosage. The relativistic-electron distribution in the equatorial plane peaks at $1.8 R_{E}$ (the inner $\operatorname{Van} A l$ len $B e l t$ ) and at $5 R_{E}$ (the outer Van Allen Belt). The minimum in between is located near $3 \mathrm{R}_{E}$. This distribution is strongly correlated with magnetic storm activity. 128

Dynamical interactions between the magnetosphere and the solar wind are ultimately responsible for populating these high-energy-particle regions. Their populations are diminished by interactions with plasma turbulence that causes the magnetically trapped particles to be scattered into their loss-cones so that they mirror at altitudes where collisions with the denser neutral atmosphere are more probable than normal. Such collisions cause the
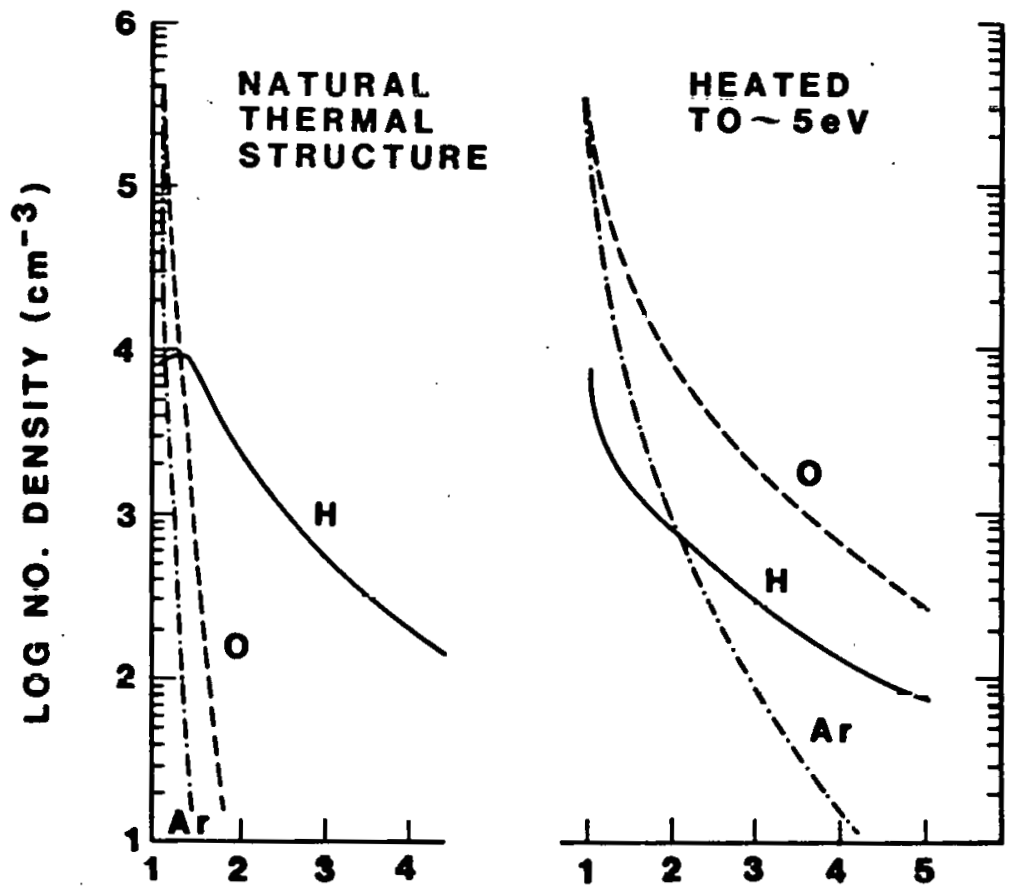

$\mathbf{R} / \mathbf{R e}$

Fig. 27 Principal Components of Plasmasphere 
trapped particles to deposit their energy into the ionosphere and thermosphere where they escape magnetic confinement. One of the mechanisms for loss of relativistic electrons from the radiation belts is a resonance between waves generated by gyrating ring-current protons and relativistic-electron gyrations. The removal of relativistic electrons by operation of this so-called ion-cyclotron instability occurs when the ring currents and radiation belts occupy the same region of space. This double occupancy occurs during the recovery phase of a magnetic storm.

As pointed out by Chiu et al.,93 the presence of cold, heavy plasma components such as $\mathrm{O}^{+}$and $\mathrm{Ar}^{+}$are likely to damp out the ion-cyclotron instability and, therefore, prevent the natural removal or precipitation of relativistic electrons into the atmosphere, increasing their mean dosage with time. Based on the assumption that this instability is the principal mechanism for relativistic-electron precipitation, they estimate a twofold to threefold increase in dosage in the nuter-radiation belt. There is, according to Chiu et al., no danger of a correspunding increase in ring-current-proton dosage, since the main mechanism for its limitation is not expected to be affected by the presence of cold, heavy ions. Also, the high atomic-numbered ions with high energy (HZE particle population) are not expected to be affected by the addition of the heavy, cold ions $\left(\mathrm{O}^{+}\right.$and $\left.\mathrm{Ar}^{+}\right) .93$ On the other hand, the thermal electrons associated with the $\mathrm{O}^{+}$and $\mathrm{Ar}^{+}$ions probably (not proven) would cause the precipitation of the lower energy electrons ( $<100 \mathrm{keV})$ that populate the ring current. This precipitation is in contrast to the stabilizing influence that the $\mathrm{O}^{+}$and $\mathrm{Ar}^{+}$ions would have on the relativisticelectron population ( $E>1 \mathrm{MeV}$ ) of the outer radiation belt. The rapid loss of ring-current electrons also contributes to the reduction of geomagnetic activity.

If a portion of the $\mathrm{Ar}^{+}$ions would escape from the beam with most of its original kinetic energy $(3.5 \mathrm{keV})$, it would constitute a relatively hot plasma addition. Such an addition could have completely different consequences as suggested by Chiu et al.,93 and elaborated upon by Curtis and Grebowsky 123 and by Holze and Liemohn. 121 The energetic $\mathrm{Ar}^{+}$ions would add a ring-currentlike population that could interact resonantly with the radiationbelt electrons to remove them from their trapped orbits. This activity would, effectively cause artificial aurorae and reduce relativistic-electron dosage. Hence, the state of the $\mathrm{Ar}^{+}$ions that become trapped in the geomagnetic field is important for determining their impact.

Additionally, as pointed out by Curtis and Grebowsky, 122 if the bulk of the beam escapes the geomagnetic field altogether so that only about $10 \%$ of the ions are deposited in the magnetic field and if that portion becomes trapped at nearly its original kinetic entergy; then virtually no energy would be dissipated in artificial mid-latitude auroral processes, no. artificial mid-ionospheric currents would be generated, and no currents would be induced in terrestrial conductors. Hence, the ionosphere and plasmasphere would not be heated to a few eV causing the drastic compositional changes . predicted by Chiu et $\mathrm{al} .93$

Finally, before leaving the subject of radiation belt modification, it should be mentioned that a new analysis relevant to this subject has recently been reported by Cladis, et al.128 They investigated the changes, in relativistic-electron populations in the outer trapping regions (near GEO) 
during magnetic storms, based on data obtained from the OGO-5 satellite in 1968, but only recently reported in the literature.129,130 Though their analysis is too new to have been properly reviewed in the scientific literature or independently confirmed, it is nevertheless sufficiently important to be noted here.

$\mathrm{Cladis,}$ found that during typical magnetic storms, there is very little loss of relativistic flux in magnetic shells with $L<4$ or $5 . *$ In fact, there appears to be a substantial enhancement in that flux in the region from $L=3$ to 4 , suggesting the inward migration of flux during the early phases of a storm. However, outside of $L=5$, the apparent loss of flux was very large. Although part of this loss could be explained in terms of inward movement, the remainder of the loss could not be explained in this manner and was thought to represent a true loss. As a storm subsides, they found that the flux increases throughout the trapping region from $\mathrm{L} \leqslant 3$ to $\mathrm{L} \leqslant 7$. This increase is caused by both the return of the old flux to its original position plus the injection of new electrons. They emphasized that because the decrease in relativistic-electron $f 1 u x(L \approx 5)$ in the outer radiation belt precedes the establishment of a ring current, the so-called ion-cyclotron resonance, involving an interaction between the relativistic electrons and ring-current, ion-cyclotron waves, could not be entirely responsible for the loss of the relativistic electrons during the recovery phase. In contrast, Chiu et al. 93 assumed, in their analysis that the ion-cyclotron resonance was the major loss mechanism for the relativistic electrons. As a consequence, they concluded that since the addition of cold, heavy ions $\left(0^{+}\right.$and $\mathrm{Ar}^{+}$) would suppress this resonant interaction, the injection of $\mathrm{O}^{+}$and $\mathrm{Ar}^{+}$ would lead to the enhancement of the relativistic-electron population. If cladis et al. are correct, then the suppression of resonant interaction would be inconsequential, at least during the recovery phase of a magnetic storm. However, they do not claim that the addition of the $\mathrm{Ar}^{+}$plasma from the CoTVs is benign. Quite to the contrary, they suggest that a probable consequence of $\mathrm{Ar}^{+}$injcction would be to increase the inner magnetospheric density and consequently to reduce its susceptibility to generation of magnetic and electric fluctuations. This consequence would tend to prevent the inward migration of relativistic electrons that naturally occurs during magnetic storms. Prevention of such inward migration would cause in turn a reduction of energetic electron fluxes inside the plasmasphere and an enhancement of the fluxes in the extreme outer regions. The ring current, the peak of the outer radiation belt, and the outer boundary of the trapping region would be moved outward by 1 or 2 integer L-values. While they are uncertain about the magnitude of the effects, they suggest that the electron flux at geosynchronous altitude $(L=6.6$ ) would be increased by a factor between 1 and 5 by the presence of $\mathrm{Ar}^{+}$ions. Such an increase could decrease the 1 ifetime of solar cells correspondingly. Hence, if the lifetime of solar cells in the normal GEO radiation environment is 40 years, it could be reduced to as little as 8 years :

$*_{\mathrm{L}}$ is the magnetic-shell parameter. The intersection of a magnetic shell with the equatorial plane forms an approximate circle. The radius of the circle is very nearly equal to $L$ Earth radii. Hence, GEO is located on the magnetic shell corresponding to an L-value of 6.6 . It is $6.6 \mathrm{R}_{\mathrm{E}}$ from the center of the Earth: $L$ is also an adiabatic invariant of the motion of a magnelically trapped charged particle. 
To recapitulate, based on the assumption that the $\mathrm{Ar}^{+}$beam is stopped within the magnetosphere (which leads to a substantial increase in $\mathrm{Ar}^{+}$and $\mathrm{O}^{+}$ density in the plasmasphere) and the assumption that the principal mechanism for removal of relativistic electrons from the outer radiation belt is the ion-cyclotror instability (which is suppressed by the presence of $\mathrm{Ar}^{+}$and $\mathrm{O}^{+}$), Chiu, et al. 93 conclude that there would be a buildup of relativistic-electron flux in the outer belt $(4 \leqslant L \leqslant 6)$. Cladis et al., 128 on the other hand, claim that it is doubtful that the ion-cyclotron instability is important in removing relativistic electrons from the outer belt and that the consequences of adding $\mathrm{Ar}^{+}$would be to diminish the electron flux within the inner magnetosphere $(L \leqslant 5)$ and increase it outside that region. At GEO $(L=6.6)$ the increase could be as much as a factor of 5 . The sensitivity of $\mathrm{cladis}$ et a1.' 128 results to the manner in which the Art ions are stopped within the magnetosphere has not been investigated. It is obviously very important to confirm their new findings.

\subsubsection{Generation of Plasma Turbulence and Interference with Satellite Communication Systems}

On one point, there seems to be general agreement, and that is, that the injection of the $\mathrm{Ar}^{+}$plasma beam will generate plasma turbulence. In fact, a recent experiment in an ionospheric simulation chamber at the Johnson Space Flight Center reported on by Chiu et al. 93 suggests that the $\mathrm{Ar}^{+}$plasma beam itself is much more turbulent than previously thought. Curtis and Grebowsky123 suggest that even if only $10 \%$ of the energetic $\mathrm{Ar}^{+}$ions are trapped in the magnetosphere, they could lead to the generation of a substantial amount of $\mathrm{pl}$ asma turbulence. While an enhancement of the radiation belts is not expected in the Curtis-Grebowsky picture, as discussed earlier, the generation of plasma turbulence is likely to scatter radiation belt particles out of their stably trapped orbits so that they will precipitate into the atmosphere and produce artificial auroral dicplayo and radiowave interference. In addition, the injection of energetic $\mathrm{Ar}^{+}$ions into the ambient plasma predicted by the Curtis-Grebowsky model is likely to drive plasma instabilities that may produce sufficient srintillations to impair satellite-based communication systems. Chiu et al. 93 point out that many forms of plasma instabilities may be triggered by the plasma turbulence created by the interaction of the beam with the ambient plasma. In particular, they suggest that the electrostatic modes may generate density irregularities in the form of plasma striations aligned with the geomagnetic fiold. Such striations have been observed in barium release experiments. The irregularities are of the proper size, say Chiu et al.,93 to be potential scattering centers for satellite communication signals. Such scattering would give: rise to signal scintillations in agreement with Curtis and Grebowsky'si23 findings. However, the strength of such scintillations cannot be determined at this time. Experiments are required.

\subsection{ENERGY DEPOSITION AND ABSORPTION}

The construction and operation of the satellite power system would result in the deposition of energy as well as rocket effluent into the different regions of the atmosphere. In addition, a small fraction of the energy in the microwave beam is absorbed by the atmosphere. The question of energy 
deposition from the argon plasma engines used by the coTv was discussed previously, as was the possibility of energy absorption from the microwave beam in the troposphere. The question of energy deposition and absorption in the stratosphere, mesosphere, and lower thermosphere is discussed briefly in this section.

One possible source of energy is the total energy content, thermal and streaming energy combined, of the exhaust from a large rocket such as the HLLV. An estimate of the amount of energy involved may be obtained by considering the energy balance for an accelerating rocket. The heat of combustion of the known fuel burned to produce the given mixture of exhaust products provides an estimate of the total energy production rate, from which is subtracted the rate of change of the rocket's potential and kinetic energies. When this calculation is carried out, the total energy deposition into the stratosphere amounts to $7.5 \times 10^{-8} \mathrm{~mW} / \mathrm{cm}^{2}$ when averaged over the globe. This figure should be compared with the average energy input to the stratosphere due to solar UV absorption of $4 \mathrm{~mW} / \mathrm{cm}^{2}$. Any local energy effects due to the passage of a large rocket are quickly dissipated by the atmosphere. Similar conclusions apply to the mesosphere and lower thermosphere.

Estimates are available for the upper-atmosphere absorption of microwaves at the SPS frequency of $2.45 \mathrm{GHz}$. The fractional absorption of microwaves with a frequency of $2.45 \mathrm{GHz}$ vertically incident on the atmosphere has been reported to be approximately 0.01 , of which only 0.001 occurs in the stratosphere and mesosphere.131 The peak power in the microwave beam is expected to be approximately $23 \mathrm{~mW} / \mathrm{cm}^{2}$ with an average power level of about 5 $\mathrm{mW} / \mathrm{cm}^{2}$. Thus, a net continuous energy deposition in the stratosphere and mesosphere of approximately $0.005 \mathrm{~mW} / \mathrm{cm}^{2}$ would be expected per satellite. This figure is about $0.13 \%$ of the solar UV absorption input, and may be considered negligible. When averaged over the globe, even assuming the presence of sixty 5-GW rectennas, the average energy flux to the upper atmosphere would be only $6 \times 10^{-5} \mathrm{~mW} / \mathrm{cm}^{2}$.

Microwave attenuation at $2.45 \mathrm{GHz}$ above the troposphere is due almost entirely to absorption by molecular oxygen, 131 with an absorption cross-section of approximately $1.3 \times 10^{-31} \mathrm{~m}^{2}$ (estimated from results presented in Ref. 131). Using this cross section together with data on the variation of atmospheric number density with altitude, 132 the microwave attenuation values for both the stratosphere and mesosphere have been independently calculated and the results are in agreement with the total value given in Ref. 19 for altitudes above the troposphere. A total absorption rate of $0.0056 \mathrm{~mW} / \mathrm{cm}^{2}$ $\left(0.14 \%\right.$ of the solar input of $\left.4 \mathrm{~mW} / \mathrm{cm}^{2}\right)$ is estimated in the stratosphere, and an absorption rate of $0.0001 \mathrm{~mW} / \mathrm{cm}^{2}(0.4 \%$ of the corresponding solar input of $0.025 \mathrm{~mW} / \mathrm{cm}^{2}$ ) is estimated in the mesosphere.

These values are small in an absolute as well as a relative sense. The effect of absorption is to heat the air. The total temperature change depends on the length of time that an individual parcel of air spends in the microwave beam, and therefore on the beam diameter and wind speed. Assuming typical wind speeds and residence times and a beam diameter of $10 \mathrm{~km}$, corresponding estimated temperature changes have been calculated and are totally negligible.

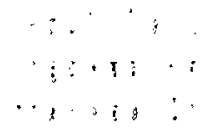




\subsection{EFFECTS OF LARGE STRUCTURES ON THE SATELLITE ENVIRONMENT}

It was necessary to set priorities early in the assessment program in order to limit the number of issues addressed to those judged to be most important. The workshops described earlier provided a considerable list of issues as well as valuable information needed to set priorities. It was the consensus at that time that the rocket effluent effects would be more important than the large structure effects. Hence, little if any new work was performed on the assessment of satellite structure effects on the upper atmosphere. Below we describe some of the more important issues related to structure effects.

Several authors, including Vondrak133,134 and Rosen 135 have suggested that large structures in the magnetosphere will serve as sinks for particles striking them. The CoTV, depending upon which photocell option is chosen, will have a cross-sectional area of 1.3 to $2.9 \mathrm{~km}^{2}$. Such a structure according to Rosen 134 could have a sweeping effect on the inner Van Allen Belt particles as it moves back and forth between LEO and GEO. However, the extent of that kind of a sweeping action, and the impact on the space environment is not clear at this time. Presumably it would have a net positive influence through the reduction of ionizing radiation levels.

The 60 SPS satellites will each cover an area of about $55 \mathrm{~km}^{2}$ and be distributed along an equatorial line over the U.S. on the magnetic shell defined by an $L$ value of about 6.6. One would expect therefore that flux tubes passing through these satellites and perhaps even the whole region of the magnetic shell could suffer some reduction of the energetic component of the plasma. This reduction, according to Vondrak, 133,134 would be analogous to the "sweeping" nf the Jovian radiation bclts by the Galilean sacellites.

The satellites are expected to become charged and, consequently, will accelerate ambient charged particles. This activity could lead to alteration of the ambient plasma and to enhanced radiation damage over and abnve that expected by unaccelerated particle bombardment. (The satellites will reside in the outer portion of the outer Van Allen Belt.) Project ECATHA (Spaceciaft Charging at High Altitudes, see Garrett ${ }^{136}$ ) is relevant to this issue. For example, scATHA experiments have demonstrated that electric potentials established on spacecraft can accelerate and decelerate plasma components to tens of keV. These experiments have also indicated that klystron operations can be adversely influenced by the plasma environment, which may be aludified by gaseous and particulate emissions in GEO.

The SPS satellite structure will dissipate most of the solar input energy as either reflected light or infrared radiation, since the proposed solar cells are expected to be, at most, 17-19\% efficient. In addition, the DC-to-RF converters will dissipate approximately 1.2 GW of waste heat, probably at relatively high temperatures $\left(>500^{\circ} \mathrm{C}\right)$. The effects of this radiation, as well as the effects of $R F$ radiation on the astronomical community, could be important. 131

Satellite structural members will be exposed continuously to direct solar and cosmic radiation and are expected to be sources of photoelectrons and other charged and neutral particles. The ejected neutral particles could form relatively long-lived orbiting dust clouds or rings near GEO.134,138 
Finally, the structures will be sources of various neutral contaminant gases (as well as $\mathrm{Ar}^{+}$ions and electrons from attitude control and station keeping thrusters). Sources of neutral gases include: (a) chemicallyfueled attitude control and stationkeeping thrusters used during eclipses of the sun by Earth, (b) leakage from pressurized chambers including living quarters, containment vessels, etc., and (c) satellite-surface erosion and outgassing of volatiles. 134

In addition to these satellite-structural sources, both chemical and ion propellants will be injected near GEO from thrusters required in spaceconstruction operations and maneuvers. The neutral gases probably will have relatively low exhaust speed and be more randomly directed. Thus, they probably will be trapped and may form gas clouds in the GEO environment. The minimum gas release rates needed to produce. significant effects have been evaluated by Vondrak.133,134 Garrett and Forbes also have performed some calculations relevant to this topic.138 They suggest that it may be possible to measure an actual contaminant cloud ( $\mathrm{Xe}^{+}$ions) during the 1979-1980 time frame by using the GEOS II satellite. 
4 UPPER-LOWER ATMOSPHERIC COUPLING AND IMPLICATIONS FOR
SPS IMPACTS ON CLIMATE AND WEATHER

It has already been stressed that as one moves to progressively higher altitudes the magnitude of possible perturbations grows because of the SPS rocket effluents. On the other hand, our understanding of the influence of phenomena in the upper atmosphere on weather-related phenomena in the troposphere diminishes with altitude. Consequently, our present ability to assess SPS impacts of upper atmospheric effects on the weather (short-term, local) or on the climate (long-term, global) is very limited.

Questions regarding coupling of upper and lower atmospheric processes are, of course, much older than the SPS concept, and interest in this subject has only recently been stimulated by concern over the influence that man-made changes in upper atmospheric properties might have on the climate. The most prominent issues have been those of $\mathrm{CO}_{2}$ and fine-particle emissions by fossi.l. fuel combuotion and $0_{3}$ removal by $\mathrm{NO}_{x}$ emissions from high altitude aircraft and by aerosol propellants. Somewhat less tramatic, but of equal impustalle from a hasic underotanding poinl of view is the issue of how small changes in the sun's properties, such as exhibited hy the sun-epot cycle and changes in the solar wind, are correlated with fluctuations in weather patterns. The so-called solar-terrestrial weather effect was quite thoroughly reviewed at the symposium/workshop held at Ohio State University in 1978.115

Three general mechanisms have been suggested that could couple upper and lower atmospheric processes. First, are the radiative mechanisms that involve changes in upper atmospheric composition and/or temperature that affect, in turn, heating at the surface. Two possible perturbations include change in transmission of visible solar radiation and change in the race of emission or absorption of IR radiation. Second, are the dynamical mechanisms that involve relationships between upper and lower atmospheric circulation, pressure patterns, and temperature. Third, are those that influence atmospheric electricity. Each of these mechanisms and the implications for SPS are discussed briefly below:

Wurk on radiative mechanisms has been reviewed by whitten et al.80 They report that $10 \%$ increases in stratospheric water and increases of $1 \%$ in $\mathrm{O}_{3}$ concentrations at all heights result in estimated changes of less than $0.1 \mathrm{~K}$. Since SPS changes are predicted to be even smaller than these $\mathrm{H}_{2} \mathrm{O}$ and $\mathrm{O}_{3}$ changes, the corresponding surface temporature shanges would be quite negligible. It was at first thought that corridor effects, i.e., buildups of $\mathrm{H}_{2} \mathrm{O}$ and $\mathrm{NO}_{x}$ and corresponding reductions in $\mathrm{O}_{3}$ in narrow latitude bands around the globe might lead to significant changes in surface temperatures, However, according to Whitten et al.' a estimates, the rime scale for smoothing out local temperature changes is much shorter than that for buildup of corridors. Furthermore, their estimates indicate that significant corridors of $\mathrm{H}_{2} \mathrm{O}$, $\mathrm{NO}_{x}$ and reduced $\mathrm{O}_{3}$ levels are unlikely to occur anyway.

Whitten et al.80 have also reviewed recent work on dynamical coupling mechanisms. One such mechanism that was suggested by Hines, 139 involves the propagation of planetary pressure waves around the globe and their association with the large-scale pressure and circulation patterns in the troposphere. These waves are reflected in the upper atmosphere by the natural variation of temperature and pressure with altitude. If the properties that govern the 
amplitude and phase of the reflected waves can be influenced by compositional changes in the upper atmosphere, then the pattern of the standing planetary waves may change as well with the consequence of changes in global circulation. Based upon investigations reviewed by Whitten et al., they conclude that the magnitudes of compositional changes they have predicted for the SPS are far below the threshold for significant effects on reflected planetary waves.

Markson 100,101 has proposed a mechanism to describe the solar-terrestrial weather effect based upon the global electrical circuit that is driven by thunderstorm activity around the globe. Basically, the circuit consists of two equipotential surfaces, namely, the Earth's ground surface and the ionosphere, between which a small globally distributed current density flows in one direction during periods of fair weather and is returned through large local current flows in regions experiencing thunderstorms. Markson suggests that the modulation of ionizing radiation by interaction of the solar wind with the magnetosphere could affect the level of ionization and therefore the electrical conductivity above thunderstorms. The conductivity presumably influences the flow of electrical currents and as a result the nature and intensity of the storm activity. The suggestion that the solar wind can influence storm activity is particularly interesting because it is susceptible to modification by the compositional and dynamical changes of the magnetosphere discussed in Sec. 3.4. It is known, for example, that during magnetic storms, high-energy charged particles are precipitated into the high-latitude atmosphere where they produce ionizing radiation as a result of collisions. with the dense neutral atmosphere. The radiation then alters the degree of ionization in the upper atmosphere. However, it is not known how change in ionization influences thunderstorms, nor is it known for certain how particle precipitation will be affected by COTV and POTV emissions.

In summary, based on present knowledge, it does not appear that the SPS will significantly influence tropospheric weather or climate through the upper-lower atmospheric coupling mechanisms discussed above. In view of the developing state of our knowledge regarding these mechanisms, it would be prudent to reexamine the question of large-scale rocket activity from time to time in the future. The atmospheric-electricity phenomenon should be examined more carefully, especially if the magnetospheric effects described in this report are borne out by future studies.

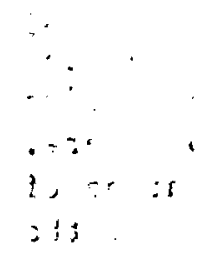




\section{CONCLUSIONS}

Effluents from the Earth-space transportation system are the major cause of SPS-related atmospheric effects. These effects include inadvertent weather modification, air quality degradation, compositional changes in the stratosphere and mesosphere, formation of noctilucent clouds, plasma density changes, airglow-emission enhancements, and changes in composition and dynamics of the plasmasphere and magnetosphere. In most cases, these effects have been difficult to assess because they involve processes that are incompletely understood by the scientific community or are speculative in nature, or because they involve extrapolations of known effects to unprecedented scales. Therefore, with few exceptions, the results should be regarded as tentative.

HLLV launches have been predicted to have a significant potential for inadvertent weather modifications on a short-term local scale. Under selected meteorological conditions such launches can affect convective patterns, alter cloud populations, and induce detectable precipitation. None of these effects are judged to be serious. Long-term, large-scale effects are unlikely, but have not been examined in detail.

Air quality impacts of HLLV launches are predicted to be very small, except possibly with respect to nitrogen dioxide. If a short-term, airquality standard is set as anticipated, then ground-level concentrations of $\mathrm{NO}_{2}$ resulting from rocket launches could exacerbate existing problems. However, the launches by themselves are not expected to cause an exceedance of the expected standard. The production of $\mathrm{NO}_{2}$ can also lead to slight increases in acidity of precipitation on a local, intermittent basis. It seems unlikely that the enhancement would be great enough to cause significant environmental effects.

Stratospheric $\mathrm{CO}_{2}$ and $\mathrm{H}_{2} \mathrm{O}$ injections are estiulated to be negligible from both the ozone depletinn and greenhouoc effcet poiuls of view. 'lhe expected fractional increase in the $\mathrm{CO}_{2}$ concentration is only $1-2$ parts in $10^{5}$. Small predicted reductions $(0.01-0.02 \%$ ) in the total ozone column (and therefore on the incidence of UV radiation at ground level) because of water injections would not be detectable.

The production of No during reentry of the HLLV second stage is predicted theoretically to lead to an increase of about $0.02 \%$ in the globallyaveraged, ozone-column density, with latitude-dependent variations of a factor of 2 around this value. The uncertainty in the calculations is such that no increase or even a small decrease is pubbible.

Repeated injections of $\mathrm{H}_{2} \mathrm{O}$ in the mesosphere will result in an increase of about $8 \%$ (globally averaged) in the water vapor content at $80 \mathrm{~km}$. Over a narrow region surrounding the launch latitude at the same height, the increase may be as much as 15\%. At lower altiludes, the buildup is smaller and no corridor effects are expected. At higher altitudes, preliminary estimates suggest that the buildup in water vapor content will be greater, increasing the globally averaged natural content by as much as a factor of 100 or more at $120 \mathrm{~km}$ and above. On the short-term, smaller scale basis associated with individual rocket launches, significant increases in water vapor concentrations are also expected. On the same basis, small-scale ice clouds 
(noctilucent clouds) are expected to be formed but are not expected to reach global scales. and, therefore, are not expected to cause climatic impacts. Temperature effects, not fully understood at present, may alter the likelihood of cloud formation and possibly increase cloud persistence. Visual displays at low- to mid-latitudes may result near sunrise or sunset.

The injection of water vapor and hydrogen molecules, above $80 \mathrm{~km}$ will lead to an enhancement in the upward flux of hydrogen through the thermosphere. It has been estimated that the natural total flux of hydrogen (in all chemical forms) will be approximately doubled. The consequences of such an enhancement have not been examined in detail as yet. Possible consequences include an increase in escape rate of hydrogen to outer space and or an increase in atmospheric density above $800 \mathrm{~km}$.

Several mechanisms that are not completely independent of each other have been estimated to produce both large positive and negative changes in $D-$ and E-region plasma densities on a short-term local scale. It is not clear how large or persistent the net plasma density changes will be or even what sign they will take. Long-term, global-scale D- and E-region effects appear to be quite small and probably unimportant although the predictions are uncertain at this time.

The picture is much clearer in the F-region. We can predict with considerable confidence the scale and, with somewhat less confidence, the duration, of short-term F-region holes caused by various engine burns of SPS space vehicles. Each POTV injection burn will result in an ionospheric hole 2 to 3 times as large as the continental U.S. HLLV circularization burns will produce holes one-tenth of that size. (POTV and HLLV burns occur once or twice per month and once or twice per day, respectively.) More speculatively, the periodic engine burns may lead to a chronic partial depletion in a ringshaped global region centered around the launch latitude. Crude estimates suggest a $10 \%$ plasma reduction in this region superimposed on periodic, small-scale, but much more complete depletions. Confirmation with more detailed model calculations taking into account global transport processes is required. Probably the major consequences of this partially depleted ring will be perturbations of VLF, HF, and possibly VHF wave propagation. According to present information such perturbations are not expected to be large. However, sufficient uncertainties exist in the current data and theoretical modeling studies to warrant considerable caution in attempting to scale up radio wave propagation effects.

Another impact of potential importance is the enhancement of airglow emissions. The greatest enhancements observed to date are on the order of 10 kiloRayleighs for certain emissions in the visible and near infrared band. The significance of these effects in terms of their impacts on astronomical observations, remote sensing, and satellite-borne surveillance systems should be determined in the future with the aid of the corresponding communities.

The effect of POTV and COTV emissions in the magnetosphere is perhaps least understood at the present time and least supported by observations. This area of investigation could benefit by field and laboratory experiments and further improvements in theory. The masses and energies injected are inquestionably large compared to naturally occurring values and, therefore, zause concern. Some effects are sumarized in Table 20. Heating by the argon 
Table 20. Satellite Power System Magnetospheric Effectsa

\begin{tabular}{|c|c|c|c|c|}
\hline & Effect & Cause & Mechan1sm & $\begin{array}{c}\text { System/Activities } \\
\text { Impacted }\end{array}$ \\
\hline 1. & $\begin{array}{l}\text { Dosage Enhancement } \\
\text { of Trapped Relativ- } \\
\text { 18t1c Electrong }\end{array}$ & $\begin{array}{l}\mathrm{O}^{+} \text {and } \mathrm{Ax}^{+} \text {in magneto- } \\
\text { sphere due to exhaust } \\
\text { and plasmasphere } \\
\text { heat Ing }\end{array}$ & $\begin{array}{l}\text { Thermal heavy lons } \\
\text { suppress ring-current- } \\
\text { lon cyclotron turbu- } \\
\text { lence, uhich keeps } \\
\text { electron dosage in } \\
\text { balance in natural } \\
\text { gtate }\end{array}$ & $\begin{array}{l}\text { - Space equipment } \\
\text { - Mod1f 1cation of } \\
\text { human epace } \\
\text { activity }\end{array}$ \\
\hline 2. & $\begin{array}{l}\text { Artificial Ionos- } \\
\text { pheric Current }\end{array}$ & $\begin{array}{l}\text { Ionospheric electric } \\
\text { fleld Induced by } \\
\text { argon beam }\end{array}$ & $\begin{array}{l}\text { Beam Induced Alfvén } \\
\text { Bhocks propagate into } \\
\text { lonosphere }\end{array}$ & $\begin{array}{l}\text { - Powerline tripping } \\
\text { - Pipeline corrosion } \\
\text { (probably undqpor- } \\
\text { tant) }\end{array}$ \\
\hline 3. & $\begin{array}{l}\text { Modified Auroral } \\
\text { Responge to Solar } \\
\text { Activity. }\end{array}$ & $\begin{array}{l}\text { Neutrals and heavy } \\
\text { lons in lorge quant 1- } \\
\text { thes }\end{array}$ & $\begin{array}{l}\text { Rapld charge--exchange } \\
\text { loss of ring-clirrent } \\
\text { particles }\end{array}$ & $\begin{array}{l}\text { - May teduce magnetic } \\
\text { otorm interference } \\
\text { with earth and } \\
\text { opace-based oystems }\end{array}$ \\
\hline 4. & Artificial A1rglow & $3.5 \mathrm{keV}$ argon Lons & $\begin{array}{l}\text { Direct Impact on atmo- } \\
\text { sphere from LEO source }\end{array}$ & $\begin{array}{l}\text { - Interference with } \\
\text { optical earth- } \\
\text { senanrs }\end{array}$ \\
\hline 5. & $\begin{array}{l}\text { Plasma Denulty D18- } \\
\text { turbance on Small } \\
\text { Spactal Scale }\end{array}$ & Plasma Injection & Plasma Instabilities & $\begin{array}{l}\text { - S1gnel scintilla- } \\
\text { tlon for apace- } \\
\text { baged communica- } \\
\text { tions }\end{array}$ \\
\hline
\end{tabular}

${ }^{a}$ From Ref. 93.

plasma beam and the addition of cold, heavy ions may lead to enhancement of dosage of trapped relativistic electrons in the outer Van Allen Belt and perhaps in the GEO environment. Production of artificial ionospheric electric currents similar to those associated with naturally occurring magnetic storms could be driven by the magnetosphere-argon-ion-beam interartions. Such currents could result in tripping circuit-breakers in long telephone and power 1 ines and enhance pipeline corrosion. The presence of large quantities of neutrals (from the POTV) could lead to substantial depletion of energetic, trapped, charged particles and modification of auroral response to solar activity. The possibility. also exists for the triggering of plasma instabilities that could cause satellite communications interference. Finally, an appreciable amount of airglow emission may be generated, especially near LEO, by the impingement of the dense $\mathrm{Ar}^{+}$beam on the thermosphere. Again, the significance of this artificial airglow should be judged by the remote sensing and astronomical communities.

The sun-weather effect that has been widely debated in the rcccnt climate literature, if it is real, is likely to involve a coupling of the upper and lower atmosphere. Several mechanisms have been proposed to explain such a coupling. It has been conjectured that, if indeed modifications in the solar wind can influence climate through some such coupling scheme, then perhaps the SPS upper atmospheric efferts that have been discussed herein could disturb the coupling scheme. In that sense, upper atmospheric SPS effects may be causally connected to possible climate effects. However, until the sun-weather effect is placed on a firmer footing, and until the SPS upper atmospheric effects themselves are better understood, the potential effect of SPS on climate and weather cannot be evaluated except in terms of the direct tropospheric effects discussed earlier in this section. Based on 
present knowledge, significant influence of SPS-induced upper atmospheric effects on tropospheric weather is regarded unlikely.

One final effect that has been investigated in the current assessment is the inadvertent weather modification likely to be caused by the rectenna structure coupled with its release of waste heat. From the weather and climate points of $v i e w$, the rectenna seems likely to have effects comparable with those arising from other nonindustrial land-use changes covering the same surface area; that is, local, detectable meteorological effects that probably have little consequence. 


\section{REFERENCES}

1. Glaser, P.E., Power from the Sun: Its Future, Science, $162: 857-861$ (Nov. 1968).

2. U.S. Dept. of Energy, Satellite Power System (SPS) Concept Development and Evaluation Progran, Reference System Report, DOE/ER-0023, (Oct. 1978).

3. U.S. Dept. of Energy, Preliminary Environmental Assessment for the Satellite Power System, Vol. 1, Executive. Summary, DOE/ER-0021/1 (Oct. 1978).

4. Ibid., Vol. 2, Detailed Assessment.

5. U.S. Dept. of Energy, Preliminary Environmental Assessment for the Satellite Power System, Rev. 1, Vol. 1, Executive Summary, DOE/ER-0036/1 (Jan. 1980).

6. Ibid., Vol. 2, Detailed Assessment.

7. Lee, J.L., Proc. of the Workshop on Meteorological Effects of Satellite Power System Rectenna Operation and Related Microwave Transmission Problems, U.S. Dept. of Energy Report CONF-7808114 (Dec. 1979).

8. Goldford, A.I., Proc. of the Heavy Lift Launch Vehicle Tropospheric Effects Workshop, U.S. Dept. of Energy Report, CONF-7809192 (Dec. 1979).

9. Brubaker, K.L., Proc. of Workshop on Stratospheric and Mesospheric Impacts of Satellite Power Systems, U.S. Dept. of Energy Report, CONF-7809197 (Dec. 1979).

10. Rote, D.M., Proc. of the Workshop on Ionospheric and Magnetospheric Effects of Satellite Power Systems, U.S. Dept. of Energy Report, CONF7808115 (Dec. 1979).

11. Bauer, E., Workshop on Upper Atmnsphemic Environmental Effeote Arioing from Propulsion Effluents Associated with Placing Large Payloads on Orbit: Satellite Power System Envirormental Assessment, U.S. Dept. of Energy (1979, in press).

12. Rotty, R.M., Uncertainties Associated with G1.nhal. Effects of Atmosphorio $\mathrm{CO}_{2}$, Sci. Total Env., $15: 73-86$ (1980).

13. Sagan, C., O.B. Toon, and J.B. Pollack, Anthropogenic Albedo Changes and the Earth's Climate, Science, 206:1363-1368 (1979).

14. Landsberg, H.E., and T.N. Maisel, Micrometeorological observations in an Area of Urban Crowth, Boundary Layer Meteorology, 2:365 (1972). 
15. Principal Investigators of Project METROMEX, METROMEX Update, Bull. Amer. Meteoro. Soc., 57:304-308 (1976). Additional findings also appearing in recent literature, e.g., J. Appl. Meteor. 17(5), (May 1978).

16. Schickedanz, P.T., Inadvertent Rain Modification as Indicated by Surface Rain Cells, J. App1. Meteoro1., 13:891-900 (1974).

17. Huff, F.A., et al., Effect of Cooling Tower Effluents on Atmospheric Conditions in Northern Illinois, Circ. 100, I11. State Water Survey, Urbana (1971).

18. Hanna, S.R., and F.A. Gifford, Meteorological Effects of Energy Dissipation at Large Power Parks, Bul1. American Meteorol. Soc., 56:1069,1076 (1975).

19. Allen, N.C., Preliminary Study of Possible Weather Effects Due to Solar Power Satellite Rectenna Operation, Internal Note No. JSC-12519, Johnson Space Center, NASA, Houston, Tex. (1977).

20. Robinson, G.D., Investigation of the Interaction of an SPS Rectenna with its Environment, prepared by The Center for the Environment and Man, Inc., for Argonne National Laboratory, Argonne Report ANL/EES-TM-93 (Jan. 1980).

21. Yamada, T., A Three-dimensional, Second-order Closure Numerical Model of Mesoscale Circulation in the Lower Atmosphere, Argonne National Laboratory, Report. No. ANL/RER-78-1 (1978).

22. Skolnik, M.I., ed., Radar Handbood, McGraw-Hil1 Book Co., New York, pp. 24-1 to 24-40 (1970).

23. Hindman, E.E. II, and L.F. Radke, Cloud Nuclei from Launches of Liquid and Solid Fueled Rockets, Extended Abstracts 7 th Conf. on Inadvertent and Planned Western Modification, American Meteor. Soc., Pp. 18-19 (Oct 8-12, 1979).

24. Radke, L.F., et al., Measurements of the Particles and Gases in the Ground Cloud from an Atlas/Centaur Rocket, prepared by U. of Washington Dept. of Atmospheric Sciences for Argonne National Laboratory, ANL/ EES-TM-98 (Feb. 1979).

25. Parungo, F.P., and P.A. Al lee, Rocket Effluent - It's Ice Nucleation Acitivity and Related Properties, J. App1. Meteor., 17:1856-1868 (1978).

26. Radke, LF., et al., Airborne Measurements in the Column and Ground Cloud from a Titan TII Rocket, informal tech. report prepared by U. of Washington, Atmospheric Sciences Dept., for the Dept. of the Navy, Naval Weapons Center, China Lake, CA 93555, under Contract 非60530-70-C-0033 (March $12,1979)$.

27. Lee., J.L., A Numerical Study of Shallow Convection, Report No. 19 to NSF, Dept; of Meteornlngy, Penn State U. (1971). (Also Ph.D. dissertation, Penn State U., 1972). 
28. Cotton, W.R., On Parameterization of Turbulent Transport in Cumulus Clouds, J. Atm. Sci. 32:548-564 (1975).

29. Stephens, J.B., et al., An Analytical Analysis of the Dispersion Predictions for Effluents from the Saturn $V$ and Scout-Algol III Rocket Exhausts, NASA TM X-2935, NASA Marshall Space Flight Center, Ala. (1973).

30. Stephens, J.B., et al., Compendium of Meteorological Data for the Titan III C (AF-777) Launch in May 1975, NASA TM X-73338, NASA Marshall Space Flight Center, Ala. (1976).

31. Ibid., Compendium of Meteorological Data for the Viking $B$ Launch in September 1975 , NASA TMX-73340 (1976).

32. Bollay, E., et al., Position Paper on the Potential of Inadvortont Woathor Modification of the Florida Penineula Resulting from Neutralization of Spdice Shuttle Solid Rocket Booster Exhaust Clouds, Institute on Man and Science, Rensselaerville, NY, NASA Contractor Report 3091 (Nov. 1979).

33. U.S. EPA, National Summary of State Implementation Plan Reviews, Report No. EPA-450/3-75-053-b, U.S. Environmental Protection Agency, Research Triangle Park, NC 27711 (1975).

34. Forrest, J., and L. Newman, Further Studies on the Oxidation of Sulfur Dioxide in Coal-Fired Power Plant Plumes, Atm. Env. 11:465-474 (1977).

35. Hegg, D., et al., Reactions of Ozone and Nitrogen Oxides in Power Plant Plumes, Atm. Env. 11:521-526 (1977).

36. NASA, Environmental Impact Statement for the Kennedy Space Center, (draft submitted to U.S. ÉrA and made puhiirly availablc); MACA, Julin F. Kemindy Space Center, F'la. (March 1979).

37. Hindman, E.E., et al, Airborne Monitoring of foses and Partioloo from Liquid and Solid Fueled Rockets, Paper No. 79-572, 72nd Annual Meeting, Air Pollution Control Association, Cincinnati (1979).

38. Demerjian, K.L., et al., The Mechanism of Photochemical Smog Formation, Adv. Env. Sci. Tech. 4:1-262 (1974).

39. Finlayson-Pitts, B.J., and J,N. Pitts, The Chemica7. Bnsi.s of Air Quality: Kinetics and Mechanisms of Photochemical Air Pollution and Application to Control Strutegies, Adv. Env. Sci. Tech \%:75-162 (1977).

40. Hampson, R.F., and D. Garvin, Reaction Rate and Photochemical Data for Atmospheric Chemistry-1977, NBS Special Publication No. 513, U.S. Department of Commerce, Washington, (1978),

41. Seinfeld, J.H., Correspondence, Env. Sci. Tech: 11:1218-1219 (1977).

42. Calvert, J.G., Test of the Theory of Ozone Generation in Los Angeles Atmosphere, Env. Sci. Tech. 10:248-256 (1976). 
43. Chock, D.P., and S. Kumar, On the Photostationary State Assumption in the Atmospheric Nitric Oxide-Nitrogen Dioxide-Ozone System, Atm. Env. $13: 419-420$, (1979).

44. O'Brien, R.J., Photostationary State in Photochemical smog Studies, Env. Sci. Tech. 8:579-583, (1974).

45. White, W.H., $\mathrm{NO}_{x}-\mathrm{O}_{3}$ Photochemistry in Power Plant Plumes: Comparison of Theory with Observation, Env. Sci. Tech. 11:995-1000 (1977).

46. Lamb, R.G., et al., Numerico-Empirical Analyses of Atmospheric Diffusion Theories, J. Atm. Sci. 32:1794-1807 (1975).

47. Davis, D.D., et al., Trace Gas Analysis of Power Plant Plumes Via Aircraft Measurement: $\mathrm{O}_{3}, \mathrm{NO}_{x}$ and $\mathrm{SO}_{2}$ Chemistry, Science 186:733-736 (1974).

48. Gillani, N.V., et al., Project MISTT: Kinetics of Particulate Sulfur Formation in Power Plant Plume out to $300 \mathrm{~km}$, Atm. Env. 12:589-598 (1978).

49. Miller, D.F., et al., Ozone Formation Related to Power Plant Emissions, Science 202:1186-1188 (1978).

50. Lusis, M.A., et al., Plume Chemistry Studies at a Northern Alberta Power Plant, Atm. Env. 12:2429-2437 (1978).

51. Sexton, K., and H. Westberg, Ambient Hydrocarbon and Ozone Measurements Downwind of a Large Automotive Painting Plant, Env. Sci. Tech. 14:329-332 (1980).

52. Likens, G.E., and F.H. Bormann, Acid Rain: A Serious Regional Environmental Problem, Science 184:1176-1179 (1974).

53. Likens, G.E., Acid Precipitation, Chemical and Engineering News, pp. 29-44 (Nov. 22, 1976).

54. Babich, H., et al., Aoid Precipitation, Couses and Consequences, Environment $22: 6-12(1980)$.

55. U.S. EPA, Research Stmmary - Acid Rain, Report No. EPA-600/8-79-028, U.S. Environmental Protection Agency, Washington, 20460 (1979).

56. Lewis, W.M., and M.C. Grant, Acid Precipitation in the Western United States, Science $207: 176-177$ (1980).

57. Brezunik, F.L., ct al., Acid Preripitation and Sulfate Deposition in Florida, Science 208:1027-1029 (1980).

58. Robbins, R.C., et a1., The Conversion of Sodium Chloride to Hydrogen Chloride in the Atmosphere, J. Meteor. 16:53-56 (1959).

59. Cotton, F.A., and G. Wilkinson, Advanced Inorganic Chemistry, 2nd ed., Interscience Pub., (John Wiley \& Sons, Inc.) New York (1966). 
60. Nebergal1, W.H., et al., College Chemistry, 4th ed., D.C., Heath \& Co., Lexington, Mass. (1972).

61. Deutschen Chemischen Gesellschaft, Gmelins Handbuch der Anorganischen Chemie, Verlag Chemis G.M.B.H., Berlin (1936).

62. Stedman, G., Mechanism of the Azide-Nitrate Reaction, Part I, J. Chem. Soc., pp. 2943-2949 (1959).

63. Ibid, pp. 2949-2954.

64. Bunton, C.A., and G. Stedman, ibid., Part III, pp. 3466-3474.

65. Bray, w.C., The Mechanism of Reactions in Aqueous Solutions, Chem. Rev. 10:161-177 (1932), and references theieill Lu the work of $E$. Ahe 1 and H. Schmid, Z. Thysik Chemie $(1928=1930)$.

66. Abel, E., and H. Schmid, cited in refs. 12 and 16 above.

67. Orel, A.E., and J.H. Seinfeld, Nitrate Formation in Atmospherio Aerosols, Env. Sci. Tech. 11:1000-1007 (1977).

68. Peterson, T.W., and J.H. Seinfeld, Sulfate and Nitrate Levels in Aqueous, Atmospheric Aerosols, Chap. 15 in Nitrogenous Air Pollutants, Chemical Biological Implications, D. Grosjean, ed., Ann Arbor Science Pub., Inc., Mich. (1979).

69. Middleton, P., and C.S. Kiang, Relative Importance of Nitrate and Sulfate Aerosol Production Mechanisms in Urban Atmospheres, Chap. 16, ibid.

70. Chang, T.Y., et al., An Estimate of the $\mathrm{NO}_{x}$ Removal Rate in an Urban Atmosphere, Env. Sci. Tech. 13:1534-1537 (1979).

71. Harries, J.E., The Distribution of Water Vapor in the Stratosphere, Rev. Geophys. Space Physics 14:565-575 (1976).

72. Penndorf, R., Analysis of Ozone and Water Vapor Field Measurement Data, Report No. FAA-EE-78-29, FAA, II.S. Department of Transpulalion, Waohingrón 2U5Y1 (Nov. 1978).

73. Hudson, R.D., and E.I. Reed, eds., The Stratosphere: Present and Future, Ref. Pub. No. 1049, NASA, Washington (Dec. 1979).

74. Hunten, D.M., and D.F. Strobel, Production and Escape of Terrestrial Hydrogen, J. Atm. Sci. 31:305-317 (1974).

75. Liu, S.C, and T.M. Donahue, The Aeronomy of Hydrogen in the Atmosphere of the Earth, J. Atm. Sci, 31:1118-1136 (1974).

76. Mendillo, M. et al., A Sudden Vanishing of the Ionospheric F Region Due to the Launch of Skylab, J. Geophys. Res. 80:2217-2228 (1975). 
77. Bernhardt, P.A., et al., Ionospheric Modification by Rocket Effluent6, Final Report prepared for Argonne National Laboratory, ANL Report No. ANL/EES-TM-100 (June 1, 1980).

78. Banks, P.M., and G. Kockarts, Aeronomy Parts A, $B$, Academic Press Inc., New York (1973).

79. Chiu, Y.T., et al., What Large-Scale Use of Ion Engines would do to the Magnetosphere and Ionosphere, Astronautics and Aeronautics, p. 46 (Feb. 1980).

80. Whitten, R.C., et al., Ervirormental Impact of the Satellite Power System on the Middle Atmosphere - An Assessment, U.S. Dept. of Energy Report (1980 in press).

81. Turco, R.P., and R.C. Whitten, The NASA Ames Research Center One- and Two-Dimensional Stratospheric Models, Part I: The One-Dimensional Model, NASA Technical Paper 1002, NASA, Washington (Sept. 1977).

82. Whitten, R.C., et al., ibid., Part II: The Two-Dimensional Model, NASA Technical Paper 1003.

83. Zinn, J., and C.D. Sutherland, Effects of Rocket Exhaust Products in the Thermosphere and Ionosphere, Space Solar Power Review, 1:109-132 (1980).

84. Bauer, E., A Catalog of Perturbing Influences on Stratospheric Ozone, 1955-1975, J. Geophys. Res. 84:6929-6940 (1979).

85. Benech, B., and J. Dessens, Mid-Latitude Artificial Noctilucent Clouds Initiated by High-AZtitude Rockets, J. Geophys, Res. 79:1299-1301 (1974).

86. Meinel, A., et al., Low-Latitude Noctilucent Cloud of 15 June 1963, Science $141: 1176-1178$ (1963).

87. Daniel, 0.H., et al., High-Altitude Minuteman Exhuast Trail, Monthly Weather Rev. 101:56-57 (1973).

88. Zinn, J., et al., Ionospheric Effects of Rocket Exhaust Products -$H E A O-C$, Skylab, and HLLV, Los Alamos Scientific Laboratory Report No. LA-UR 80-1160-REV (July, 1980).

89. Hunten, D.M., and T.M. Donahue, Hydrogen Loss from the Terrestrial Planets, Ann. Rev. Earth \& Plant, Sci. 4:265-292 (1976).

90. Tinsley, B.A., Hydrogen in the Upper Atmuspliere, Fund. Cusmic Phys. $1: 201-300(1974)$.

91. Donahue, T.M., Hydrogen, Chap. 4 in The Upper Atmosphere and Magnetosphere, National Academy of Sciences, Washington (1977). 
92. Chenurnoy, V.N., and G.A. Charina, Semi-Anrual Temperature Variations in the Thermosphere and their Relation with Atmospheric Circulation and Mesospheric Clouds, Geomagnetism and Aeronomy, 17(1):58-60 (1977).

93. Chiu, Y.T., et al., Magnetospheric Effects of Ion and Atom Injections by the Satellite Power System, Argonne National Laboratory Report No. ANL/EES-TM-94, prepared by the Aerospace Corp. (July 1, 1980).

94. Pongratz, M.B., and G.M. Smith, The Lagopedo Experiments - An Overview, Paper 非A15, Amer. Geophys. Union 1978 Spring Meeting, Miami, Fla. (March 1978).

95. Pongratz, M.B., et al., The Lagopedo Experiments, Los Alamos Scientific Laboratoity Repurl No. LA-UR-80-1130; Also, Proc. of the DOE/NASA Satellite Power System Program Revipw, The Ilniversity of Alabama Prcoo ( 1980 in press).

96. Kofsky, I.L., et al., Preliminary Report on Aircraft Measurements of Optical/IR Afterglows from a Major Ionosphere Perturbation, Proc. of the Workshop/Symposium, Preliminary Evaluation of the Ionospheric Disturbences Associated with the HEAO-C Launch, with Applications to the SPS Environmental Assessment, M. Mendillo, ed., Argonne National Laboratory Report, in press (1980).

97. Stone, S.N., and J. Zinn, Quick-Look Summary of AtZa6-Centaur AirgZow Observations, ibid.

98. Forbes, J.M., Upper Atmospheric Modifications Due to Chronic Discharges of Water Vapor from Space Launch Vehicle Exhausts, in Space Systems and their Interactions with the Earth's Space Environment, H.B. Garrett and C.P. Pike, eds. Vol. 71 - Progress in Astronautics and Aeronautics Series, American Institute of Aeronautics and Astronautics, Publishers (1980 in press).

99. Meltz, G., and J.A. DarRold, VLF OMEGA Observations of the Ionospherie Disturbance Produced by an Atlas/Centaur HEAO-C Launch, in Proc. of the Workshop/Symposium, op.cit., Ref. 95 (1980).

100. Markson, R., see comments in Ref. 10 .

101. Markson, R., and M. Muir, Solar Wind Control of the Earth's Electric Field, Science, 208(4447):979-990 (May 1980).

102. Mendillo, M., et al., Opporturily to Observe a Large-Scale Hole in the Ionosphere, EOS, Trans. Amer. Geophys. Union, 60:513-514 (July 1979).

103. Bernhardt, P.A., et a1., The Great Ionospheric Hole Experiment, QST,

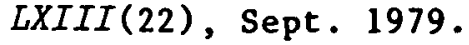

104. Mendillo, M., ed., Proc. of the Workshop/Symposium, op.cit. Ref. 96. 
105. Goodman, J., An Overview of the NRL Radio Propagation Studies Undertaken in Conjunction with the HEAO-Hole Experiment, in Ref. 104, p. 40.

106. Uffelman, D.R., and J.R. Davis, Preliminary Results from the NRL MADRE $H F$ Radar for the HEAO-C Launch, in Ref. 104, p. 207.

107. Klobuchar, J.A., et al., High Fequency Propagation Results from the Great Ionospheric Hole Experiment, in Ref. 104, p. 159.

108. Sarrazin, D.B., and C.B. Brooks, Preliminary Analysis of the Effects of the HEAO-C Launch on Short-Wave Broadcasts, in Ref. 104, p. 184.

109. Clynch, James R., Differential Doppler Measurements of the HEAO-C Dopletion - A Preliminary Report, in Ref. 104, p. 79.

110. Baumgardner, J., et al., Multi-Station TEC Observations of the HEAOHole Using the SIRIO Satellite, in Ref. 104, p. 10.

111. Bernhardt, P.A., et al., HEAO-C Launch Observations and Related Theoretical Studies, in ref. 104, p. 18.

112. Mendillo, M., Unified TEC Morphology of the HEAO-Hole Using SIRIO Satellite Measurements, in Ref. 104. p. 71 .

113. Checcaci, P.F., The SIRIO Satellite Program, in Ref. 104, p. 78.

114. Cousins, M.D., Transionospheric Propagation Measurements of $250 \mathrm{MHz}$ Signals Observed during the Launch of $H E A O-C$, in Ref. $104, \mathrm{p} .88$.

115. Mendillo, M., et al., Skylab-2 Plasma Depletion Experiments, Trans. of Am. Geophy. Union, 59:334 (April 1978).

116. Mendillo, M., et al., Modification of the Aerospace Envirorment by Large Space Vehicles, J. of Spacecraft and Rockets, 17(3):226-231 (May/June 1980).

117. McCormac, B.M., and Seliga, T.A., Solar Terrestrial Influences on Weather and Climate, Reidel Publishing Co., Boston (1979).

118. Rockwe11 International, Satellite Power Systems (SPS) Concept Definition Study, Final Report, Vol. V, Transportation and Operations Analysis, Report No. SD-78, AP-0023-5, Pp. 5-15, Rockwell International, Space Division, 12214 Lakewood Blvd., Downey, CA 90241 (April 1978).

119. Reynolds, T.W., Mathematical Representation of Current Density Profiles from Ion Thrusters, AIAA paper no. 71-693, AIAA/SAE 7th Propulsion Joint Specialist Conf. (June 1971).

120. Park, C., See Comments in Ref. 11 . 
121. Holze, D.H., and H.B. Liemohn, Disposition of SPS Electric Thruster Exhaust, Proc. of the DOE/NASA Satellite Power System Program Review, The University of Alabama Press (April 1980 in press).

122. Chiu, Y.T., Theoretical Aspects of Heavy Ion Injections in the Magnetosphere: A Review, Advances in Space Exploration, Pergammon Press, Oxford (1980).

123. Curtis, S.A., and J.M. Grebowsky, Energetic Ion Becm Magnetosphere Injection and Solar Power Satellite Transport, J. of Geophysical Res., 85(A4): 1729-1735 (April 1, 1980).

124. Anderson, C.W., III, et al., Outage of the L4 System and the Ceomagnatio Distirbances of 4 August 1972, The Bell System Technical Journal, 53 : 1.817-1837 (Nov. 1974).

125. Albertson, V.D., and J.A. Van Baelen, Electric and Mangetic Fields at the Earth's Surface Due to Auroral Currents, IEEE Transactions on Power Apparatus and Systems, 89:578-584 (April 1970).

126. Slothower, J.C., and V.D. Albertson, The Effects of Solar Magnetic Activity on Electric Power Systems, J. of the Minnesota Academy of Science, 34(2):94-100 (1967).

127. Roble, R.G., The Thermosphere, in The Upper Atmosphere and Magnetosphere, Studies in Geophysics Series, National Research Council, 1977. (Available from Printing and Publishing Office, National Academy of Sciences, 2101 Constitution Ave., Washington, D.C. 20418.)

128. Cladis, J.B., et al., Magnetospheric Effects of Solar Power Satellite, AIAA Paper No. 80-0892, presenter at the AIAA Clobel 2000 Meeting in Baltimore (May, 1980).

129. West, H.I., Jr., et al., Study of Energetic Electrons in the Outer Radiation-Belt Regions Using Data Obtained by the LLL Spectrometer on 0CO-5 in 1968, Lawrence Livermore Laboratory, Livermore, CA, Report No. UCRL-52807, 1979 .

130. West, H.I., Jr., et al., The Dynomics of Energetic Electrons in the Earth's Outer Radiation Belt During 1968 as Observed by the Lawrence Livermore Laboratory's Spectrometer on 0CO-5, to be published in J. of Geophysical Research (July 1980).

131. Crane, R.K., Propagation Phenomena Affecting Satellite Communication Systems Operating in the Centimeter and Millimeter Wavelength Bands, Proc. IEEE, $59: 173-188,1971$.

132. U.S. Standard Atmosphere, 1976, U.S. Government Printing office, Washington, 1976.

133. Vondrak, R.R., Envirormental Impact of Space Manufacturing, AIAA Paper 77-539 (May 1977). 
134. Vondrak, R.R., Mangetospheric Modification by Cas Releases from Large Space Structures, Chapter in Space Systems and their Interactions with the Earth's Space Environment, eds., H.B. Garrett and C.P. Pike, (1980 in press).

135. Rosen, A., The Effects of Large Space Structures on the Earth's Radiation Belts, presented at the AIAA Conference Held in Pasadena, CA. (Jan. 1980).

136. Garrett, H.B., Spacecraft Charging - A Review, AIAA paper no. 80-0851, presented at the AIAA Global 2000 Meeting in Baltimore (May, 1980).

137. Stokes, G.M., and Ekstrom, P.A., Workshop on Satellite Power Systems Effects on Optical and Radio Astronomy, U.S. Dept. of Energy, Report No. Conf-7905143 (Apri1 1980).

138. Garrett, H.B., and J.M. Forbes, Time Evaluation of Ion Containent Clouds at Geosynchronous Orbit, Geophysical Research Letters, 6(12): 941-944 (Dec. 1979).

139. Hines, C.0., A Possible Mechanism for the Production of Sun-Weather Correlations, J. Atmos. Sci., 31(2):589-591 (1974). 


\section{APPENDIX A \\ ESTIMATE OF THE RATE OF CONVERSION OF $\mathrm{NO}_{2}$ TO \\ $\mathrm{HNO}_{3}$ IN WATER DROPLETS}

A possible chemical mechanism that is capable of qualitatively explaining the observed general features of the chemistry of $\mathrm{NO}_{2}$ and $\mathrm{NO}$ in aqueous solution was shown in Fig. 12, reproduced here for convenience as Fig. A.1. In order to use the given mechanism to quantitatively simulate the rate of production of $\mathrm{HNO}_{3}$ in aqueous solution, reaction rate coefficients for all the reactions shown must be known; this information is not currently available. It is possible, however, to estimate an upper-bound rate of $\mathrm{HNO}_{3}$ production in water droplets in the presence of gaseous $\mathrm{NO}_{2}$ and $\mathrm{NO}$, and the purpose of chis appendix is to describe how this estimation may be done.

The most significant piece of experimental information availablc is the initial rate law for the decomposition of $\mathrm{HNO}_{2}$ in the presence of NO, as determined by Abel and Schmid:A.1

$$
-\frac{\mathrm{d}\left[\mathrm{HNO}_{2}\right]}{\mathrm{dt}}=\mathrm{k}_{\exp } \frac{\left[\mathrm{HNO}_{2}\right]^{4}}{\mathrm{P}_{\mathrm{N} O}^{2}}
$$

with $k_{\text {exp }}=46$ at $25^{\circ} \mathrm{C}$ (concentrations in mol/L, pressures in atm, and time in min). The mechanism shown in Fig. A.l. is consistent with this rate law, and gives the following expression for $k_{\text {exp: }}$

$$
k_{\exp }=k_{d} k_{a} \cdot k_{b}^{2} k_{c}
$$

This expression is derived by assuming that reactions (a) - (c) below represent rapid equilibria, as indicated in more detail in Fig. A.l, and that reaction (d) is the rate-determining step:

$$
\begin{aligned}
& 2 \mathrm{HNO}_{2}=\mathrm{N}_{2} \mathrm{O}_{3}+\mathrm{H}_{2} \mathrm{O} \\
& \mathrm{N}_{2} \mathrm{O}_{3}=\mathrm{NO}_{(\mathrm{g})}+\mathrm{NO}_{2} \\
& 2 \mathrm{NO}_{2}=\mathrm{N}_{2} \mathrm{O}_{4} \\
& \mathrm{~N}_{2} \mathrm{O}_{4}+\mathrm{H}_{2} \mathrm{O} \quad \mathrm{HNO}_{2}+\mathrm{H}^{+}+\mathrm{NO}_{3}^{-}
\end{aligned}
$$

The quantities $\mathrm{K}_{\mathrm{a}}-\mathrm{K}_{\mathrm{c}}$ in Eq. A.2 represent the equilibrium constants for reactions $(a)-(c)$, respectively, and $k_{d}$ represents the rate coefficient for reaction (d).

The quantity $\mathrm{K}_{e}=\mathrm{K}_{\mathrm{a}} \mathrm{k}_{\mathrm{b}}^{2} \mathrm{~K}_{\mathrm{c}}$ represents the equilibrium constant for the net reaction obtained by adding reaction (c) to twice the sum of reactions (a) and $(b)$ :

$$
4 \mathrm{HNO}_{2}=\mathrm{N}_{2} \mathrm{O}_{4}+2 \mathrm{NO}(\mathrm{g})+2 \mathrm{H}_{2} \mathrm{O}
$$

The value of $k_{d}$ may be estimated if $k_{e}$ can be estimated, since the value of $k_{\exp }$ is known. 


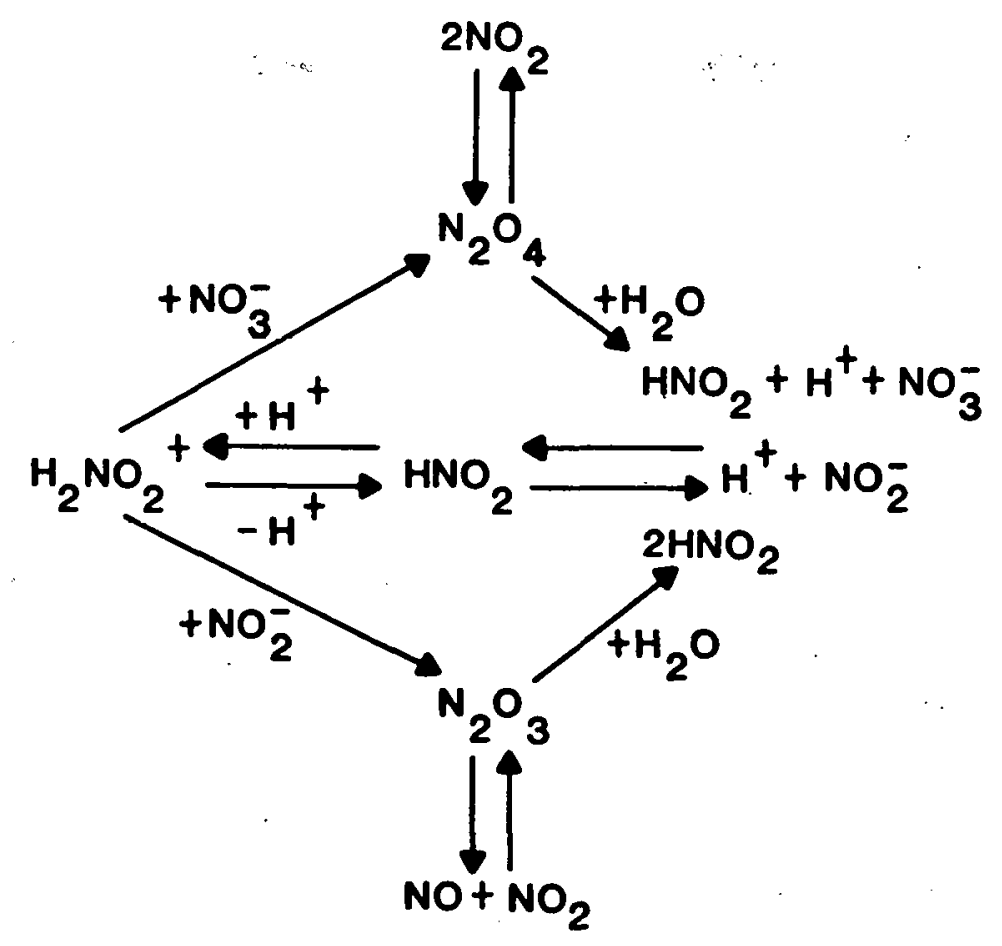

Fig. A.1 Possible Mechanism of the Aqueous Chemistry of Nitrogen Oxides

The value of $\mathrm{K}_{e}$ may be written in terms of the standard free energy change for reaction (e)

$$
K_{e}=\exp \left(-\Delta G^{\circ} / R T\right)
$$

and the standard free energy change $\Delta G^{\circ}$ may be written, using known free enteries of formation ${ }^{A} .2$

$$
\Delta G^{\circ}=\Delta G_{f}^{\circ}\left(N_{2} O_{4}(\mathrm{aq})\right)-20.66 \mathrm{kcal}
$$

and $G_{f}^{\circ}\left(\mathrm{N}_{2} \mathrm{O}_{4}(\mathrm{aq})\right)$ in turn may be expressed as

$$
\Delta \mathrm{G}_{\mathrm{f}}^{\circ}\left(\mathrm{N}_{2} \mathrm{O}_{4}(\mathrm{aq})\right)=-\mathrm{RT} \ln \mathrm{K}_{\mathrm{C}}+2 \Delta \mathrm{G}_{\mathrm{f}}^{\circ}\left(\mathrm{NO}_{2}(\mathrm{aq})\right)
$$

A value for $\Delta G_{f}^{\circ}\left(N_{2}(a q)\right)$ does not seem to be available in the standard tabulations of thermodynamic properties. However, the equilibrium constants for both ozone and $\mathrm{CO}_{2}$ between gas phases and aqueous phases are available:

$$
\begin{aligned}
& \frac{\left[\mathrm{CO}_{2}\right]}{\mathrm{PcO}_{2}}=0.034^{\mathrm{A} .3} \\
& \frac{\left[\mathrm{O}_{3}\right]}{\mathrm{Po}_{3}}=0.0123^{\mathrm{A} .4}
\end{aligned}
$$


Since $\mathrm{N}$ lies between $\mathrm{C}$ and $\mathrm{O}$ in the periodic table, it is perhaps reasonable to estimate the corresponding equilibrium constant (or, equivalently, the standard free energy of formation of dissolved $\mathrm{NO}_{2}$ ) by interpolation. This procedure was followed, using the known values of the molecular dipole moments to interpolate between the standard free energies of formation in aqueous solution, with the result that $\Delta \mathrm{G}_{\mathrm{f}}^{\circ}\left(\mathrm{NO}_{2}(\mathrm{aq})\right)$ is estimated to be $+14.7 \mathrm{kcal} /$ mol. Substitution into Eq. A.3 yields.

$$
\mathrm{K}_{\mathrm{e}}=\left(3.74 \times 10^{-7}\right) \mathrm{K}_{\mathrm{c}}
$$

It will be convenient to write $\mathrm{K}_{\mathrm{c}}=\zeta \mathrm{K}_{\mathrm{c}}(\mathrm{g})$ where $\mathrm{K}_{\mathrm{c}}(\mathrm{g})$ is the equilibrium constant for reaction (c) but in the gas phase. $\mathrm{K}_{c}$ may be evaluated using known free energies of formation (A.2) and is equal to 8.85 at $25^{\circ} \mathrm{C}$. Thus, using Eqs. A.2 and A.8, and the known value of $k_{\text {exp }}$,

$$
\mathrm{k} / 4_{4}=\left(1.2 \times 10^{7} \mathrm{~min}^{-1}\right) / \mathrm{c}
$$

be written

The rate of formation of $\mathrm{HNO}_{3}$ in an aqueous solution of $\mathrm{NO}_{2}$ may

$$
\frac{d\left[I I N O_{3}\right]}{d t}=k_{4}\left[\mathrm{~N}_{2} \mathrm{O}_{4}\right]
$$

or

$$
\frac{\mathrm{d}\left[\mathrm{HNO}_{3}\right]}{\mathrm{dt}}=\mathrm{k}_{4} \mathrm{~K}_{\mathrm{c}}\left[\mathrm{NO}_{2}\right]^{2}
$$

or, using $\mathrm{k}_{\mathrm{c}}=\zeta \mathrm{k}_{\mathrm{c}}(\mathrm{g})$,

$$
\frac{\mathrm{d}\left[\mathrm{HNO}_{3}\right]}{\mathrm{dt}}=\mathrm{k}_{4} \zeta \mathrm{K}_{\mathrm{c}}(\mathrm{g})\left[\mathrm{NO}_{2}\right]^{2}
$$

and the numerical value of $\mathrm{k}_{4} \zeta \mathrm{k}_{\mathrm{c}}(g)$ is, using Eq. A.9, the numerical value of $\mathrm{K}_{\mathrm{c}}(\mathrm{g})$, and including the proper units, $\mathrm{k}_{4} 5 \mathrm{~K}_{\mathrm{c}}(\mathrm{g})=1.5 \times 10^{6}$ mo $1^{-1} \mathrm{~s}-1$. Given the rate law of Eq. A.10, the rate of acid formation in droplets in an atmosphere containing $\mathrm{NO}_{2}$ may be estimated. Notice that if NO is also present in the atmosphere, the rate of $\mathrm{HNO}_{3}$ production will be retarded, due to the reaction between dissolved $\mathrm{NO}$ and $\mathrm{NO}_{2}$ to form dissolved $\mathrm{N}_{2} \mathrm{O}_{3}$ and the associated formation of $\mathrm{HNO}_{2}$, as shown in Fig. A.1. Thus the presence of NO, by competing for $\mathrm{NO}_{2}$, reduces the concentration of $\mathrm{NO}_{2}$ in solution and, therefore, the rate of $\mathrm{HNO}_{3}$ formation. Ignoring the presence of No will, therefore, give an upper bound to the rate of $\mathrm{HNO}_{3}$ formation, and this procedure is implicit in the adoption of Eq. A.10 as the appropriate rate law.

Denoting the atmospheric partial pressure in atmospheres of $\mathrm{NO}_{2}$ by $w$, the concentration (mol/L) of unreacted $\mathrm{NO}_{2}$ in aqueous solution by $x$ and the aqueous concentration (mol/L) of nitric acid by $y$, the set of differential equations describing the approximate evolution of the system is as follows:

$$
\frac{d w}{d t}=-\Lambda\left(w-H_{\mathrm{NO}_{2}} x\right)
$$




$$
\begin{aligned}
& \frac{d x}{d t}=\Lambda\left(\frac{v_{\text {air }}}{v_{1 \text { iq }}} \cdot \frac{1}{R T}\right)\left(w-\mathrm{H}_{\mathrm{NO}_{2}} \mathrm{x}\right)-2 \mathrm{kx}^{2} \\
& \frac{\mathrm{dy}}{\mathrm{dt}}=\mathrm{kx}^{2}
\end{aligned}
$$

In writing these equations, the assumptions are made that gas-1iquid exchange of $\mathrm{NO}_{2}$ is a simple first-order process with rate constant (i.e., that the droplets are of uniform composition and that gas-phase diffusion is sufficiently fast that it is not a controlling factor), and that the only important chemical processes occurring are the rapid equilibrium of $\mathrm{NO}_{2}$ and $\mathrm{N}_{2} \mathrm{O}_{4}$ in solution and the reaction of $\mathrm{N}_{2} \mathrm{O}_{4}$ with water to produce $\mathrm{HNO}_{2}$ and $\mathrm{HNO}_{3}$. The quantity $\mathrm{H}_{\mathrm{NO}_{2}}$ is the Henry's law constant for $\mathrm{NO}_{2}$ (obtainable from $\Delta G_{\mathrm{f}}^{\circ}$ for $\mathrm{NO}_{2}$ (aq) and $\mathrm{NO}_{2}$ (gas)), and the rate constant for $\mathrm{NO}_{2}$ chemical removal is written $2 \mathrm{k}$ since $\mathrm{NO}_{2}$ disappears twice as fast as $\mathrm{HNO}_{3}$ is produced, the extra $\mathrm{NO}_{2}$ going into the production of $\mathrm{HNO}_{2}$. It is also assumed that $\mathrm{HNO}_{3}$ remains in solution.

In order to solve analytically the $x$ and $y$ equations, the partial pressure of $\mathrm{NO}_{2}(w)$ is kept fixed at its initial value. The solutions of Eqs. A.12 and A.13 are then found to be:

$$
x(t)=\frac{\omega_{-}+\omega_{+} a \exp (-\lambda t)}{1-a \exp (-\lambda t)}
$$

in which

$$
\begin{aligned}
& \omega_{ \pm}=\frac{\lambda+\beta}{4 \mathrm{k}} \\
& \lambda=\left(\beta^{2}+8 \alpha \mathrm{k}\right)^{\frac{1}{2}} \\
& \alpha=\Lambda\left(\frac{\mathrm{V}_{\mathrm{air}}}{\mathrm{V}_{1 \mathrm{iq}}} \cdot \frac{1}{\mathrm{RT}}\right) \mathrm{P}_{\mathrm{NO}_{2}} \\
& \beta=\Lambda\left(\frac{\mathrm{V}_{\mathrm{air}}}{\mathrm{V}_{1 \mathrm{iq}}} \cdot \frac{1}{\mathrm{RT}}\right) \mathrm{H}_{\mathrm{NO}_{2}} \\
& \mathrm{a}=\frac{\mathrm{x}(0)-\omega_{-}}{\mathrm{x}(0)+\omega_{+}}
\end{aligned}
$$

and

$$
\left.y(t)=y(0)+k\left[\omega_{-}^{2} t+\frac{1}{\lambda}\left(\omega_{-}+\omega_{+}\right)^{2} A+\left(\omega_{+}^{2}-\omega_{-}^{2}\right) \ln B\right)\right]
$$

with

$$
A(t)=\frac{1}{1-a}-\frac{1}{1-a \exp (-\lambda t)}
$$


and

$$
B(t)=\frac{1-a}{1-a \exp (-\lambda t)}
$$

Inserting the following numerical values:

$$
\begin{aligned}
\mathrm{H}_{\mathrm{NO}_{2}} & =52 \mathrm{~L} \mathrm{~atm} / \mathrm{mol}\left(\text { from } \Delta \mathrm{G}_{\mathrm{f}}^{\circ}\left(\mathrm{NO}_{2}(\mathrm{aq})\right)=14.7 \mathrm{kcal} / \mathrm{mol}\right) \\
\mathrm{P}_{\mathrm{NO}_{2}} & =5 \times 10^{-7} \mathrm{~atm}(500 \mathrm{ppb}) \\
\mathrm{RT} & =24.46 \mathrm{~L} \text { atin } \mathrm{mol} 1^{-1}\left(\mathrm{at}^{\circ} 25 \mathrm{C}\right) \\
\mathrm{k} \quad & -1.5 \times 10^{6} \mathrm{I} \cdot \mathrm{mu} 1^{-1} \mathrm{~s}^{-1} \\
\left(\frac{\mathrm{V}_{\mathrm{air}}}{\mathrm{V}_{1 \text { iq }}}\right) & =1.8 \times 10^{5} \mathrm{~L} / \mathrm{L} \\
\Lambda & =8.7 \times 10^{-4} \mathrm{~s}^{-1 \mathrm{~A} .5}
\end{aligned}
$$

and

$$
x(0)=0
$$

one finds that $\lambda=3.3 \times 10^{2} \mathrm{~s}^{-1}$; thus the $\mathrm{NO}_{2}$ gas-1iquid equilibrium is reached very rapidly and, accordingly, for times longer than a small fraction of a second, $x=\omega_{-}=\alpha / \beta$

or

$$
\left[\mathrm{NO}_{2}\right]=\mathrm{x}=\mathrm{P}_{\mathrm{NO}_{2}} / \mathrm{H}_{\mathrm{NO}_{2}}=9.6 \times 10^{-9} \mathrm{~mol} / \mathrm{L}
$$

Finally, one finds that

$$
\begin{aligned}
{\left[\mathrm{H}_{\mathrm{NU}_{3}}\right] } & =y=y(0)+k\left(\frac{\mathrm{P}_{\mathrm{NO}_{2}}}{\mathrm{H}_{\mathrm{NO}}}\right)^{2} \tau \\
& =y(0)+\left(1.4 \times 10^{-10} \mathrm{~mol} \mathrm{~L}^{-1} \mathrm{sec}^{-1}\right) t
\end{aligned}
$$

This equation represents an upper bound to the nitric acid concentration in water droplets (for the specified volume of. water per unit volume of $\mathrm{air}$ ) exposed to $500 \mathrm{ppbv} \mathrm{NO}_{2}$ and a somewhat larger No concentration. The result is an upper bound due to (1) omission of the aqueous chemical effects of NO; (2) the assumption of constant $\mathrm{P}_{\mathrm{NO}_{2}}$; and (3) the assumption that all $\mathrm{H}_{\mathrm{NO}_{3}}$ produced remains in solution. 
A.1 Abel, E., and H. Schmid, cited in Deutschen Chemischen Gesellschaft, Gmelins Handbuch der Anorganischen Chemie, Verlag Chemie G.M.B.H., Berlin (1936); and in Bray, W. C., The Mechanism of Reactions in Aqueous Solutions, Chem. Rev. 10:161-177 (1932).

A.2 Weast, R.C. ed., Handbook of Chemistry and Physics, 52nd ed., The Chemical Rubber Co., Clevel and (1971).

A.3 Orel, A.E., and J.H. Seinfeld, Nitrate Formation in Atmospheric Aerosols, Env. Sci. Tech. 11:1000-1007 (1977).

A.4 Middleton, P., and C.S. Kiang, Relative Importance of Nitrate and Sulfate Aerosol Production Mechanisms in Urban Atmospheres, Chap. 16 in Nitrogenous Air Pollutants, Chemical and Biological Implications, D. Grosjean, ed., Ann Arbor Science Pub., Inc., Ann Arbor, Mich. (1979).

A.5 Beilke, S., Laboratory Investigations on Washout of Trace Gases. Proc. Symposium Precipitation Scavenging (1970), U.S. AEC Symposium Series No. 22, available as CONF-700601 from NTIS, Springfield, VA. (1970). 
United States

Department of Energy

Washington, D.C. 20585
THIRD -CLASS MAIL.

POSTAGE \& FEES PAID

U.S. DEPT. OF ENERGY

PERMIT NO. G 20

THIRD CLASS MAIL

Official Business

Penalty for Private Use, $\$ \mathbf{3 0 0}$ 